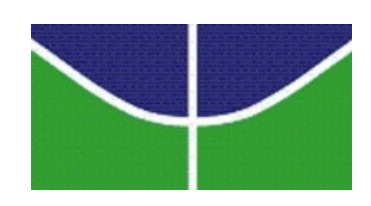

UNIVERSIDADE DE BRASÍLIA

FACULDADE DE CIÊNCIA DA INFORMAÇÃO

PROGRAMA DE PÓS-GRADUAÇÃO EM CIÊNCIA DA INFORMAÇÃO

\author{
JULIA BELLIA MARGOTO
}

FENÔMENOS DE COMUNICAÇÃO E MEDIAÇÃO DA INFORMAÇÃO EM UMA REDE SOCIAL DE RESPOSTA A UM DESASTRE NATURAL: O CASO DAS CHUVAS DE 2013 NO ESTADO DO ESPÍRITO SANTO 


\section{FENÔMENOS DE COMUNICAÇÃO E MEDIAÇÃO DA INFORMAÇÃO EM UMA REDE SOCIAL DE RESPPOSTA A UM DESASTRE NATURAL: O CASO DAS CHUVAS DE 2013 NO ESTADO DO ESPÍRITO SANTO}

Tese apresentada ao curso de Doutorado do Programa de Pós-Graduação em Ciência da Informação da Faculdade de Ciência da Informação da Universidade de Brasília no âmbito do Doutorado Interinstitucional (DINTER) entre a Universidade de Brasília e a Universidade Federal do Espírito Santo como requisito parcial à obtenção do título de Doutora em Ciência da Informação.

Área de concentração: Gestão da Informação

Linha de pesquisa: Comunicação e Mediação da Informação

Orientador: Prof. Dr. Jorge Henrique Cabral Fernandes. 
Ficha catalográfica elaborada automaticamente, com os dados fornecidos pelo(a) autor(a)

MM329f

Margoto, Julia Bellia

Fenômenos de comunicação e mediação da informação em

uma rede social de resposta a um desastre natural: o caso das chuvas de 2013 no estado do Espírito Santo / Julia Bellia Margoto; orientador Jorge Henrique

Cabral Fernandes. -- Brasillia, 2015.

$284 \mathrm{p}$.

Tese (Doutorado - Doutorado em Ciência da Informação) - - Universidade de Brasília, 2015.

1. Comunicação. 2. Mediação da Informação. 3 . Análise de Redes Sociais. 4. Desastres Naturais . 5. Inteligência Coletiva. I. Fernandes, Jorge Henrique Cabral, orient. II. Título. 


\section{FOLHA DE APROVAÇÃO}

Título: "Fenômenos de comunicação e mediação da informação em uma rede social de resposta a um desastre natural: o caso das chuvas de 2013 no estado do Espírito Santo"

\section{Autor (a): Julia Bellia Margoto}

Área de concentração: Gestão da Informação

Linha de pesquisa: Comunicação e Mediação da Informação

Tese submetida à Comissão Examinadora designada pelo Colegiado do Programa de Pósgraduação em Ciência da Informação da Faculdade em Ciência da Informação da Universidade de Brasília como requisito parcial para obtenção do título de Doutor em Ciência da Informação.

Tese aprovada em: 04 de dezembro de 2015.

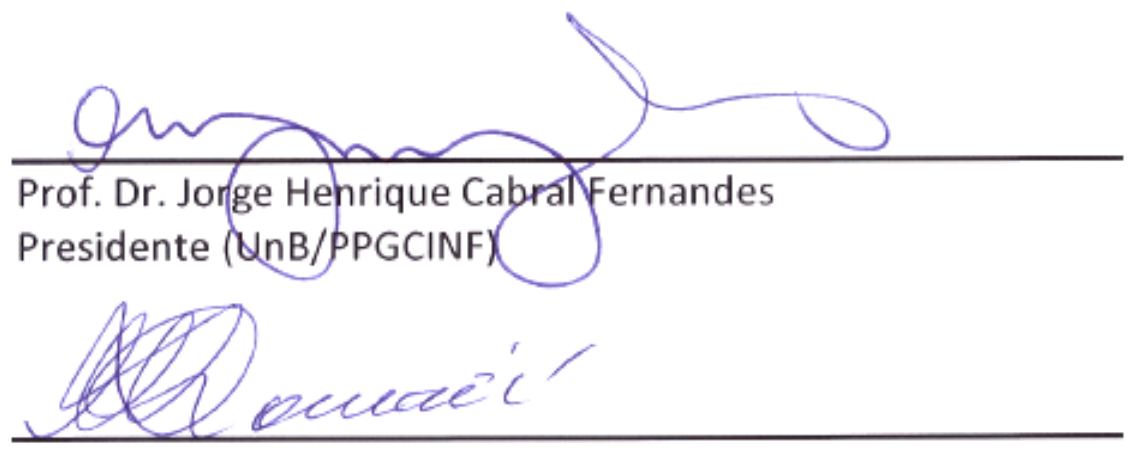

Prof.a Dr.a Maria Inês Tomael

Membro Externo (UEL)

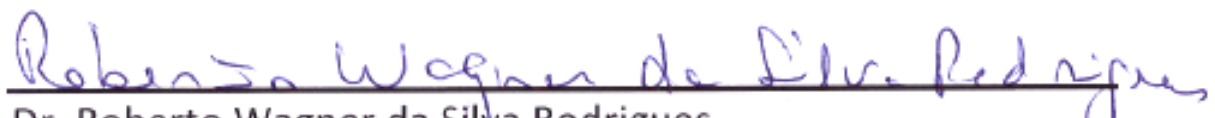

Dr. Roberto Wagner da Silya Rodrigues

Membro Externo (Ministério do Desenvolvimento Agrário)

Prof.Dr. Rogério Henrique de Araújo Júnior

Membrolinterno (UnB/PPGCINF)

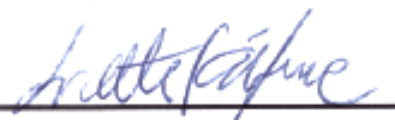

Prof. Dr.a Ivette Kafure Munoz

Membro Interno (UnB/PPGCINF) 


\section{AGRADECIMENTOS}

À Professora Dulcinea Sarmento Rosemberg, incansável batalhadora pela causa do Dinter UnB/UFES em Ciência da Informação.

Ao Professor Gelson Silva Junquilho, grande incentivador da minha caminhada para o doutorado.

Ao Programa de Pós Graduação em Ciência da Informação da Universidade de Brasília, pela oportunidade.

Ao Professor Dr. Jorge Henrique Cabral Fernandes, pela orientação precisa e pelos conhecimentos transmitidos.

Aos Professores:

$\mathrm{Dr}^{\mathrm{a}}$. Ivette Kafure Muñoz

Drà. Maria Inês Tomaél

Dr. Roberto Wagner da Silva Rodrigues

Dr. Rogério Henrique de Araújo Júnior

pelas valiosas contribuições oferecidas a este trabalho.

Aos colegas do Dinter, companheiros de jornada, pelo suporte e acolhimento.

À amiga Lucileide Andrade de Lima Nascimento, por ter sido ombro, amparo e sabedoria ao longo da minha caminhada.

À Fabrine Schwanz Dias e Alessandro Rizzi de Bruyn, pelo apoio e enorme disponibilidade para colaboração com a pesquisa.

A todos os Apoiadores, sem os quais essa tese jamais poderia ter sido concretizada.

Aos meus amigos e familiares, que souberam compreender minhas ausências.

Aos queridos tios Eliza e Fausto, por sempre acreditarem que eu conseguiria.

À minha mãe Sueli, por ter sofrido comigo as angústias do caminho.

Ao meu pai Luiz Alberto, por me tornar capaz de chegar até aqui.

À minha irmã Cristina, pelo exemplo de força e coragem para continuar, sempre.

Ao meu filho João, minha inspiração para seguir em frente, meu grande incentivador.

Ao meu esposo Guilherme, pelo amor, carinho, compreensão e suporte, em todos os momentos. 
"Não temos em nossas mãos as soluções para todos os problemas do mundo, mas diante de todos os problemas do mundo temos as nossas mãos."

Friedrich Von Schiller (poeta, filósofo e historiador alemão, 1759-1805) 


\section{RESUMO}

O objetivo geral da pesquisa foi analisar os fenômenos de comunicação e mediação da informação, estruturados em uma rede social de resposta a um desastre natural. Os modelos e fenômenos de comunicação e mediação da informação, pertinentes a agentes do Estado e da sociedade são contrastados. Para tanto foi realizado um estudo de caso, com enfoque nas fortes chuvas ocorridas no Estado do Espírito Santo em dezembro de 2013. Na ocasião, os órgãos de defesa civil foram acionados, mas ações desencadeadas por um grupo emergente na sociedade civil deram forma a um movimento de arrecadação e envio de donativos para as vítimas, ainda sem precedentes na história do Estado. Um perfil no Facebook foi criado para dar visibilidade à ação, que se nucleou em torno de uma rede de 77 atores, dentre os quais 24 membros da sociedade civil. Tal rede é aqui denominada Núcleo de Apoiadores. Trata-se de um estudo exploratório em que foram utilizadas entrevistas, questionários e análise do site de rede social Facebook, como formas de coleta de dados. Estruturalmente definido o núcleo dessa rede, o método de análise de redes sociais (ARS) foi aplicado ao mesmo, a partir da utilização do software Pajek, específico para esta finalidade. A análise da topologia dessa rede social nucleadora da resposta da sociedade civil a esse desastre contribui para uma melhor compreensão dos fenômenos de comunicação e mediação da informação, existentes em situações dessa natureza. Como principais conclusões do estudo temse que: a comunicação pode ser tida como elemento estruturante e condicionante dos relacionamentos estabelecidos entre os atores do Núcleo de Apoiadores, tendo sido efetivada por meio de relacionamentos pré-existentes e também a partir de novos relacionamentos criados pelos atores; a ação colaborativa desenvolvida demonstrou características de um fenômeno de inteligência coletiva, fortemente ancorado no uso de novas tecnologias da informação e comunicação; o grupo emergente na sociedade civil foi capaz de atuar na comunicação e mediação da informação entre agentes de organizações estabelecidas, expandidas e estendidas, conferindo uma natureza alternativa e diferenciada a esses processos.

Palavras-chave: Comunicação. Mediação da Informação. Análise de Redes Sociais. Desastres Naturais. Inteligência Coletiva. 


\section{ABSTRACT}

The main objective of the research was to analyze the phenomena of communication and information mediation, structured in a social network response to a natural disaster. Models and phenomena of communication and information mediation pertaining to agents of the state and society are contrasted. To this end we conducted a case study, focusing on heavy rainfall in the state of Espirito Santo in December 2013. At the time, the civil defense agencies were triggered, but actions triggered by an emerging group in civil society have formed a raising movement of collecting and sending donations for the victims, yet unprecedented in state history. A Facebook profile was created to call attention to the action, which was structured around a network of 77 actors, among them 24 members of civil society. Such a network is here called Core of Supporters. It is an exploratory study in which interviews, questionnaires and analysis of the Facebook social networking site, were used as forms of data collection. Structurally defined the core of this network, the method of social networks analysis (SNA) was applied to it, from the use of Pajek software, specific for this purpose. The analysis of the topology of this nucleation social network of civil society's response to this disaster contributes to a better understanding of the phenomena of communication and information mediation, existing in such scenarios. As main conclusions we have that: communication can be taken as a structural element and conditioning of the relations established between the actors of the Core of Supporters, having been made by means of pre-existing relational ties and also from newly created connections by actors; the developed collaborative action demonstrated characteristics of a collective intelligence phenomenon, strongly anchored in the use of new information and communication technologies; the emerging group in civil society was able to work on communication and information mediation between operators of established, expanded and extended organizations, providing an alternative and differentiated nature for technologies these processes.

Keywords: Communication. Information mediation. Social Network Analysis. Natural Disasters. Collective intelligence. 


\section{LISTA DE FIGURAS}

Figura 1 - As pontes de Königsberg

Figura 2 - Sociograma para demonstração da estrutura de reconhecimento entre crianças.

Figura 3 - Topologias de Rede de Paul Baran.

Figura 4 - Papéis de intermediação numa estrutura de grupos em uma rede social.

Figura 5 - Representação da estrutura burocrática.

Figura 6 - Definição de risco

Figura 7 - Dinâmica dos desastres

Figura 8 - Estrutura Organizacional padrão do SCO.

Figura 9 - Órgãos componentes do Comitê Estadual de Combate às Adversidades Climáticas - ES.

Figura 10 - Atores de redes sociais em contextos de desastres - Modelo IN/OUT/SEEKER/PROVIDER (IOSP)

Figura 11 - Foto do perfil dos Apoiadores no Facebook

Figura 12 - Post sobre municípios em situação crítica.

Figura 13 - Post sobre pontos de coleta no interior.

Figura 14 - Post sobre lista de entrega de doações em 23/12/2013.

Figura 15 - Post convidando voluntários na área de saúde. 
Figura 16 - Post sobre suspensão de atividades na Praça do Papa durante o dia de Natal..

Figura 17 - Post sobre pedido do Corpo de Bombeiros para voluntários com embarcações.

Figura 18 - Informações sobre frentes de trabalho dos Apoiadores.

Figura 19 - Estruturas: o Núcleo de Apoiadores e o SCO. 


\section{LISTA DE GRAFOS}

Grafo 1 - Exemplo de grafo conectado........................................ 92

Grafo 2 - Um grafo e seus cliques............................................. 93

Grafo 3 - Exemplo de um ponto de corte em um grafo......................... 94

Grafo 4 - Exemplo de uma ponte em um grafo.................................. 95

Grafo 5 - Núcleo de Apoiadores com identificação dos respondentes ao questionário.

Grafo 6 - Núcleo de Apoiadores com identificação das organizações representadas na rede

Grafo 7 - Centralidade de grau dos atores do Núcleo de Apoiadores

Grafo 8 - Centralidade de intermediação dos atores no Núcleo de Apoiadores

Grafo 9 - Centralidade de proximidade dos atores no Núcleo de Apoiadores

Grafo 10 - Quantidade de papeis de elementos de ligação

desempenhados pelos atores.

Grafo 11 - Intensidades dos relacionamentos no Núcleo de Apoiadores ...

Grafo 12 - Relacionamentos com intensidade superior a 3 no Núcleo de Apoiadores

Grafo 13 - Relacionamentos com intensidade inferior a 4 no Núcleo de Apoiadores

Grafo 14 - K-cores existentes no Núcleo de Apoiadores. 
Grafo 15 - Relacionamentos novos e pré-existentes no Núcleo de

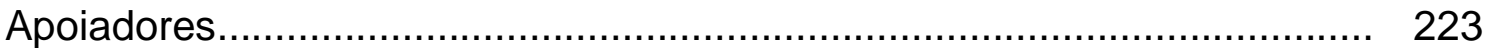

Grafo 16 - Relacionamentos pré-existentes no Núcleo de Apoiadores........ 228

Grafo 17 - Núcleo de Apoiadores sem a presença de A01 ........................ 230 


\section{LISTA DE QUADROS}

Quadro 1 - Sociedades Históricas.

Quadro 2 - Classificação dos grupos e subgrupos dos desastres naturais (COBRADE)

Quadro 3 - Desastres naturais recorrentes no ES entre 2000 e $2013 .$.

Quadro 4 - Relações dos objetivos da pesquisa com as seções do referencial teórico.

Quadro 5 - Nomenclatura para identificação dos atores da rede analisada..

Quadro 6 - Formas de coleta de dados da pesquisa e suas finalidades.

Quadro 7 - Pressupostos da pesquisa, objetivos específicos e aspectos metodológicos relacionados.

Quadro 8 - Resumo da estratégia de pesquisa proposta.

Quadro 9 - Atividades e atores envolvidos.

Quadro 10 - Temas gerais de informação presentes em cada um dos relacionamentos do Núcleo de Apoiadores.

Quadro 11 - Origem dos relacionamentos pré-existentes. 


\section{LISTA DE TABELAS}

Tabela 1 - Exemplo de matriz retangular de dados.

83

Tabela 2 - Exemplo de matriz quadrada de dados sobre redes.

83

Tabela 3 - Códigos, cores e número de atores em cada partição da rede núcleo de apoiadores.

Tabela 4 - Formas de comunicação utilizadas nos relacionamentos

Tabela 5 - Os seis maiores valores de centralidade de grau

208

Tabela 6 - Atores com maiores valores de centralidade de intermediação...

210

Tabela 7 - Atores com maiores valores de centralidade de proximidade......

Tabela 8 - Papeis de intermediação secundários

213

Tabela 9 - Quantidade de contatos por relacionamento

Tabela 10 - Relacionamentos pré-existentes e novos

Tabela 11 - Quantitativo de relacionamentos pré-existentes e relacionamentos novos por ator 


\section{LISTA DE SIGLAS}

Abong - Associação Brasileira de ONGs

ANA - Agência Nacional de Águas

ARS - Análise de Redes Sociais

CBMES - Corpo de Bombeiros Militar do Espírito Santo

CEMADEN - Centro Nacional de Monitoramento e Alertas de Desastres Naturais

CENAD - Centro Nacional de Gerenciamento de Risco e Desastres

CEPDECs - Coordenadorias Estaduais de Proteção e Defesa Civil

CEPED/UFSC - Centro Universitário de Estudos e Pesquisas sobre Desastres da Universidade Federal de Santa Catarina

$\mathrm{Cl}$ - Ciência da Informação

COBRADE - Classificação Brasileira de Desastres Naturais

COMPDECs - Coordenadorias Municipais de Proteção e Defesa Civil

CONPDEC - Conselho Nacional de Proteção e Defesa Civil

CPRM - Serviço Geológico Nacional

CRED - Centro para Pesquisa sobre Epidemiologia de Desastres

DRC - Disasters Research Center

EM-DAT - Banco de Dados Internacional de Desastres

ES - Espírito Santo

FEMA - Federal Emergency Management Agency

GEOBASES - Sistema Integrado de Bases Geoespaciais do Espírito Santo

INCAPER - Instituto Capixaba de Pesquisa Assistência e Extensão Rural

IOSP - In/Out/Seeker/Provider

MG - Minas Gerais

NASA - National Aeronautics and Space Administration

OMS/ONU - Organização Mundial de Saúde 
PEPDEC - Plano Estadual de Proteção e Defesa Civil

PNGRD - Plano Nacional de Gestão de Riscos e Resposta a Desastres

PNPDEC - Política Nacional de Proteção e Defesa Civil

REBEA - Rede Brasileira de Educação Ambiental

REPDECs - Coordenadorias Regionais de Proteção e Defesa Civil

RITS - Rede de Informações para o Terceiro Setor

SCO - Sistema de Comando em Operações

SEMS - Standardized Emergency Management System

SIEPDECs - Sistemas Estaduais de Proteção e Defesa Civil

SINPDEC - Sistema Nacional de Proteção e Defesa Civil

SRS - Sites de Redes Sociais

TGS - Teoria Geral dos Sistemas

TICs - Tecnologias de Informação e Comunicação

UNOOSA - Escritório das Nações Unidas para Assuntos do Espaço Sideral 


\section{SUMÁRIO}

1. INTRODUÇÃO

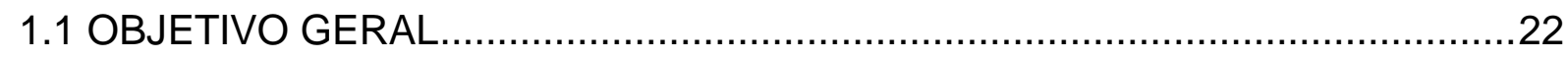

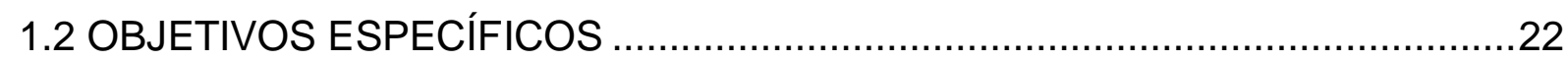

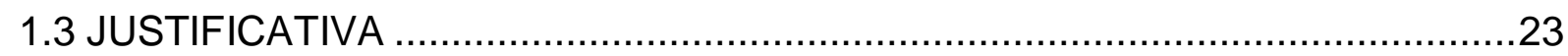

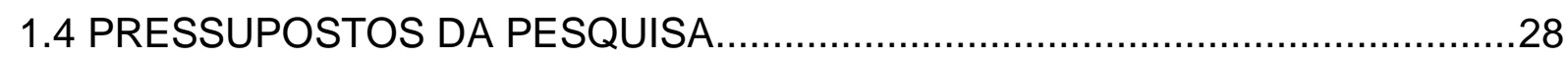

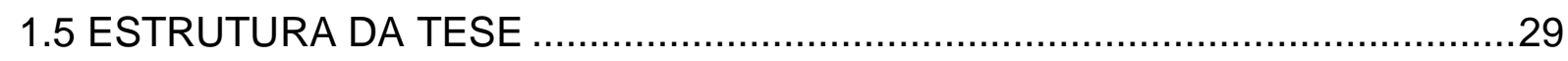

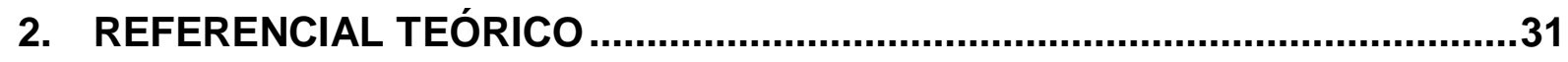

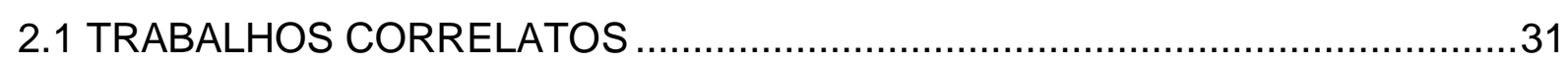

2.2 SOCIEDADE DA INFORMAÇÃO: APROXIMAÇÕES RELEVANTES PARA O

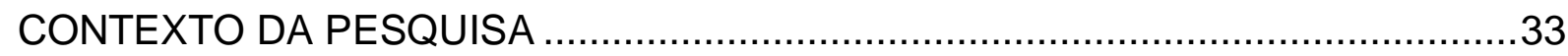

2.3 INTELIGÊNCIA COLETIVA: UM FENÔMENO COMPLEXO …..........................38

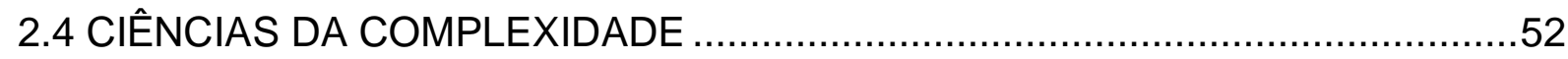

2.4.1 Algumas características dos sistemas complexos ……............................59

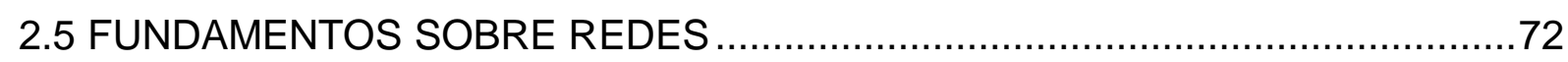

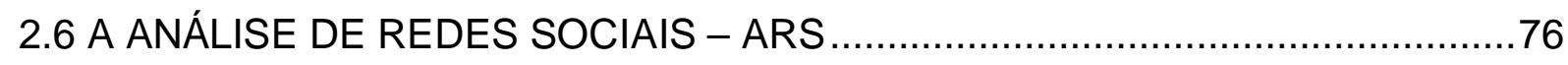

2.6.1 ARS: alguns importantes conceitos e propriedades .................................85

2.7 SOBRE ESTRUTUTURAS BUROCRÁTICAS E REDES ..................................98

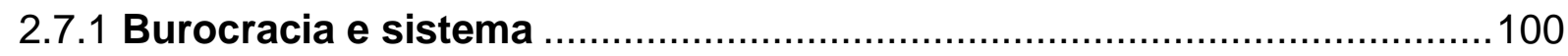

2.7.2 Redes sociais como alternativas emancipatórias ……............................109

2.8 COMUNICAÇÃO E MEDIAÇÃO DA INFORMAÇÃO EM REDES SOCIAIS .....116

3. ESTRUTURAS BUROCRÁTICAS E GRUPOS EMERGENTES NA RESPOSTA A DESASTRES NATURAIS …................................................................127

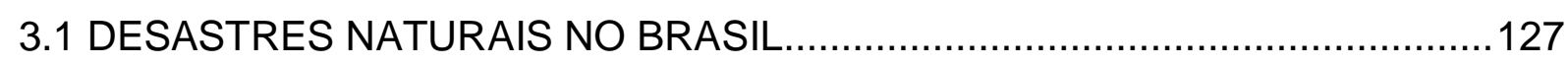

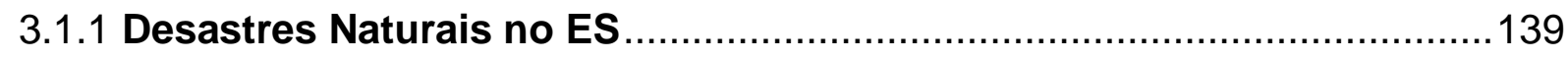

3.2 OS GRUPOS EMERGENTES NA RESPOSTA A DESASTRES NATURAIS ... 146

4. PERCURSO METODOLÓGICO DA PESQUISA............................................158

4.1 DELIMITAÇÃO DO ESTUDO E TIPO DE PESQUISA ….............................158

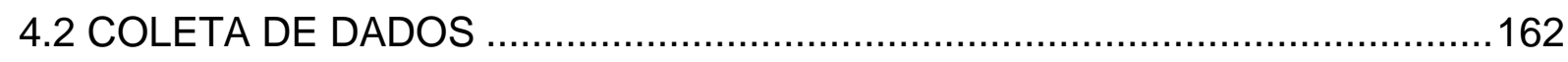

4.3 TRATAMENTO, APRESENTAÇÃO E ANÁLISE DE RESULTADOS................172

5. APRESENTAÇÃO E DISCUSSÃO DOS RESULTADOS …............................177 
5.1 O SURGIMENTO E A ORGANIZAÇÃO DA REDE .......................................177

5.1.1 Como tudo começou e o papel do Facebook ........................................178

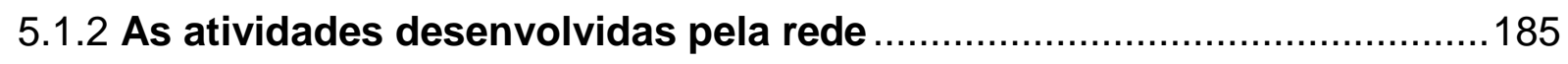

5.1.3 A topologia da rede em análise ............................................................193

5.1.4 Os dispositivos de comunicação entre os atores ..................................199

5.2 A COMUNICAÇÃO E A MEDIAÇÃO DA INFORMAÇÃO NA REDE ..................201

5.2.1 As informações trocadas na rede ........................................................202

5.2.2 Algumas métricas de centralidade ....................................................207

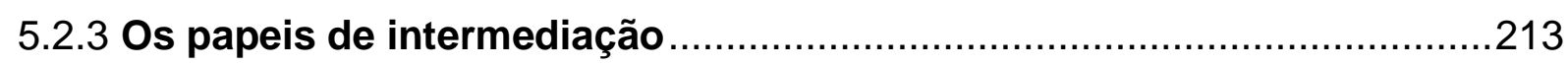

5.2.4 Intensidade dos relacionamentos......................................................216

5.3 SOBRE VELHOS E NOVOS RELACIONAMENTOS ......................................221

5.3.1 O velho e o novo se complementam .................................................221

5.3.2 A relevância de cada um..................................................................226

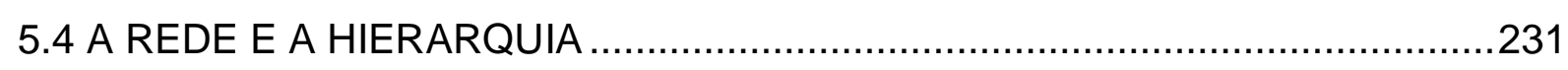

5.4.1 Solidariedade e gratuidade como molas propulsoras ............................2. 233

5.4.2 Divergências: a emergência $x$ o comando e controle ..............................235

6. FENÔMENOS DE COMUNICAÇÃO E MEDIAÇÃO DA INFORMAÇÃO EM REDES SOCIAIS DE RESPOSTA A DESASTRES NATURAIS: O CASO DAS CHUVAS DE 2013 NO ESTADO DO ESPÍRITO SANTO...................................249

6.1 COMUNICAÇÃO E MEDIAÇÃO DA INFORMAÇÃO NO NÚCLEO DE

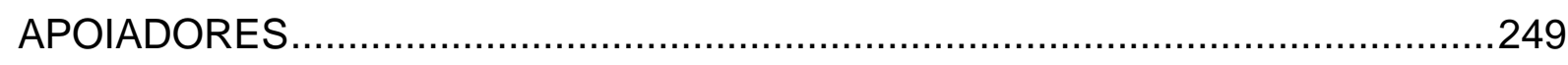

6.2 COMPROVAÇÃO DOS PRESSUPOSTOS DA PESQUISA ...........................254

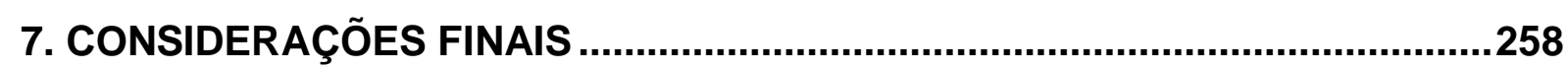

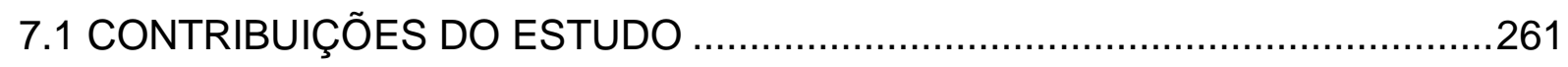

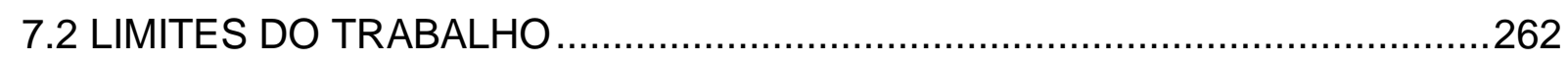

7.3 SUGESTÕES PARA TRABALHOS FUTUROS............................................263

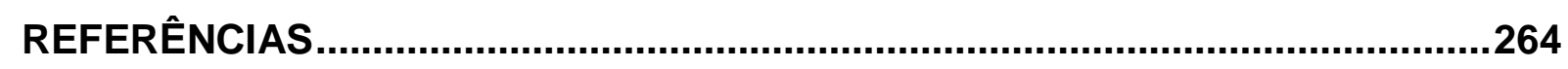

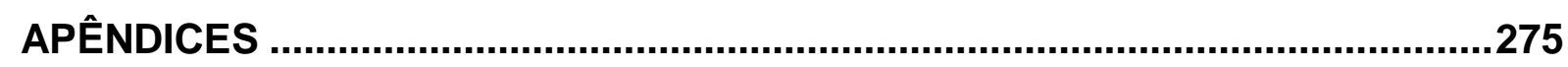

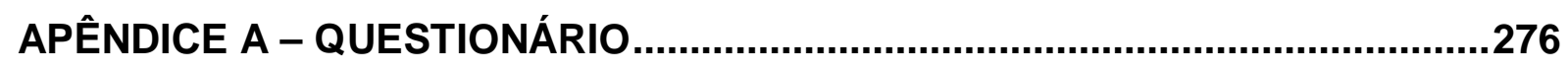




\section{INTRODUÇÃO}

Em dezembro de 2013, o estado do Espírito Santo (ES) e o leste de Minas Gerais (MG) foram atingidos por fortes chuvas que causaram 46 mortes no total. Ao lado das enchentes de 1979, esse desastre natural está entre os maiores já registrados nessa região (GOMES, 2013). Entre os dias 12 e 25 de dezembro de 2013 as chuvas foram as maiores já registradas no ES desde quando foram iniciadas as medições de precipitações pluviométricas no estado, há 92 anos (CHUVA..., 2013). Apenas após o dia 26 a situação começou a dar sinais de melhora, com as chuvas ocorrendo em pancadas isoladas, porém ainda fortes em alguns pontos.

Do total de 78 municípios capixabas, 55 decretaram estado de emergência. Mais de sessenta mil pessoas ficaram desabrigadas ou desalojadas e ocorreram 24 mortes no ES. Informações oriundas da agência americana National Aeronautics and Space Administration (NASA), a partir de imagens do satélite Tropical Rainfall Measuring Mission, indicam que entre os dias 17 e 19 de dezembro de 2013, a região litorânea onde ocorreu a maior precipitação no mundo, foi o município de Linhares, no norte do ES (PERIM, 2013).

Inúmeros rios que cortam o ES não suportaram o volume de chuva e transbordaram, causando inundações em diversos municípios. Moradias, pontes e estradas foram arrastadas pela força da água. Muitas residências não resistiram e desabaram. Deslizamentos de terra ocorreram em várias cidades, destruindo casas e soterrando pessoas. Cerca de 20 mil quilômetros de estradas foram danificados. (ES..., 2013).

O governo do ES estimou, em janeiro de 2014, que seriam necessários 540 milhões de reais para a reconstrução do estado, envolvendo a oferta de casas populares, recuperação de rodovias, ações no âmbito da infraestrutura, educação, agricultura, entre inúmeras outras como o fornecimento de crédito a diversos setores produtivos afetados (GOVERNO..., 2014).

O Estado, no seu tradicional papel de garantidor da segurança da sociedade, acionou os órgãos de defesa civil. O relatório operacional divulgado pelo Corpo de 
Bombeiros Militar do Espírito Santo (CBMES), em fevereiro de 2014, mostrou que as ações de resposta ao desastre natural de dezembro contaram com a participação de 1.100 militares do CBMES, 85 viaturas e 32 embarcações. Cerca de outros 500 profissionais da Polícia Militar do ES, Polícia Rodoviária Federal, Força Aérea Brasileira, Exército, Marinha, polícias do Rio de Janeiro e de São Paulo, além de equipes de saúde do Governo Federal e das secretarias de governo do ES, também participaram das ações humanitárias (CORPO DE BOMBEIROS MILITAR DO ESPÍRITO SANTO, 2014).

Mas não foram apenas as instituições governamentais (o Estado) que desenvolveram ações de resposta. Em meio à grande devastação e ao caos que se abateu sobre a população local, emergiu uma rede na sociedade civil, que passou a apoiar as vítimas das chuvas, numa frente principal: a arrecadação e envio de donativos às populações dos municípios afetados.

A forma de surgimento dessa rede sugere a presença de características de um fenômeno emergente, no sentido compreendido em estudos de complexidade. Esses grupos emergentes são estruturas coletivas que não existiam antes do desastre e que surgem para dar condições à execução de novas atividades. Um time informal de busca e resgate é um exemplo típico desse formato emergente de grupo social em situações de pós-desastre (BEAGRIE, 2009; QUARANTELLI, 1993, 1995).

Os grupos emergentes de resposta a desastres possuem em sua maioria, uma natureza transitória, mas nem por isso deixam de ser fundamentais ao atuarem na execução de determinadas tarefas e no desenvolvimento de estruturas que grupos ou organizações tradicionais (ex: órgãos de segurança do Estado) já existentes podem não estar sendo capazes de realizar naquele momento. Uma situação muito comum a desastres naturais extremamente devastadores, é que não raro superam a capacidade das instituições governamentais locais de suprirem todas as demandas relacionadas às ações emergenciais (BEAGRIE, 2009; QUARANTELLI, 1993, 1995).

Uma rede social pode ser definida como um conjunto ou conjuntos finitos de atores e os relacionamentos existentes entre eles (MARIN; WELLMAN, 2010; WASSERMAN; FAUST, 2009). Grupos emergentes podem ser configurados como redes sociais em 
que pessoas se relacionam com outras, comunicando e mediando informações e articulando soluções para a realização das atividades necessárias no contexto após o desastre natural.

As redes sociais apresentam-se como um fenômeno de considerável visibilidade e evidência na sociedade da informação, onde novos dispositivos de comunicação e sistemas de computador configuram-se como objetos materiais em torno dos quais existem registros de relacionamentos em grupos humanos em uma ação coletiva complexa. Essa configuração leva em consideração a ação das redes sociais em torno de uma infraestrutura informacional, evidenciando o advento de um social tecnológico (DI FELICE, 2007). Em decorrência de tais registros, emergem oportunidades inéditas para se pensar as ações de comunicação e mediação da informação, aspecto essencial no campo da Ciência da Informação.

Marteleto (2010) chama atenção para a existência de formas inovativas e transformadoras de transferência de informação nas redes da sociedade civil. Nesse sentido, no estudo das redes, além da importância devida sobre os modelos e tecnologias de informação e comunicação utilizadas pelos atores, é essencial a busca pela compreensão das formas de mediação da informação ali existentes. 0 seu reconhecimento parte do entendimento adequado das posições e conexões envolvidas, bem como da dinâmica e das atividades desenvolvidas numa rede.

De uma maneira geral, as redes estão sendo atualmente estudadas a partir de um contexto bastante amplo, que envolve as chamadas ciências da complexidade, as quais evoluem constantemente no sentido de desvendar a natureza e as características dos sistemas complexos (BORGATTI NETO, 2008; ÉRDI, 2008). Ramos como a biologia, a física, a matemática, além das ciências sociais tem buscado explorar e melhor explicar a dinâmica de sua auto-organização e de seu desenvolvimento (JOHNSON, 2003).

Pela natureza da dinâmica e das características existentes na maioria das redes, essas podem ser consideradas sistemas complexos. O comportamento complexo pode ser reconhecido a partir de determinadas características distintivas como a não linearidade, a dinâmica evolutiva, a auto-organização e a emergência de padrões não planejados (BARABÁSI, 2009; BORGATTI NETO, 2008; JOHNSON, 2003). 
Para as ciências sociais, a perspectiva das redes e da complexidade tem se mostrado bastante frutífera no reconhecimento da importância das relações estabelecidas entre diferentes atores em contextos diversos, como: resolução de problemas em grupo, difusão e adoção de inovações (SCOTT, 2012; VALENTE, 2012), consenso e influência social, formação de coalizões, dentre outros (WASSERMAN; FAUST, 2009).

Ao possibilitar tratar da dinâmica, auto-organização, emergência, não linearidade e complexidade, a chamada Análise de Redes Sociais (ARS) cria uma perspectiva diferenciada dentro do campo das ciências sociais e comportamentais. Seu arcabouço compreende uma série de teorias, modelos e aplicações que são expressos em termos de conceitos e processos relacionais. Os relacionamentos definidos como ligações entre diferentes unidades denominadas atores são seus componentes fundamentais (CARRINGTON; SCOTT; WASSERMAN, 2012; WASSERMAN; FAUST, 2009).

Especificamente na esfera dos desastres naturais, a ARS vem sendo apontada e discutida como uma opção importante para compreender e melhorar a resiliência das comunidades (NATIONAL RESEARCH COUNCIL, 2009). De acordo com o minidicionário Houaiss da língua portuguesa, (HOUAISS; VILLAR, 2001, p. 382), a resiliência é a "propriedade de retornar à forma original após ter sido submetido a uma deformação; capacidade de se recobrar ou de se adaptar à má sorte, às mudanças".

A utilização da perspectiva da ARS auxilia na compreensão do funcionamento geral de organizações e de comunidades, do ponto de vista da comunicação e mediação da informação, como também da maneira com que se preparam e respondem a desastres, especificamente (NATIONAL RESEARCH COUNCIL, 2009).

Entretanto, pouco ainda se sabe acerca da configuração de redes sociais nas entidades governamentais ou do Estado em determinada região ou de como essas redes se integrariam ou não a outras redes sociais que se originam na sociedade civil para o propósito da resposta a situações de emergência em desastres naturais (NATIONAL RESEARCH COUNCIL, 2009). 
A compreensão desse complexo contexto proporcionada pela aplicação da ARS poderá vir a contribuir para a consecução dos objetivos propostos no chamado Marco de Ação de Hyogo (ONU, 2005). A partir dele, governos de todo o mundo comprometeram-se, desde 2005, a tomar medidas para a redução da vulnerabilidade aos desastres naturais. Baseando-se em uma série de medidas prioritárias que envolvem desde a redução dos riscos até uma maior preparação para as respostas, espera-se reduzir significativamente o número de vidas e fontes de sustento ceifadas pelos desastres naturais.

Buscando ampliar e aperfeiçoar as discussões sobre o tema da resiliência a desastres naturais, o Escritório das Nações Unidas para Assuntos do Espaço Sideral (UNOOSA) promoveu em dezembro de 2012, um evento denominado "Encontro Internacional de Especialistas em Mapeamento Crowdsource de Gestão de Risco de Desastres e Resposta de Emergência" (ONU, 2012a).

Importante destacar que a lógica das redes emergentes pode se fazer presente em diversas fases da resposta e reconstrução das áreas afetadas por desastres naturais. A comunidade pode participar do processo com informações importantes como a localização de áreas de risco, de sobreviventes e de pontos onde se faz necessário o resgate de pessoas e/ou o envio de suprimentos. Isso permite, entre outras coisas, a construção coletiva de mapas, a partir do uso de tecnologias espaciais e do aproveitamento de imagens de satélite, que são capazes de apontar claramente onde estão as demandas a serem atendidas por cada uma das frentes e instituições envolvidas (MULLINS, 2010).

No Brasil, o Plano Nacional de Gestão de Riscos e Resposta a Desastres (PNGRD) prevê uma série de ações a serem implantadas até 2015, porém, não se evidencia em nenhuma de suas etapas o recurso a ações que utilizem redes da sociedade civil no apoio à resposta a desastres naturais (BRASIL, 2012a).

Observa-se também que diversos órgãos de defesa civil municipal e até mesmo o sistema de defesa civil nacional possuem perfis em mídias sociais, principalmente o Facebook. Contudo, tais perfis caracterizam-se muito mais como fontes de divulgação de informações do que propriamente como receptoras e direcionadoras de demandas em contextos pós-desastre natural. 
Diante do exposto, a tese pressupõe que a ação de redes da sociedade civil na resposta a desastres naturais possui uma natureza essencialmente emergente, isto significa dizer que tais redes não existiam para essa finalidade, quando do planejamento da gestão do desastre. Pressupõe-se também que tais redes revelamse de grande valia nesses contextos turbulentos, em que as instituições formais normalmente se encontram sem condições de atender adequadamente a todas as demandas. Como ocorrido no estado do ES em dezembro de 2013, a rede iniciada pela sociedade civil organizada não pareceu nascer de qualquer planejamento anterior, mas sim emergiu da capacidade, da vontade e da solidariedade da população local que decidiu apoiar as vítimas das chuvas em todo o estado.

Pelo exposto, considera-se relevante a compreensão de tal fenômeno, especialmente nos aspectos relativos ao seu surgimento e topologia, na busca por respostas à seguinte questão principal de pesquisa: Qual a natureza dos fenômenos de comunicação e mediação da informação, estruturados em redes sociais voltadas a ações de resposta a desastres naturais?

\subsection{OBJETIVO GERAL}

Analisar os fenômenos de comunicação e mediação da informação, estruturados em uma rede social de resposta a um desastre natural.

\subsection{OBJETIVOS ESPECÍFICOS}

- $\mathrm{OE}_{1}$ : Descrever o surgimento de uma organização estruturada na forma de rede social, no caso específico da resposta às chuvas de dezembro de 2013 no ES, bem como as atividades por ela desenvolvidas; 
- $\mathrm{OE}_{2:}$ Identificar os fenômenos de comunicação e mediação da informação, existentes nessa rede social;

- $\mathrm{OE}_{3:}$ Identificar o relacionamento dessa rede social, com as organizações estabelecidas para a gestão de desastres no ES, especialmente com a Defesa Civil Estadual;

- $\mathrm{OE}_{4:}$ Realizar uma análise comparativa entre as estruturas de ação da Defesa Civil Estadual e da rede social de apoio às vítimas das chuvas de dezembro de 2013 no ES;

- $\mathrm{OE}_{5:}$ Mapear a topologia dessa rede social, identificando e analisando algumas de suas propriedades a partir da Análise de Redes Sociais.

\subsection{JUSTIFICATIVA}

Ao longo da história humana, as comunidades vêm moldando o meio ambiente de forma a satisfazer suas necessidades de sobrevivência e interesses, utilizando-se para isso, de mecanismos cada vez mais agressivos e sofisticados. Em muitas situações, essa remodelagem ambiental acaba por aumentar a vulnerabilidade de muitas áreas geográficas, ampliando as dimensões e consequências de um possível desastre natural.

Os desastres naturais vêm provocando inúmeras perdas materiais e humanas ao longo do tempo, assumindo variadas formas nas diferentes partes do mundo. Tem havido um aumento significativo não só na sua frequência e intensidade, mas também nos impactos gerados às populações, causando danos e prejuízos cada vez maiores.

Em âmbito global, a discussão da relação das mudanças climáticas em curso no planeta, com a ocorrência cada vez mais acentuada de desastres naturais, ocupa o centro das atenções de diversas instituições, autoridades e especialistas no assunto, incluindo esferas diversificadas como a política, a econômica e a acadêmico científica. Além do risco de incontáveis perdas humanas que justificam tal preocupação, é preciso considerar também os aspectos econômicos que circundam 
o problema. Estima-se, por exemplo, que 4,3\% do PIB global estão situados em regiões que com frequência são afetadas por ciclones tropicais (ONU, 2013).

São vários os exemplos de desastres naturais ocorridos somente nos últimos anos ao redor do mundo. O tsunami na Indonésia em 2004; nos Estados Unidos, o furacão Katrina na cidade de Nova Orleans em 2005, além do furacão Sandy em 2012, que afetou importantes cidades norte americanas como Nova Jersey e Nova York além de países da América Central; o terremoto que atingiu o Haiti em 2010; o terremoto seguido de tsunami no nordeste do Japão em 2011; o furacão Haiyan nas Filipinas em 2013; o terremoto no Nepal em 2015, além de tantos outros que alimentam as estatísticas sobre o assunto.

A Estratégia Internacional das Nações Unidas para a Redução do Risco de Desastres divulgou em maio de 2013 um Relatório de Avaliação Global em que realizou uma revisão das perdas ocorridas com desastres naturais em 56 países, concluindo que perdas diretas de inundações, terremotos e secas estavam sendo subestimadas em aproximadamente cinquenta por cento. Apenas nos primeiros treze anos desse século as perdas com desastres naturais chegam a 2,5 trilhões de dólares, chegando a ser consideradas fora de controle pelas Nações Unidas. Entre outros aspectos, destaca-se no relatório que o modelo de negócios vigente no desenvolvimento urbano, agronegócio e turismo costeiro, que são três setores chave em termos de investimento econômico, têm alavancado os riscos de desastres, exigindo, portanto, uma mudança de atitude no setor privado. Assim, o documento sugere que parcerias entre as iniciativas privada e pública sejam capazes de colocar em prática e melhorar as atuais estratégias vigentes para a gestão de desastres (ONU, 2013).

Percebe-se que, no Brasil, a vulnerabilidade das comunidades afetadas é fator preponderante na intensidade e frequência dos desastres naturais, muito mais até do que a própria magnitude dessas ocorrências adversas.

Entre 1991 e 2010, foram mais de 96 milhões de pessoas afetadas por 31.909 desastres naturais no país, sendo 8.671 (27\%) na década de 90 e 23.238 (73\%) na década de 2000. A fragilidade do sistema de registro da Defesa Civil Nacional é reconhecida e histórica (UNIVERSIDADE FEDERAL DE SANTA CATARINA, 2012). Entretanto, os números permitem constatar que: ou há um aprimoramento e um 
compromisso maior dos responsáveis com a realização dos registros, ou há uma sensível tendência de aumento de tais ocorrências na última década, podendo até mesmo coexistir as duas situações (UNIVERSIDADE FEDERAL DE SANTA CATARINA, 2012).

No ano de 2011, o Brasil esteve entre as nações mais afetadas por desastres naturais em todo o mundo. Em um ranking liderado pela Tailândia, seguida pelo Camboja e Paquistão e composto pelos dez países mais afetados naquele ano, o Brasil ocupou o sexto lugar (ONU, 2012a).

Estudos realizados pelo Banco Mundial em parceria com governos estaduais e a Secretaria Nacional de Defesa Civil, mostram prejuízos de aproximadamente 15 bilhões de reais, referentes apenas à enchente em Santa Catarina em 2008, às chuvas em Alagoas e Pernambuco em 2010 e aos deslizamentos de terra na Região Serrana do Rio de Janeiro em 2011 (ONU, 2012b).

Além dessas catástrofes, não se pode deixar de mencionar as secas e estiagens que em 2012, foram as piores dos últimos 30 anos no Semiárido brasileiro, levando mais de $50 \%$ dos municípios do nordeste a decretarem situação de emergência (BERTONE; MARINHO, 2013).

Apresenta-se como fator agravante da realidade acima exposta, o fato de apenas $11,8 \%$ dos municípios brasileiros estarem preparados para lidar com situações de desastres naturais, sendo o Centro-Oeste a região com menor número de municípios com planos de contingência ou emergência para casos de desastres ambientais já definidos (IBGE, 2013).

As inundações ocorridas em Santa Catarina em 2008, em Alagoas e Pernambuco em 2010 e as grandes enxurradas e deslizamentos que atingiram a região serrana do Rio de Janeiro em 2011 elevaram a necessidade de priorização, por parte do Governo Federal, da questão da Defesa Civil no Brasil. A ênfase na prevenção, a partir de uma abordagem multidisciplinar tem sido predominante nas reflexões sobre o tema (BRASIL, 2012a).

As formas mais tradicionais de organização para a resposta de desastres envolvem gabinetes de emergência ou de crise compostos por representantes de diferentes esferas públicas, seja no nível municipal, estadual ou federal. A tomada de decisão 
normalmente cabe a um órgão central, que conta com o apoio de unidades de trabalho voltadas para diferentes áreas de atuação, como saúde, logística, operações, assistência social, fazenda, dentre outras (PREFEITURA MUNICIPAL DE VITÓRIA, 2007). Ou seja, verifica-se a predominância de uma lógica hierárquica de comando e controle nesses contextos.

No Brasil, uma ferramenta gerencial padronizada para responder aos desastres, denominada Sistema de Comando em Operações (SCO), tem sido bastante utilizada pelas instituições governamentais responsáveis pela gestão de desastres naturais. O SCO possui, entre outros objetivos, permitir que as esferas federal, estadual e municipal atuem de maneira integrada com o setor privado e também com organizações não governamentais.

O SCO se sustenta nas diretrizes da Federal Emergency Management Agency (FEMA) e do Standardized Emergency Management System (SEMS), da Califórnia, EUA. A Defesa Civil do Estado de Santa Catarina, apoiada pelo Centro Universitário de Estudos e Pesquisas sobre Desastres da Universidade Federal de Santa Catarina (CEPED/UFSC), tem disseminado o uso dessa ferramenta para os demais estados do país (OLIVEIRA, 2010).

Entretanto, conforme já mencionado, para além do preconizado no planejamento da gestão de desastres pelo Estado, percebe-se que formas de organização em rede têm atuado de maneira decisiva em situações críticas ao redor do planeta. Essas formas envolvem essencialmente a colaboração da sociedade civil e configuram-se como redes emergentes. Tais configurações evidenciam a interconexão de variados atores com competências diferenciadas entre si, mas que potencializam sua capacidade de ação a partir de sua inserção em redes sociais comprometidas com objetivos de assistência humanitária, por exemplo.

No ES, o processo de gestão de desastres pode ser tido como um exemplo típico dessa realidade que convive ao mesmo tempo com aspectos formais e aspectos emergentes.

A partir de um levantamento realizado pela defesa civil estadual referente ao período compreendido entre 2000 e 2012, constatou-se que sete são os tipos de desastres 
mais comuns no ES: inundação, enxurrada, estiagem, vendaval, granizo, deslizamento e erosão marinha (ESPÍRITO SANTO, 2014).

De acordo com a Defesa Civil Estadual, a situação do ES é preocupante, tendo sido registrados com bastante frequência, especialmente no período de outubro a março, desastres relacionados com chuvas fortes, como as enchentes, as enxurradas e os deslizamentos. Não menos preocupantes são as estiagens e secas, que também vêm causando inúmeros danos e prejuízos ao longo do tempo no estado (ESPÍRITO SANTO, 2014).

Conforme determina a Política Nacional de Proteção e Defesa Civil e buscando uma atuação mais assertiva nos processos de gestão de desastres, o ES, de forma pioneira no Brasil, elaborou seu Plano Estadual de Proteção e Defesa Civil (PEPDEC). Desenvolvido pelo Governo do Estado o plano teve sua primeira versão publicada no início de 2013 e já está em sua quinta atualização. Prevê uma série de ações para a prevenção, preparação e resposta a desastres naturais, por meio da articulação entre diversas instituições que compõem o chamado Comitê Estadual de Combate às Adversidades Climáticas. Mais especificamente para as ações de resposta, o CBMES faz uso do SCO, conforme já descrito anteriormente (OLIVEIRA, 2010; ESPÍRITO SANTO, 2014).

Contudo, como ocorreu em dezembro de 2013 como consequência das fortes chuvas que se abateram sobre o ES, um novo elemento ainda pouco conhecido e explorado também pode atuar nessa situação: a sociedade civil que se organiza em rede e apoia as vítimas das chuvas, desenvolvendo, principalmente, ações humanitárias de recebimento e distribuição de donativos.

Considera-se que ferramentas como o PEPDEC e o SCO são elementos pertencentes ao universo da gestão formal dos processos de gestão de desastres no estado, tendo seus mecanismos já bastante reconhecidos e divulgados, principalmente no âmbito das instituições estabelecidas responsáveis, ou seja, no âmbito do Estado e não da sociedade.

Entretanto, a maneira com que redes emergentes se estruturam e atuam, bem como a sua topologia ainda carece de investigação e detalhamento, para que se possa 
compreender de maneira mais abrangente o contexto da resposta a desastres naturais.

Como uma representação típica da realidade nacional, o caso das fortes chuvas no estado do ES em 2013 foi delineado e estudado de forma exploratória, especialmente no que tange aos fenômenos de comunicação e mediação da informação na rede emergente nas ações de resposta. Espera-se que a descrição e análise da topologia e do funcionamento de tal rede possam ser úteis para uma maior aproximação a esses fenômenos, contribuindo tanto para a esfera da gestão de desastres por parte das instituições responsáveis, quanto para um maior conhecimento científico sobre o tema, especialmente no campo da Ciência da Informação.

É de fundamental importância, uma compreensão que seja capaz de colocar ao lado dos processos gerenciais formais, hierárquicos e centralizados, a imprevisibilidade, a informalidade e a descentralização típicas dos formatos em rede.

\subsection{PRESSUPOSTOS DA PESQUISA}

Sobre as redes sociais atuantes na resposta a desastres naturais, considera-se que:

$P_{1}$ : Inserem-se no âmbito da Ciência da Informação como um fenômeno não clássico, cuja organização e animação encontram significativo suporte nas novas TICs.

$\mathrm{P}_{2:}$ A comunicação se apresenta como elemento regulador e essencial à sua autoorganização, a partir da qual se tornam possíveis a articulação das multilideranças e a coordenação de diferentes ações.

$\mathrm{P}_{3}$ : Em seu âmbito, a mediação da informação possui características diferenciadas em relação a algumas conceituações mais usuais da Ciência da Informação. 
$\mathrm{P}_{4}$ : Em seu processo de estruturação, os atores contam com laços relacionais préexistentes, mas também estabelecem novos laços de forma dinâmica.

$P_{5}$ : As estruturas usuais do Estado para a resposta a desastres naturais possuem como princípios o comando, o controle e a hierarquia. Por outro lado, a estruturação em rede, representada pelos grupos emergentes no pós-desastre natural, possui natureza autônoma, voluntária e solidária, cujas características denotam aproximações com a racionalidade substantiva.

\subsection{ESTRUTURA DA TESE}

O trabalho está dividido em outros seis capítulos além deste primeiro. O capítulo 2 apresenta o referencial teórico que dá suporte às discussões essenciais ao alcance dos objetivos propostos na pesquisa. Ele está subdividido em oito seções principais. A primeira apresenta os trabalhos correlatos identificados na etapa de levantamento bibliográfico. A segunda aborda aspectos relacionados à sociedade da informação, ao conceito de informação e à ciência da informação, com enfoque voltado para o contexto da pesquisa. A seção 2.3 trata mais especificamente da chamada inteligência coletiva, trazendo algumas de suas diversas abordagens e conceituações. A quarta seção analisa as teorias da complexidade. A seção 2.5 apresenta alguns fundamentos sobre redes e a seção 2.6 dedica-se a apresentar a Análise de Redes Sociais - ARS por meio de alguns de seus principais conceitos e propriedades. A seção 2.7 apresenta alguns paralelos entre as estruturas burocráticas e as redes sociais. Na seção 2.8 estão presentes questões relativas à comunicação e à mediação da informação nas redes sociais.

O capítulo 3 trata de estruturas burocráticas e grupos emergentes na resposta a desastres naturais. A seção 3.1 destaca aspectos essenciais à compreensão dos fenômenos dos desastres naturais no Brasil, realizando uma contextualização mais específica da gestão de desastres no Espírito Santo. Na seção 3.2 estão 
apresentados aspectos teóricos e conceituais acerca da atuação dos chamados grupos emergentes em situações de desastres naturais.

O capítulo 4 descreve o percurso metodológico trilhado para o alcance dos objetivos propostos na pesquisa. O capítulo 5 contém a apresentação e análise dos resultados obtidos na pesquisa e o capítulo 6 apresenta aspectos dos fenômenos de comunicação e mediação da informação no contexto estudado. O capítulo 7 destaca as conclusões e considerações finais da tese. 


\section{REFERENCIAL TEÓRICO}

Este capítulo apresenta as principais definições, conceituações e abordagens relacionadas ao tema da pesquisa, identificadas a partir da revisão de literatura realizada. Inicia-se com a apresentação dos trabalhos correlatos.

\subsection{TRABALHOS CORRELATOS}

Esta seção apresenta e descreve sucintamente os trabalhos identificados durante a fase de levantamento bibliográfico e que apresentam semelhanças com a temática do estudo aqui desenvolvido.

No que tange à pesquisa científica brasileira relacionada às redes sociais atuantes em resposta a desastres naturais, foi possível identificar apenas um trabalho correlato. Trata-se de artigo científico intitulado "Análise de redes sociais em uma situação de gerenciamento de crise" apresentado no Congresso Latino Iberoamericano de Investigação Operativa e Simpósio Brasileiro de Pesquisa Operacional de 2012. O trabalho propõe a aplicação de ARS no estudo de desastre natural decorrente de fortes chuvas, na cidade de São José dos Campos, em São Paulo. O estudo realiza duas análises principais: análise de atraso do fluxo de informação e análises de centralidade. $O$ enfoque encontra-se na rede interorganizacional formal de atuação na resposta ao desastre (JUSTI JUNIOR et al., 2012).

No contexto externo, foram identificados, entre outros, dois trabalhos australianos. O primeiro, de Barraket e outros (2013), vinculado ao The Australian Centre for Philanthropy and Nonprofit Studies da Queensland University of Technology, intitulado "Spontaneous volunteering during natural disasters". O estudo teve como principais objetivos: examinar as características e motivações dos voluntários que se oferecem espontaneamente para atuarem numa situação de resposta a uma crise 
além de esclarecer os efeitos do voluntariado espontâneo em redes pessoais, sociais e cívicas.

O segundo trabalho australiano é do de Beagrie (2009), resultado de um projeto vinculado à Cruz Vermelha Australiana e que analisa características dos grupos emergentes em situações de resposta a desastres. $O$ trabalho é intitulado "Emergent Groups in Disaster Response".

Além desses, no contexto internacional foi identificado o enorme destaque que possuem os trabalhos de Quarantelli, acerca da sociologia dos desastres. O autor é vinculado ao Disasters Research Center (DRC), da Universidade de Delaware, nos Estados Unidos e possui vários estudos acerca das ações de resposta a desastres naturais, incluindo uma tipologia para as diferentes organizações que costumam atuar nessas circunstâncias. Entre esses artigos destacam-se: "Organizational response to the Mexico City earthquake of 1985: characteristics and implications" de 1993 e "Response to social crisis and disaster", de 1977.

Trabalho importante também possui o "National Research Council' dos Estados Unidos. Trata-se do sumário de um Workshop, intitulado "Aplications of social network analysis for building community disaster resilience”, que busca identificar como aplicações de Análises de Redes Sociais podem auxiliar na construção de resiliência por parte das comunidades afetadas por desastres naturais.

O artigo de Majchrzak, Jarvenpaa e Hollingshead (2007), intitulado "Coordinating expertise among emergent groups responding to disasters", apresenta análises sobre a expertise dos membros de grupos emergentes na resposta a desastres e busca identificar, entre outras questões, como a especialização é coordenada entre os membros de grupos dessa natureza.

Nolte e Boenick (2013) exploram os elementos que impactam sobre o desempenho de redes públicas e sem fins lucrativos na resposta a desastres no artigo intitulado "A study of ad hoc network performance in disaster response". Também foi identificado o artigo de Voorhees (2008), que busca analisar características da organização de um grupo emergente que atuou após o ataque terrorista ao World Trade Center. O trabalho se intitula "New Yorkers Respond to the World Trade Center Attack: An Anatomy of an Emergent Volunteer Organization". 
Tendo sido apresentados os trabalhos correlatos, passa-se à próxima seção, onde estão estruturados e discutidos os demais conteúdos relativos ao suporte teórico utilizado nesta tese.

\subsection{SOCIEDADE DA INFORMAÇÃO: APROXIMAÇÕES RELEVANTES PARA O CONTEXTO DA PESQUISA}

Ao iniciar as discussões teóricas que dão suporte à pesquisa, torna-se necessário abordar aspectos relativos às transformações sociais e tecnológicas em desenvolvimento, bem como situar a informação e a ciência da informação nesse contexto. Com isso, busca-se o delineamento do panorama que circunda o objeto de pesquisa em análise, assim como a abordagem que será dada ao conceito de informação durante a busca pela consecução dos objetivos propostos no trabalho.

O paradigma da sociedade da informação (CASTELLS, 1999) apresenta a tecnologia e a informação como partes integrantes tanto dos processos produtivos quanto das relações sociais. Nessa forma peculiar de organização social, tem-se que a geração, o processamento e a transformação das informações são fatores essenciais ao processo de sociabilidade. Assim, o cerne de tal transformação referese às tecnologias de informação, processamento e comunicação.

As novas Tecnologias de Informação e Comunicação (TICs) são o grande fio condutor para a consolidação da lógica das redes nesse novo contexto. Conforme analisa Benkler (2006), quando o denomina de Economia da Informação em Rede, esse novo contexto representa uma profunda transformação também nos parâmetros técnicos e econômicos da sociedade.

Em resumo, o paradigma da tecnologia da informação não evolui para seu fechamento como um sistema, mas rumo à abertura como uma rede de acessos múltiplos. É forte e impositivo em sua materialidade, mas adaptável e aberto em seu desenvolvimento histórico. Abrangência, complexidade e disposição em forma de rede são seus principais atributos (CASTELLS, 1999, p. 113). 
A característica extremamente complexa das novas interações parece fazer da estruturação em rede o formato ideal para essa nova dinâmica de interconexões cada vez mais rápidas e imprevisíveis. As redes são capazes de ao mesmo tempo conferir estrutura e manter a flexibilidade tão necessária aos processos criativos e inovadores em curso (CASTELLS, 1999).

Portanto, ao lado da lógica das redes, a flexibilidade é também essencial ao novo paradigma tecnológico, na medida em que a mudança e a fluidez organizacional, tão características da sociedade da informação, necessitam encontrar apoio em sua capacidade constante de reconfiguração (CASTELLS, 1999).

Esse ambiente dinâmico é visto por Takahashi (2000) como possuidor de um potencial social indiscutível em sua capacidade de reduzir distâncias e aumentar o nível de informação das pessoas. Organizando-se a partir de constantes transformações, não apenas propicia novas formas de interconexão, como também possibilidades de diferentes experimentações capazes de transformar a natureza da própria estrutura e da ação social que passam a se ressignificar continuamente.

Assim, tais avanços permitem a construção de um social em rede que tem como consequência, profundas transformações em vários aspectos do convívio humano. Nele, as práticas e as interações sociais são transformadas a partir de sua inserção em circuitos informativos interativos. O significado do próprio contexto social torna-se modificado a partir da introdução de novas tecnologias comunicativas (BENKLER, 2006; DI FELICE, 2007; CASTELLS, 1999).

O chamado social tecnológico é fruto da mediação entre sujeitos, grupos, empresas e instituições e meios de comunicação, potencializada pelo surgimento das redes interativas e da comunicação digital. Nesse contexto, a visão estrutural funcionalista, típica da sociedade industrial e da concepção analógica de comunicação, onde unidades estanques interagem entre si a partir de funções e mecanismos bem delimitados, cede lugar a uma realidade metamórfica e híbrida, marca preponderante no social digital (DI FELICE, 2007).

De uma forma geral, as ciências sociais passam a ser desafiadas em vários aspectos a partir dessas transformações. 
O resultado do surgimento desse novo social interativo e ilimitado questiona as ciências sociais, não somente em nível de técnica de pesquisa que busquem alcançar ao lado do social tradicional as suas novas expressões virtuais, mas, sobretudo, em nível de categorias, paradigmas e conceitos. Como definir e, portanto, delimitar um social em rede? De que forma distinguir as territorialidades e os atores das suas sociabilidades mutantes na rede? (DI FELICE, 2007, p.6)

Tal desafio está posto para os diferentes campos do conhecimento. Entretanto, para a Ciência da Informação $(\mathrm{Cl})$, que toma a informação como seu principal objeto de interesse, esse desafio parece ser ainda maior (PINHEIRO, 2004). Além disso, estando a $\mathrm{Cl}$ fortemente atrelada à tecnologia da informação, pode ser considerada como participante ativa na evolução da sociedade da informação. Suas fortes dimensões humanas e sociais circundam amplamente a questão tecnológica (SARACEVIC, 2009).

O processo de transformação tecnológica cresce de maneira exponencial justamente por sua capacidade de "criar uma interface entre campos tecnológicos por meio de uma linguagem digital comum na qual a informação é gerada, armazenada, recuperada, processada e transmitida" (CASTELLS, 1999, p. 68). Assim, as tecnologias são desenvolvidas para agir sobre a informação, sendo que suas novas formas de uso podem ser consideradas como fios condutores das grandes transformações tecnológicas atualmente em curso.

É preciso ponderar, contudo, que a $\mathrm{Cl}$ trata a informação a partir de uma visão multifacetada, "tanto podendo ser informação numa determinada área quanto sob determinada abordagem" (PINHEIRO, 2004, p. 03). E como cada área do conhecimento parece ter uma concepção particular de informação, são muitas as definições existentes para o termo, chegando a ser considerado um caso extremo de polissemia (WERSIG; NEVELING, 1975).

Dentre as definições existentes, estão aquelas que relacionam a informação à produção de conhecimento no indivíduo. A partir delas, a informação é considerada como capaz de transformar o indivíduo, seu grupo, e por consequência, a sociedade como um todo. O conhecimento que se torna concreto a partir da percepção da informação é que permite ao individuo uma melhor convivência consigo mesmo e uma oportunidade de modificação de sua consciência (BARRETO, 1994).

A informação, quando adequadamente assimilada, produz conhecimento, modifica o estoque mental de informações do indivíduo e traz benefícios ao 
seu desenvolvimento e ao desenvolvimento da sociedade em que ele vive. Assim, como agente mediador na produção do conhecimento, a informação qualifica-se, em forma e substância, como estruturas significantes com a competência de gerar conhecimento para o indivíduo e seu grupo (BARRETO, 1994, p. 2).

As transformações ocorridas nas formas de relação social a partir da chamada sociedade da informação parecem demandar essas formas de visualização do fenômeno da informação, mas também outras mais amplas. Formas essas que sejam capazes de abarcar o fenômeno inserido no contexto complexo e dinâmico das redes e do social tecnológico. Contudo, percebe-se que considerável parcela dos estudos da informação nas ciências sociais, tem sido ancorada na visão sistêmica, sobretudo em CI (MARTELETO, 1987).

A lógica sistêmica implantou-se na ciência e passou a habitar de forma marcante os campos social, político e econômico. No âmbito dessa concepção, a informação possui um propósito regulador, cuja função é permitir o equilíbrio homeostático do sistema, seja ele físico, biológico ou social. Nesse contexto, "a informação é então um elemento quantificável, sujeito a formulações matemáticas, como as células e as partículas atômicas"(MARTELETO, 1987, p.10).

As abordagens críticas ou dialéticas da informação, por sua vez, consideram a importância das relações sociais. Assim, ao invés de possuir um papel regulador e mantenedor de estruturas, a informação nessas abordagens assume seu viés transformador, capaz, portanto, de romper com o status quo. Ao ser compreendida como um fenômeno social, as dimensões políticas, econômicas e históricas da informação são evidenciadas (MARTELETO, 1987).

Assim, considerando-se a abordagem sistêmica e também a crítica, a informação pode assumir tanto seu caráter técnico (formatação, tratamento e recuperação automáticos) quanto seu caráter cultural (conhecimento). Portanto, atua ora como um bem de produção e ora como um bem cultural. A questão que se coloca diante da complexa realidade consolidada a partir da sociedade da informação é o reconhecimento do que seja o campo técnico e do que seja o campo cultural no papel da informação (MARTELETO, 1987).

Complementarmente, torna-se necessário tomar a informação em seu sentido mais amplo, o que considera seu uso sempre em um contexto específico e em relação a 
algumas motivações. Evidencia-se, nessa abordagem de informação, o papel social da Ciência da Informação. Nele, a informação envolve não somente mensagens que são processadas cognitivamente, mas também motivações e intencionalidades dadas a priori. Sendo assim está intimamente relacionada a um contexto social que pode estar representado pela cultura, pelo trabalho ou pela necessidade de solução de um problema específico (SARACEVIC, 2009).

No mesmo sentido está a concepção de que para a $\mathrm{Cl}$ os aparatos tecnológicos, bem como suas possibilidades e limitações, passam a assumir maior importância na medida em que afetam as relações sociais estabelecidas em um determinado contexto. Assim, para a $\mathrm{Cl}$, torna-se importante uma abordagem de informação que leve em consideração o seu entorno social e que busque compreender mais profundamente a natureza das relações sociais (VICKERY; VICKERY, 2004).

No contexto das novas tecnologias da informação e comunicação, tal postura tornase quase um imperativo, considerando-se que o próprio desenvolvimento tecnológico se constitui como produto de uma ação coletiva complexa.

O que denominamos novas tecnologias são na verdade a atividade multiforme de grupos humanos, um devir coletivo complexo que se cristaliza sobretudo em volta de objetos materiais, de programas de computador e de dispositivos de comunicação (LÉVY, 2011, p. 23).

Não se trata de dizer que a sociedade determina a tecnologia ou vice-versa, mas sim de considerar que tecnologia e sociedade influenciam-se, reciprocamente, dado que "a tecnologia é a sociedade e a sociedade não pode ser representada sem suas ferramentas tecnológicas" (CASTELLS, 1999, p. 43).

No contexto das implicações culturais e sociais do desenvolvimento das novas TICs é que se passa a conceber a ideia de uma cibercultura. Esta, por sua vez, constituise como um "conjunto de técnicas (materiais e intelectuais), de práticas, de atitudes, de modos de pensamento e de valores que se desenvolvem juntamente com 0 crescimento do ciberespaço (LÉVY, 2011, p. 13)”.

O ciberespaço tem sua formação baseada em três princípios essenciais, quais sejam: a interconexão, a criação de comunidades virtuais e a inteligência coletiva. Tais princípios atuam em uma dinâmica de retroalimentação que proporciona o acompanhamento das rápidas mudanças em curso e a emergência de redes de coletivos inteligentes e articulados. 
Não há comunidade virtual sem interconexão, não há inteligência coletiva sem virtualização ou desterritorialização das comunidades no ciberespaço. A interconexão condiciona a comunidade virtual que é a inteligência coletiva em potencial. (LÉVY, 2011, p. 23).

Assim, a consolidação de um ciberespaço é vista como decorrência direta da interconexão mundial de computadores. Essa redução e barreiras comunicativas impacta fortemente a física da comunicação. Trata-se de uma grande rede que se configura como dispositivo de comunicação interativo e comunitário capaz de dar suporte ao desenvolvimento de uma inteligência coletiva (LÉVY, 1999).

Em sentido semelhante, Braga (2009) e Rheingold (2012) apresentam a inteligência coletiva como um fenômeno emergente possibilitado em grande medida pelas novas tecnologias digitais que permitem o surgimento de maneiras diferenciadas de organização social. A seguir passa-se a apresentar algumas importantes ponderações acerca do fenômeno da inteligência coletiva.

\subsection{INTELIGÊNCIA COLETIVA: UM FENÔMENO COMPLEXO}

Pode-se dizer que o conceito de inteligência coletiva é bastante difuso, possuindo abordagens diferenciadas, porém muitas vezes complementares, conforme o campo de estudo e os autores em análise (HEYLIGHEN, 2013; JENKINS, 2006; LÉVY, 2011; NOUBEL, 2006; RHEINGOLD, 2012; SOLACHIDIS et al., 2010; WOOLLEY et al., 2010). Trata-se de um fenômeno com variadas nuances e perspectivas.

Uma das linhas de análise mais comuns para o fenômeno da inteligência coletiva é a que o localiza onde um grupo de agentes inicialmente independentes, desenvolve uma abordagem coletiva para a solução de um determinado problema de uma maneira compartilhada, que é mais poderosa do que a abordagem que qualquer um deles poderia ter desenvolvido de forma individual (HEYLIGHEN, 2013; LÉVY, 2011; NOUBEL, 2006; RHEINGOLD, 2012).

Um dos autores que mais tem se destacado nos estudos e propostas sobre a inteligência coletiva é Lévy (2011). Para ele, a inteligência coletiva proposta pela 
cibercultura possui caráter participativo, socializante, descompartimentalizante e emancipador.

\begin{abstract}
A inteligência coletiva é uma inteligência variada, distribuída por todos os lugares, constantemente valorizada, colocada em sinergia em tempo real, que engendra uma mobilização otimizada das competências. Assim como a entendo, a função da inteligência coletiva é colocar os recursos de grandes coletividades a serviço das pessoas e dos pequenos grupos e não o contrário. É, portanto, um projeto fundamentalmente humanístico, que retoma para si, com os instrumentos atuais, os grandes ideais de emancipação da filosofia das luzes (LÉVY, 2011, p.183,184).
\end{abstract}

Além de se relacionar fortemente à inteligência coletiva, a ideia de emancipação também se encontra diretamente relacionada ao fenômeno das redes sociais, conforme pode se obervar a partir das discussões realizadas, mais à frente, na subseção 2.7.2. Constata-se que o caráter emancipador permeia tanto a inteligência coletiva, quanto as redes sociais, fortalecendo ainda mais a percepção de que a utilização do conceito de inteligência coletiva pode enriquecer as reflexões e discussões aqui realizadas.

A essência da definição de Lévy se encontra na afirmação de que ninguém é detentor de todos os conhecimentos, mas todos sabem alguma coisa e, assim, cai por terra a lógica da ignorância. Ao mesmo tempo, os conhecimentos individuais são acessíveis a todos os demais membros de certa coletividade, por meio de diferentes mecanismos, atualmente representados, em grande medida, pelas novas TICs.

Outro aspecto essencial à conceituação de Lévy é que a coordenação das inteligências em tempo real evidencia a importância da intervenção de tecnologias digitais de informação, objetivando a efetivação da comunicação entre os agentes.

A abordagem da inteligência coletiva foge a um contexto exclusivamente cognitivo e extrapola seu alcance para uma lógica colaborativa, de trabalho conjunto, típica da realidade proporcionada pelas interações realizadas em rede.

Bernal (2010) ao analisar o conceito de inteligência coletiva proposto por Lévy, identifica que é predominante no seu pensamento a ideia de que a inteligência humana é capaz de encontrar soluções para os desafios resultantes de seu próprio exercício, se auto-corrigindo. Sendo assim, destaca-se que:

[...] a inteligência coletiva não incorpora discursos prontos, axiomas, verdades comprovadas - não nos demanda, portanto, qualquer tipo de sujeição ideológica ou de adesão a um programa concluído e fechado. Ao 
contrário, a proposta da inteligência coletiva é a da instituição de um estado de coisas - ou ambiente político - singularmente favorável a que a sociedade, por si mesma e por inteiro, de forma livre, dialogada, permanente e intensamente cooperativa, decida o que tem valor e o que é útil, julgue o que é problemático, descubra as soluções de que precisa, as aperfeiçoe em comum e as adote, impulsando sua normatização por quem de direito, enquanto resistirem às novas críticas - em tudo isso assumindo sua responsabilidade compartilhada e decidindo conscientemente o seu percurso histórico (BERNAL, 2010, p. 14, grifo do autor).

Nesse sentido, os dispositivos técnicos que propagam a inteligência coletiva não são vistos como resultados de um planejamento elaborado por especialistas em um poder central. Assim não há em seu contexto distinção entre beneficiários e responsáveis, não há submissão, pois se assim for, não se trata de inteligência coletiva. A inteligência coletiva é por natureza integradora, includente e participativa (LÉVY, 1999).

Ainda de acordo com Bernal (2010), percebe-se nas conceituações de Lévy dois importantes traços intelectuais que por vezes se tornam objeto de crítica às suas ideias: otimismo antropológico e pensamento utópico. Tais críticas vêm sendo tecidas por outros pensadores como Baudrillard, que conferem a Lévy o erro de possuir um otimismo tecnológico delirante, ou um encantamento messiânico do virtual, que o condenam a visualizar apenas o lado maravilhoso da expansão da esfera da informação.

Esse exagerado otimismo configura-se como um grande risco de confiar à tecnologia, em seus novos avanços e formatos, a missão de eliminar os problemas da humanidade. Entretanto, Lévy (1999) constrói sua própria defesa, afirmando que:

Em geral me consideram um otimista. Estão certos. Meu otimismo, contudo, não promete que a Internet resolverá, em um passe de mágica, todos os problemas culturais e sociais do planeta. Consiste apenas em reconhecer dois fatos. Em primeiro lugar, que o crescimento do ciberespaço resulta de um movimento internacional de jovens ávidos para experimentar, coletivamente, formas de comunicação diferentes daquelas que as mídias clássicas nos propõem. Em segundo lugar, que estamos vivendo a abertura de um novo espaço de comunicação, e cabe apenas a nós explorar as potencialidades mais positivas desse espaço nos planos econômico, político, cultural e humano. (LÉVY, 1999, p.11)

Moraes (2011), ao analisar as críticas à Lévy, considera que não se trata de atribuir, necessariamente, ao crescimento do ciberespaço, a existência de uma inteligência coletiva, mas sim de compreender que o ciberespaço é apenas capaz de criar condições adequadas para que essa inteligência se estruture. 
Também em defesa de Lévy, Bernal (2010) enfatiza que apesar desse autor poder ser tido claramente como um otimista, seu otimismo não pode ser considerado tão ingênuo a ponto de desconsiderar o embate de forças sobre o qual se estrutura 0 contexto social. Trata-se, portanto, na opinião de Bernal (2010), de um otimismo realista, aquele proferido por Lévy.

Pode-se verificar tal visão, na análise da obra do próprio Lévy (1999) quando esse afirma que ao mesmo tempo em que pode questionar poderes, ampliar a participação social e diminuir efeitos indesejáveis da mutação técnica, como a exclusão digital, a inteligência coletiva, em certos aspectos, pode atuar contrariamente, ampliando as inconsistências dessa mutação. A crítica da dominação posiciona a inteligência coletiva como aceleradora da globalização econômica, capaz de acentuar as dominações tradicionais e promover ainda formas inéditas e mais sofisticadas de poder e de exploração (LÉVY, 1999).

Em uma abordagem complementar e bastante semelhante à proposta por Lévy (2011), Rheingold (2012) aponta a inteligência coletiva como uma das principais formas de colaboração em massa integrantes da nova dinâmica da sociedade da informação, ao lado de outros elementos como o crowdsourcing, as comunidades virtuais, a colaboração em wikis e a produção social. A seguir, estão apresentados sucintamente cada um desses elementos.

O termo crowdsourcing foi utilizado pela primeira vez em 2006, por Jeff Howe. O autor se apoiou na ideia de outsourcing, muito utilizada por empresas e organizações visando à solução de determinados problemas ou a busca de inovações a partir da contribuição de pessoas externas à corporação, sem a geração de nenhum vínculo formal. Ampliou então a visão do termo, a partir do apoio das ferramentas da Web 2.0, nas quais as pessoas deixam de ser passivas para se tornarem contribuintes ativas (HOWE, 2006).

O crowdsourcing é, portanto, baseado em um sistema sócio-técnico que busca a mobilização de competências e habilidades dispersas na "multidão", para a solução de questões variadas em diferentes formatos (ZHAO; ZHU, 2012). O crowdsourcing tem sido aplicado e vem transformando diferentes campos de atuação. 
O surgimento da chamada citizen science ou, ciência do cidadão, caracteriza uma série de ações que vão muito além de simplesmente coletar e analisar dados via crowdsourcing. Trata-se de um momento em que grandes grupos de criadores de conhecimento científico passam a usar seus dispositivos móveis como instrumentos científicos, transformando a ciência em um empreendimento coletivo em uma escala completamente nova (RHEINGOLD, 2012).

Ao mesmo tempo, empresas têm utilizado seus clientes para auxiliá-las no desenvolvimento de novos produtos. Jornalistas, ativistas e empreendedores tem explorado o chamado crowdfunding, uma forma colaborativa de levantamento de recursos necessários ao desenvolvimento de determinado projeto. Um grupo denominado First Aid Corps realizou uma ação interessante de crowdsourcing em que distribuiu um jogo para IPhone que permite aos usuários indicarem a localização geográfica de desfibriladores cardíacos, quando os localizam (RHEINGOLD, 2012).

No que tange às comunidades virtuais, pode-se dizer que essas são tecnologias de cooperação. Apesar de serem palco inúmeras vezes de bate-papos despretensiosos acerca de alguns interesses comuns entre seus membros, também são capazes de organizar ações coletivas no mundo físico. Exemplos são a Harry Porter Alliance, uma comunidade virtual de fãs que financiou, arrecadou e transportou mais de 4 mil toneladas de donativos para o Haiti após o terremoto de 2010 e os participantes da EVE fantasy community que arrecadaram mais de US\$ 60.000 em fundos para auxílio às vítimas do tsunami do Japão em 2011 (RHEINGOLD, 2012).

As wikis são páginas da Web cuja característica marcante é a possibilidade e a facilidade de serem editadas por diferentes pessoas. Wiki significa quick (rápido) na língua Havaiana. Esse nome lhe foi dado justamente pela rapidez com que podem ser realizadas as suas edições. Esse novo formato colaborativo de criação de conteúdo representa uma sensível modificação em vários paradigmas relacionados à produção de conhecimento. Talvez a mais importante transformação, refira-se ao fato de que as wikis são documentos criados por comunidades e não por algum autor em específico. Além disso, representam uma possibilidade real de criação de valor a partir de ações voluntárias. A Wikipédia e tantas outras wikis bem sucedidas sustentam-se a partir de alguns pilares centrais, quais sejam: facilidade de edição, armazenamento das revisões anteriores, facilidade de comparação e de reversão de 
atividades, combinadas a algumas normas, regras e estatutos organizacionais ou comunitários (RHEINGOLD, 2012).

Diante do novo contexto das tecnologias da informação, usuários e criadores podem se tornar a mesma coisa, assumindo o controle da tecnologia, como no caso da Internet. A capacidade intelectual humana passa a ser uma força direta de produção, numa relação muito próxima entre a cultura da sociedade, a partir de seus processos de criação e manipulação de símbolos, e a sua capacidade de produção e distribuição de bens e serviços (BENKLER, 2006; CASTELLS, 1999). Consolida-se assim o que passou a se denominar produção social.

Essa tem sido apontada como uma nova e poderosa forma de atividade econômica, especialmente a partir da consolidação dos métodos que tornaram possível a criação de diversos softwares do tipo open source, materializando o que se pode chamar de uma contracultura à indústria tradicional. O exemplo mais conhecido dessa realidade é o Linux, atualmente utilizado como plataforma para atividades de gigantes como o Google e a Amazon. Outro projeto open source idealizado por voluntários e extremamente bem sucedido é o Firefox, o segundo mais popular navegador de Internet (RHEINGOLD, 2012).

Assim, para Rheingold (2012) a inteligência coletiva atuaria em uma dinâmica de interdependência e complementaridade, junto ao crowdsourcing, às comunidades virtuais, à colaboração em Wikis e à produção social, em função dos diferentes produtos e processos de colaboração em massa a serem desenvolvidos.

Como exemplos dessa interdependência tem-se que certas habilidades relacionadas à participação e a colaboração em massa, como a inserção em comunidades virtuais, são fundamentais para a construção da inteligência coletiva (RHEINGOLD, 2012). Ao mesmo tempo, a Wikipedia, atualmente a maior wiki do mundo, torna-se um claro exemplo de produção social a partir de uma inteligência coletiva culturalmente desenvolvida que integra grandes e pequenos esforços de muitos (JENKINS, 2006; RHEINGOLD, 2012).

A próxima abordagem de inteligência coletiva a ser discutida é a proposta por Noubel (2006). Para esse autor, a inteligência coletiva não se trata de uma descoberta, ou de um termo novo. Está há tempos relacionada à modelagem de 
organizações sociais diversas como grupos, tribos, empresas, times, governos, nações e sociedades. Ela se faz presente sempre que indivíduos se reúnem para compartilhar e colaborar, encontrando vantagens individuais e coletivas que são maiores do que se cada um dos indivíduos tivesse agido de forma isolada.

As comunidades de inteligência coletiva não são uma prerrogativa exclusivamente humana, já que pode ser observada em diversas espécies animais, como formigas, peixes e lobos, nas quais existe um nível coletivo emergente superior aos seus componentes individuais. Esse aspecto da visão de Noubel (2006) se opõe à maneira com que Lévy (2011) compreende o fenômeno da inteligência coletiva.

\footnotetext{
O formigueiro fornece o exemplo contrário da inteligência coletiva [...] Longe de apontar para o Espaço do saber, o formigueiro é anterior à Terra, é simplesmente pré-humano. Serão consideradas odiosas e bárbaras todas as tentativas de aproximar, em maior ou menor medida, o funcionamento da sociedade ao de um formigueiro. (LÉVY, 2011, p. 31)
}

A inteligência coletiva apontada por Lévy (2011) é como algo que só existe a partir do início da cultura e que só pode crescer com ela, e ainda, que questiona essa própria cultura, na medida em que negocia permanentemente a ordem estabelecida. Assim, a divisão estanque em castas a partir de uma estrutura rígida como a do formigueiro, além do fato de que as formigas não possuem noção de como suas ações se relacionam às dos outros indivíduos do grupo, explicam porque um formigueiro não pode, para esse autor, representar a inteligência coletiva.

Esse embate entre os dois autores, talvez se deva ao fato de que Noubel (2006) analisa a inteligência coletiva a partir de um processo evolutivo que parte de uma inteligência coletiva original e chega ao que o autor denomina inteligência coletiva global. Assim, a comparação com a estrutura do formigueiro pode ser realizada com algumas formas de inteligência coletiva anteriores à chamada inteligência coletiva global. Essa última sim, bastante próxima ao conceito de inteligência coletiva proposto por Lévy (2011).

Assim, Noubel (2006) apresenta diferentes formas de inteligência coletiva e descreve suas características e limitações. Para ele, essas formas coexistem na sociedade, podendo ser assim denominadas: inteligência coletiva original, inteligência piramidal, inteligência de enxame e inteligência coletiva global. 
A inteligência coletiva original é uma inteligência praticada em pequenos grupos, como bandas de jazz e equipes esportivas. Tal forma de inteligência encontra limitações naturais que se relacionam ao número de membros e a aspectos espaciais. Seu funcionamento só ocorre de forma eficaz em grupos pequenos, pois um aumento significativo do número de membros do grupo eleva a complexidade das interações necessárias, o que pode trazer mais prejuízos que ganhos (NOUBEL, 2006).

Além disso, é preciso a proximidade física entre os participantes, para que as interações possam ocorrer adequadamente. A visão holística, compreendida como aquela que permite uma visão do todo, levando a ajustes de conduta por parte dos membros, só pode ser alcançada a partir da proximidade física entre os indivíduos do grupo (NOUBEL, 2006).

Como principais características da segunda forma de inteligência, a piramidal, temse a lógica da divisão do trabalho, da autoridade, da escassez monetária, além de normas e padrões pré-estabelecidos. Tais princípios se reforçam e legitimam uns aos outros, daí a extrema força da inteligência piramidal. Essa forma de inteligência coletiva tem aumentado seu alcance e poder nos últimos anos, a partir da evolução das tecnologias de telecomunicações, sendo típica das estruturas burocráticas (conforme será discutido na seção 2.7.1) e base para o paradigma econômico atual (NOUBEL, 2006).

A partir de sua capacidade de organizar e sincronizar comunidades baseadas na inteligência coletiva original, a inteligência piramidal permitiu inúmeros avanços como o desenvolvimento industrial, a criação de vacinas, a produção de aeronaves, o lançamento de satélites ao espaço, dentre outros de fundamental importância para a construção do mundo atual (NOUBEL, 2006).

Entretanto, essa inteligência piramidal também possui uma forte limitação derivada de sua própria natureza e que se define como a sua incapacidade de se adaptar a contextos complexos onde a instabilidade e a dinâmica são constantes. Uma das principais consequências dessa limitação é o fato de que muitas organizações, na tentativa de lidar com a extrema complexidade do ambiente em que estão inseridas (e não conseguirem) caminham em direções completamente opostas às dos seus próprios membros (NOUBEL, 2006). 
A terceira forma de inteligência coletiva apresentada por Noubel (2006) é a inteligência de enxame, ou swarm intelligence, nas palavras do autor. É reconhecida como aquela presente nas sociedades de insetos e vem sendo estudada e aplicada em diferentes campos, como a ciência da computação, onde originou diversas formas de simulação computacional (JOHNSON, 2003). Os participantes não possuem visão do todo, ou seja, não há uma perspectiva holística, sendo considerados indivíduos idiotas, mas cuja interação, condicionada em grande medida pelo ambiente externo, é capaz de dar origem a algum tipo de comportamento coletivo inteligente (NOUBEL, 2006).

Em um nível macroscópico, pode se dizer que as sociedades humanas gerenciam e equilibram seus recursos a partir dessa forma de inteligência. Num nível local, organizacional continuaria predominante a inteligência piramidal. A inteligência de enxame é a que explica a emergência de um sistema coletivo muito elaborado nas sociedades humanas, com capacidade de resposta e propriedades adaptativas (NOUBEL, 2006).

Contudo, a inteligência de enxame uniformiza e desindividualiza seus agentes, considerando-os verdadeiros idiotas, incapazes de perceber a emergência de um todo inteligente. Assim, essa forma de inteligência pode ser considerada apenas um estágio transitório de inteligência coletiva nas sociedades humanas, cuja função é abrir caminho para a existência de uma inteligência coletiva global. Esta, por sua vez, engloba e transcende todas as demais formas anteriores e sustenta-se na construção de um nível mais amplo de complexidade (NOUBEL, 2006).

Assim, rapidamente, as duas principais limitações da inteligência coletiva original têm deixado de existir. Comunidades com um número muito elevado de pessoas, a grandes distâncias umas das outras, estão começando agora a possuir uma boa parte das propriedades da inteligência coletiva original. Isso se deve, em grande parte, a alguns importantes elementos atribuídos por Noubel (2006) à inteligência coletiva global. Um dos principais são os sistemas de informação que permitem a interconexão entre os indivíduos a partir de interfaces cada vez melhores. Software sociais, conforme define o autor, são catalisadores e agentes estruturadores das comunidades virtuais emergentes, possibilitando a organização de uma memória coletiva e a conexão das pessoas ao ciberespaço. 
Esse, por sua vez torna-se o local privilegiado para as interações entre os indivíduos, tornando-se o novo espaço de organização e coordenação para as comunidades.

O ciberespaço, ainda na sua infância, está apenas começando a construir, através de um processo de catálise, as comunidades que irão gradualmente substituir a velha guarda de organizações de inteligência piramidal. É apenas uma questão de tempo. A cada dia, milhões de novos vínculos interpessoais são tecidos e novas comunidades surgem. A inteligência coletiva global está emergindo. Ela deve agora crescer. Nosso planeta está grávido de uma nova humanidade (NOUBEL, 2006, p.45, tradução nossa).

É também no ciberespaço que grande parte das tecnologias de inteligência coletiva são atualmente desenvolvidas. Os weblogs, por exemplo, constituem-se um agregado de experiências coletivas que podem ser conectadas. Além desses, podem ser citadas as wikis que representam a possibilidade de integração de conhecimentos entre uma coletividade. (NOUBEL, 2006; RHEINGOLD, 2012)

Jenkins (2006), por sua vez, para tratar do conceito de inteligência coletiva, realiza uma contra posição ao conceito de wisdom of crowds, ou sabedoria das multidões, cunhado por Surowiecky (2004). Segundo Jenkins, apesar de muitas confusões estarem sendo feitas entre tais conceitos, trata-se de construtos com características bastante distintas.

Para Surowiecky (2004) a sabedoria das multidões encontra-se estruturada em quatro pilares essenciais. O primeiro deles é a diversidade necessária entre os participantes. Assim, diferentes visões e experiências são asseguradas à construção da experiência coletiva. Uma segunda característica importante é a descentralização, para que não haja nenhum tipo de direcionamento superior às respostas que emergem da multidão. A terceira refere-se à necessidade da existência de mecanismos capazes de sumarizar, resumir as respostas dadas pelos participantes de forma a se construir um veredito único. Uma última, mas não menos importante, é a independência de cada um dos membros da coletividade, de maneira que mantenham o foco em suas opiniões e informações e não se deixem influenciar pelo que outros membros possam pensar ou desejar.

Dessa maneira, o modelo da sabedoria das multidões baseia-se em inputs isolados, onde cada membro apresenta a sua solução individual para um determinado problema proposto. Nesse modelo, a cooperação entre os indivíduos visando uma 
solução conjunta não é vista de forma positiva por criar certos vícios e tendenciosidades entre os participantes.

Um dos exemplos mais claros da lógica da sabedoria das multidões está nos jogos em que os participantes são convidados a opinar ou a propor soluções para questões complexas, muitas vezes baseando-se em dados reais das condições de gestão de determinada cidade ou mesmo das características de algumas doenças para as quais se necessita ampliar as possibilidades de reconhecimento e tratamento (JENKINS, 2006).

Assim, Jenkins (2006) apoiando-se nas concepções de Lévy (2011) acerca da inteligência coletiva, e nas de Surowieck (2004) acerca da sabedoria das multidões, realiza uma análise interessante. Segundo ele, enquanto a sabedoria das multidões encontra-se vinculada a inputs isolados em que as pessoas participam de maneira independente das demais, a inteligência coletiva se relaciona a um processo de produção de conhecimento, em que seus participantes atuam de forma integrada e colaborativa em comunidades online onde partilham informações, corrigem e avaliam seus pares de maneira a se chegar a uma conclusão consensual.

Para Heylighen (2013) a inteligência coletiva está diretamente relacionada à necessidade de existência de uma coordenação cognitiva entre os agentes envolvidos. Assim, a inteligência coletiva parte do pressuposto de que variadas expertises como conhecimentos, informação e a habilidades, estão distribuídas de maneira diferenciada entre os agentes. Dessa forma, certos problemas só poderão ser resolvidos pelo grupo e não por indivíduos isoladamente, numa visão bastante semelhante à de Noubel (2006), Lévy (1999) e Rheingold (2012).

Para que a inteligência coletiva possa se tornar prática, quatro mecanismos de coordenação cognitiva são essenciais: alinhamento, divisão do trabalho, fluxo de trabalho e agregação.

A ideia de alinhamento proposta por Heylighen (2013) não pretende significar a necessidade de que os agentes realizem as mesmas ações, já que assim, não existiria inteligência coletiva. Para tarefas físicas, como empurrar algo bastante pesado na mesma direção, poderia até ser verdadeiro o conceito de alinhamento em que todos fazem a mesma coisa, mas isso não é válido para quando se está 
processando informações. Uma mesma informação agregada a outra informação idêntica não produziria nenhum efeito diferente do inicial. $O$ alinhamento se caracteriza pela concepção de que os agentes devem buscar o mesmo objetivo, apontar na mesma direção, numa busca por auto-organização que normalmente se origina em processos de tentativa e erro.

Por essa razão é que a divisão do trabalho, que para o autor se refere à ideia de que cada agente contribuirá com informações e habilidades distintas ao processo, é tão fundamental ao conceito de inteligência coletiva. Pode-se pensar que a divisão do trabalho não possa prescindir de uma liderança que defina quem deve fazer o que. Para Heylighen, entretanto, trata-se de uma questão de pura auto-organização. Assim, os agentes naturalmente escolheriam as atividades para as quais percebessem possuir maior habilidade e facilidade para o desenvolvimento, de maneira que a divisão ocorresse de forma espontânea entre os indivíduos. Pressupõe-se, contudo, a necessidade de certo grau de flexibilidade dos agentes para se ocuparem de tarefas com as quais possuam uma menor aderência de maneira que nada fique sem ser realizado.

O fluxo de trabalho, por sua vez, representa os estágios subsequentes de uma determinada atividade, normalmente complexa. Nele, pressupõe-se que uma atividade se torna completa a partir da execução de estágios intermediários dessa atividade, executados por diferentes agentes em uma determinada sequência. Heylighen (2013) ilustra o conceito de maneira bastante simples, ao apresentar a situação de construção de uma casa, em que os estágios finais como a pintura não podem ser executados antes que outros anteriores tenham sido finalizados, como a construção do telhado.

Pode parecer que tal estruturação e planejamento de atividades dependam de uma atividade de supervisão ou até mesmo de ferramentas de gestão mais sofisticadas. Entretanto, de uma maneira bastante similar à que ocorre com a divisão do trabalho, o fluxo do trabalho também parece encontrar o caminho da auto-organização.

Heylighen (2013) aponta o exemplo do desenrolar espontâneo de um fluxo de trabalho, quando em conversas ou discussões em grupo, em que uma pessoa propõe uma ideia e, em seguida, inspira outro para adicionar mais um refinamento, 
que, em seguida, pode provocar uma correção de uma terceira pessoa, etc. Nesses casos, quando existe um número suficientemente grande pessoas e habilidades necessárias à solução de determinada questão, pode ocorrer uma sequência espontânea de ações nas discussões em grupo, onde uma ideia proposta por alguém gera em outro membro do grupo a possibilidade de proposição de uma complementação e assim sucessivamente. Nessas situações em que exista um grande número de agentes com habilidades suficientemente diversas e abrangentes, pode ser bastante eficiente esse tipo de solução de auto-organização do fluxo de trabalho. O planejamento da atividade de um determinado agente deixa de ser necessário, desde que exista um número suficientemente grande de agentes dentre os quais um esteja apto, em termos de habilidades, para assumir a próxima etapa do trabalho, assim que a etapa anterior for concluída.

O fluxo de trabalho pode não ser tão evidente em todas as situações. A sua função está condicionada à complexidade do problema a ser resolvido. Problemas mais simples podem ser resolvidos em poucas interações, outros mais complicados, necessitam de várias rodadas de interações entre os agentes.

A agregação, como etapa final do processo, é fundamental para uma conclusão coerente entre as contribuições apresentadas por cada um dos agentes.

A construção de inteligência coletiva também pode ser abordada a partir de uma perspectiva extremamente prática como é o caso de Solachidis e outros (2010) que analisam a geração de conteúdos por usuários na Web. Para esses autores, as atuais ferramentas Web utilizadas para a criação e compartilhamento de conteúdos e participação em redes sociais, como Flickr, Youtube e Facebook, apesar de representarem excelentes oportunidades para a criação de serviços inovadores, já atingiram algumas limitações importantes em sua evolução. Assim, a criação de novos serviços denominados "inteligentes" é o que permitirá uma maior troca e compartilhamento de informações entre usuários, clientes e cidadãos em diferentes contextos, que podem ir desde o comércio eletrônico às ações de resposta a emergências (SOLACHIDIS et al., 2010).

Numa abordagem mais voltada para aspectos da psicologia social e da performance de grupos em variados contextos, Woolley e outros (2010) encontraram evidências de um fator geral capaz de indicar a presença de inteligência coletiva em grupos de 
pessoas, denominado pelos autores de "fator c". Os pesquisadores realizaram dois estudos com 699 participantes, trabalhando em grupos de 2 a 5 pessoas onde foram aplicadas análises estatísticas.

O fator c, ao contrário do que se possa imaginar, não possui uma forte correlação com a média entre as mais altas inteligências individuais existentes no grupo. A presença de fatores como: sensibilidade social média elevada entre os membros do grupo; maior igualdade na distribuição da conversação realizada; e proporção elevada de mulheres no grupo é que determinaram a existência da inteligência coletiva.

A maior presença de mulheres no grupo é um fator decorrente da constatação de que as mulheres possuem uma maior sensibilidade social em relação aos homens, conforme constatações da pesquisa. A ideia de sensibilidade social está relacionada, para os pesquisadores, à capacidade de compreender as atitudes e sentimentos dos demais membros do grupo mesmo sem a necessidade de muitas interações ou de conhecimento prévio muito longo entre eles.

Assim, para esses pesquisadores, os grupos, tanto quanto os indivíduos possuem níveis característicos de inteligência que podem ser medidos e utilizados para se prever a seu desempenho futuro em uma enorme gama de tarefas. A partir de uma analogia com o conceito de inteligência individual, a inteligência coletiva foi conceituada como "a capacidade geral de um determinado grupo de realizar uma grande variedade de tarefas" (WOOLLEY et al., 2010). Empiricamente, a inteligência coletiva se mostra quando o desempenho do grupo em uma determinada tarefa está correlacionado com a possibilidade daquele mesmo grupo realizar em conjunto muitas outras tarefas. Essa inteligência seria uma propriedade do grupo, e não dos indivíduos que dele fazem parte.

As discussões teóricas até aqui realizadas destacam a característica emergente do fenômeno da inteligência coletiva que se configura intrinsecamente como um processo de auto-organização (HEYLIGHEN, 2013).

Compreende-se a inteligência coletiva como pano de fundo para as demais discussões teóricas realizadas nesta pesquisa. Além disso, ela se apresenta como fenômeno emergente imbricado na lógica das redes sociais, no sentido de que para 
além de seu contexto cognitivo, alcança em grande parte uma lógica de ação colaborativa, típica do contexto das redes operativas, como é o caso da rede aqui analisada. Ao mesmo tempo, considera-se que redes sociais podem ser compreendidas como fios condutores do processo de inteligência coletiva.

Assim, a lógica das redes, apontadas como fenômenos emergentes e complexos, possuem sua constituição e modelagem fortemente relacionadas à inteligência coletiva (NOUBEL, 2006).

Nesse sentido, a discussão acerca da inteligência coletiva contribuirá para a consecução dos objetivos (geral e específicos) da presente pesquisa, já que oferece suporte às análises acerca da maneira de atuação, do surgimento e das atividades desenvolvidas pela rede de apoio às vítimas das chuvas de 2013 no ES.

Antes de uma discussão mais específica sobre redes, compreende-se que para um melhor entendimento de algumas de suas características essenciais como a emergência e a auto-organização, torna-se também necessário abordar, ao lado da inteligência coletiva, o chamado paradigma da complexidade, o que será realizado na próxima seção.

\subsection{CIÊNCIAS DA COMPLEXIDADE}

A discussão sobre as ciências da complexidade é de suma importância na construção da base teórica e no alcance dos objetivos da pesquisa. Há uma forte relação entre essas e a lógica das redes, já que os estudos sobre redes são suportados pelo paradigma da complexidade.

Sendo assim, para se compreender como o enfoque às redes passou a merecer um maior nível de atenção da comunidade científica, torna-se essencial o entendimento do que se costumou denominar paradigma da complexidade. Além disso, importantes características das redes como a emergência, a auto-organização e a 
adaptação são analisados e compreendidos a partir do enfoque dos sistemas complexos.

A chamada nova ciência das redes vem descobrindo inúmeros pontos em comum entre diferentes sistemas como comunidades sociais, a Internet, as epidemias e os sistemas metabólicos em organismos vivos (MITCHELL, 2009). Não é por acaso que a dinâmica das redes tem possuído destaque cada vez maior nos trabalhos científicos sobre sistemas complexos, tanto em nível nacional quanto internacional, nas mais diversas disciplinas (BORGATTI NETO, 2008).

Conforme destaca Érdi (2008), as redes possuem excelentes propriedades que permitem representar muito bem os mais diversos tipos de sistemas naturais, tecnológicos e sociais. Daí decorre sua tão grande importância na análise dos sistemas complexos.

Para Kelly (2008), as redes dinâmicas são o ícone da ciência para o próximo século, como:

[...] um arquétipo do qual se lança mão para representar todos os circuitos, toda a inteligência, toda interdependência, tudo o que é econômico, social e ecológico, todas as comunicações, toda a democracia, todos os grupos, todos os grandes sistemas [...] (KELLY, 2008, p. 25, tradução nossa).

Principalmente a partir do pensamento de René Descartes, por volta dos anos 1600, o chamado paradigma reducionista, segundo o qual todo o problema pode ser analisado a partir de seu desmembramento em tantas partes quanto possível, passou a dominar o campo da ciência. Assim, ao se compreender cada um das partes, poderia se compreender o todo (BARABÁSI, 2009; KAUFFMAN, 1995; MITCHELL, 2009).

Esses princípios demonstram de forma bastante clara o que Morin (1990, p. 86) conceitua paradigma da simplicidade, que "põe ordem no universo e expulsa dele a desordem". Para Morin (2006), é preciso reconhecer que tal visão reducionista foi capaz de promover enormes avanços ao conhecimento científico e à reflexão filosófica. Entretanto, algumas questões essenciais a inúmeras áreas da ciência, permaneciam sem resposta até o início do século XX.

Ainda era intrigante a imprevisibilidade do clima na Terra, a capacidade de adaptação dos organismos vivos, a forma de disseminação das doenças, o 
crescimento e os efeitos da tecnologia moderna e das redes de comunicação, a natureza da inteligência e a possibilidade da sua utilização em computadores, o comportamento cultural, político e econômico de diferentes grupamentos sociais, além de tantas outras questões (MITCHELL, 2009).

Conforme destaca Morin (1974), diante de tais questões ainda inexplicáveis, foi se tornando cada vez mais difícil para as ciências, de maneira geral, continuar se ocupando apenas daquilo que pudesse ser simplificado, banindo o complexo para a periferia. É possível aplicar uma teoria simples a fenômenos complexos, contudo, nesses casos, um processo de simplificação acontece. Porém, o grande problema da complexidade é a existência de fenômenos que não podem ser reduzidos aos padrões de pensamento simples do observador.

Assim, para além do reducionismo, começou a ser delineada uma nova visão de ciência que busca compreender como tais fenômenos complexos são capazes de emergir a partir da reunião de elementos individuais relativamente simples (BARABÁSI, 2009; KAUFFMAN, 1995; JOHNSON, 2003; MITCHELL, 2009). Nesse sentido, o todo passa a ser maior que a simples soma das partes (MORIN, 1990).

A ideia de que o todo é maior do que a simples soma das partes traduz a percepção da existência de efeitos interdependentes combinados, que podem ser produzidos por duas ou mais partes, elementos ou indivíduos. Assim, a sinergia é uma questão central no paradigma da complexidade. Essa visão implica em um foco combinado, tanto no todo, quanto em suas partes, e, especialmente, nas interelações existentes entre as partes, entre partes e todos e entre todos em vários níveis de interação e causalidade. Os mecanismos e as leis, essenciais à ciência clássica, dão assim lugar a uma ciência em que as relações entre os elementos passam a se constituir como fatores centrais (CORNING, 2000). Nesse sentido, compreende-se que a abordagem dos sistemas é capaz de integrar as abordagens reducionista e holística, ao manter o foco tanto nas partes, quanto no todo e nas inter-relações.

De acordo com Morin (1974), a complexidade sistêmica manifesta-se, especialmente, no fato de que o conjunto possui qualidades e propriedades que não podem ser encontradas nas partes quando analisadas isoladamente. Por outro lado, as partes possuem qualidades e propriedades que acabam por ser neutralizadas como resultado dos limites impostos pela própria organização do sistema. 
Importante ainda é destacar que a complexidade sistêmica aumenta, por um lado, com o aumento do número e diversidade de seus elementos constitutivos e por outro lado, com o aumento da flexibilidade e complicação das inter-relações (interações, efeitos de feedback, interferências, etc.) e a consequente diminuição de seu determinismo.

Tal prerrogativa antirreducionista carregou em seu bojo a necessidade de uma abordagem interdisciplinar, já que nenhuma disciplina individualmente seria capaz de congregar todo o conhecimento necessário à elucidação que se buscava. Além disso, em boa parte das disciplinas, esses conhecimentos ainda nem sequer haviam sido sistematizados (MITCHELL, 2009).

Sobre essa questão, Barabási (2009) assim se posiciona:

Agora estamos prestes a saber tudo o que há para conhecer acerca das partes. Estamos, porém, tão longe quanto sempre estivemos de entender a natureza como um todo. Com efeito, a remontagem revelou-se mais difícil do que previam os cientistas. A razão é simples: sob a égide do reducionismo, deparamo-nos com a dura muralha da complexidade. Aprendemos que a natureza não é um quebra-cabeça bem projetado que possui apenas uma única forma de montagem. Em sistemas complexos, os componentes podem articular-se de modos tão diferentes que levaríamos bilhões de anos para tentar todos eles. Não obstante, a natureza reúne as partes com uma graça e precisão aguçada ao longo de milhões de anos. Ela o faz explorando as leis gerais da auto-organização, cujas raízes, em ampla medida, ainda constituem um mistério para nós (BARABÁSI, 2009, p. $6)$.

A visão do mundo na perspectiva complexa é multidimensional, conforme destaca Neto (2014). Também o homem, nessa concepção, deve ser compreendido como um ser biológico-sociocultural, inserido, de forma simultânea em diferentes campos, como o social, o econômico, o organizacional, o cultural, o psicológico e o espiritual.

Em uma de suas inúmeras abordagens ao conceito de complexidade, Morin (1974) argumenta que, numa primeira definição, a ideia de complexidade só pode ser negativa, no sentido de que denota algo que não pode ser simples. Como um dos autores que mais tem se dedicado ao tema, Morin apresenta outras questões centrais ao entendimento da complexidade, opondo-a ao paradigma reducionista:

O que é a complexidade? A um primeiro olhar, a complexidade é um tecido (complexus: o que é tecido junto) de constituintes heterogêneas inseparavelmente associadas: ela coloca o paradoxo do uno e do múltiplo. Num segundo momento, a complexidade é efetivamente o tecido de acontecimentos, ações, interações, retroações, determinações, acasos, que constituem nosso mundo fenomênico. Mas então a complexidade se 
apresenta com os traços inquietantes do emaranhado, do inextricável, da desordem, da ambiguidade, da incerteza... Por isso o conhecimento necessita ordenar os fenômenos rechaçando a desordem, afastar o incerto, isto é, selecionar os elementos da ordem e da certeza, precisar, clarificar, distinguir, hierarquizar... Mas tais operações, necessárias à inteligibilidade, correm o risco de provocar a cegueira, se elas eliminam os outros aspectos do complexus; e efetivamente, como eu o indiquei, elas nos deixaram cegos (MORIN, 2006, p. 13 e 14).

A essa altura, torna-se necessário destacar alguns outros aspectos importantes sobre as chamadas ciências da complexidade. O termo ciência está colocado no plural, pois efetivamente não se pode afirmar a existência de uma única ciência da complexidade, mas sim várias diferentes ciências, cada uma com uma noção distinta do significado de complexidade (MITCHELL, 2009).

Entre outros fatores que podem ser apontados, essa realidade multifacetada dos estudos sobre complexidade deve-se ao fato de que o próprio conceito de complexidade não possui uma definição clara e rigorosa (ÉRDI, 2008; HOLLAND, 2014; SAWYER, 2005). Parece sim, se tratar de um assunto bastante fragmentado, ao invés de um campo unificado, talvez por isso, tenha a capacidade de exercer uma tão forte influência sobre diversos campos científicos.

Assim, é nesse sentido que Borgatti Neto (2008) destaca que termos como teoria da complexidade, estudo de sistemas dinâmicos, estudos de não linearidades, teoria de sistemas adaptativos complexos, ciência da complexidade e ciências da complexidade, aparecem como expressões equivalentes em muitas situações.

Holland (2014) atribui essa fragmentação ao fato de que as pesquisas sobre os sistemas complexos ainda estão em seus estágios iniciais e entende que a partir da evolução e da consolidação dos achados científicos, o campo possui potencial para a construção de uma teoria bastante abrangente.

Alguns conceitos essenciais sobre sistemas são necessários ao entendimento das questões relativas à complexidade. Um sistema pode ser definido como um todo que funciona a partir da interação de suas partes. Dessa forma, um sistema é definido por seus elementos e pelas relações existentes entre eles (ÉRDI, 2008).

Conforme destaca Érdi (2008), o conceito de sistema complexo emerge em oposição ao que se pode denominar sistema simples em que uma única causa gera um único efeito e onde uma pequena mudança nas causas também implica 
necessariamente uma pequena alteração nos efeitos. Assim, uma essencial característica dos sistemas simples é a sua previsibilidade, ao contrário do que ocorre nos sistemas complexos.

Sistemas podem ser também diferenciados entre fechados e abertos. Um sistema considerado fechado é aquele que não estabelece relações com o seu ambiente. Assim, um pedaço de rocha, por exemplo, é um sistema isolado, já que suas propriedades tendem a ser perfeitamente compreendidas sem que se necessite considerar a sua interação com o ambiente. Os sistemas abertos, por sua vez, estabelecem um fluxo contínuo de interações com seu meio, podendo a partir de tais interações intermediadas por ciclos de feedback, criar formas de auto-regulação, auto-organização, aprendizado e adaptação (ÉRDI, 2008).

Os componentes de um sistema complexo são denominados agentes. Esses, por sua vez, podem ser analisados como sistemas individuais que agem sobre seu ambiente como forma de responder a determinados eventos que experienciam. Assim, pessoas, empresas, células, programas de computador e moléculas, são clássicos exemplos de agentes utilizados em modelos de sistemas complexos (HEYLIGHEN, 2013).

Os agentes, por sua vez, atuam de maneira direcionada a um determinado objetivo que pode ser variado, como o aumento de sua adequação a determinado ambiente, ou sua utilidade em um contexto qualquer. Importante considerar que a ação realizada por um determinado agente sobre o ambiente é capaz de desencadear uma série de ações de outros agentes, criando assim uma cadeia de propagação ao longo de todo o sistema. Embora tais ações se iniciem em um nível local, possuem a capacidade de levar suas consequências a um nível global, "como uma onda produzida por uma pedra que localmente perturba a superfície da água, mas que se alarga para abranger toda a lagoa" (HEYLIGHEN, 2013, p.3, tradução nossa).

Assim, os sistemas complexos estão inseridos em um campo de estudos que pretende explicar como um grande número de entidades relativamente simples consegue se organizar, sem a submissão a nenhum tipo de controle central, em um todo coletivo capaz de criar padrões, utilizar informações, e, em alguns casos até mesmo evoluir e aprender. Ou seja, embora haja bastante simplicidade no nível 
individual, existe um elevado grau de sofisticação no nível coletivo (MITCHELL, 2009).

Com o desenvolvimento das pesquisas relacionadas a sistemas complexos, o campo acabou sofrendo uma divisão entre dois outros sub campos: os chamados sistemas físicos complexos e os sistemas adaptativos complexos. Nos sistemas físicos complexos, os elementos individuais seguem determinadas leis fixas, normalmente expressas por meio de equações. Assim, nem os agentes nem as leis mudam com o passar do tempo, apenas se considera a modificação da posição dos elementos. "A complexidade emergente sem adaptação é como os intrincados cristais formados pelos blocos de neve: são bonitos, mas não tem função (JOHNSON, 2003, p.53)".

Assim, nos sistemas físicos complexos há um pressuposto de determinismo e regularidade, sob o qual se compreende que, sistemas que partem das mesmas condições iniciais vão necessariamente possuir os mesmos desdobramentos. Embora isso possa ser verdadeiro para alguns tipos de sistemas, pesquisas e descobertas realizadas no final do século $X X$ demonstram que existem inúmeras situações que fogem a esse comportamento regular (HOLLAND, 2014).

Nesse sentido é que o estudo dos sistemas adaptativos complexos considera a capacidade dos seus elementos individuais, denominados agentes, de modificar suas características, aprendendo e se adaptando conforme as interações realizadas com outros agentes. Sobre esses, é que se trata a grande maioria dos aspectos aqui abordados.

Mitchell (2009) apesar de reconhecer a diferença existente entre sistemas complexos adaptativos e não adaptativos, não realiza essa distinção em sua definição de sistema complexo, sendo a que segue:

[...] um sistema no qual grandes redes de componentes com nenhum controle central e regras simples de operação dão origem a um comportamento coletivo complexo, a um sofisticado processamento de informações e adaptação por meio de aprendizado ou evolução. (MITCHELL, 2009, p. 315, tradução nossa)

Conforme discutido, de forma geral os estudos acerca de sistemas complexos contribuem atualmente para a definição de uma série de estratégias e políticas em 
diferentes níveis e esferas globais, nacionais e organizacionais. A seguir encontramse apresentadas as suas principais características.

\subsubsection{Algumas características dos sistemas complexos}

Para os pesquisadores das ciências da complexidade, um dos mais importantes pontos de partida é que diferentes sistemas complexos presentes na natureza como colônias de insetos, sistemas imunológicos, cérebros e economias possuem muito em comum (MITCHELL, 2009).

As colônias de insetos talvez sejam um dos exemplos mais estudados e ricos para a ilustração de sistemas complexos, embora ainda remanesçam sem explicação muitos detalhes acerca das suas formas de auto-organização.

Uma colônia de formigas pode ser formada por centenas a milhares de indivíduos. Possuem uma capacidade de organização coletiva bastante complexa, revelada a partir dos detalhes das estruturas subterrâneas por elas construídas, permeadas por túneis e ninhos minuciosamente protegidos, com admirável força e estabilidade. A troca de sinais entre cada formiga se dá a partir de tipos diferenciados de feromônios, cuja química e grau de intensidade revelam mensagens específicas que podem ser decodificadas pelos seus semelhantes.

Assim, a busca por alimento, a defesa da colônia, a proteção da rainha, são tarefas concretizadas a partir de mecanismos de interação entre cada um dos indivíduos da colônia. Conforme o tipo e a intensidade do sinal recebido, originam-se comportamentos diferenciados que levam à transmissão de outros sinais para os demais indivíduos. (MITCHELL, 2009; JOHNSON, 2003).

De forma semelhante, sabe-se que o cérebro é formado por diferentes tipos de células além dos neurônios. Por meio de sinais elétricos que são transformados em sinais químicos a partir dos chamados neurotransmissores, as células cerebrais se comunicam em uma complexa e intrincada rede que dá origem à execução das 
diferentes funções cerebrais. Assim, boa parte dos cientistas da área acredita que é na ação dos neurônios e nos padrões de conexões estabelecidas entre grupos de células nervosas que se originam a memória, a percepção, a consciência, o pensamento, além de outras importantes funções (MITCHELL, 2009).

O sistema imunológico, por sua vez, apesar de diferir em sofisticação entre os diferentes seres vivos, carrega determinadas características comuns a todos eles. Tais características o colocam como um rico exemplo de sistema em que componentes relativamente simples dão origem a um comportamento extremamente complexo, por meio de sinais e de formas peculiares de controle, onde a adaptação ocorre a todo o momento. Um conjunto de células diferenciadas existentes no sangue, na medula óssea, nos linfonodos, além de outros órgãos, atua de forma bastante eficaz e eficiente, sem nenhum controle central, protegendo o organismo contra infecções (MITCHELL, 2009).

Um exemplo também bastante típico de complexidade encontra-se no sistema econômico, em que os agentes individuais são representados por pessoas e empresas que atuam em um contexto de compra e venda de produtos e serviços. A complexidade pode ser observada a partir da forma de flutuação dos preços de aluguéis e ações, por exemplo (MITCHELL, 2009; JOHNSON, 2003).

Uma análise da World Wide Web, permite observar que ela tem crescido exponencialmente desde a década de 90, podendo ser considerada um sistema social auto-organizado. Cada indivíduo que se conecta à rede, realiza pequenas tarefas simples individuais, como criar um blog, postar um vídeo ou realizar um comentário numa mídia social. Entretanto, cientistas do campo da complexidade já conseguiram demonstrar que essa rede como um todo possui determinadas características inesperadas quando analisada em grande escala. A maneira com que a rede cresce, a forma de propagação das informações por meio dos links, além das situações de coevolução existentes entre mecanismos de busca e a estrutura dos links da Web, todas essas questões podem ser consideradas como mecanismos de adaptação desse sistema (MITCHELL, 2009).

Colônias de insetos, cérebros, sistemas imunológicos, economias e a World Wide Web são mesmo estruturas claramente diferenciadas em seus detalhes. Porém, uma abstração nessa análise é capaz de revelar a existência de algumas propriedades 
comuns a tais sistemas, típicas dos chamados sistemas complexos: autoorganização, sinalização e processamento da informação, comportamento caótico, adaptação interativa e emergência (BORGATTI NETO, 2008; HOLLAND, 2014; JOHNSON, 2003; KAUFFMAN, 1995; MITCHELL, 2009; SAWYER, 2005).

A observação dos sistemas complexos até aqui descritos permite perceber que se constituem de grandes redes de componentes individuais que atuam seguindo determinadas regras simples, supostamente, sem nenhum controle central. Assim, desde átomos até sociedades inteiras, são decorrências das ações coletivas desse vasto número de agentes que permitem o surgimento de um comportamento complexo, de difícil previsão e em constante adaptação (HEYLIGHEN, 2013; HOLLAND, 2014; MITCHELL, 2009).

Morin (1999) destaca que, em algumas situações, a ideia de rede para ser mais adequada que a de sistema, no sentido de que um sistema tende a ter limites e fronteiras mais bem definidos, enquanto uma rede possui limites bastante variáveis. Ambos, contudo, são interconexões de elementos com uma natureza organizada. Assim, uma rede pode se tornar um sistema, na medida em que se tornar fechada em si mesma, ou adquirir um centro organizador, como um sistema de ferrovias. Contudo, há uma característica central e comum entre redes e sistemas que é a ideia de organização.

Na seção 2.7, o termo organização será também discutido, envolvendo, inclusive, conceituações advindas da Teoria das Organizações. Aqui, entretanto, estão apontadas conceituações do termo, considerando a perspectiva da complexidade.

Na visão de Heylighen (2013, p. 5, tradução nossa) organização pode ser definida como "uma estrutura com função: os componentes (agentes) do sistema são arranjados de uma forma ordenada (estrutura) para que se atinja um determinado objetivo (função)".

Para Morin (1999), entretanto, a organização liga, forma, transforma, produz, mantém e ordena a autonomia. Ela não pode ser reduzida à estrutura. Estrutura significa apenas regras de invariância e transformação em um sistema. A organização, por sua vez, engloba a estrutura, mas também a relação com a totalidade, os caracteres específicos, as relações entre o todo e as partes, a 
unidade-multiplicidade e as emergências. Para o autor, a ideia de estrutura mutila a ideia de organização, acaba com a ideia de sistema, e extirpa a ideia de complexidade. Assim, quanto mais complicada é a organização, mais a ideia de estrutura torna-se inadequada.

O que Morin (1999) denominou "unitas-multiplex" traduz a ideia de que uma entidade organizada é única do ponto de vista do todo, mas diferente e heterogênea do ponto de vista das partes que a constituem, ou seja, é ao mesmo tempo única e múltipla.

O que temos que entender são as características complexas do unitasmultiplex: é, uma entidade global e não elementar, pois consiste em diferentes partes. É uma unidade não homogênea, mas hegemônica, porque o todo organizado domina os elementos distintos e os mantêm em seu poder. É uma unidade não primitiva, mas original: ele tem suas próprias propriedades irredutíveis. É uma unidade individual, bem indivisível: pode ser decomposto em elementos separados, mas isso muda a sua existência (MORIN, 1999, p.116, tradução nossa).

Na perspectiva apresentada por Morin (1974) a riqueza e a complexidade da autoorganização apresentam-se para a nossa compreensão sob a forma de incerteza, imprecisão e conceitos ambíguos e até mesmo contraditórios. Esse é o caso, quando se analisa as questões de ordem / desordem e entropia / negentropia ou entropia negativa, que serão tratados em maior detalhe mais adiante. É também o caso com a noção mais básica de todas, ou seja, a vida. Segundo o autor, não podemos considerar um sistema vivo como um objeto separado do meio ambiente, e as relações entre um sistema aberto e o seu ecossistema que já são ambíguas, tornam-se ainda mais com o desenvolvimento de complexidade, pois um aumento da autonomia do sistema é também um aumento da sua dependência em relação ao seu ecossistema.

Heylighen (2013) destaca ainda o fato de que a auto-organização é um campo científico bastante dinâmico e por vezes até confuso, considerando-se que as diferentes áreas da ciência a tem analisado a partir de perspectivas variadas e com foco em aspectos distintos.

Esse autor ainda realiza uma interessante análise da questão da auto-organização em grupos de pessoas, ao relacioná-la à emergência da inteligência coletiva, discutida na seção 2.3. Nesse âmbito, a noção de coordenação se apresenta como aspecto central, viabilizando a atuação dos agentes de maneira harmônica para a consecução dos objetivos coletivos. Para que isso ocorra de forma bem sucedida, os 
agentes buscam maneiras para evitar o que Heylighen chama de fricção, ou seja, ações que podem impedir, dificultar ou se opor à atuação dos outros agentes. Assim, a atuação de cada um dos componentes do grupo é complementar a dos demais, possuindo assim, características sinérgicas. Nesse contexto, "a coordenação pode ser definida como: a estruturação de ações em um espaço temporal e social, de maneira que se minimize a fricção e se maximize a sinergia entre essas ações" (HEYLIGHEN, 2013, p. 5, tradução nossa). A coordenação para a auto-organização pode ser decomposta em quatro processos elementares: o alinhamento, a divisão do trabalho, o fluxo de trabalho e a agregação, já previamente discutidos no item 2.3 desta tese, onde se tratou da inteligência coletiva.

Ashby (1999) foi quem primeiro utilizou o termo auto-organização. Em seus estudos, esse pesquisador percebeu que os sistemas tendem a evoluir na direção do que se denomina atrator. Tal atrator configura-se como uma situação de estabilidade para a qual o sistema busca caminhar mesmo após ter sido perturbado. Para que isso ocorra, os diferentes componentes do sistema estão em uma situação de adaptação mútua, de forma que possam funcionar de maneira organizada. Outro princípio bastante importante para a compreensão da auto-organização é aquele que considera que quanto maior a variação aleatória do sistema, maior é a sua velocidade de auto-organização. Tal princípio tornou-se conhecido como "order from noise", ou numa tradução literal, ordem pelo barulho. Sua formulação é atribuída a Von Foerster (HEYLIGHEN, 2013).

Para Morin (1974; 2005) o advento do Homo Sapiens, em especial o desenvolvimento da complexidade do cérebro humano, traz à tona um salto qualitativo na questão da auto-organização: a noção de hipercomplexidade. Para o autor, a distinção entre sistemas complexos e hipercomplexos se faz a partir da acentuação de determinadas características e a atenuação de outras, numa dinâmica capaz de modificar a configuração do conjunto, fazendo emergir um novo tipo de sistema. Assim, nos sistemas hipercomplexos ocorre um desenvolvimento progressivo da organização e habilidades criativas, juntamente com uma redução gradual das limitações, hierarquias e da centralização. 
Morin (1974) considera que, mesmo sendo impossível isolar ou separar um sistema hipercomplexo, é possível se obter uma ideia da hipercomplexidade a partir das características principais de organização e funcionamento do cérebro humano:

A esse respeito a hipercomplexidade é caracterizada por um baixo nível de
diferenciação entre as unidades (neurônios) e a existência de regiões sem
funções específicas; por uma fraca relação hierárquica entre os
subsistemas cerebrais; pelo policentrismo (enquanto o cérebro como um
todo é um centro de tomada de decisão, não há nenhum ponto no cérebro
que decide); por inter-relações múltiplas e as interferências entre os
componentes individuais e os subsistemas; por fortes inter-reações
múltiplas com o meio ambiente; e pela importância considerável de
conexões aleatórias, ou seja, de "desordem" e "ruído" (MORIN, 1974, p.
569,570 tradução nossa).

Os conceitos de desordem e ruído são essenciais à compreensão dos sistemas hipercomplexos, onde a questão da entropia é abordada de uma forma bastante peculiar. Conforme destaca Lopes (2001), em um estudo baseado nas visões de Morin acerca da hipercomplexidade, os sistemas hipercomplexos trabalham com o erro, apesar do erro e a partir do erro.

Morin (2005) realiza uma comparação entre os organismos vivos ou autômatos naturais (expressão cunhada por Von Neuman) e as máquinas artificiais e sustenta que a diferença marcante na capacidade organizativa desses sistemas é justamente a questão da desordem, do erro e do ruído.

A desordem está relacionada a qualquer fenômeno que, em relação ao sistema em questão, parece ser devido ao acaso, em vez de sujeito a determinismos. É tudo aquilo que não obedece à rigorosa aplicação de forças mecânicas contidas em esquemas organizacionais predefinidos. O ruído é, no âmbito da comunicação, qualquer distúrbio que altere ou interrompa a transmissão de informações. O erro, por sua vez, se refere a qualquer reprodução imprecisa de informações recebidas. A partir do momento em que se estabelece uma conexão entre as noções de organização e informação, a noção de entropia passa a estar relacionada não apenas à noção de desordem, mas também ao ruído e ao erro.

Nas máquinas artificiais, tudo o que é desordem, ruído e erro aumenta a entropia do sistema, ou seja, eleva suas chances de degradação, degeneração e desorganização. De forma oposta, os organismos vivos funcionam apesar da desordem, ruído e erro, e isso não implica necessariamente num aumento na entropia do sistema, pelo contrário, pode até contribuir para a sua regeneração. 
Em outras palavras, os organismos vivos possuem uma alta confiabilidade como um todo, embora as suas unidades constituintes (moléculas e sistemas multicelulares como as células e tecidos) sejam elementos facilmente degradáveis. Esses princípios organizativos da vida são também os da complexidade. Tal fenômeno de reorganização permanente é que dá aos sistemas vivos a sua flexibilidade e liberdade em relação às máquinas artificiais. Enquanto as últimas necessitam funcionar de maneira perfeitamente determinada, os sistemas auto-organizados são tanto mais complexos quanto menos determinados forem, quanto maior for a autonomia relativa de seus componentes e quanto mais difícil for dissociar suas complementaridades de suas competências e antagonismos, que se configuram como certo tipo de ruído (MORIN, 2005).

Assim "ruído" está ligado não só ao funcionamento, mas também à evolução dos sistemas vivos. A mutação, por exemplo, é um tipo de perturbação que pode ser comparada a um ruído que ocorre durante o processo de duplicação no momento em que a mensagem genética é transmitida. Esse "ruído" faz com que ocorra um "erro" na informação emitida, o que deveria levar a algum tipo de degeneração no novo sistema vivo. No entanto, em certos casos, tal "ruído" leva a uma inovação e ao enriquecimento da complexidade do sistema. Observa-se que o erro, nesses casos, ao invés de degradar as informações, torna-as mais ricas. O "ruído", longe de causar um distúrbio fatal, leva ao surgimento de uma nova ordem. Nesse sentido, tal mutação aleatória, não interrompe o sistema, mas de forma paradoxal, desempenha um papel organizador (MORIN, 2005).

Em sistemas vivos que possuem um número bastante elevado de componentes, e consequentemente, uma gama praticamente imensurável de relações por eles estabelecidas, seria razoável supor uma prevalência da entropia (proporcional ao seu número de componentes), levando-os à desorganização e parada de funcionamento. Entretanto, apesar de sua alta complexidade, é exatamente o oposto disso, o que ocorre: o erro se torna fonte de reordenação e de redirecionamento.

Nesse sentido, os sistemas hipercomplexos são aqueles que desenvolveram uma capacidade de converter as consequências da entropia a seu próprio favor, crescendo e se adaptando a novas circunstâncias a partir de si mesmos, num processo que Maturana e Varella denominaram autopoiese (LOPES, 2001). 
Para Morin (1974) a própria história das sociedades humanas pode ser vista como um embate, uma tensão, entre soluções envolvendo um baixo grau de complexidade, ou soluções envolvendo hipercomplexidade. O quadro 1 apresenta as características das sociedades, que apontam para cada um dos dois lados dessa oscilação, ao mesmo tempo complementar, competitiva e antagonista.

\begin{tabular}{|c|c|}
\hline \multicolumn{2}{|c|}{ SOCIEDADES HISTÓRICAS } \\
\hline $\begin{array}{l}\text { - Orientadas para um baixo nível de } \\
\text { complexidade; }\end{array}$ & - Orientadas para a hipercomplexidade \\
\hline - Elevado nível de especialização dos indivíduos; & $\begin{array}{l}\text { - Baixo nível de especialização dos indivíduos; } \\
\text { Versatilidade; }\end{array}$ \\
\hline - Forte relação (controle) hierárquica; & - Fraca relação (controle) hierárquica; \\
\hline - Alto grau de centralização; & - Policentrismo; Descentralização; \\
\hline $\begin{array}{lccc}\text { - Rígidos direcionamentos } & \text { para } & 0 \\
\text { comportamento individual; } & & & \\
\end{array}$ & $\begin{array}{l}\text { - Estratégias heurísticas e inventivas ao invés de } \\
\text { comportamentos sociais programados; }\end{array}$ \\
\hline - Baixa autonomia individual; Coerção; & - Elevada autonomia individual; Liberdade; \\
\hline - Limites rígidos; & - Limites flexíveis; \\
\hline $\begin{array}{l}\text { - Baixo nível de comunicação e interação entre } \\
\text { indivíduos e subsistemas; }\end{array}$ & $\begin{array}{l}\text { - Alto nível de comunicação e interação entre } \\
\text { indivíduos e subsistemas; }\end{array}$ \\
\hline $\begin{array}{l}\text { - Supressão da incerteza, do ruído e da } \\
\text { desordem; }\end{array}$ & - Mais ruído, incerteza e desordem; \\
\hline $\begin{array}{l}\text { - Estabilidade; Não muita abertura para invenção } \\
\text { e inovação; }\end{array}$ & $\begin{array}{l}\text { - Instabilidade; Muita abertura para invenção e } \\
\text { inovação; }\end{array}$ \\
\hline
\end{tabular}

QUADRO 1 - SOCIEDADES HISTÓRICAS

Fonte: Adaptado de Morin (1974).

Caminhar para uma nova fase qualitativa na direção da hipercomplexidade, representaria o início de uma nova era para a humanidade (MORIN, 1974). Essa interessante análise de Morin abre espaço para uma reflexão acerca do papel que teriam as redes sociais no direcionamento da sociedade para um patamar mais próximo da hipercomplexidade. Tal discussão será retomada à frente, na seção 2.7.2, quando as redes sociais serão abordadas do ponto de vista de sua capacidade emancipatória.

Conforme já mencionado, outra característica bastante marcante nos sistemas complexos é a emergência, cuja compreensão passa também pela ideia de autoorganização. Os sistemas em que um comportamento organizado ocorre sem a intervenção de um controle, seja ele interno ou externo, são denominados sistemas auto-organizados, conforme exposto anteriormente. Tais sistemas possuem, para tanto, uma característica essencial, que é a emergência, ou seja, o surgimento de uma organização complexa a partir de ações individuais relativamente simples 
(MITCHELL, 2009). Nesse sentido, o comportamento emergente é condição essencial para que se denomine um sistema como complexo (HOLLAND, 2014).

O conceito de emergência não possui contornos muito bem definidos, são muitas as abordagens e definições. Contudo, para boa parte dos autores como Heylighen (1991); Holland (2014), Johnson (2003), Mitchell (2009), Morin (2006) a emergência é vista como consequência de interações entre componentes individuais em que o resultado agregado exibe propriedades que não podem ser explicadas pela simples soma desses componentes. Em termos matemáticos, trata-se de interações não lineares, em que os efeitos não são proporcionais às causas.

Assim, nas situações em que os efeitos se evidenciam maiores que suas causas, ocorre o que se denomina amplificação ou feedback positivo. Em situações opostas, trata-se do chamado feedback negativo. Nas situações de feedback positivo, perturbações iniciais nos sistemas são capazes de se auto alimentarem para que se tornem cada vez mais intensas. Esse tipo de ocorrência se evidencia facilmente na disseminação de doenças, em que um único indivíduo infectado pode levar à existência de uma pandemia global (HEYLIGHEN, 2013).

Tais aspectos relativos a interações recursivas não lineares em sistemas abertos, que são responsáveis pela dificuldade de pré-determinação de um resultado (estado futuro), são tratadas como uma questão central pelos teóricos e pesquisadores da abordagem da complexidade. A conhecida metáfora do efeito borboleta, típica das explicações relativas à Teoria do Caos, que se tornou bastante popular nos anos 80 , revela a essência dos fenômenos não lineares.

Em 1972, Edward Lorenz realizou uma palestra para o Programa Global de Pesquisa Atmosférica, intitulada: "Predictability: Does the Flap of a Butterfly's Wings in Brazil set off a Tornado in Texas?", em uma tradução livre "Previsibilidade: o bater de asas de uma borboleta no Brasil desencadeia um tornado no Texas?" Os estudos de Lorenz trataram de esmiuçar a questão da não linearidade, evidenciando que certos sistemas dinâmicos apresentam uma grande dependência das condições iniciais, uma das características essenciais dos chamados sistemas caóticos. Suas experiências mostraram que pequenos erros de arredondamento em modelos de previsão de clima podem levar a previsões bastante equivocadas (ÉRDI, 2008). 
Entretanto, mesmo que não se possa prever em detalhes o comportamento dos sistemas caóticos, a existência de determinadas regras de funcionamento comuns a esses sistemas é capaz de auxiliar na previsão de aspectos em nível geral, portanto, considera-se que exista algum tipo de ordem no caos. A ideia de criticalidade autoorganizada é o que descreve a existência dessa ordem (FERNANDES, 2008).

A criticalidade auto-organizada é um princípio por trás do comportamento de sistemas cujas frequências não obedecem às leis de distribuição estatísticas em torno da média, tal que na natureza muitas mudanças ocorrem mais por meio de eventos catastróficos do que apenas por mudanças graduais. (BORGATTI NETO, 2008, p. 225).

A demonstração típica e por vários autores destacada como representativa da criticalidade auto-organizada é a da pilha de areia que vai paulatinamente recebendo um fino fluxo de grãos em seu topo. Essa experiência, primeiramente desenvolvida por Per Bak, demonstra que à medida que a pilha vai aumentando, ocorrem vários pequenos desmoronamentos, e poucos grandes deslizamentos, de maneira que um mesmo grão de areia pode ser responsável por uma pequena avalanche ou por um grande deslizamento. Entre pequenos eventos e grandes catástrofes, a pilha de areia busca sempre o alcance de um novo estado de equilíbrio, por meio de pequenos ajustes (no caso dos pequenos deslizamentos) ou de uma quase total reestruturação (no caso das grandes avalanches), até que novos grãos de areia sejam derramados e provoquem um novo desalinhamento no sistema. Assim, o fenômeno da criticalidade auto-organizada evidencia que grandes e pequenos eventos podem ocorrer em função de uma mesma causa (BORGATTI NETO, 2008; HOLLAND, 2014; KAUFFMAN, 1995; MITCHELL, 2009).

Se pequenas avalanches ocorrem com grande frequência na pilha de areia, e grandes avalanches são relativamente raras, evidencia-se que tal fenômeno obedece a uma lei de potência, denominada de scale free, que significa que repete seu padrão independente de uma escala. Na natureza, observa-se que terremotos, enchentes assim como outros fenômenos, obedecem a uma lei de potência (BORGATTI NETO, 2008; FERNANDES, 2008; KAUFFMAN, 1995, HOLLAND, 2014; MITCHELL, 2009).

Voltando a tratar mais especificamente do conceito de emergência, pode-se afirmar que regras em um nível mais baixo geram uma grande sofisticação do nível mais alto, numa combinação interessante entre ordem e anarquia (JOHNSON, 2003). As 
interações entre componentes individuais em um nível geram propriedades emergentes em um nível mais elevado, "como quando moléculas de $\mathrm{H} 2 \mathrm{O}$ se transformam em blocos de construção para a água" (HOLLAND, 2014, p. 4, tradução nossa).

A partir do reconhecimento dessa forma de organização dos sistemas complexos, torna-se necessária a compreensão das interações existentes entre os componentes emergentes em cada um dos níveis dessa hierarquia. A combinação entre efeitos de interação denominados top-down (de cima para baixo), com os denominados bottom-up (de baixo para cima) são uma característica que pode ser considerada global nos sistemas complexos (HOLLAND, 2014).

Complexos sistemas adaptativos que revelam comportamento emergente apresentam interações do tipo bottom-up, evidenciando uma conexão coletiva em que a organização ocorre de baixo para cima. Para a consecução de seus objetivos, os sistemas complexos funcionam a partir de um detalhado aparato de produção e troca de sinalização e de informações em seus ambientes interno e externo. Assim, "formigas criam colônias, cidadãos criam comunidades, um software simples de reconhecimento de padrões aprende a recomendar novos livros" (JOHNSON, 2003, p. 165).

Capra (1996), entretanto, apesar de reconhecer a existência de relações entre elementos em níveis diferenciados, considera que aplicar o conceito de hierarquia aos sistemas vivos, não seria muito adequado.

Desde que os sistemas vivos, em todos os níveis, são redes, devemos
visualizar a teia da vida como sistemas vivos (redes) interagindo à maneira
de redes com outros sistemas (redes). [...] Em outras palavras, a teia da
vida consiste de redes dentro de redes. Em cada escala, sob estreito e
minucioso exame, os nodos da rede se revelam como redes menores.
Tendemos a arranjar esses sistemas, todos eles aninhados dentro de
sistemas maiores, num sistema hierárquico, colocando os maiores acima
dos menores, à maneira de uma pirâmide. Mas isso é uma projeção
humana. Na natureza, não há 'acima' ou 'abaixo', e não há hierarquias. Há
somente redes aninhadas dentro de redes (CAPRA, 1996, p. 44 e 45).

Essa discussão será retomada adiante, na subseção 2.7.2, quando se apresenta, entre outras questões, a natureza não hierárquica das redes sociais.

Conforme destaca Johnson (2003) estamos vivenciando a terceira fase da pesquisa sobre emergência, em que as interações bottom up encontram-se em evidência 
cada vez maior. Na primeira fase, buscou-se inicialmente, apenas a compreensão dos mecanismos de auto-organização.

A segunda fase, por sua vez, marcou o início da visão de que os problemas da autoorganização extrapolavam as possibilidades de uma única disciplina. Em meados da década de 80 , os estudos sobre emergência provocavam certa efervescência em vários pontos da comunidade científica. A criação do Instituto Santa Fé, no Novo México, EUA, em 1984, tornou-se um importante marco dessa segunda fase, além de uma forte referência que permanece até os dias atuais, no estudo dos sistemas complexos. Na ocasião, um grupo formado por 24 pesquisadores entre matemáticos e importantes cientistas de diferentes disciplinas compreendeu que para a abordagem aos sistemas complexos, seria necessária uma junção de conhecimentos, uma aproximação interdisciplinar que contrariava o movimento de polarização científica da época (JOHNSON, 2003; MITCHELL, 2009).

A terceira fase é marcada pela construção de sistemas de auto-organização com software, vídeo games, arte e música, que permitem que se passe a criar a emergência, para além de analisá-la. Assim, se constitui a lógica da emergência artificial, onde as mesmas leis de organização dos organismos complexos são exploradas por sistemas construídos para essa finalidade (JOHNSON, 2003).

Estamos na terceira fase da evolução do paradigma da complexidade.
Iniciada no início da década de 90 quando Will Right lançou um jogo
chamado SimCity [...]. O SimCity também inauguraria uma nova fase do
desenvolvimento da história da auto-organização: o comportamento
emergente deixou de ser apenas um objeto de estudo, algo a ser
interpretado e modelado em laboratório. Passou a ser também algo que se
podia construir, com que se podia interagir e que se podia vender. Quando
SimCity apareceu como uma novidade do mundo bottom up, mostrou-se
uma nova abertura: SimCity era uma obra de cultura, não de ciência.
Propunha-se a divertir, não a explicar. (JOHNSON, 2003, p.804).

Muitos jogos como o SimCity atualmente se baseiam no poder da auto-organização digital, em grande medida, graças ao desenvolvimento dos chamados modelos baseados em agentes, também conhecidos como sociedades artificiais ou ecossistemas artificiais.

Simulações são criadas em software, objetivando modelar ambientes interativos, a partir da atuação de uma grande quantidade de agentes autônomos em vários ciclos de interações. Nesses ciclos interativos os agentes compartilham, combatem e trocam recursos com outros agentes. Experimentos virtuais realizados a partir dos 
anos 90 com a utilização de tais modelos dedicaram-se em grande medida à simulação de sistemas sociais (SAWYER, 2005).

A conexão dos agentes em grandes redes de atuação leva a crer que as descobertas no campo das pesquisas sobre redes podem ser bastante relevantes para o desenvolvimento da modelagem baseada em agentes. Assim, apesar do desenvolvimento das teorias de redes possuir uma linha bem delimitada, originada na teoria dos grafos, vê-se a possibilidade de um futuro de integração entre redes e modelos baseados em agentes, conforme destaca Borgatti Neto (2008), uma Teoria de Networks de Agentes ou de Agentes em Networks.

Destaca-se também, nesse contexto, o papel de John Holland, que em 1975 concebeu os chamados algoritmos genéticos, fundamentais para o avanço das pesquisas sobre sistemas complexos. Suas propostas foram apresentadas em seu livro intitulado "Adaptation in Natural and Artificial Systems", ou, Adaptação em Sistemas Naturais e Artificiais, apresenta uma série de princípios sobre adaptação, incluindo uma proposição para a construção de algoritmos genéticos (MITCHELL, 2009).

Um algoritmo genético configura-se como uma série de passos, em um procedimento definido, por meio do qual um input (entrada) é transformado num output (saída) e cuja finalidade é a busca de solução para um determinado problema, por meio de uma evolução do software. Assim, tais algoritmos são desenvolvidos para que persigam sua sobrevivência a partir da utilização de comportamentos de sucesso no espaço de soluções do sistema computacional. Trata-se de uma técnica de inteligência artificial.

Por meio de tais algoritmos encontra-se refletida uma grande gama de paralelismos entre programas de computador e as formas de vida na terra (FERNANDES, 2008; JOHNSON, 2003; MITCHELL, 2009). Os algoritmos genéticos vêm dando sua contribuição em diversas simulações, visando, entre outras coisas, à construção de modelos e análise de situações complexas de cooperação, em inúmeras áreas da ciência, especialmente na teoria social (AXELROD, 1987). Alguns exemplos estão no estudo de alguns fenômenos emergentes como a cooperação entre parentes, estruturas de oligopólios, manutenção de minorias genéticas e comportamento altruísta (FERNANDES, 2008). 
A tendência pela busca de características comuns aos sistemas complexos tem sido abarcada na atualidade pelos estudos sobre redes. Seus impactos para a ciência encontram-se relacionados à sua capacidade de, ao buscar características comuns aos sistemas complexos, funcionar como um hub, ou seja, um conector entre diferentes áreas de conhecimento, muitas vezes bastante distantes entre si, mas que tem no estudo de redes, um ponto em comum (MITCHELL, 2009; WATTS, 2004). Dessa forma, a seção seguinte se dedica a discutir em maiores detalhes a perspectiva das redes complexas.

\subsection{FUNDAMENTOS SOBRE REDES}

O estudo de características comuns entre as redes permeando diferentes disciplinas acelerou-se e ampliou-se a partir da década de 90, com o surgimento de computadores com capacidade e rapidez suficientes para a realização de estudos empíricos, tanto no que diz respeito às simulações, quanto ao tratamento de grandes massas de dados coletados no mundo real. A existência desse volume significativo de dados analisáveis deve-se, em grande medida, à intensificação do uso da internet para diversas finalidades (MITCHELL, 2009; STROGATZ, 2001).

Embora para algumas áreas da sociologia possa parecer estranho, tendo em vista a sua familiaridade histórica com os estudos sobre redes sociais, a denominação "Nova Ciência das Redes" tem sido utilizada para refletir um momento de rápido e amplo crescimento do estudo das redes em diversos campos científicos. Tais estudos têm sido marcados por uma constante reformulação de ideias, pela introdução de novas técnicas de pesquisa e pela descoberta de conexões entre problemas que pareciam possuir naturezas completamente distintas (WATTS, 2004).

Assim, do ponto de vista tecnológico, o pensamento em rede tem proporcionado novas formas de encarar questões importantes como o controle de epidemias, melhorias nos mecanismos de busca na Internet, preservação de ecossistemas, ataque a doenças que afetam determinados sistemas complexos no organismo, e 
tantas outras. Ainda, de maneira mais geral, a nova ciência das redes tem apresentado caminhos diferenciados para descobertas de vulnerabilidades e resiliências relacionadas a redes naturais, sociais e tecnológicas, na busca por uma melhor utilização e proteção de tais sistemas (MITCHELL, 2009).

\begin{abstract}
Escondido na Rede está o mistério da Mão Invisível - o controle sem autoridade. Enquanto o Átomo representa a simplicidade pura, a Rede aciona o poder confuso da complexidade. A Rede, como uma bandeira, é difícil de conviver. É a bandeira do não controle. Onde quer que a Rede surja, ali também surge um rebelde para resistir ao controle humano. $O$ símbolo da rede significa o pântano da psique, o emaranhado da vida, a multidão necessária à individualidade (KELLY, 2008, p. 25, tradução nossa)
\end{abstract}

Nesse sentido, Kelly (2008) menciona o que se denomina de cultura de rede, apresentando a capacidade das redes de mudar a cultura humana a partir de constituição de um mundo interconectado. Onde quer que existam mudanças constantes e irregulares, aí está o fenômeno da rede.

Um das questões centrais ao pensamento de rede é o seu foco muito mais nas relações existentes entre os seus componentes, do que nas características individuais de cada um desses componentes (BARABÁSI, 2009; CARRINGTON; SCOTT; WASSERMAN, 2012; MITCHELL, 2009; WASSERMAN; FAUST, 2009). A existência de determinados padrões regulares nessas relações é compreendida como a estrutura da rede (WASSERMAN; FAUST, 2009).

A Teoria dos Grafos configura-se como componente essencial ao desenvolvimento do estudo das redes. Tal teoria acabou por se consolidar como a mais importante técnica matemática para representação das relações estruturais existentes entre os elementos dos sistemas naturais e sociais. Os grafos são utilizados para a representação dos diferentes vértices, e das arestas existentes entre esses vértices (BARABÁSI, 2009; ÉRDI, 2008; WASSERMAN; FAUST, 2009).

O matemático Frank Harary foi uma das figuras mais importantes tanto no desenvolvimento quanto na aplicação da teoria dos grafos em diferentes áreas como a antropologia, biologia, química, ciência da computação, geografia, linguística, música, física, ciência política, dentre tantas outras. Essas aplicações, realizadas por Harary permitiram a atual abordagem a variados problemas por meio da teoria das redes (ÉRDI, 2008; WASSERMAN; FAUST, 2009). 
É também essencial destacar o trabalho pioneiro do matemático suíço Leonhard Euler ao resolver por volta de 1740, o famoso problema de Königsberg. O raciocínio para a solução proposta teve como consequência a formulação do que se considera o primeiro grafo (BARABÁSI, 2009; BOCCALETTI et al., 2006; OTTE; ROUSSEAU, 2002).

Euler foi um proeminente matemático cuja carreira se desenvolveu nas cidades de Berlim e São Petersburgo. Sua obra é marcada por uma quantidade impressionante de formulações e pela influência bastante significativa que exerceu não apenas na matemática, mas também na física e na engenharia (BARABÁSI, 2009).

Königsberg, na época cidade próspera da Prússia Oriental, era relativamente próxima da residência de Euler em São Petersburgo. Cercada pelo rio Pregel, a cidade possuía sete pontes. A população local, como forma de passatempo, buscava solução para uma questão aparentemente elementar: seria possível atravessar as sete pontes sem jamais cruzar a mesma ponte mais de uma vez?

A grande contribuição de Euler na busca pela resposta a essa questão, foi transformar a geografia das pontes em um grafo, o que quer dizer encará-la como um conjunto de nós conectados por links. Assim, considerou as faixas de terra separadas pelo rio $(A, B, C, D)$ como nós e as pontes como os links ("a" a " $g$ ") entre esses nós (BARABÁSI, 2009). A figura 1 apresenta o raciocínio de Euler.

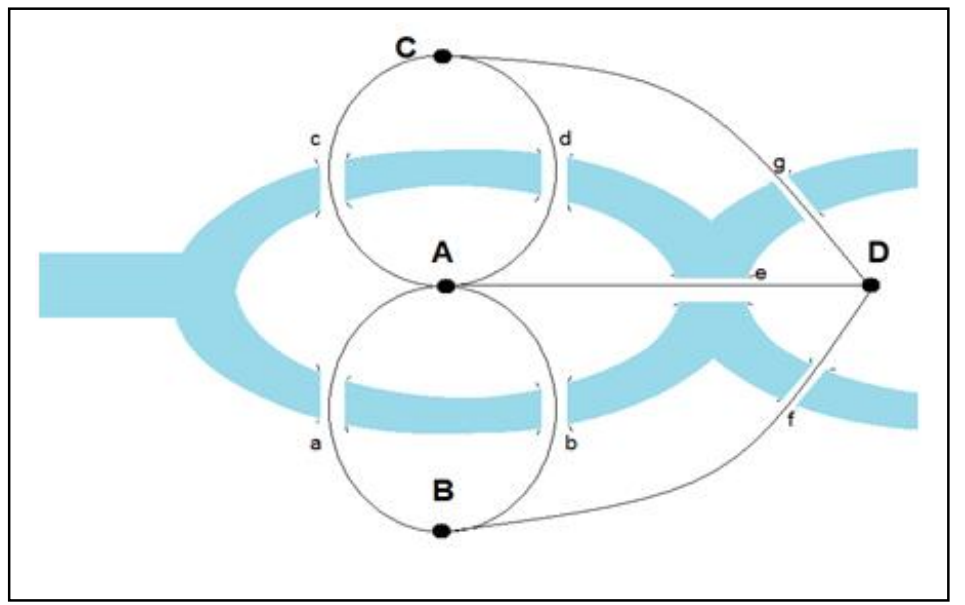

FIGURA 1 - AS PONTES DE KÖNIGSBERG

Fonte: Barabási (2009).

A partir de uma lógica relativamente simples mesmo para os não matemáticos, Euler construiu sua prova para a impossibilidade de se fazer o caminho cruzando cada uma das pontes apenas uma única vez. Suas formulações o levaram a concluir que 
o ponto de partida ou o ponto de chegada do percurso devem ser constituídos por nós com número impar de links. Uma passagem que não atravessasse duas vezes a mesma ponte deveria possuir apenas um ponto de partida e um ponto de chegada. Dessa forma, num grafo em que houvesse mais de dois nós com um número ímpar de links, o caminho que não repetisse nenhuma passagem não poderia existir. 0 grafo de Königsberg possuía quatro desses nós, assim, o caminho não seria possível (BARABÁSI, 2009; BOCCALETTI et al., 2006; OTTE; ROUSSEAU, 2002).

Dessa maneira, o que se tornou claro a partir da proposição de Euler, é que os grafos possuem certas propriedades que, ao serem desvendadas permitem a solução de determinados problemas de maneira muito mais fácil e objetiva. Por outro lado, tais propriedades, quando negligenciadas ou desconhecidas, podem ser responsáveis por certas dificuldades e limitações à abordagem de determinadas questões. Assim, no caso das sete pontes a solução não era uma função da esperteza necessária para se encontrar o caminho, mas sim do conhecimento sobre a natureza e as propriedades dos grafos.

A construção, em 1875, de uma nova ponte ligando as faixas de terra B e C, fez com que esses dois nós passassem a possuir quatro links cada, ficando apenas $A$ e D com um número impar de links, o que possibilitou a realização do caminho desejado. Desde então, a teoria dos grafos evoluiu significativamente a partir da contribuição de outros célebres nomes como Cauchy, Hamilton, Cayley, Kirchhoff e Pólya (BARABÁSI, 2009).

O grande legado da solução do problema de Königsberg é, portanto, a percepção de que compreender a estrutura dos grafos ou redes é também a possibilidade de desvendar a complexidade na qual estamos imersos. "Pequenas mudanças na topologia, afetando tão somente alguns poucos nós ou links, podem abrir portas ocultas, permitindo a emergência de novas possibilidades” (BARABÁSI, 2009, p. 11)

Em sentido complementar, Strogatz (2001) destaca que é muito importante caracterizar a chamada topologia das redes, tendo em vista a estreitíssima relação existente entre estrutura e função. "Por exemplo, a topologia de redes sociais afeta a propagação de informações e da doença, e a topologia da rede de energia afeta a robustez e estabilidade de transmissão de energia” (STROGATZ, 2001, p. 268, 
tradução nossa). Considerando tal relevância passa-se a apresentar alguns dos conceitos e propriedades da Análise de Redes Sociais.

\subsection{A ANÁLISE DE REDES SOCIAIS - ARS}

O termo rede social vem sendo empregado nas Ciências Sociais de uma maneira geral, muito mais para designar um campo, do que propriamente uma disciplina específica, tendo em vista que vem sendo utilizado por diferentes áreas como a Antropologia, Sociologia, Economia, Ciências Políticas, Ciência(s) da Informação, Ciências da Comunicação, entre outras (MARTELETO, 2010).

Redes sociais são redes cujos nós são atores ou agentes sociais, e cujos relacionamentos sociais são representados por links entre pares de nós. A ARS estuda a estrutura das redes sociais.

A partir da ARS, propriedades matemáticas de nós e links são analisadas com vistas à compreensão da forma de estruturação de grupos sociais. Tais redes e estruturas, ao serem visualizadas e contextualizadas, permitem desvendar a forma de atuação da rede, sua maneira de funcionamento, conforme se pretende demonstrar nesta seção. Nesse sentido, a aplicação da ARS está diretamente associada ao alcance dos objetivos da pesquisa, sendo essencial ao percurso metodológico aqui adotado, conforme se encontra demonstrado nas seções 3 e 4.

A perspectiva das redes sociais leva a uma compreensão pouco tradicional de sociedade, pois permite considerá-la do ponto de vista dos vínculos relacionais (relacionamentos) estabelecidos entre os indivíduos. Tais vínculos seriam capazes de reforçar a capacidade de atuação desses indivíduos, considerando possibilidades de compartilhamento, aprendizagem, mobilização e captação de recursos (MARTELETO, 2010).

A ARS configura-se em essência, como um campo interdisciplinar. Para Otte e Rousseau (2002), a ARS não é um arcabouço teórico formal, mas sim uma 
estratégia abrangente para o estudo das estruturais sociais. De acordo com Marin e Wellman (2010) a ARS é muito mais uma perspectiva, do que propriamente uma teoria ou uma metodologia.

Segundo Scott (2012) três das principais áreas aonde a ARS vem sendo aplicada são os estudos sobre a difusão de inovações, sobre as redes acadêmicas de pesquisa e sobre o poder corporativo, por meio da investigação das interligações existentes entre detentores de cargos administrativos, por exemplo. Além desses, também podem ser mencionados os estudos acerca de estruturas de colaboração e muitas outras formas de interação social (OTTE; ROUSSEAU, 2002).

A ARS apresenta-se como uma alternativa metodológica bastante consistente para a abordagem de variados problemas de pesquisa no campo da Ciência da Informação (TOMAÉL; MARTELETO, 2013; MATHEUS; SILVA, 2006; OTTE; ROUSSEAU, 2002).

No Brasil, os estudos utilizando a metodologia de ARS têm crescido significativamente, em especial a partir da última década, conforme apontam Tomaél e Marteleto (2013). Alguns exemplos brasileiros de estudos em Ciência da Informação envolvendo a perspectiva da ARS são: Análise de redes sociais como método para a Ciência da Informação (MATHEUS; SILVA, 2006); Redes Sociais de dois modos: aspectos conceituais (TOMAÉL; MARTELETO, 2013); Redes Sociais, Conhecimento e Inovação localizada (TOMAÉL, 2007); Análise de Redes Sociais como metodologia de apoio para a discussão da interdisciplinaridade na Ciência da Informação (MATHEUS et al., 2006); e Análise de Redes Sociais - aplicação nos estudos de transferência da informação (MARTELETO, 2001).

Os pioneiros da ARS são oriundos de disciplinas como a sociologia, a psicologia social e a antropologia. Nomes importantes nessas áreas como Moreno, Cartwright, Newcomb, Bavelas, Barnes e Mitchel realizaram significativas contribuições ao desenvolvimento dos estudos sobre redes sociais (WASSERMAN; FAUST, 2009). Não se pode deixar de mencionar também as fortes influências exercidas pelo trabalho de Kurt Lewin na psicologia de pequenos grupos (SCOTT, 2012) e as de Georg Simmel (TOMAÉL; MARTELETO, 2013; SCOTT, 2012) sobre interações, círculos sociais e afiliações. 
Ao longo de seu desenvolvimento a ARS veio sendo objeto de estudo por parte dessas diferentes ciências sociais, que, na década de 70 reuniram seus esforços e transformaram as ações isoladas em um campo de pesquisa único, a partir de uma perspectiva estrutural (WASSERMAN; FAUST, 2009).

A mensuração dos relacionamentos existentes entre indivíduos em pequenos grupos encontra suas raízes na sociometria, uma abordagem metodológica surgida na década de 1930 e que tem em Moreno (1953) sua principal referência.

Conforme apontam Marteleto e Silva (2004), a sociometria associa o comportamento do indivíduo à estrutura social à qual ele pertence e possui como instrumento de análise o chamado sociograma. $O$ tamanho dos grupos estudados inicialmente era reduzido em função da ausência de instrumentos, ferramentas e métodos automatizados para análise de redes.

Moreno era um psicanalista austríaco que havia migrado para os Estados Unidos. Para a efetivação de seus estudos, com foco especial nas relações de amizade entre crianças no ambiente escolar, propôs o conceito de sociograma. Trata-se de um desenho bidimensional em que pessoas ou quaisquer outras unidades sociais são representadas por meio de pontos e as ligações existentes entre esses pontos são desenhadas como linhas (FREEMAN, 2000; MORENO, 1953; SCOTT, 2012; WASSERMAN; FAUST, 2009). Matematicamente, um sociograma é um grafo.

Moreno observou a interação das crianças e contou o número de escolhas
de amizade feitas e recebidas por diferentes membros da classe,
combinando-as em sociogramas que representavam cada criança como um
ponto e as suas escolhas de amizade como linhas com pontas de flechas.
Essas flechas mostravam a direção em que a escolha foi feita: distinguindo
as escolhas 'de saída' dirigidas a outros das escolhas 'de entrada' recebidas
de outras pessoas. Esse método permitiu a Moreno identificar as 'estrelas'
mais populares da atração e os relativos 'isolados' que receberam pouca ou
nenhuma escolha de amizade (SCOTT, 2012, p. 1, tradução nossa) A partir do sociograma, o desenvolvimento da representação visual das estruturas de grupos, incluindo atualmente até mesmo modelos tridimensionais, permitiu que as técnicas analíticas sobre essas estruturas pudessem avançar de forma rápida e abrangente (FREEMAN, 2000; WASSERMAN; FAUST, 2009). A figura 2 mostra o desenho de um sociograma realizado por Moreno (1953) como demonstração da fase inicial do desenvolvimento de um grupo. 


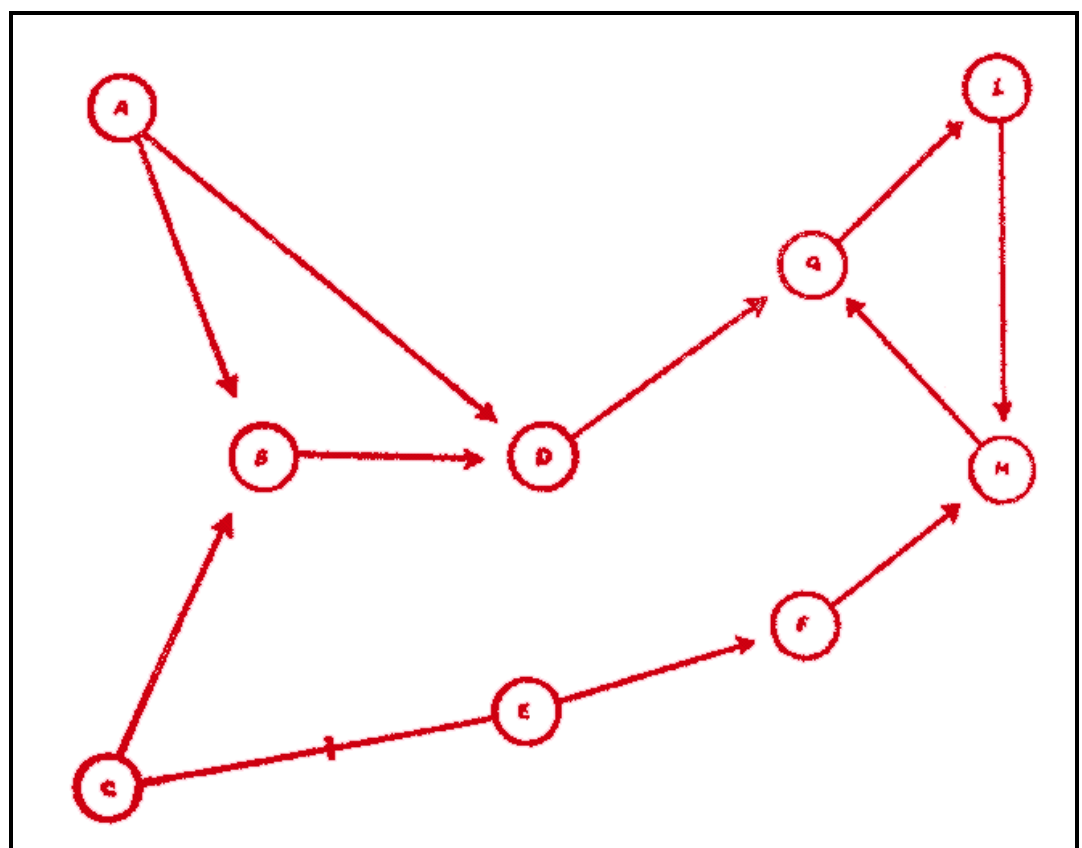

FIGURA 2 - SOCIOGRAMA PARA DEMONSTRAÇÃO DA ESTRUTURA DE RECONHECIMENTO ENTRE CRIANÇAS

Fonte: Moreno (1953).

Com a descoberta de que a representação dos dados sobre redes sociais poderia ser também realizada por meio de matrizes, ocorreu uma maior aproximação da ARS com a matemática. A teoria dos grafos (discutida na seção anterior), as teorias estatísticas e os estudos de probabilidade são importantes aplicações matemáticas à ARS (IZQUIERDO; HANNEMAN, 2006; WASSERMAN; FAUST, 2009).

A partir da teoria dos grafos, conceitos como densidade dos sociogramas e também de centralidade dos indivíduos, começaram a ser trabalhados pelos cientistas sociais. Assim, propriedades matemáticas de pontos e linhas são analisadas com vistas à compreensão da forma de estruturação da rede (IZQUIERDO; HANNEMAN, 2006; SCOTT, 2012).

Da mesma forma que a matemática, pesquisadores de outras áreas como a física e a computação, com o tempo passaram a considerar a ARS uma disciplina essencial na busca de soluções para suas questões de pesquisa. Mas a união de esforços entre essas ciências exatas e as ciências sociais, embora pareça bastante desejável agora que seus profícuos resultados podem ser obervados, não foi tão bem vinda especialmente pelos sociólogos, à época em que passou a ocorrer (FREEMAN, 2011). 
A perspectiva estrutural das redes inseriu-se também no rol de interesse da física. Apesar de ser encarada pelos estudiosos das ciências sociais como um campo completamente estranho à ARS, a física passou assim, a demonstrar seu interesse pelo estudo das relações sociais. Alguns físicos chegaram até mesmo a considerar a ARS como parte de seu campo científico. Essa situação pode ser explicada por um contexto específico vivenciado à época, tanto pela física quanto pela biologia (FREEMAN, 2011).

No final da década de 90, volumes gigantescos de dados sobre redes passaram a estar disponíveis para análise. Na física, como resultado do advento da Internet conectando milhões de computadores a partir de diferentes tecnologias. Na biologia, em decorrência, por exemplo, das pesquisas sobre o genoma humano, que proporcionaram a evidenciação de grandes redes genéticas e metabólicas. Tais ciências necessitavam dispor de ferramentas para lidar de forma adequada com esse enorme volume de dados.

Nesse contexto, a ARS configurou-se como uma grande saída para o problema posto, já que se tratava de um campo que há 60 anos se incumbia de lidar com a análise de dados sobre redes. Assim se iniciou essa aproximação da física e da biologia com a ARS, envolvendo a apropriação, o melhoramento e também o desenvolvimento de ferramentas analíticas (FREEMAN, 2011).

Em certos aspectos desse processo, alguns físicos foram criticados por não mencionarem em seus estudos, os trabalhos, fundamentos e conceitos, já desenvolvidos no campo da ARS por cientistas sociais. Não se pode afirmar se por ignorarem a sua existência ou se por realmente terem desconsiderado tais descobertas já realizadas.

Sobre as contribuições dos físicos para a ARS, Freeman (2011) destaca:

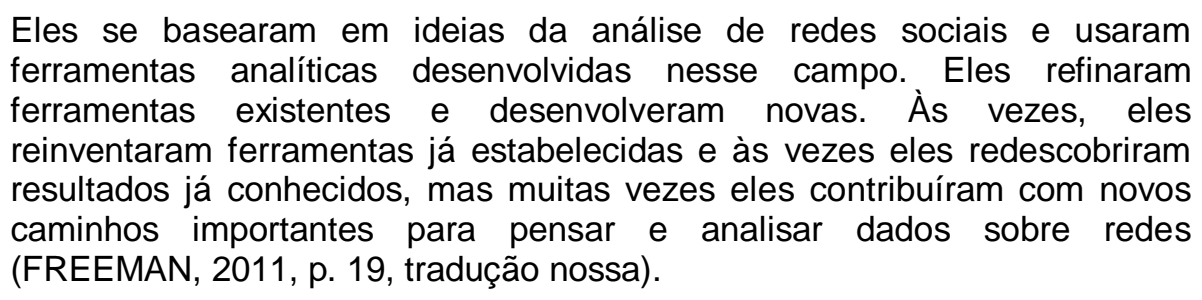

Esse intercâmbio de conhecimentos entre a física e a ARS fez-se notar nas citações por parte dos físicos, de artigos sobre ARS produzidos nas ciências sociais. 
Entretanto, não houve muita reciprocidade, nesse sentido, por parte dos cientistas sociais. Também programas de computador produzidos por cientistas sociais para análises de dados sobre redes passaram a ser utilizados pelos físicos. Além de utilizar esses programas, os físicos também criaram novos, a partir de modelos desenvolvidos nas ciências sociais (FREEMAN, 2011).

Depois de algumas disputas pelo domínio do campo da ARS, a aproximação entre as ciências exatas, especialmente a física, e as ciências sociais, parece estar se consolidando nos últimos anos, conforme aponta ainda Freeman (2011). Em sua visão, há mais benefícios que argumentos contrários à efetivação desse processo.

De acordo com Marteleto (2010), são três os princípios gerais para o estudo das redes sociais:

(a) Sua extensão e não finitude em relação ao espaço local.

(b) Compreensão das redes densas, advindas das relações de proximidade (familiares e de vizinhança) e das redes ampliadas (relações de trabalho, associativas e participativas).

(c) O entendimento de que, por meio da configuração das redes sociais e dos elos entre os atores, é possível analisar o comportamento individual e coletivo de seus membros.

O traço comum desses trabalhos é a ênfase nas relações sociais para estudar fenômenos sociais, culturais, econômicos ou políticos, o que constitui preocupação clássica e perene nas Ciências Sociais (MARTELETO, 2009, p. 29).

Assim, a ARS marca uma perspectiva diferenciada nas Ciências Sociais, ao transferir sua unidade central de análise tradicionalmente focada no indivíduo, para grupos de indivíduos e, mais especificamente, para os relacionamentos existentes entre esses no grupo. Embora os atributos dos atores possam também ser considerados na ARS, a visão usual das ciências sociais, de estudar essencialmente características individuais como comportamentos, sentimentos e atitudes, cede lugar a uma perspectiva relacional (TOMAÉL; MARTELETO, 2013; OTTE; ROUSSEAU, 2002; SCOTT, 2012; WASSERMAN; FAUST, 2009).

De acordo com Recuero (2009), o enfoque dos relacionamentos na perspectiva da ARS traz como uma de suas principais consequências o reconhecimento da cooperação, da competição e do conflito como processos dinâmicos sociais naturais e emergentes nas redes sociais. Como fortes influenciadores do funcionamento das redes sociais, tais processos necessitam fazer parte dos estudos sobre o tema. 
A cooperação pode ser compreendida como uma forma de agir organizado sem o qual, a própria sociedade não pode existir. Suas origens podem estar em interesses individuais e também nas finalidades existentes no grupo. A competição, por sua vez, configura-se a partir de uma lógica de luta, mas não de hostilidade. Essa última é típica das situações de conflito. Nesse sentido, a competição pode ser a geradora de processos de cooperação, com vistas a fazer frente às ações de outros grupos organizados. Já o conflito pode ser capaz de gerar até mesmo a ruptura da estrutura social, por sua capacidade de conduzir à hostilidade e desgaste dessa estrutura. Assim, no conflito há a presença de um antagonismo claro, enquanto na competição esse não se faz necessário (RECUERO, 2009).

Nesse sentido, pode-se depreender que enquanto a estrutura social é criada e mantida por elementos de cooperação, o desequilíbrio social tem no conflito uma de suas principais razões. Por sua vez, a competição tanto pode contribuir para o fortalecimento da estrutura social ao gerar cooperação em prol de um bem comum, quanto pode gerar conflito, levando a rupturas e desgaste nas relações (RECUERO, 2009).

Também por ter seu foco nos relacionamentos entre entidades sociais, e não apenas nas características específicas dessas entidades, é que a ARS requer a utilização de métodos e ferramentas distintas daquelas tradicionalmente aplicadas à estatística e à análise de dados (HANNEMAN; RIDDLE, 2009; WASSERMAN; FAUST, 2009).

Uma das práticas mais tradicionais da análise de dados nas ciências sociais é a sua organização em matrizes retangulares que relacionam pessoas e características, como demonstra a tabela 1. As linhas representam os casos analisados, temas ou observações realizadas. As colunas apresentam a descrição que pode ser quantitativa ou qualitativa, das variáveis, dos atributos e das medidas consideradas. Esse tipo de matriz de dados proporciona análises comparativas entre linhas e entre colunas, focando ora nos atores, ora em seus atributos. 
TABELA 1 - EXEMPLO DE MATRIZ RETANGULAR DE DADOS

\begin{tabular}{llcc}
\hline Nome & Gênero & Idade & Grau de Entrada \\
\hline Luiz & Masculino & 32 & 2 \\
\hline Maria & Feminino & 27 & 1 \\
\hline João & Masculino & 29 & 1 \\
\hline Alice & Feminino & 28 & 3 \\
\hline
\end{tabular}

Fonte: Adaptado de Hanneman; Riddle (2009).

Contudo, a organização dos dados relativos às redes sociais possui características um tanto distintas dessas, considerando que estabelecem matrizes quadradas que relacionam, por exemplo, atores sociais e outros atores sociais, conforme demonstra a tabela 2. As linhas podem representar os casos analisados, temas ou observações realizadas. A diferença essencial deste tipo de matriz é que as colunas também representam o mesmo conjunto de casos, temas ou observações.

TABELA 2 - EXEMPLO DE MATRIZ QUADRADA DE DADOS SOBRE REDES

Quem relata se relacionar com quem?

\begin{tabular}{lcccc}
\hline & Escolha & & & \\
\hline Escolhedor & Luiz & Maria & João & Alice \\
\hline Luiz & ----- & 0 & 1 & 1 \\
\hline Maria & 1 & ---- & 0 & 1 \\
\hline João & 0 & 1 & ---- & 1 \\
\hline Alice & 1 & 0 & 0 & ---- \\
\hline
\end{tabular}

Fonte: Adaptado de Hanneman; Riddle (2009).

Adicionalmente ao seu foco relacional, outros importantes princípios também distinguem a ARS de outras abordagens de pesquisa (WASSERMAN; FAUST, 2009).

Um primeiro princípio essencial da ARS é a interdependência existente entre os atores sociais e suas respectivas ações (ROBINS; PATTISON, 2012; WASSERMAN; FAUST, 2009). Outra questão é que as ligações ou links existentes entre os atores são vistos como canais de transmissão de recursos, sendo essenciais a um determinado fluxo seja ele material ou não material. Além disso, o ambiente estrutural da rede é visto como contingencial, ou seja, capaz de oferecer oportunidades ou limitações às ações individuais, em decorrência de suas características estruturais. O quarto princípio considera, conforme já mencionado, 
que a estrutura da rede se configura a partir da existência de padrões nos relacionamentos entre os atores (WASSERMAN; FAUST, 2009).

Nesse sentido, torna-se importante retomar algumas relevantes contribuições de Franco (2008), acerca da topologia das redes. Segundo o autor, a compreensão das ações dos grupos sociais passa necessariamente pela identificação da topologia das redes sociais. Baseando-se em um memorando de Baran (1964), Franco aponta três topologias básicas possíveis, conforme demonstrado na figura 3: distribuída, centralizada e descentralizada.
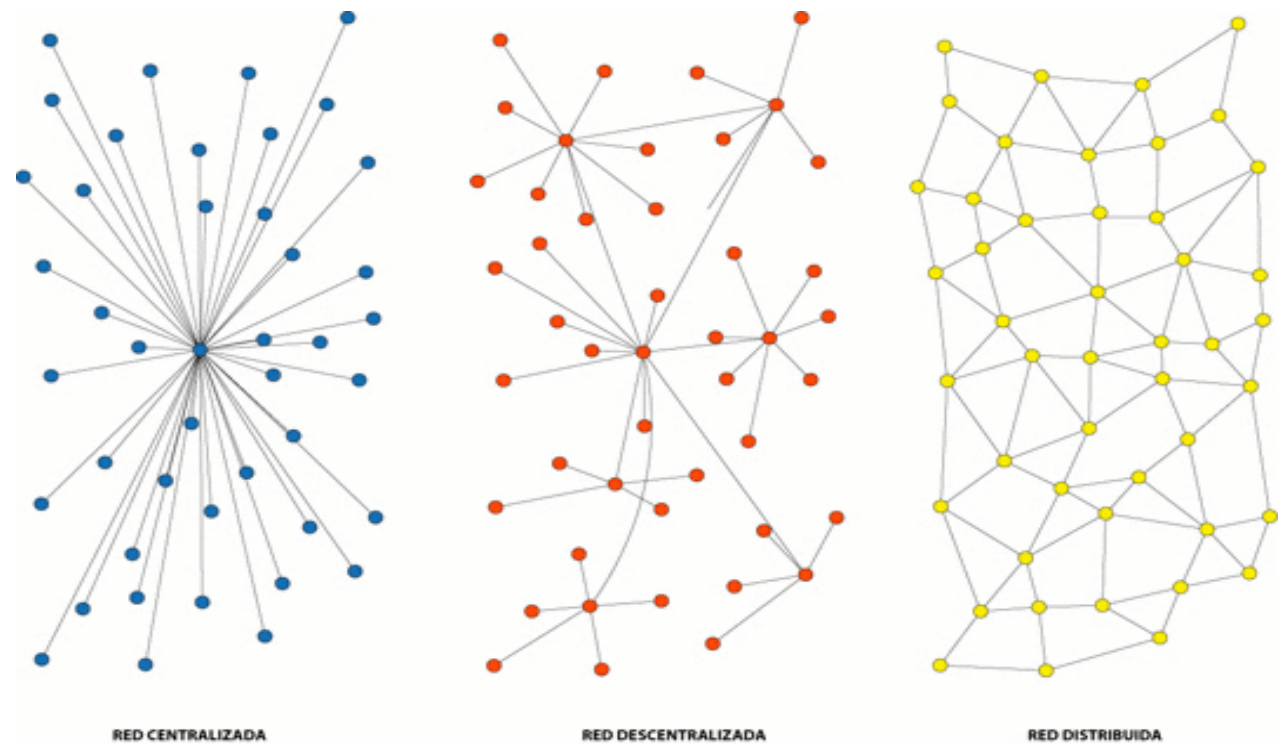

FIGURA 3 - TOPOLOGIAS DE REDE DE PAUL BARAN Fonte: Franco (2008).

A eficiência da rede está relacionada em grande medida, à sua estrutura. Essa seria capaz de influenciar fortemente os fluxos de comunicação nas redes. Na rede centralizada um único nó centraliza boa parte das conexões, revelando-se um formato em estrela. A rede que não se mantém conectada apenas por um único nó é a chamada descentralizada, nome decorrente do fato de possuir vários centros, configurados a partir de um número pequeno de nós que conecta vários grupos.

Por sua vez, uma rede denominada distribuída é aquela em que vários nós possuem quase que a mesma quantidade de conexões, inexistindo uma valoração hierárquica entre os nós. Conforme aponta Franco (2008), na visão de Baran apenas essa última concepção seria considerada verdadeiramente uma rede, embora todos sejam tidos pelo autor como maneiras de exemplificação dos modelos de redes. Tal 
questão será retomada na subseção 2.7.2, quando se discute 0 caráter emancipatório das redes sociais.

A seguir passam a ser apresentados alguns conceitos e propriedades específicos da ARS, considerados necessários ao alcance dos objetivos da pesquisa.

\subsubsection{ARS: alguns importantes conceitos e propriedades}

A ARS possui uma vasta gama de conceitos e definições. Conforme mencionado, esta seção trata de alguns deles, cuja escolha reflete uma relação mais direta com as questões e objetivos propostos na tese.

De acordo com as conceituações apresentadas na seção 2.5, o grafo é o que representa a estrutura de uma rede e pode ser definido como um conjunto de vértices (nós, atores, agentes) e um conjunto de linhas (links, relacionamentos, conexões, laços) entre pares de vértices. A rede configura-se como o grafo e as demais informações adicionais acerca de vértices e de linhas (DE NOOY; MRVAR; BATAGELJ, 2005).

Uma rede social pode ser definida como um conjunto ou conjuntos finitos de atores e os relacionamentos existentes entre eles (MARIN; WELLMAN, 2010; WASSERMAN; FAUST, 2009). Ao se ocupar essencialmente do estudo dos relacionamentos existentes entre esses atores, a ARS busca a identificação dos padrões e implicações desses relacionamentos estabelecidos na rede. É, então, nessa descoberta, que se desvenda a estrutura da rede (WASSERMAN; FAUST, 2009).

Atores são as entidades sociais relacionadas na rede. Podem ser individuais, corporativas ou coletivas. Assim, um ator pode ser uma pessoa em um determinado grupo, um departamento de uma empresa, ou até mesmo um país, se o foco da análise for um determinado sistema mundial (WASSERMAN; FAUST, 2009).

$\mathrm{Na}$ teoria dos grafos, um nó pode também ser referenciado como vértice ou ponto e as linhas são também chamadas de arcos ou arestas. Em um grafo representativo 
de uma rede social, os vértices representam os atores e as linhas representam os relacionamentos existentes entre esses atores. O vértice é a menor unidade em uma rede. Uma linha é definida a partir dos dois vértices que são incidentes a ela. Uma linha que conecta um vértice a ele mesmo é denominada loop (DE NOOY; MRVAR; BATAGELJ, 2005).

O laço relacional é o que estabelece a ligação entre dois atores. Os laços podem possuir variadas características e tipos. Wasserman e Faust (2009) citam vários exemplos de laços relacionais como: associação ou afiliação, avaliação de uma pessoa por outra, transferência de bens materiais ou não materiais, conexão física (como uma ponte conectando duas faixas de terra, uma estrada ou um rio) dentre vários outros (WASSERMAN; FAUST, 2009).

As relações configuram-se como o conjunto de relacionamentos de um mesmo determinado tipo entre membros de um grupo (WASSERMAN; FAUST, 2009). Tais relações possuem duas importantes propriedades na ARS. Assim, relações podem ser direcionadas ou não direcionadas e também dicotômicas ou valoradas.

Numa relação direcionada, o relacionamento existente entre determinado par de atores, possui uma origem e um destino, como numa relação entre países, onde um é o exportador de produtos manufaturados para o outro. Uma linha direcionada é denominada arco. Já na relação não direcionada o relacionamento não possui direção determinada, como o existente entre dois países que fazem fronteira entre si. Uma linha não direcionada é denominada aresta (DE NOOY; MRVAR; BATAGELJ, 2005; WASSERMAN; FAUST, 2009).

Martinho e outros (2003) ressaltam que a verdadeira medida da rede social é o número de relacionamentos, e não de atores. Uma rede com muitos atores pouco interligados têm menos qualidade do que uma rede com poucos atores profundamente relacionados. Por isso, é mais interessante que um grande número de atores coexista com um grande número de relacionamentos.

Os mesmo autores lembram ainda que os desenhos de redes apresentados com um número finito de pontos existem apenas por uma finalidade didática, já que as redes não podem ser consideradas verdadeiramente como conjuntos finitos. Assim, os limites são usualmente definidos de forma arbitrária. Isso se deve em grande parte à 
própria característica de conectividade das redes. Cada ponto, ao estabelecer uma conexão, é capaz de ampliar os limites da rede. "Conexões produzem conexões, e novos pontos conectados incorporam ao sistema as conexões que carregam! (MARTINHO, et. al., 2003, p. 25)".

A ARS pode ser realizada a partir de duas principais abordagens. A primeira considera a rede como um todo, visualizando-a a partir de uma perspectiva geral e externa em que considera todos os dados relativos aos seus atores e seus relacionamentos. A outra considera uma visão interna da rede e é denominada análise de rede ego, pois considera os dados de um ator apenas (considerado o ego da rede) e os relacionamentos desse com os demais (MARIN; WELLMAN, 2010; WILLIAMS; DURRANCE, 2008).

A análise de redes ego centradas tem sido muito utilizada por antropólogos nos estudos voltados para a compreensão do ambiente social em torno de determinados indivíduos. Também em estudos que focam identificar características do chamado suporte social, voltado para o entendimento das relações que contribuem para a saúde e o bem estar dos indivíduos (WASSERMAN; FAUST, 2009).

Modo é definido como o número de categorias de entidades (atores, nós ou vértices) com relação às quais as variáveis estruturais serão mensuradas. Quando uma rede apresenta relacionamentos com apenas um tipo de ator, ela é denominada rede de um modo (one-mode network). As redes de um modo são o tipo mais comum de rede. Em algumas situações, a análise pode se referir, entretanto, a contextos em que dois ou mais diferentes tipos de atores se relacionam. Quando se tratar de apenas duas categorias diferentes, tem-se a chamada rede de dois modos (twomode network) (MARIN; WELLMAN, 2010; TOMAÉL; MARTELETO, 2013; WASSERMAN; FAUST, 2009).

Redes de dois modos com dois tipos diferentes de atores são chamadas redes diádicas de dois modos (dyadic two-mode networks). As redes de afiliação (affiliation networks) são tipos especiais de redes de dois modos, onde o tipo de ator é o mesmo, porém os atores pertencem a eventos ou situações distintas, que definem diferenças entre eles. Portanto, os dois modos são os atores e os eventos aos quais pertencem (TOMAÉL; MARTELETO, 2013; WASSERMAN; FAUST, 2009). 
Uma relação dicotômica é aquela que se define a partir de sua existência ou não entre um determinado par de atores. Situa-se, portanto, entre duas posições opostas: sim (para a existência do laço) e não (para a inexistência do laço relacional). Os relacionamentos valorados, por sua vez, podem possuir determinados valores indicativos de força, intensidade ou frequência dos relacionamentos existentes entre cada par de atores.

Uma díade pode ser definida como um par de atores e os possíveis laços relacionamentos existentes entre eles. Díades são analisadas visando à compreensão da natureza dos relacionamentos existentes entre pares, como na tentativa de buscar elucidar questões como a reciprocidade do relacionamento ou, se há uma tendência a ocorrer diferentes tipos de relacionamento ao mesmo tempo entre os atores do par (WASSERMAN; FAUST, 2009).

Uma tríade consiste de um subconjunto de três atores e dos (possíveis) relacionamentos existentes entre eles. Muitos importantes modelos de ARS tem seu foco na análise de tríades. A análise de díades e tríades em uma rede é um exemplo de análise de subgrupos, ou seja, partes menores, subdivisões da rede formadas por atores e seus respectivos relacionamentos (WASSERMAN; FAUST, 2009).

Um grupo, por sua vez, é o conjunto de atores que por questões conceituais, teóricas ou empíricas é tratado como um conjunto finito de indivíduos sobre o qual as medidas de rede são realizadas. A delimitação dos limites do grupo é essencial na análise de dados sobre redes, embora não se configure como tarefa das mais fáceis em boa parte das vezes (WASSERMAN; FAUST, 2009).

A unidade básica de observação em uma rede é a unidade sobre a qual as medidas são realizadas. Na ARS, os dados podem ser coletados a partir de observações, entrevistas e questionários aplicados a atores individuais com a finalidade de mapeamento dos relacionamentos desses atores com os demais presentes no conjunto a ser analisado (WASSERMAN; FAUST, 2009).

Também é possível a extração direta de dados de sites de mídias sociais, a partir da utilização de aplicativos específicos, especialmente a partir da intensificação da utilização da Internet. A unidade de observação principal pode ser o ator, a partir do qual são descobertas as informações acerca dos laços, mas também as díades ou 
eventos, em função do que se pretende analisar sobre a rede (WASSERMAN; FAUST, 2009).

Entrevistas realizadas para a coleta de dados sobre redes sociais usualmente envolvem solicitações aos entrevistados para que relatem com quem possuem relacionamentos particulares. A coleta de dados sobre redes inteiras pode ser feita através da apresentação aos respondentes de uma lista de membros da rede e da solicitação para que indiquem as pessoas com quem eles compartilham laços. Quando as redes são grandes demais para fazer uma lista completa viável ou onde não há lista completa disponível, os entrevistados são convidados a fazer uma lista relembrando as pessoas com quem eles compartilham a relação relevante. $O$ uso de questionários baseados em sistemas de computador também tem sido uma técnica bastante comum na coleta de dados em ARS (MARIN; WELLMAN, 2010).

Conforme apontam Wasserman e Faust (2009), são diferentes os níveis de modelagem dos dados sobre a rede, sendo eles: ator, díade, tríade, subgrupo ou a rede inteira. As propriedades a serem analisadas correspondem a níveis diferenciados de modelagem.

Por exemplo, a organização dos grupos em uma rede social pode ser mais bem compreendida a partir da análise dos papeis de intermediação secundários. Tais papeis permitem identificar o controle do fluxo de informações desempenhado por um determinado ator, considerando-se a estrutura dos grupos na rede. A partir da figura 4, pode-se identificar quais os papeis de intermediação que cada um pode desempenhar em uma rede, com base na ARS e na relação de troca de informação entre os atores em um grupo (DE NOOY; MRVAR; BATAGELJ, 2005).

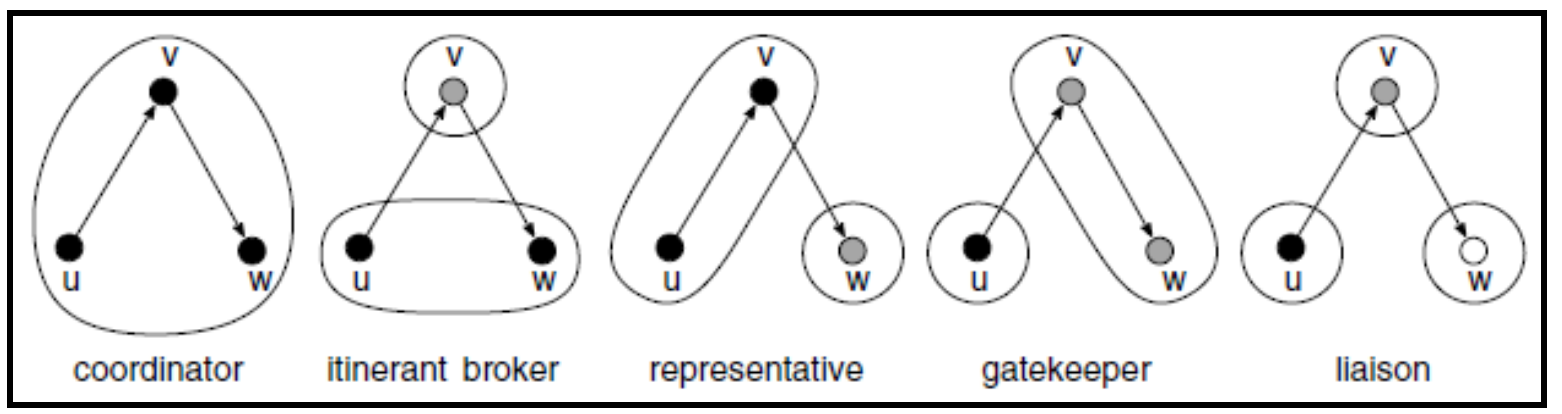

FIGURA 4 - PAPEIS DE INTERMEDIAÇÃO NUMA ESTRUTURA DE GRUPOS EM UMA REDE SOCIAL.

Fonte: De Nooy; Mrvar; Batagelj ( 2005). 
Os cinco papeis de intermediação em uma rede são denominados: coordenador, intermediador itinerante, representante, porteiro e elemento de ligação. Cada um deles possui características distintas, de acordo com sua capacidade de regular o fluxo de informação, e considerando o grupo ao qual pertence cada um dos atores $u$, v e w. No exemplo do coordenador, sendo os atores $u, v$ e w todos pertencentes a um mesmo grupo, se a comunicação entre u e w só se processa indiretamente, através de v, então v assume o papel de coordenador. Por sua vez, v se torna um intermediador itinerante, se u e w pertencem ao mesmo grupo, e a comunicação se estabelece indiretamente por v. Na situação seguinte, quando u e v pertencem ao mesmo grupo, mas v intermedia a comunicação de u para w, então v é se torna um representante. Inversamente, se $u$, pertence a um grupo distinto de $w$, ao qual v pertence, e os primeiros se comunicam indiretamente por intermédio de $v$, então $v$ é um porteiro. E, finalmente, se $u, v$ e w pertencem a grupos distintos, e v intermedia a comunicação entre $u$ e $w$, então $v$ é considerado um elemento de ligação (DE NOOY; MRVAR; BATAGELJ, 2005).

As redes também possuem determinadas propriedades que são fundamentais para a ARS, e que derivam da teoria dos grafos, as quais passam a ser mais bem detalhadas a seguir.

O grau (degree) é a quantidade de arestas que um determinado vértice possui. Dois vértices conectados entre si são chamados vértices adjacentes (FREEMAN, 1979). Os vértices aos quais um determinado vértice é adjacente são denominados vizinhança. Assim, o grau pode ser entendido como a descrição de quantos vértices compõem a vizinhança de um determinado vértice. Como consequência, quanto maior é o grau de um vértice, mais popular e mais central será esse vértice na rede. Um vértice com grau igual a zero é, portanto, considerado um vértice isolado (WASSERMAN; FAUST, 2009).

De acordo com Recuero (2009), nos grafos chamados direcionados (digrafos), ou seja, naqueles em que são identificadas de maneira distinta as arestas que um vértice recebe (indegree) das arestas que os conectam com outros (outdegree), 0 grau pode ser explicado a partir dessas duas formas de relacionamento. Segundo a autora, essas distinções são fundamentais para que se analise especificamente um determinado vértice em relação à rede e também a rede como um todo. 
Assim, os chamados outdegrees podem ser de grande importância na identificação da expansividade dos atores, enquanto os indegrees relacionam-se às medidas de receptividade e popularidade (WASSERMAN; FAUST, 2009). Um grafo direcionado é aquele que contem um ou mais relacionamentos dirigidos (arcos), enquanto nos grafos não direcionados existem apenas relacionamentos não dirigidos (arestas) (DE NOOY; MRVAR; BATAGELJ, 2005).

Caminho (walk) é uma sequência de vértices e de arestas, que se inicia e que termina com vértices, e em que cada um dos vértices é incidente com as arestas que o antecedem e sucedem (WASSERMAN; FAUST, 2009). O menor caminho que conecta um determinado par de vértices é denominado geodésica (FREEMAN, 1979; HANNEMAN; RIDDLE, 2009). Assim, a chamada distância geodésica entre dois vértices pode ser definida como o tamanho da geodésica existente entre eles.

A excentricidade de um vértice é dada pelo tamanho da maior geodésica existente entre esse vértice e qualquer outro vértice da rede. Assim, a excentricidade mede o quão distante está um vértice do outro que é o mais distante dele na rede (WASSERMAN; FAUST, 2009).

A partir da medida de excentricidade, chega-se ao diâmetro da rede, considerado a maior medida de excentricidade existente entre os nós da rede (HANNEMAN; RIDDLE, 2009).

Um ator é dito "alcançável" por outro, quando existir um caminho a partir da fonte para esse ator-alvo, independentemente de quantos outros existam entre eles (HANNEMAN; RIDDLE, 2009). Quando todos os vértices do grafo são alcançáveis a partir de qualquer outro vértice, tem-se o chamado grafo conectado (FREEMAN, 1979), conforme demonstra o grafo 1. 


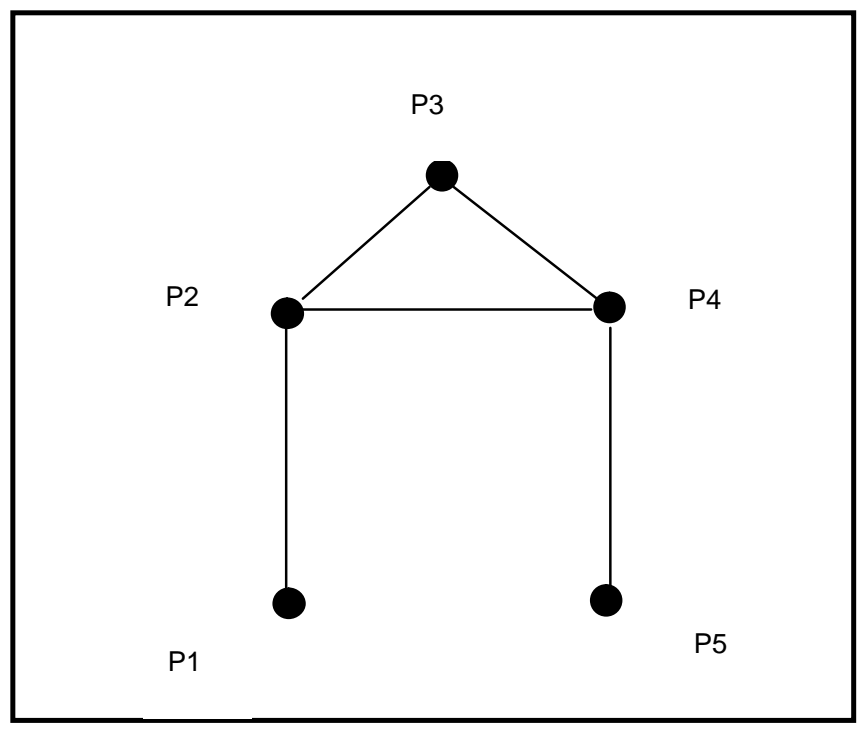

GRAFO 1 - EXEMPLO DE GRAFO CONECTADO Fonte: Freeman (1979).

Assim, o diâmetro de um grafo conectado é igual ao tamanho da maior geodésica existente entre qualquer par de nós da rede (HANNEMAN; RIDDLE, 2009).

Num grafo desconectado, os vértices podem ser divididos em dois ou mais subgrafos, denominados componentes. Um componente forte é um subgrafo dirigido em que todos os pares de vértices são alcançáveis pelos demais, seja de forma direta, ou transitiva(DE NOOY; MRVAR; BATAGELJ, 2005). Assim, quando há apenas um componente no grafo, ele é dito conectado. Quando há mais de um componente, ele é então, um grafo desconectado (WASSERMAN; FAUST, 2009).

Um clique, por sua vez, é um subgrafo de um grafo em que todos os vértices são ligados a todos os demais vértices (MARIN; WELLMAN, 2010). Trata-se de um subgrafo máximo completo de três ou mais vértices, conforme apresentado no grafo 2. O tamanho de um clique é o seu número de vértices (DE NOOY; MRVAR; BATAGELJ, 2005). 


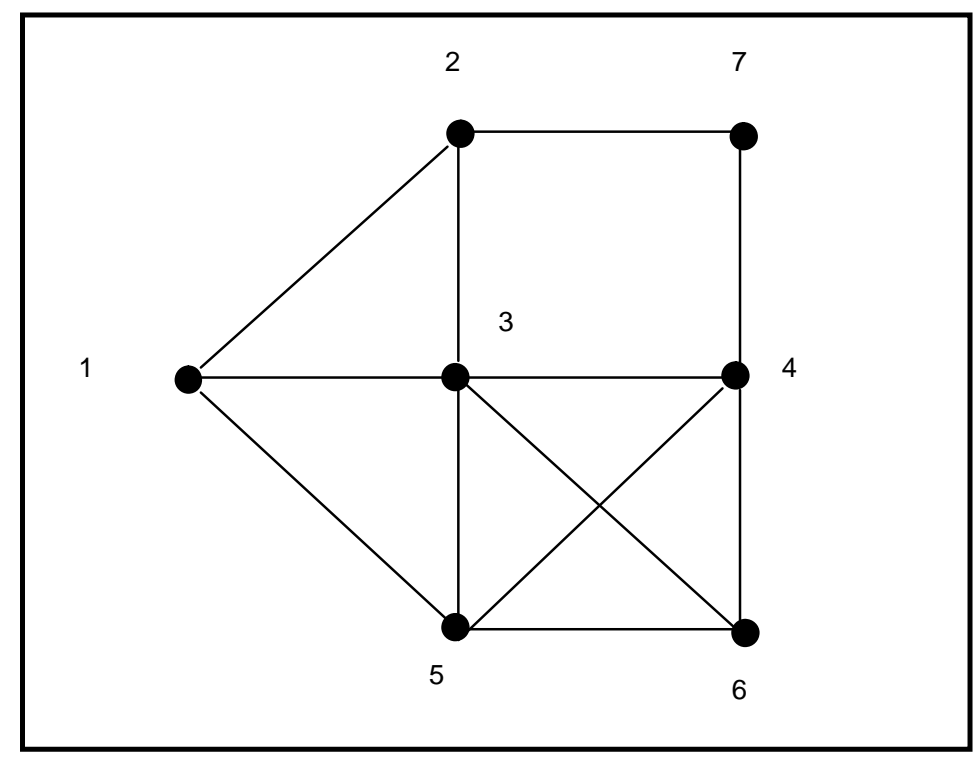

Cliques: $\{1,2,3\},\{1,3,5\},\{3,4,5,6\}$

GRAFO 2 - UM GRAFO E SEUS CLIQUES

Fonte: Wasserman e Faust (2009).

Um K-núcleo (K-core) é um sub-grafo maximal na qual cada vértice apresenta grau igual ou superior a $\mathrm{K}$ no sub-grafo. Num 4-core, por exemplo, cada vértice apresenta pelo menos grau quatro (DE NOOY; MRVAR; BATAGELJ, 2005).

A noção de conectividade do grafo é essencial à ARS. Ela é uma função que se relaciona à permanência ou não da conexão em um grafo a partir da retirada de vértices ou arestas.

Nesse sentido, tem-se que um vértice se configura como um ponto de corte (cutpoint), quando o número de componentes do grafo que contém esse vértice é menor do que o número de componentes que passa a existir nesse mesmo grafo a partir da retirada desse vértice (HANNEMAN; RIDDLE, 2009; WASSERMAN; FAUST, 2009). Análises dessa natureza são essenciais em redes de comunicação, por exemplo, em que a destruição de um ponto de corte pode representar a ruptura do fluxo de informações na rede. $O$ vértice $n_{1}$ no grafo 3 apresenta um exemplo de um ponto de corte em um grafo. 


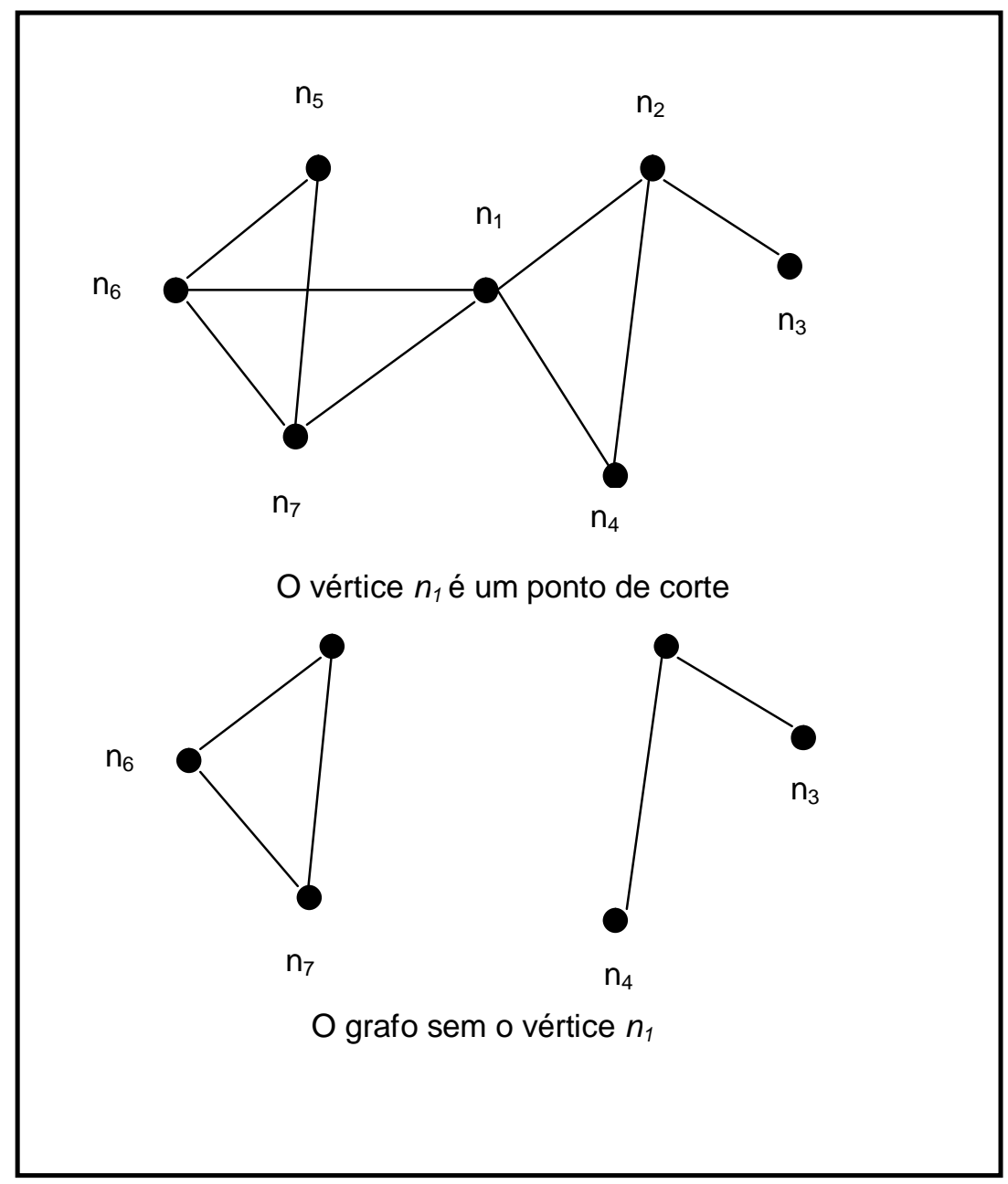

GRAFO 3 - EXEMPLO DE UM PONTO DE CORTE EM UM GRAFO Fonte: Wasserman e Faust (2009).

Uma noção semelhante em termos de conectividade do grafo existe também para arestas. Considera-se como ponte (bridge) uma aresta que é crucial para a conectividade de uma determinada rede. Assim uma ponte é uma aresta cujo gráfico que a contém possui um número menor de componentes do que o grafo existente após essa aresta ser retirada. Observa-se pelo grafo 4 que os nós incidentes a essa aresta permanecem no grafo. 


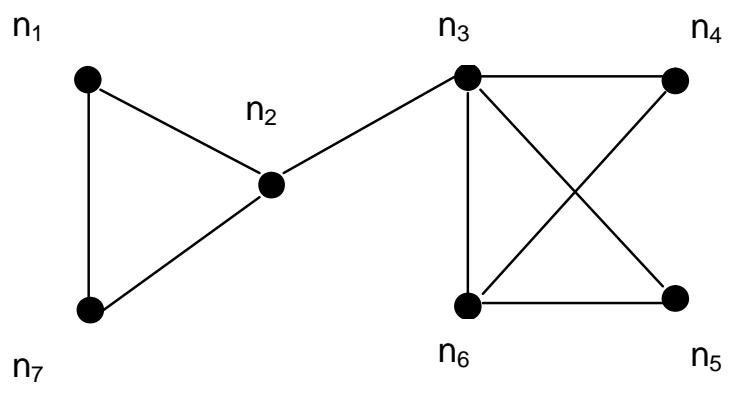

A aresta $n_{2} n_{3}$ é uma ponte

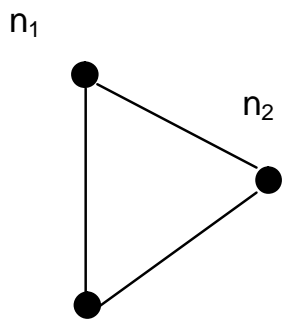

$n_{7}$

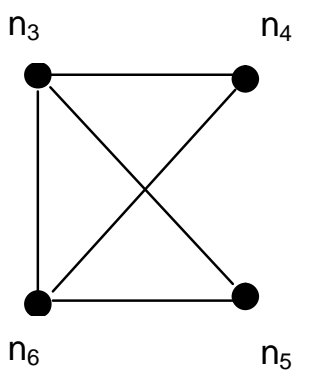

Grafo sem a aresta $n_{2} n_{3}$

GRAFO 4 - EXEMPLO DE UMA PONTE EM UM GRAFO Fonte Wasserman e Faust (2009).

A centralidade e o prestígio são outras importantes propriedades relacionadas aos atores de uma rede social, podendo ser compreendidas a partir de relacionamentos direcionados e não direcionados e evidenciando, inclusive, relações de poder existentes na rede (HANNEMAN; RIDDLE, 2009). Em grafos não direcionados, um vértice é considerado central se está envolvido em muitas arestas na rede. Assim, essa medida de centralidade se relaciona aos graus de cada vértice. Se um vértice possui então um alto grau de conexão em relação aos demais, torna-se importante para as distâncias sociais na rede, sendo, portanto, um vértice central (RECUERO, 2009; WASSERMAN; FAUST, 2009).

O prestígio, entretanto, é uma medida realizada a partir da análise de grafos direcionados que permitem a distinção entre o grau de entrada e o grau de saída do vértice. Nesse sentido, um vértice de prestígio é aquele que possui alto grau de entrada (WASSERMAN; FAUST, 2009). 
Para Freeman (1979), o conceito de centralidade deve ser compreendido de forma mais ampla, que incorpora o grau de um vértice, mas que também considera os chamados índice de proximidade $e$ índice de intermediação do vértice. A centralidade que se relaciona ao índice de proximidade (closeness), é a que se verifica a partir dos valores de distância entre os nós. Nesse sentido, a soma das distâncias geodésicas entre todos os outros vértices do grafo em relação a um específico seria o índice de proximidade entre eles (RECUERO, 2009). Em redes bastante conectadas e para a identificação de grupos sociais densos, essa é uma medida bastante interessante.

A terceira maneira de análise da centralidade de acordo com Freeman (1979) é o chamado índice de intermediação (betweenness). Trata-se de uma medida de quanto um vértice possui valor de intermediário em um grafo, indicando, por exemplo o quanto um vértice é importante para garantir que determinadas informações circulem na rede. Para cálculo do índice de intermediação considera-se a proporção de geodésicas que passam pelo vértice analisado e que conectam cada par de vértices da rede.

Para Lourenço (2012, p. 42):

Dos diferentes subprodutos envolvidos no método quantitativo da Análise de Redes, a definição de centralidade é que a melhor se relaciona com esse conceito do poder de corretagem. Mais especificamente, a medida conhecida como "Betweenness" ou centralidade de Freeman é diretamente a formalização da posição de proximidade a buracos estruturais, uma vez que mensura a propensão de cada indivíduo a encontrar-se no "caminho" mais curto entre dois indivíduos quaisquer. Como, por óbvio, quando esses dois indivíduos estão ligados diretamente é essa ligação o caminho mais curto entre eles, um agente da rede com alta centralidade de Freeman pode ser considerado um agente com alta proximidade a buracos estruturais.

Tomaél e Marteleto (2006) afirmam que a centralidade de intermediação identifica quem medeia, controla e direciona a informação na rede. As mesmas autoras destacam ainda a chamada centralidade de fluxo de intermediação. Baseando-se em Hanneman, Tomaél e Marteleto (2006) esclarecem a natureza dessa métrica, que classifica os atores que são intermediários em todos os fluxos de informação possíveis da rede.

Atores que estão localizados entre outros atores controlam e fazem, entre estes, a mediação da informação; deles depende a troca indireta de informação, quando os intermediários bloqueiam a comunicação, por serem indiferentes à temática tratada, se existirem outros caminhos, Hanneman (2001) afirma que os atores provavelmente os usarão, mesmo que sejam 
mais longos ou menos eficientes. Os atores podem usar todas as ligações que os conectam à rede, não apenas os geodésicos. Na centralidade de fluxo, continua Hanneman, a intermediação mede-se pelo volume de fluxo entre os atores, o qual passa por caminhos em que o ator esteja inserido (TOMAÉL E MARTELETO, 2006, p.82).

A densidade, por sua vez, trata da proporção do número de conexões de um grafo em relação ao número máximo de conexões que o mesmo grafo suporta. Quando todas as arestas estão presentes, então todos os vértices são considerados adjacentes e tem-se assim um grafo completo (HANNEMAN; RIDDLE, 2009; WASSERMAN; FAUST, 2009). Redes maiores tendem a possuir menor densidade, e vice-versa. Assim, como medida de coesão estrutural da rede, o grau médio dos vértices pode ser considerado uma medida mais adequada, pois ao ser independente do tamanho da rede, permite comparações entre redes de tamanhos diferentes (DE NOOY; MRVAR; BATAGELJ, 2005).

Martinho e outros (2003) indicam a relação entre a densidade e a percepção da "capacidade produtiva" da rede em determinado momento, considerando que quanto mais pontos estabelecem conexões com os demais, maior é a possibilidade de que venham a interagir e a construir algo juntos.

O padrão de estratificação centro-periferia permite análises interessantes acerca da configuração das redes sociais. Rossoni e Graeml (2009) destacam que tal concepção, considera que os atores pertencentes ao centro da rede encontram-se densamente conectados entre si, enquanto atores situados na chamada periferia apresentam maior densidade de laços com os atores do centro do que com seus pares periféricos.

A ARS vem sendo em muito facilitada pela utilização de programas de computador específicos para a finalidade. De acordo com Scott (2012), uma série de programas dessa natureza está agora disponível de forma bastante fácil e barata, permitindo mesmo àqueles pouco familiarizados com a ARS, a realização de análises relativamente sofisticadas sobre os dados acerca de redes.

Dentre os programas disponíveis, alguns tem se destacado, como o UCINET e o Pajek, conforme aponta Scott (2012). Entretanto, muitos outros estão disponíveis de forma livre ou a baixo custo. Dentre eles estão: NetMiner3, MultiNet, Gephi e o ORA (HUISMAN; VAN DUIJN, 2012). 
Conforme já exposto no início desta seção, os conceitos e propriedades da ARS aqui apresentados são de suma importância para a compreensão da estrutura e da forma de funcionamento da rede social objeto da presente pesquisa. Entretanto, essa compreensão pode ser ainda mais ampla, na medida em que se considerem outros aspectos teóricos também bastante elucidativos sobre a natureza das redes, como seu caráter não hierárquico, seus limites fluidos e sua natureza dinâmica e flexível. Assim, a seção seguinte visa trazer essas e também outras questões complementares àquelas discutidas até aqui acerca das redes sociais.

\subsection{SOBRE ESTRUTURAS BUROCRÁTICAS E REDES}

As formas organizacionais tradicionais utilizadas na gestão de desastres naturais baseiam-se em sistemas de comando e controle, configurados a partir de procedimentos pré-definidos e formatos hierárquicos rígidos, típicos da burocracia (vide as características do SCO que estão mais bem detalhadas na seção 3.1).

O formato em rede, no entanto, apresenta diversas características que se contrapõem a tal modelo essencialmente burocrático, especialmente do ponto de vista da autonomia, da flexibilidade, do dinamismo e da capacidade de adaptação a situações eventuais e adversas. É nesse sentido que Martinho e outros (2003) apontam para uma clara distinção entre as estruturas burocráticas e aquelas em forma de rede.

Os autores consideram que se fosse levado em conta apenas o aspecto da ligação entre elementos, poderia se afirmar que uma burocracia seria uma rede, já que conta com elementos próximos e distantes, interligados. Mas não o é, por uma característica distintiva central: a lógica hierárquica. Mesmo nos formatos mais horizontalizados como em organizações matriciais que possuem uma capilaridade elevada, há uma forte relação entre a matriz e as filiais, mais uma integração muito baixa das filiais entre si. Sendo assim, a despeito de possuir uma base bem ampla, 0 
formato piramidal tradicional ainda é o que traduz mais adequadamente esse tipo de organização.

A natureza democrática, aberta e emancipatória das redes é enfatizada por Martinho e outros (2003), que alertam para uma possível banalização do termo rede, e suas implicações.

Há aqui um problema: quando tudo indiscriminadamente torna-se rede,
essa vigorosa idéia-força perde brilho e poder explicativo e, o que é pior,
deixa de ostentar algumas de suas características mais preciosas: seu
poder criador de ordens novas e seu caráter libertador. Quando tudo é rede,
estruturas velhas e novas, modos convencionais e modos inovadores de
fazer, estratégias de opressão e estratégias de libertação confundem-se sob
uma pretensa mesma aparência. Se não puder estabelecer algumas
distinções, o conceito de rede deixa de ter sentido e passa a não servir para
nada (MARTINHO et. al. 2003, p.9)

Os autores consideram que existem hoje no Brasil estruturas organizativas diferenciadas que se intitulam redes, mas que apresentam arquitetura vertical, processos decisórios centralizados e um perfil não participativo e autoritário de gestão, e que portanto, não poderiam ser assim chamadas. Tal confusão seria consequência do uso indiscriminado do termo rede, da própria imprecisão conceitual da área, de um modismo em torno da ideia de complexidade e, ainda, do baixo conhecimento disponível sobre redes no país.

Por outro lado, estima-se que centenas de estruturas organizativas atualmente em ação no Brasil, possam ser consideradas verdadeiramente redes da sociedade civil, embora, muitas vezes estejam ancoradas em nomenclaturas variadas como fórum, articulação ou movimento coletivo. É um formato peculiar e muito importante de expressão e organização coletiva, seja no âmbito nacional ou internacional (MARTINHO et.al., 2003)

A expansão das redes no Brasil ocorre a partir dos anos 90, com a criação de Associações, ONGs e Fóruns, com os mais variados interesses e em diferentes áreas. Apenas a título de exemplo podem ser citadas: a Associação Brasileira de ONGs (Abong) e a Rede Nacional Feminista de Saúde e Direitos Sexuais e Direitos Reprodutivos, ambas criadas em 1991; o Fórum Brasileiro de ONGs e Movimentos Sociais e a Rede Brasileira de Educação Ambiental (REBEA) de 1992 e a ONG Rede de Informações para o Terceiro Setor (RITS) criada em 1998. Essa última merece destaque por ter sido a primeira organização voltada especificamente para 0 
fomento da organização em rede e do uso de ferramentas para o trabalho colaborativo à distância, em âmbito nacional (MARTINHO et.al., 2003).

Diante do exposto até aqui, considera-se que uma comparação entre as características das redes sociais e das estruturas burocráticas será capaz de evidenciar as principais distinções entre os dois tipos de estrutura organizativa, o que facilitará a compreensão do que pode ser entendido efetivamente como sendo uma rede social.

\subsubsection{Burocracia e sistema}

É fundamental iniciar esclarecendo algumas questões em relação ao termo organização e às formas em que poderá ser empregado nesta discussão. Do ponto de vista das teorias administrativas, também conhecidas como Teorias das Organizações, o termo organização se refere, de uma maneira bastante geral, a um grupo social organizado em uma estrutura pré-definida para o cumprimento de determinados objetivos. Nesse rol encontram-se variadas empresas, instituições, entre outras, com ou sem finalidades lucrativas.

Maximiano (2009, p.4) define organizações como "sistemas de recursos que procuram realizar algum tipo de objetivo". O desempenho das organizações é muito importante para seus clientes e usuários, além de funcionários, acionistas, fornecedores e de uma maneira mais ampla, para toda a comunidade. Para que possam atender de maneira adequada a todos esses interesses envolvidos, é essencial que as organizações sejam bem administradas.

Portanto, para que possam atingir plenamente os objetivos a que se propõem, as organizações necessitam ser conduzidas a partir de práticas gerenciais adequadas às suas peculiaridades e diferentes realidades, baseadas em uma visão profissional que considere ações de curto, médio e longo prazos. 
São muitas as escolas teóricas ao longo do desenvolvimento da Administração e, como consequência, são variadas as visões acerca das organizações. Desde a Escola Clássica da Administração, passando pela Escola de Relações Humanas, Teoria Sistêmica, Teoria da Contingência até a Teoria Crítica e os Estudos PósModernos (para citar apenas as mais conhecidas), muitas concepções do termo podem ser encontradas, com ênfase em aspectos diferenciados do fenômeno organizacional (MOTTA; VASCONCELOS, 2009).

Um dos autores que talvez tenha conseguido capturar de forma mais abrangente as diferentes nuances utilizadas para a visualização das organizações é Morgan (1996). Em seu livro "Imagens da Organização", o autor apresenta uma visão que considera a complexidade, a ambiguidade e os paradoxos presentes nas organizações. Para isso, utiliza sete metáforas representativas de diferentes escolas de pensamento acerca do fenômeno organizacional, quais sejam: organizações como máquinas, organizações como organismos, organizações como cérebros, organizações como culturas, organizações como sistemas políticos, organizações como prisões psíquicas e organizações como fluxo e transformação.

Justamente por serem visões parciais da realidade, é que Morgan (2007) sugere que várias delas sejam utilizadas simultaneamente, e não somente uma, buscando melhorar a compreensão dos diferentes aspectos da realidade organizacional.

A lógica das metáforas possui, portanto, implicações importantes para a teoria das organizações, pois sugere que nenhuma metáfora pode captar toda a natureza da vida organizacional. Metáforas diferentes podem constituir e captar a natureza da vida organizacional de maneiras diferentes, cada uma gerando tipos de insight poderosos, distintos, mas essencialmente, parciais (MORGAN, 2007, p. 19).

Assim, todas as metáforas são essenciais para uma visão ampla da gama de características presentes nas organizações. No entanto, apenas duas estão aqui enfatizadas considerando as finalidades das discussões teóricas realizadas nesta seção: a metáfora da máquina e a metáfora dos organismos. As demais metáforas estão tratadas de maneira mais sucinta.

A metáfora da máquina dá suporte à visão ortodoxa do fenômeno organizacional. Nela, as organizações devem ser planejadas e operadas de forma mecânica, onde princípios como eficiência, rotinização, confiabilidade e previsibilidade são termos 
chave. A partir dessa metáfora, as organizações são reconhecidas como estruturas burocráticas.

Ao se abordar as questões relacionadas à burocracia, é imprescindível a análise do pensamento de Max Weber. Para Weber (1982), o poder refere-se à possibilidade de imposição da vontade por parte de alguém ou de algum grupo sobre outrem. $O$ processo de racionalização, por si mesmo, acaba se configurando em dominação, onde princípios de impessoalidade nas relações, apego às regras, associação entre meios e fins acabam se transformando em uma nova configuração de escravidão.

A dominação é considerada um tipo especial de poder, pois nela existe a necessidade de um fator legitimador e estabilizador para o seu exercício. São três os tipos de dominação para Weber, conforme a sua forma de legitimação: tradicional, carismática e racional-legal. As suas próprias denominações são indicativas do tipo de legitimação que traduzem.

Assim, a dominação tradicional é aquela legitimada pela tradição, pela crença na capacidade de se manter relações a partir do que se fazia no passado, baseando-se nos costumes, na forma como os antepassados comportavam-se. A carismática, por sua vez, refere-se ao carisma como fonte legitimadora da relação de poder, acreditando-se, portanto, que as características pessoas de quem exerce o papel de dominador, são qualificações suficientes para garantir a sua autoridade. Mas, dentro das análises aqui realizadas, a dominação racional-legal é a que merece maior aprofundamento, considerando-se que é a essência da legitimação das relações de poder na estrutura burocrática. Não se quer dizer, com isso, que os outros dois tipos descritos anteriormente não estejam presentes na arena da burocracia, mas atuam apenas de forma coadjuvante nesse aparato.

A dominação racional-legal é aquela que se sustenta sobre a crença nas leis, normas e regulamentos como capazes de determinar a legitimidade das relações de dominação. O poder é exercido dentro de limites fixados por um sistema de regras que funciona com requisitos de lei. A burocracia é, portanto, o aparato administrativo que se configura a partir desse tipo de dominação, onde as regras estabelecidas independem das pessoas. A empresa moderna consolida-se assim, ao longo do tempo, como a organização que melhor reflete a burocratização. 
Weber (1982) aponta que:

\begin{abstract}
"a razão decisiva para o progresso da organização burocrática foi sempre a superioridade puramente técnica sobre qualquer outra forma de organização. O mecanismo burocrático plenamente desenvolvido comparase às outras organizações exatamente da mesma forma pela qual a máquina se compara aos modos não mecânicos de produção" (WEBER, 1982, p.249).
\end{abstract}

O autor continua, enfatizando a superioridade burocrática sobre outras formas de organização, considerando sua precisão, velocidade, clareza, conhecimento dos arquivos, continuidade, discrição, unidade, subordinação rigorosa, redução do atrito e dos custos de material e pessoal.

Para Weber (1982) na burocratização é essencial ainda o princípio da especialização das funções administrativas, por meio de critérios que devem ser meramente objetivos. As tarefas são atribuídas individualmente a funcionários com treinamento especializado e que vão se tornando "experts" em seus campos, pela prática constante de tais atividades.

Emerge dessa prática o princípio burocrático da impessoalidade, sob o qual as tarefas devem ser cumpridas com base em regras calculáveis e sem relação com pessoas. O autor descreve tal princípio como característico "do mercado, e em geral de todos os empreendimentos onde há apenas interesses econômicos" (WEBER, 1982, p.251).

Weber (1982) destaca que uma das virtudes mais louváveis da burocracia, tida como uma virtude especial, é justamente a sua "desumanização", já que consegue eliminar de sua estrutura, todos os elementos pessoais, irracionais, emocionais que afastam a possibilidade de cálculo, como o amor e o ódio.

Os autores da Escola Clássica da Administração são os responsáveis pelo delineamento da visão mecânica de organização, na qual se destacam: o francês Henry Fayol e o americano Frederick Taylor. Os pressupostos da chamada Administração Científica tratam de um projeto de organização em que existe um "padrão de cargos precisamente definidos e organizados em linhas de comando ou de comunicação precisamente definidas (MORGAN, 1996, p. 29)". 
A figura 5 representa a estruturação burocrática, em que os níveis correspondem a graus diferenciados de autoridade e responsabilidade, onde o maior grau se concentra no topo da hierarquia.

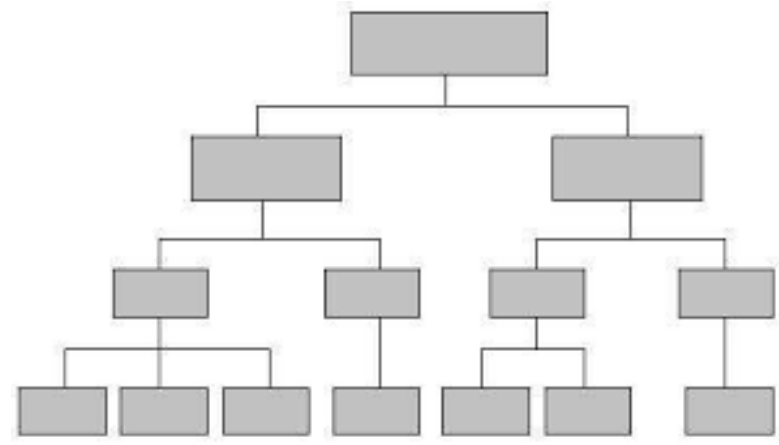

FIGURA 5 - REPRESENTAÇÃO DA ESTRUTURA BUROCRÁTICA Fonte: Motta e Vasconcelos (2009).

A comunicação entre os diferentes setores especializados é determinada rigidamente por intermédio das linhas existentes, sendo que quanto mais verticalizadas as estruturas, mais lento pode se tornar o fluxo de informações entre os níveis mais elevados e os mais baixos na hierarquia.

Nesses contextos, o tempo entre a decisão tomada e a execução da ordem tende a ser elevado, levando a respostas lentas e muitas vezes até confusas por parte da organização, considerando as grandes possibilidades de existência de ruídos na comunicação enquanto a informação flui entre o topo e a base da pirâmide.

Importante destacar a característica isomórfica desse tipo de estrutura, em que o alto grau de formalização e a impessoalidade, facilitam a sua transposição e permitem a expansão dos negócios (MOTTA; VASCONCELOS, 2009).

Para que essa estrutura funcione de forma eficaz e organizada, os princípios administrativos centrais são o planejamento, organização, direção, coordenação e controle, advindos basicamente de uma junção de princípios militares e de engenharia.

Fayol (1987) preconiza esses cinco princípios centrais que norteiam a metáfora da máquina e assim os caracteriza:

Planejar é perscrutar o futuro e traçar o programa de ação.

Organizar é constituir o duplo organismo, material e social, da empresa. Comandar é dirigir o pessoal.

Coordenar é ligar, unir e harmonizar todos os atos e todos os esforços. 
Controlar é velar para que tudo corra de acordo com as regras estabelecidas e as ordens dadas. (FAYOL, 1987, p.26)

A metáfora dos organismos está apoiada fundamentalmente na teoria dos sistemas e aborda as organizações como sistemas abertos, em constante contato com o ambiente que as cerca. A compreensão da metáfora dos organismos parte do paradigma tradicional das organizações como sistemas, que são vistas como possuidoras de limites bem definidos, fundamentadas em normas rígidas às quais todos devem obedecer e se sujeitar. A interface com o meio é bem delimitada e controlada. Nesse sentido, a ideia de sistema, já abordada na seção 2.3, fornece ao gestor uma visão integrada e complexa das organizações e do processo administrativo.

Considera-se que ambiente e sistema encontram-se em interação e dependência mútuas. Sendo consideradas sistemas abertos, as organizações devem atingir uma relação adequada com o ambiente que as cerca, caso desejem sobreviver no longo prazo (MORGAN, 1996).

É importante considerar que sob esse ângulo de aproximação, as relações inter e intraorganizacionais são evidenciadas a partir do conceito de subsistemas. Tais subsistemas podem ser concebidos em certo aspecto, como os conjuntos de necessidades que a organização deve buscar satisfazer para sustentar seu funcionamento. Nesse sentido, é necessário administrar esses conjuntos de necessidades individualmente, mas é também imprescindível considerá-los e gerenciá-los a partir das suas relações de interdependência. Nessa visão de subsistemas é possível compreender mais claramente as relações existentes entre os requisitos técnicos, sociais, administrativos, estratégicos e ambientais de uma determinada organização.

A partir dessas concepções, se consolida a chamada escola sócio-técnica, apoiada nos estudos realizados por Eric Trist e Fred Emery, fundadores do Tavistock Institute of Human Relations em 1946. Nessa perspectiva, a organização é formada por dois subsistemas: o técnico e o social. Salientam Motta e Vasconcellos (2009), que o subsistema técnico relaciona-se às tarefas, aos equipamentos e à estruturação física. Por isso, contém a eficiência potencial da organização. O sistema social compreende as relações sociais daqueles que realizam a atividade, responsáveis, 
portanto, por transformar a eficiência potencial em eficiência real. Assim, a inovação tecnológica está numa relação de dependência com a inovação social e cultural.

Importante salientar que a visão do ser humano dentro do paradigma sistêmico, o insere em um sistema de papéis. Nele, os aspectos relacionados ao papel desempenhado na organização são enfatizados, em detrimento da própria pessoa. Os papeis são influenciados pela posição ocupada na hierarquia organizacional, por traços de personalidade e relações pessoais estabelecidas.

Assim, a organização é compreendida "como um sistema de conjuntos de papeis, mediante os quais as pessoas se mantêm inter-relacionadas" (MOTTA; VASCONCELOS, 2009, p. 181). Como consequência, tem-se uma visão de homem funcional, e não integral. Tal concepção estabelece uma inclusão parcial do ser humano no contexto organizacional, baseada apenas nos aspectos considerados relevantes para a execução do trabalho, que são normalmente definidos por outros, e de forma bastante estreita.

Quanto às demais imagens organizacionais apresentadas por Morgan, tem-se que a metáfora da cultura salienta os aspectos simbólicos da vida organizacional, enquanto os conflitos de interesse e o papel do poder são essencialmente destacados na metáfora do sistema político. A análise da forma como os modos de dominação operam e se sustentam no ambiente organizacional a partir da sua ligação com as estruturas de poder da economia política mundial encontra suporte na metáfora do instrumento de dominação.

A metáfora das organizações como fluxo e transformação sugere uma visão abrangente para a compreensão de como organizações mudam e se transformam de acordo com seu ambiente. Na metáfora da prisão psíquica, os processos ideológicos é que moldam, controlam e aprisionam os sujeitos para atenderem aos objetivos organizacionais, considerando o uso de processos alienadores.

Apesar da existência de todas essas visões ao mesmo tempo diferenciadas e complementares para a compreensão das organizações, os princípios funcionalistas, balizadores das estruturas organizacionais burocráticas, parecem ainda dominar tanto a teoria quanto a prática administrativa. 
Ramos (1989) sustentando-se no pensamento de Weber (1968) apresenta a racionalidade instrumental ou funcional como aquela que se contrapõe à racionalidade noética ou substantiva, representando a preocupação com a coordenação entre meios e fins, com a busca da eficiência operacional, com uma expectativa de resultados e a partir da qual os critérios para ordenação das associações humanas são sempre dados socialmente. Tal é a racionalidade preponderante na essência burocrática.

A racionalidade substantiva, por sua vez, não pode ser percebida como pertencente a qualquer organização, mas sim aos indivíduos como seres racionais, já que não está diretamente relacionada às questões de eficiência, a expectativas de sucesso ou à coordenação entre meios e fins. A racionalidade noética ou substantiva é entendida então, como uma faculdade específica do homem e que afasta da ideia de razão a obediência cega às premissas e padrões de eficiência, enfocando, por outro lado, a ética e os valores.

Serva (1997) traz definições das racionalidades instrumental e substantiva, a partir de alguns elementos constitutivos essenciais. A ação instrumental é aquela baseada no cálculo, com orientação para a consecução de objetivos técnicos ou de fins vinculados a interesses econômicos ou de poder social, sempre com o intuito da maximização dos recursos disponíveis. Assim, a sua melhor representação poderia ser dada a partir do enfoque calculista, dos fins, da maximização de recursos, da busca de êxitos e resultados, da tentativa do alcance do melhor desempenho individual, da utilidade, da rentabilidade e de uma espécie de estratégia interpessoal que visaria à antecipação de comportamentos e reações de outras pessoas. Os elementos essenciais da ação racional instrumental encontram-se assim apresentados de maneira detalhada no trabalho do autor:

"[...] a) cálculo: projeção utilitária das consequências dos atos humanos;

b) fins: metas de natureza técnica, econômica ou política (aumento de poder);

c) maximização dos recursos: busca da eficiência e da eficácia máximas, sem questionamento ético, no tratamento de recursos disponíveis, quer sejam humanos, materiais, financeiros, técnicos, energéticos ou ainda de tempo;

d) êxito, resultados: o alcance, em si mesmo, de padrões, níveis, estágios, situações que são considerados como vitoriosos em face de processos competitivos numa sociedade capitalista;

e) desempenho: performance individual elevada na realização de atividades, centrada na utilidade; 
f) rentabilidade: medida de retorno econômico dos êxitos e dos resultados esperados.

g) estratégia interpessoal: aqui entendida como influência planejada sobre outrem, a partir da antecipação das reações prováveis desse outrem a determinados estímulos e ações, visando atingir seus pontos fracos. "(SERVA, 1997, p. 22 e 23.)

A ação substantiva, por outro lado, está direcionada em dois sentidos: um individual e outro social. Individual, pois se vincula às questões de autorrealização, de busca de satisfação e de consecução das potencialidades dos sujeitos. Grupal ou social, pois reflete também a preocupação com a responsabilidade e a satisfação social. Sendo assim, seus elementos constitutivos essenciais poderiam ser traduzidos na autorrealização, no entendimento, no julgamento ético, na autenticidade, na utilização de valores emancipatórios e na autonomia.

Um maior detalhamento dos elementos constituintes da chamada ação racional substantiva é assim realizado por Serva (1997):

"[...] a) autorrealização: processos de concretização do potencial inato do indivíduo, complementados pela satisfação;

b) entendimento: ações pelas quais se estabelecem acordos e consensos racionais, mediados pela comunicação livre, e que coordenam atividades comuns sob a égide da responsabilidade e satisfação sociais;

c) julgamento ético: deliberação baseada em juízos de valor, (bom, mal, verdadeiro, falso, certo, errado, etc.) que se processa por meio do debate racional sobre as pretensões de validez emitidas pelos indivíduos nas interações;

d) autenticidade: integridade, honestidade e franqueza dos indivíduos nas interações.

e) valores emancipatórios: aqui se destacam os valores de mudança e aperfeiçoamento do social nas direções do bem estar coletivo, da solidariedade, do respeito à individualidade, da liberdade e do comprometimento, presentes nos indivíduos e no contexto normativo do grupo;

f) autonomia: condição plena dos indivíduos para poderem agir e expressarem-se livremente nas interações." (SERVA, 1997, p. 22)

Serva (1992) considera a existência, em todo o mundo, de um número considerável de organizações animadas pela racionalidade substantiva, tendo sido vagamente caracterizadas como não burocráticas, substantivas, coletivistas ou ainda, alternativas. Para essas, a teoria organizacional clássica parece ter se esquecido de olhar, seja por causa de determinados pressupostos talvez ideológicos, ou mesmo pela inexistência de uma fundamentação teórica adequada à sua natureza.

Para o autor, tais organizações têm na espontaneidade a mola mestra de sua criação e também de seu funcionamento, o que leva a uma subversão dos padrões consagrados pela teoria organizacional. Sendo assim, considera que o referencial 
adequado para o exame das organizações alternativas seria o paradigma da complexidade. Essas novas formas de ordenação social e até mesmo de produção exigem para sua análise, referenciais que sejam alternativos à lógica utilitarista.

Nesse tipo de organização, aquilo que quase sempre desperta curiosidade
é que, em geral, seus princípios, formas organizativas e, sobretudo, as
práticas desenvolvidas por seus membros são substancialmente diferentes,
por vezes até opostos, daqueles empregados pelas organizações
burocráticas, glorificados e recomendados pelas teorias e metodologias
administrativas. Não obstante esse distanciamento do que é considerado
pela teoria como racionalidade, as organizações coletivistas continuam a
existir e proliferar, desenvolvendo soluções próprias não previstas nos
manuais de administração. Elas parecem animadas por outro tipo de
racionalidade, a racionalidade substantiva (SERVA, 1992, p. 34)

Diante de tais características das organizações alternativas, considera-se que as redes sociais mobilizadas nas ações de resposta a desastres naturais podem ser visualizadas a partir desse formato de organização. Tal afirmação está ancorada essencialmente na capacidade que tais redes possuem de promover a mudança e aperfeiçoamento do social nas direções do bem estar coletivo e da solidariedade, movidas por uma ação racional substantiva.

Martinho e outros (2003) também reconhecem as características peculiares e diferenciadas das redes sociais em relação às organizações tradicionais, quando as definem como formas não institucionais de organização, cuja dinâmica é muito mais espontânea do que baseada em atribuições, papéis, regulamentos, cargos e departamentos. Sendo assim, as redes sociais requerem também formas de operação distintas.

Nessa mesma linha de pensamento, as análises realizadas a seguir tratam das características gerais das redes sociais, incluindo, em alguns pontos comparações dessas com as organizações hierárquicas, evidenciando seu caráter alternativo, espontâneo e emancipatório.

\subsubsection{Redes sociais como alternativas emancipatórias}


Martinho e outros (2003) tratam das redes como organizações. Contudo, não no sentido de entidades ou instituições, como discutido no capítulo anterior, mas antes como um padrão organizativo e seu modo correspondente de operação. Organização no caso das redes sociais deve ser considerada como um processo: inacabado e em constante rearranjo.

Uma importante questão a ser destacada antes que se inicie uma abordagem mais ampla das redes sociais é, conforme lembram Franco (2012) e Recuero (2009), que não se deve confundir redes sociais com sites de redes sociais. Embora esses possam ser boas ferramentas para articulação e animação das redes e venham a refletir os vínculos interpessoais existentes, redes sociais são sempre redes de pessoas.

É preciso destacar também a tipologia existente para classificar as redes sociais quanto ao escopo de sua ação. Essas podem ser redes de troca de informação e redes operativas. As primeiras são bastante comuns no contexto da produção científica e tecnológica, mas atualmente estão presentes em diferentes campos da atividade humana, especialmente a partir do desenvolvimento da Internet. Tais redes são restritas ao trabalho de troca de informação, seu desenho é horizontal e possuem uma série de procedimentos de natureza colaborativa.

As redes operativas, por sua vez, são, necessariamente, redes de troca de informação. Porém, sua atuação vai muito além disso, sendo essa, apenas uma das funções que realiza. Estão entre as atividades desenvolvidas pelas redes operativas: o desenvolvimento de pesquisas e estudos; o estabelecimento e condução de processos de interlocução e negociação políticas; a realização do acompanhamento de políticas públicas; a promoção de processos de formação e capacitação; a realização de campanhas públicas de sensibilização, esclarecimento e mobilização; a atuação na defesa e conquista de direitos sociais e causas coletivas; a captação e distribuição de recursos e a prestação de serviços (FRANCO, 2012).

Considerando, especificamente, o tipo de atividade desenvolvida pela rede social de apoio às vítimas das chuvas de 2013 no ES, essa rede pode ser caracterizada como uma rede operativa, e é então sobre esse tipo de rede que estão desenhadas as discussões a seguir. 
Martinho e outros (2003) baseiam-se na ideia de Capra (1996), já mencionada na subseção 2.4.2, sobre o arranjo dos sistemas vivos como redes dentro de redes, para afirmar que uma das propriedades distintivas mais importantes da rede é justamente sua capacidade de operar sem hierarquia. Estudos sobre redes sociais de uma maneira geral e, em especial, aquelas de natureza fortemente informal e não institucional demonstram a existência de fenômenos organizativos não verticais e não hierárquicos e que possuem um funcionamento bastante produtivo na sociedade, semelhante ao que Serva (1992) denomina organizações alternativas.

Uma rede é uma arquitetura plástica, não linear, aberta, descentralizada,
plural, dinâmica, horizontal e capaz de auto-regulação. É uma forma de
organização caracterizada fundamentalmente pela sua horizontalidade, isto
é, pelo modo de inter-relacionar os elementos sem hierarquia.
O conceito de organização tem a ver com "ordem": é o processo de ordenar
um conjunto de elementos em razão de um objetivo ou finalidade.
Hierarquia tem a ver com controle, governo, poder de decisão. Uma
organização sem hierarquia, seria, nessa acepção, um processo no qual um
conjunto de elementos estaria ordenado sem a mediação de qualquer
controle ou governo. Essa definição parece um contrassenso, para nós
acostumados a uma noção de ordem associada a controle e comando. Mas,
como bem demonstrou Fritjof Capra (na esteira das contribuições de llya
Prigogine, Benoît Mandelbrot, Humberto Maturana e Francisco Varela, entre
outros), é nessa "ordem sem governo" que se baseia o padrão de
organização de todos os sistemas vivos. Ordem que, convenhamos, parece
funcionar muito bem (MARTINHO et. al., 2003, p 42). Assim, da mesma forma que a estrutura piramidal típica das organizações tradicionais denota de forma clara a lógica hierárquica, é justamente na arquitetura em rede que se descobre a não hierarquia. Sendo assim, as redes seriam essencialmente estruturas horizontalizadas por natureza, já que se configuram como conjuntos de atores e relacionamentos interligados de forma não hierárquica.

Uma análise de algumas características morfológicas das redes sociais permite uma compreensão mais clara entre a ideia de rede e a de horizontalidade, como construtos que se alimentam e se fortalecem mutuamente (MARTINHO et. al. 2003).

Nesse aspecto, uma questão essencial é a descentralização, que pode ser definida como "a distribuição de certa medida de atividades, informações ou poder no âmbito de um sistema qualquer (MARTINHO et. al. 2003, p. 26). Justamente por sua dinâmica não se sustentar sobre um ponto específico, mas na ocorrência e no acionamento das diferentes conexões estabelecidas, é que as redes são por natureza, descentradas. 
Lembrando as topologias de rede propostas por Baran, já mencionadas na seção 2.5, Franco (2012) destaca que as redes sociais são pessoas interagindo segundo um padrão de organização de rede distribuída. Essas, bem ao oposto das estruturas hierárquicas, são estruturas sem administração, que se regulam por emergência (e não por comando e controle), quanto mais distribuídas forem.

Estruturas como as cadeias de comando (essencialmente hierárquicas) caracterizam-se pela existência de um único caminho possível para se chegar de um ponto a outro, seja uma informação, ordem ou solicitação. Conforme destaca Franco (2012) as hierarquias consistem, portanto, em estruturas organizativas onde se gerou artificialmente uma escassez de caminhos.

Redes por sua vez, devem ser encaradas como caminhos para a desconstrução da hierarquia. Em se tratando de redes quase sempre há uma abundância de caminhos diferentes, existindo, portanto, liberdade para se realizar conexões. Essa multiplicidade de caminhos também é o que confere a capacidade regenerativa da rede. Quando conexões deixam de existir ou quando pontos são suprimidos, o sistema é capaz de se reorganizar porque existem outros caminhos a serem trilhados (FRANCO, 2012).

Para Martinho e outros (2003), outra questão central sobre redes sociais é que são fenômenos coletivos, o que significa dizer que sua dinâmica é resultado da ação de conexão de muitos em uma interação produtiva. Somente quando a rede é acionada, é que se torna possível contemplar a sua morfologia, é nesse momento que a rede aparece. Esse acionamento decorre de algo que os autores chamam de "missão a cumprir", como no caso dos protagonistas do estudo realizado por Milgram, que acionaram suas conexões, pois tinham um objetivo a ser realizado.

Da mesma maneira, esse acionamento da rede se revela em campanhas de sangue, em coletas voluntárias de doações, nas ações entre amigos e em inúmeros processos de mobilização social espontânea, como no caso das redes sociais atuantes nas ações de resposta a desastres naturais, objeto deste estudo.

Na mesma perspectiva, Franco (2012) considera que redes sociais distribuídas são sempre redes de cooperação. Martinho e outros (2003) apresentam assim, a ideia de que redes sociais são comunidades de propósito. Para isso, é necessária a 
existência de um propósito comum aglutinador, uma ideia força, uma tarefa, um objetivo que tem na ação voluntária (que será mais adiante discutida), sua mola propulsora. Acionar a rede é, portanto, dar início a uma dinâmica de comunidade.

É justamente essa ideia de dinâmica que permite analisar a organização da rede sempre como um processo em desenvolvimento, nunca inacabado, em intenso movimento e rearranjo a partir de interações que levam a erros e acertos até que se encontre um modo coordenado de funcionamento. Conforme já discutido, trata-se de um processo auto-organizativo, onde não existe, portanto, um controle ou comando central que defina ordens e regras de funcionamento (MARTINHO et. al. 2003).

A horizontalidade da rede é também sustentada por outro aspecto essencial: a participação voluntária. As pessoas decidem participar do projeto coletivo da rede porque acreditam nele, não são obrigadas a aderirem, o fazem quando querem e porque querem. Nesse sentido, os vínculos de solidariedade e a prática da cidadania passam a existir de maneira espontânea (MARTINHO et. al. 2003).

Morin (1998) apresenta a solidariedade como uma espécie de cimento social, necessário para que as sociedades complexas não se desintegrem. Entretanto, afirma que o laço entre a complexidade e a solidariedade não se dá de forma automática. A complexidade possui riscos ao permitir maior liberdade aos indivíduos e grupos, que podem optar pela criatividade, mas também pela delinquência. Assim, medidas autoritárias podem ser utilizadas para evitar que uma sociedade se desmantele no limite da complexidade, mas considerando o autoritarismo e a coerção como as últimas opções desejáveis, o que nos resta como cimento, segundo o autor, é a solidariedade vivida. Nesse sentido, as redes sociais, se apresentam como fios condutores dessa dinâmica solidária.

Tais questões trazem à tona uma forte expressão de autonomia que se evidencia na dinâmica dos relacionamentos nas redes sociais. Ela é claramente oposta ao princípio da heteronomia presente nas relações estabelecidas em estruturas hierárquicas em que os sujeitos têm suas ações dirigidas e decididas por outros, conforme discutido na subseção anterior. A perda de autonomia nessas organizações coincide com uma perda de poder que é acumulado por aqueles que ocupam os escalões imediatamente superiores na estrutura hierárquica. "Desse modo, o compartilhamento de objetivos e valores está para o trabalho colaborativo e 
a rede assim como a autoridade e o poder de mando estão para os sistemas verticais hierárquicos" (MARTINHO et. al. 2003, p. 50).

Nas redes sociais, por sua vez, a autonomia é a mola propulsora da própria conectividade. As conexões são realizadas conforme o desejo, a vontade e o interesse de seus participantes. "Redes são estruturas organizacionais frágeis como os desejos humanos, porém tão fortes quanto eles (MARTINHO et. al. 2003, p. 72)."

Os autores destacam que a autonomia está presente não apenas na realização, mas também na manutenção das conexões, o que quer dizer que o funcionamento da rede é baseado em relações autônomas. Isso não significa, contudo, que não existam acordos e normas de funcionamento ou que a autonomia se sobreponha aos aspectos coletivos. Há na prática uma coordenação de autonomias voltada simultaneamente para a ação coletiva e para a preservação das individualidades. Acordos e normas são estabelecidos como resultado de pactos e consensos onde todos são envolvidos. A partir daí percebe-se uma constante interação entre a ideia de autonomia e de respeito às diferenças nas redes sociais. Autonomia pressupõe o direito de agir, pensar e existir, de forma diferente das demais pessoas.

A arquitetura não linear e complexa das redes sociais pressupõe ainda outros importantes princípios típicos dessa morfologia: isonomia, insubordinação, desconcentração de poder, multiliderança e democracia (MARTINHO et. al. 2003).

Isonomia e hierarquia denotam princípios em constante oposição. Existe isonomia quando todos são iguais diante de normas e leis às quais todos devem seguir de maneira indistinta. Numa organização horizontal, há isonomia. Considerando que não existem níveis hierárquicos, não se cria a possibilidade de diferenciação de poder e direitos entre os membros da organização (MARTINHO et. al. 2003).

Assim, se estabelece também o princípio da insubordinação: como não há cadeia de comando, não há quem necessite se subordinar a alguém, nem quem necessite dar ordens a alguém. Por essa razão é que as decisões emergem de forma cooperativa e compartilhada, evidenciando uma desconcentração clara de poder entre os membros da coletividade, de maneira difusa, fazendo emergir multilideranças. É nesse sentido que Franco (2012) destaca que redes mais distribuídas do que 
centralizadas, ou seja, aquelas em que há abundância de caminhos, favorecem a emergência das multilideranças.

A partir delas é que se estabelece uma dinâmica de auto-regulação da rede capaz de produzir resultados multifacetados, soluções originais, capacidade adaptativa, criatividade e inventividade. Entretanto, para que essa dinâmica de auto-regulação se transforme em realidade, é preciso a existência de sinergia entre essas multilideranças, o que decorre de um processo de coordenação apoiado em práticas democráticas e na comunicação entre seus elementos (MARTINHO et. al. 2003). Os processos de comunicação nas redes sociais serão tratados em maior detalhe na próxima seção.

Gratuidade é outro termo essencial ao entendimento da participação nas redes sociais. Sobre isso, Alberto Melucci citado por Martinho e outros (2003) apresenta a seguinte análise:

\begin{abstract}
"O que distingue a ação voluntária como categoria sociológica é a voluntariedade do vínculo social dentro do qual ela está inserida: a ação voluntária implica a adesão livre a uma forma de solidariedade coletiva e ao pertencimento a uma rede de relações da qual se participa por escolha. Outra característica é a gratuidade dos serviços oferecidos pela ação voluntária. Mas a gratuidade não diz respeito simplesmente ao fato de que não se tira benefícios econômicos diretos da própria ação. Na verdade, se tivermos, por exemplo, alguma ajuda voluntária e gratuita ao próprio vizinho para cultivar o jardim, essa ação é uma forma de solidariedade privada regulada por uma troca interpessoal. Para se falar de ação voluntária na gratuidade deve-se considerar a relação que liga os atores envolvidos na ação coletiva: a ação voluntária é caracterizada pelo fato de que os benefícios econômicos não constituem a base da relação entre os que dela participam, nem entre esses e os destinatários da ação. (MELUCCI apud MARTINHO et. al., 2003, p. 43)
\end{abstract}

Sendo assim, a noção de gratuidade afasta das relações estabelecidas nas redes a lógica da troca econômica, típica da ação racional instrumental. Além disso, evidencia a cooperação como inerente à participação na rede.

Até aqui foram evidenciadas algumas distinções importantes entre as organizações burocráticas (metáfora de máquina de Morgan) e as redes sociais, a partir do pensamento de Franco (2012) e Martinho e outros (2003). Há também outras diferenças essenciais entre essas e a metáfora das organizações como sistemas, uma vertente bastante tradicional da teoria administrativa. Morin (1999) destaca que dentre essas principais distinções está a questão dos limites. 
As organizações como sistemas possuem limites claramente definidos, sua interface com o meio encontra-se bem delimitada e controlada. Nas redes, conforme mencionado, os limites são fluidos, sendo de difícil precisão as suas fronteiras, justamente por sua lógica propulsora que é a conectividade, refletindo seu caráter inacabado e em constante rearranjo.

As organizações vistas como sistemas possuem normas rígidas às quais todos devem obedecer e se sujeitar. Além disso, conforme mencionado, há uma visão parcial do ser humano (homem funcional), voltada apenas aos papeis desempenhados no âmbito organizacional. As expectativas relativas a tais papeis é que moldam as relações internas à organização. As redes, por outro lado, preveem a liberdade, a autonomia e a voluntariedade das pessoas, sendo os relacionamentos regidos por uma lógica integral de ser humano, que é capaz de buscar a comunicação e o consenso, considerando suas diferenças e valores pessoais. Essa interconexão, por sua vez, está diretamente relacionada às ideias de comunicação e mediação da informação nas redes sociais. É sobre elas que trata a próxima seção.

\subsection{COMUNICAÇÃO E MEDIAÇÃO DA INFORMAÇÃO EM REDES SOCIAIS}

Conforme aponta Marteleto (2010) as atividades de informação e comunicação longe de possuírem uma finalidade meramente acessória, são de fato estruturantes na definição da cultura e dos fenômenos sociais, especialmente quando compreendidas como a criação de quadros práticos nos quais os sujeitos desenvolvem trocas significantes.

Serra (2007), apoiando-se nas ideias de James Carey e John Fiske, destaca a existência de duas principais perspectivas acerca dos estudos sobre a comunicação. A primeira é a que visualiza a comunicação como transmissão de informação, também conhecida como perspectiva processual. Nela, os termos essenciais são fornecer, enviar, transmitir ou dar informação a outros, visando à produção de determinados efeitos sobre os receptores. Centra sua preocupação na questão da 
eficácia, da exatidão e do controle. É principalmente relacionada às ciências sociais como a sociologia e a psicologia.

A segunda principal visão de comunicação é aquela que a considera um ritual, relacionado às ideias de partilha, participação, associação e também à posse de uma fé comum. Está associada, portanto, à perpetuação da sociedade no tempo a partir da representação de crenças e significados compartilhados. É também conhecida como perspectiva semiótica, já que concebe a comunicação como produção e troca de significados. Nela, as diferenças culturais entre emissores e receptores são uma importante preocupação. Essa visão se encontra mais próxima das humanidades, como a literatura, a linguística e a filosofia.

Especificamente sobre a comunicação em redes sociais, Marteleto (2010) baseando-se em Jeanneret, entende que nem o modelo normativo e redutor da transferência de informação, nem o menos redutor, mas ainda insuficiente modelo semiótico podem ser, sozinhos, suportes suficientes à compreensão do fenômeno da comunicação nesses contextos. Em se tratando de redes sociais, a visão diádica de uma zona de intercâmbio entre emissor e receptor (relação entre dois elementos) de informação é considerada pela autora como bastante limitada. Uma análise restrita a essa perspectiva levaria a relações em grande medida redundantes, num reflexo inadequado da realidade das redes sociais, onde os papeis e posições dos atores são dinâmicos, justamente pela sua natureza interdependente a outros atores e suas posições.

Assim, para Marteleto (2010), inserida no interesse próprio da $\mathrm{Cl}$, está a necessidade de consideração de um terceiro elemento na perspectiva da comunicação em redes sociais, que a autora denomina de "zonas de mediação". Para ela, a partir dessa ideia de zonas de mediação é possível configurar diferenciados espaços de trocas simbólicas que poderiam ser aprofundadas a partir da perspectiva das redes sociais. São as seguintes as dimensões essenciais dessas zonas de mediação:

(a) A dimensão propriamente social e comunicacional, que permite traçar os elos, as interações e as motivações dos atores em função do convívio (concreto ou virtual) e dos interesses e dos objetivos compartilhados.

(b) A dimensão linguística e discursiva, na qual se observam os diferentes recursos cognitivos e informacionais que os atores acionam no compartilhamento de questões e em suas soluções. 
(c) A dimensão de produção de sentidos, que se visualiza quando os elementos interativos, comunicacionais, informacionais e cognitivos clareiam uma zona de encaminhamento das ações individuais e coletivas (MARTELETO, 2010, p. 39)

Recuero (2009) trata profundamente das questões relacionadas à compreensão das redes sociais mediadas por computador e destaca que as trocas sociais dependem, essencialmente, das trocas comunicativas. Para a autora, a metáfora da rede se apresenta como questão essencial à compreensão da comunicação mediada por computador. Em seu âmbito, os fluxos comunicativos da sociedade contemporânea tornaram-se muito mais complexos, e assim, a compreensão de como os grupos são expressos na Internet ganha significativa importância.

A rede mundial de computadores se revela como ferramenta para a organização social e informação contemporânea. Por meio dela, novos valores podem ser construídos, fluxos de informação são divididos e emergem diferentes mobilizações (RECUERO, 2009).

Recuero (2009) compreende os sites de redes sociais não como um elemento novo, mas como uma decorrência da apropriação por parte dos atores sociais, de ferramentas de comunicação mediada por computador. Na visão dessa autora, sites de redes sociais (SRS) são "toda a ferramenta que for utilizada de modo a permitir que se expressem as redes sociais suportadas por ela" (RECUERO, 2009, p. 102). Tais ferramentas de comunicação mediada por computador, entre os quais atualmente merece destaque o Facebook, possibilitam a expressão e sociabilização, por meio das trocas de mensagens e do sentido que as mesmas possuem em um contexto específico. No âmbito desta pesquisa o Facebook é então compreendido como uma zona de mediação, no sentido do que trata Marteleto (2010).

A compreensão das funcionalidades do Facebook é auxiliada pela descrição apresentada por Bohn e outros (2014). Assim, em resumo tem-se que o propósito do Facebook a partir de uma perspectiva do usuário é criar uma amizade virtual com outros usuários, para se comunicar com eles, e para se manter informado sobre as suas atividades e interesses. Para isso, o usuário faz uso de um "perfil" virtual onde tem a possibilidade de inserir uma foto de identificação e também uma foto de capa, além de outras informações pessoais, se assim desejar, que são visualizadas pelas pessoas que acessam o perfil desse usuário no site. 
Amizades são estabelecidas quando um usuário da ferramenta envia uma solicitação de amizade para outro usuário e esse último, aceita a solicitação. A partir desse ponto, os amigos podem ler os "posts" uns dos outros. Os chamados "posts" são mensagens de texto não endereçadas que podem ser enriquecidos por fotos ou vídeos. Tais mensagens podem ser comentadas e "curtidas", clicando no botão curtir. Elas aparecem em "feeds de notícias", uma coleção de mensagens e notificações de outras atividades de amigos (por exemplo, quando alguém mudou o seu / sua foto do perfil). Os usuários podem postar nas suas próprias "walls" ou "linhas do tempo" ou nas de seus amigos. Enquanto feeds de notícias mostram mensagens de todos os amigos de um usuário, a linha do tempo mostra todas as mensagens e notificações relacionadas a apenas um determinado usuário. Os usuários também podem marcar amigos em seus posts. Por meio desse recurso, o post não aparece apenas na linha do tempo do usuário, mas também na da pessoa que foi marcada. Também é possível por meio de uma ferramenta agregada ao Facebook, denominada Messenger, a realização de reuniões virtuais em que amigos podem trocar opiniões por escrito em simultâneo, em tempo real, denominadas chats.

Considerando tais fenômenos contemporâneos da comunicação, a apropriação de um conceito de mediação parece ser ainda tarefa bastante desafiadora para a ciência da informação. De acordo com Almeida (2014) pelo fato de envolver coisas muito diferentes entre si, parece ser impraticável uma posição consensual quanto à ideia de mediação. $O$ autor parte da consideração das concepções mais tradicionais de atendimento ao usuário, passando por aquelas que se relacionam ao agenciamento cultural em instituições como museus, bibliotecas, arquivos e centros culturais, até chegar àquelas voltadas para a elaboração de políticas de capacitação ou de acesso às TICs. Assim, Almeida (2014) entende a mediação como um conceito bastante plástico, que vem estendendo suas fronteiras para se adequar a realidades muito distintas.

No mesmo sentido, Davallon (2007) destaca que, cada domínio de investigação possui o seu próprio uso e também uma definição própria de mediação. Para o autor, especificamente no campo da Ciência da Informação, a conceituação exata de mediação ainda é um trabalho teórico em curso. Apesar disso, o autor considera que uma linha comum a todas as definições é a importância do terceiro elemento, 
que apesar de diferir em sua forma, de um autor para outro, parece possuir alguns pontos importantes e comuns entre as definições de sua ação. Essa ação não se restringe a uma simples interação entre elementos já constituídos, ou numa circulação de um elemento de um polo para outro, mas implica numa transformação da situação ou do dispositivo comunicacional. Nesse sentido, o autor destaca que:

[...] há recurso à mediação quando há falha ou inadaptação das concepções habituais da comunicação: a comunicação como transferência de informação e a comunicação como interacção entre dois sujeitos sociais. Com esse recurso, a origem da acção desloca-se do actuante destinador ou dos inter-actuantes para um actuante terceiro: há comunicação pela operação do terceiro (DAVALLON, 2007, p.10).

Davallon (2007) aborda ainda uma importante utilização da ideia de mediação referindo-se a análise do uso das tecnologias. Nesse campo, a mediação serve simultaneamente como mediação técnica e mediação social. Assim, no contexto do uso das novas tecnologias, tanto a tecnicização do processo de comunicação quanto a intervenção da dimensão subjetiva das práticas de comunicação estão designadas pela ideia de mediação.

Almeida Junior (2009) é o propositor de uma das definições mais conhecidas de mediação na Ciência da Informação. Segundo o autor a mediação é:

[...] toda ação de interferência - realizada pelo profissional da informação -, direta ou indireta; consciente ou inconsciente; singular ou plural; individual ou coletiva; que propicia a apropriação de informação que satisfaça, plena ou parcialmente, uma necessidade informacional (ALMEIDA JUNIOR, 2009, p. 92)

Ao tratar dos objetivos do grupo de pesquisa ao qual se vincula, denominado Interfaces: Informação e Conhecimento a partir de cujos projetos se buscou a definição acima apresentada de mediação da informação, Almeida Junior (2009, p. 90) ainda afirma que:

Embora constituído de docentes, pesquisadores e alunos pertencentes ou oriundos de cursos de Biblioteconomia, o Grupo tem norteado suas ações para os profissionais da informação, incluídos nessa categoria os bibliotecários, os arquivistas e os museólogos.

É possível observar nas proposições de Almeida Junior (2009), a importância dada aos profissionais da informação. Para ele, tais profissionais são os que interferem de maneira contundente em todo o processo da apropriação da informação pelo usuário. 
Zins (2007) por sua vez, insere a mediação no próprio conceito de Ciência da Informação quando estabelece que: "Ciência da Informação é um ramo do conhecimento que explora as perspectivas da mediação do conhecimento humano" (ZINS, 2007, p. 339, tradução nossa). Para esse autor, entre as perspectivas da mediação estão determinados aspectos cognitivos, sociais e tecnológicos, além de determinadas condições que facilitam a disseminação do conhecimento humano de uma determinada fonte informacional para o seu usuário.

Em seu famoso artigo intitulado "Knowledge map of information science", Zins (2007) apresenta um mapa de conhecimento sistematizado e bastante abrangente da $\mathrm{Cl}$, resultado de discussões realizadas entre estudiosos que foram convidados a participar de um painel Delphi. Em seu trabalho o autor identifica dez categorias básicas de elementos que compõem a Ciência da informação. Ao abordar a mediação da informação, define sete elementos, considerados fatores de mediação, que atuam entre as fontes de informação e os usuários, quais sejam: Trabalhadores do Conhecimento, Conteúdos, Aplicações, Operações e Processos, Tecnologias, Ambientes e Organizações.

Algumas perguntas essenciais, na concepção do autor estão relacionadas a cada um desses fatores e necessitam ser respondidas quando da análise do processo de mediação: Quem negocia ou medeia?; O que está sendo mediado?; Por que é mediado?; Como é mediado?; Onde e quando o processo de mediação acontece? De forma bastante sucinta, estão apresentadas a seguir as descrições realizadas por Zins (2007) para cada um dos fatores de mediação.

A dimensão dos Trabalhadores do Conhecimento corresponde ao que se conhece como profissionais de informação. Ou seja, aqueles que trabalham com a informação na sua produção, tratamento, preservação, disseminação e difusão com vistas ao atendimento das necessidades do usuário.

O fator Conteúdos está relacionado com os tipos e o conteúdo do conhecimento mediado, o que se estabelece pelos tipos de estrutura, sistemas de classificação e assuntos.

As Aplicações referem-se a questões de tipos de aplicações relacionadas com o desenvolvimento dos recursos projetados para atender às necessidades do usuário 
e os interesses que podem ser promovidos por meio da aquisição de conhecimento. Por isso, estão relacionadas aos motivos e finalidades pelos quais a informação é mediada.

As Operações e Processos estão vinculados aos métodos e meios envolvidos na mediação do conhecimento humano, incluindo a documentação, a representação, a organização, o processamento, a divulgação, a publicação, o armazenamento, a manipulação, a avaliação, a medição, a busca e a recuperação do conhecimento.

Esse fator está relacionado às Tecnologias de informação e conhecimento, que são sistemas de informação que envolvem, além do material impresso, as TICs, os suportes físicos de hardware, software, equipamentos de telecomunicações, redes de computadores, infraestruturas prediais, infraestrutura tecnológica da sociedade, entre outros.

O Ambiente, por sua vez, se relaciona com o contexto social, cultural, legal e ético, que envolvem o processo de mediação, como políticas de informação, propriedade intelectual, entre outros.

O fator Organizações estabelece a necessidade de instituições que medeiem informações, sejam elas governamentais, públicas ou privadas, realizando funções relacionadas com a organização da memória, serviços de informação, entre outros.

Quando se considera o contexto da sociedade da informação, as influências das novas TICs sobre os espaços informacionais, além da lógica das redes sociais, a questão da mediação pode se tornar ainda mais polissêmica. Especificamente, no contexto dos espaços de comunicação constituídos a partir da configuração em redes sociais, Marteleto (2001, p. 79) considera que está sendo colocada em prática "uma nova compreensão do conhecimento e da informação". Nesse sentido, a própria questão da mediação parece estar sendo de certa maneira, remodelada. $\mathrm{Na}$ esfera da ARS, os aspectos relacionados à intermediação, parecem configurar a lógica da mediação, inserida no ponto de vista das posições e interações entre os atores.

Assim para Marteleto (2001) as teias sociais e estruturais evidenciadas nas redes sociais são capazes de revelar as mediações cognitivas e comunicacionais presentes nas ações, representações e interações dos agentes. No mesmo sentido, 
Tomaél e Marteleto (2006, p. 82), quando tratam das questões relativas ao conceito de centralidade de fluxo de intermediação, já discutido na seção 2.5, indicam que "atores que estão localizados entre outros atores controlam e fazem, entre esses, a mediação da informação".

Em um trabalho que buscou analisar os modos de comunicação, a produção de conhecimentos e o uso das informações pelos grupos e entidades organizados das redes de movimentos sociais, Marteleto (2001) considerou que os agentes com papeis mais destacados de intermediação, são os que possuem maior capacidade de mediação da informação, já que detém o poder de controlar as informações que circulam na rede e o trajeto que elas podem percorrer. Nesse sentido, o papel do mediador, ou intermediário na rede, implica num "exercício de poder, de controle e filtro das informações que circulam na rede" (MARTELETO, 2001, p.79).

Tang e outros (2010) em trabalho intitulado "Analysing information flows and key mediators through temporal centrality metrics" analisam a rede de trocas de informação por email, entre 151 empregados da empresa Enron, durante o auge do escândalo contábil da companhia. Os autores consideram que métricas de centralidade de grau, de proximidade e de intermediação são capazes de evidenciar os principais mediadores de informação na rede. Análises dessas métricas são realizadas no estudo, considerando a dinâmica da interação dos atores ao longo do tempo para buscar medir a disseminação da informação e analisar o identificar o papel dos mediadores de informação.

Em linha de aplicação bastante semelhante, Soares (2014) considera que as métricas de mediação são aquelas que visam destacar os indivíduos mais importantes na rede do ponto de vista de sua capacidade de intermediação. Segundo o autor, existem várias métricas de mediação na ARS e dentre as principais estão a centralidade, os papeis de intermediação e as pontes. Elas oferecem maneiras de identificar quais são os atores mais relevantes considerando a sua posição na rede, a quantidade de relacionamentos que possuem e também os relacionamentos de seus vizinhos. Nas palavras do autor:

Em um contexto de mediação, um indivíduo pode assumir papeis diferentes, de acordo com sua posição em relação aos demais do grupo. O estudo de papeis de mediação geralmente se aplica a situações onde estão envolvidos, dentro de uma mesma rede social a ser analisada, mais de um grupo diferente de atores (SOARES, 2014, p. 55). 
É justamente sobre os relacionamentos, que se sustenta a dinâmica da comunicação da rede. Ao estabelecer relacionamentos numa rede social, os atores estão estabelecendo linhas de comunicação. Martinho e outros (2003) tratam links, linhas, laços e relacionamentos como sinônimos de comunicação em uma rede social.

O fenômeno da comunicação sustenta o processo de auto regulação da rede, que se produz a partir de laços de realimentação. Deles decorre a troca, a distribuição e a transformação de informações e sentidos. A partir da auto regulação é que os elementos distintos da rede passam a ser compreendidos como um todo orgânico, uma comunidade. As influências recíprocas desencadeadas a partir dos fluxos existentes na prática da comunicação são capazes de construir, moldar e alterar impressões, ideias, visões de mundo, valores e projetos de outras pessoas, e viceversa.

Assim, redes sociais são, em essência, dinâmicas coletivas que se definem pela comunicação. Embora haja nelas certo espaço para a valorização individual de cada nó, o relacionamento existente entre o grupo de atores é o que se destaca de forma proeminente em sua caracterização. Esse relacionamento pressupõe interação e decorre, necessariamente, de intensa comunicação (MARTINHO et. al., 2003).

Nesse sentido, a comunicação é o verdadeiro insumo para a constituição e organização da rede. Para Martinho e outros (2003, p. 49) "a rede depende dos processos de comunicação para constituir-se como tal". A informação se apresenta como elemento regulador do sistema, a partir da qual se torna possível a articulação das multilideranças e a coordenação de diferentes ações no âmbito da rede.

A ótica da circulação da informação permite visualizar o que é produzido nas redes. A informação deve ser tratada como insumo essencial à rede, como seu alimento, possuindo o papel central de organizar a ação da rede (RECUERO, 2012). Capra (2002) destaca como principais características das redes a velocidade e a qualidade da informação que por elas flui. O fluxo de informações no âmbito das redes é não linear. Direciona-se para todos os lados, não é controlado e é capaz de produzir novas formas por onde passa. 
A partir da análise acerca da organização dos sistemas vivos, Capra (1996) apresenta assim a questão da informação como elemento regulador da rede.

A primeira e mais óbvia propriedade de qualquer rede é a sua não
linearidade - ela se estende em todas as direções. Desse modo, as
relações num padrão de rede são relações não lineares. Em particular, uma
influência, ou mensagem, pode viajar ao longo de um caminho cíclico, que
poderá se tornar um laço de realimentação. (...) Devido ao fato de que as
redes de comunicação podem gerar laços de realimentação, elas podem
adquirir a capacidade de regular a si mesmas. Por exemplo, uma
comunidade que mantém uma rede ativa de comunicação aprenderá com
seus erros, pois as consequências de um erro se espalharão por toda a
rede e retornarão para a fonte ao longo de laços de realimentação. Desse
modo, a comunidade pode corrigir seus erros, regular a si mesma e
organizar a si mesma. Realmente, a auto-organização emergiu talvez como
a concepção central da visão sistêmica da vida, e, assim como as
concepções de realimentação e auto regulação, está estreitamente ligada a
redes (CAPRA, 1996, p. 78).

Ao fluir de maneira não controlada, em caminhos aleatórios, a informação é capaz de conduzir a rede a um processo circular de aprendizagem crescente que tem como consequência o rearranjo constante dos seus elementos. Assim, conforme destacam Martinho e outros (2003), a análise de Capra (1996) parte de uma característica morfológica das redes, que é a não linearidade, para desembocar em uma propriedade organizacional dessas, a capacidade de auto-organização. É nesse sentido que para Marteleto (2010), a comunicação assume um papel estruturante na rede, assim como em toda a dinâmica social.

Considerando que a comunicação no âmbito da rede deve ser, potencialmente, de todos com todos, os fluxos de informação permitem também constatar o grau de qualidade dos processos da rede. Quando a rede está operando plenamente, a informação está fluindo livremente. Por outro lado, processos de concentração ou desconexão decorrem de parada, concentração ou represamento de informação na rede. Importante destacar que a perspectiva descentralizada e não linear de rede, permite evidenciar que cada um dos nós, é, ao mesmo tempo, receptor e produtor de informação (MARTINHO, et. al. 2003). Nas redes sociais, portanto, os relacionamentos são móveis, estão sempre em mutação, a partir do compartilhamento de informações e conhecimentos.

Diante do exposto até aqui sobre as questões abordadas nesta e nas seções anteriores do referencial teórico, compreende-se que o panorama conceitual é adequado e suficiente para dar suporte às análises sobre os dados coletados na 
pesquisa de campo, especialmente no que tange aos fenômenos de comunicação e mediação da informação em redes sociais. Contudo, a outra vertente central ao tema da pesquisa, a gestão de desastres naturais, mais especificamente, a fase de resposta aos desastres, necessita ainda de maior aprofundamento.

Assim, a próxima seção destina-se a apresentar o panorama dos desastres naturais no Brasil, incluindo um breve histórico da situação, alguns conceitos essenciais à sua compreensão, bem como o formato adotado para a gestão de desastres naturais no país. Na sequência, a subseção debate a situação dos desastres naturais no Espírito Santo, com enfoque para as fortes chuvas de dezembro de 2013. 


\section{ESTRUTURAS BUROCRÁTICAS E GRUPOS EMERGENTES NA RESPOSTA A DESASTRES NATURAIS}

\subsection{DESASTRES NATURAIS NO BRASIL}

Os desastres naturais no Brasil ocorrem em função de inúmeros fatores. São bastante diferenciadas as características geológicas dos variados ecossistemas comumente existentes em um país de dimensões continentais. Muitas dessas áreas são impróprias para a ocupação, mas ainda assim, tal ocupação acaba ocorrendo e de forma bastante inadequada, aumentando a suscetibilidade das populações. Aliados a esses fatores, diferentes situações climatológicas podem ser capazes de potencializar os danos e prejuízos causados a essas áreas (BRASIL, 2012b).

Nesse contexto, a suscetibilidade e a vulnerabilidade são dois termos essenciais para se compreender o conceito de risco dessas populações. Tanto uma quanto a outra são potencializadas pela probabilidade dos eventos climáticos. Assim, considera-se que uma população encontra-se em condição de risco quando se instala em um terreno suscetível a desastres, em função da condição geológica e/ou geotécnica típica, e ainda, de forma frágil, tendo em vista as características construtivas das moradias, tornando-se, portanto, vulnerável (BERTONE; MARINHO, 2013).

Dessa maneira, no âmbito da defesa civil, a ideia de "risco expressa a medida probabilística da possibilidade de ocorrência de desastre, associado a alguma magnitude de dano ou prejuízo potencial previsível (SHADECK, et. al., 2013, p. 6)". O desastre se configura como o que resulta da combinação entre a magnitude da ameaça e o grau de vulnerabilidade do sistema receptor desse evento. Essa conceituação é apresentada na figura 6 , onde se pode observar o desastre como a combinação da vulnerabilidade com a situação de evento adverso. 


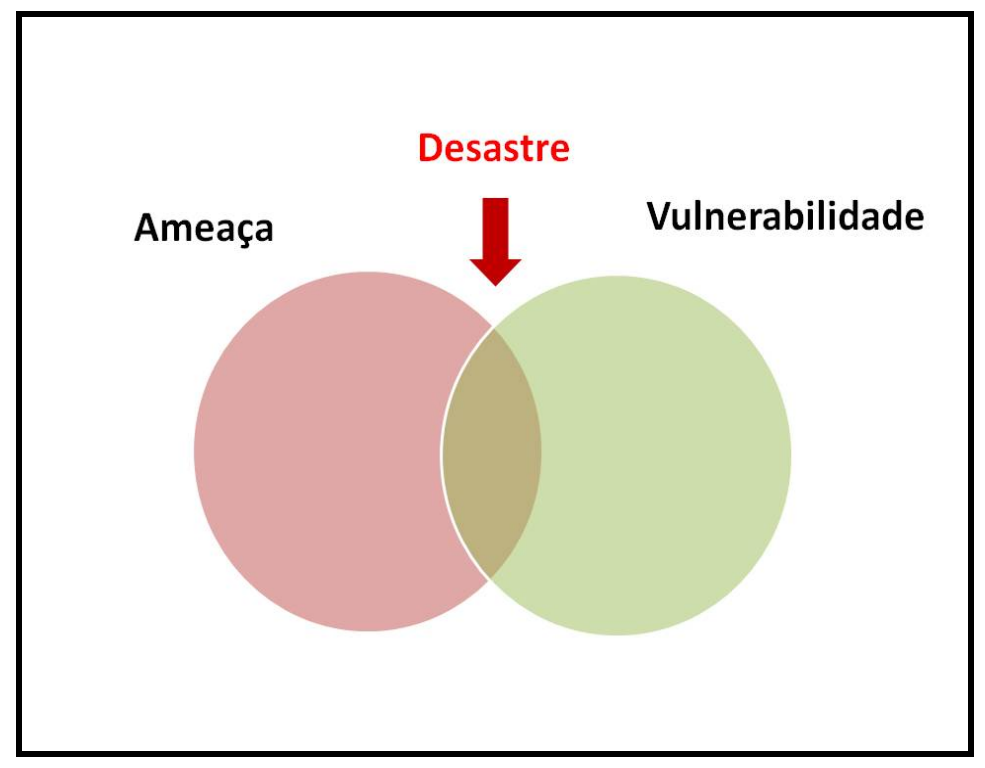

FIGURA 6 - DEFINIÇÃO DE RISCO

Fonte: Shadeck (et. al., 2013).

De forma mais específica, um desastre natural pode ser entendido como a consequência da ação de um evento natural extremo sobre um sistema social, causando sérios danos e prejuízos que normalmente excedem a capacidade da população afetada em conviver com o seu impacto (TOBIN e MONTZ, 1997).

Importante observar que o conceito de desastre está sempre ligado à consequência ou ao resultado de um evento extremo ou fenômeno, e não ao evento propriamente dito. Esse é normalmente configurado como evento adverso, aquele que é o causador do desastre. Assim, o evento adverso pode ou não se transformar num desastre, dependendo da intensidade de danos humanos, materiais e ambientais e prejuízos econômicos e sociais que tenha causado (OLIVEIRA, 2010).

Também importante é a distinção entre dano e prejuízo no contexto dos desastres naturais (BRASIL, 2007; ESPÍRITO SANTO, 2014).

Assim, OLIVEIRA (2010) destaca que:

A diferença entre dano e prejuízo em desastres é a seguinte: enquanto os danos representam a intensidade das perdas humanas, materiais ou ambientais ocorridas, os prejuízos são a medida de perda relacionada com o valor econômico, social e patrimonial de um determinado bem, em função da emergência ou desastre (OLIVEIRA, 2010, p. 10).

Observa-se que cada comunidade, cada área específica, possui determinadas características que fazem com que ela sofra mais ou menos os impactos de um desastre, e que também influenciam em sua capacidade de recuperação, conhecida 
como resiliência. Quando atua aumentando os danos, numa influência negativa à comunidade, tem-se como característica a vulnerabilidade. Quando atua positivamente, diminuindo os danos e facilitando a recuperação da área atingida, tem-se a chamada capacidade (OLIVEIRA, 2010).

Conforme já mencionado, a vulnerabilidade se relaciona a determinado contexto consequente de fatores físicos, sociais, econômicos e ambientais, que acabam por elevar a possibilidade de uma determinada área sentir mais fortemente os danos e prejuízos em consequência de um evento adverso (OLIVEIRA, 2010).

Por sua vez, a capacidade se relaciona à forma com que as comunidades atingidas utilizam os recursos que possuem visando à redução dos danos ou ao aumento da velocidade de sua recuperação, após um fenômeno natural desastroso (OLIVEIRA, 2010).

No contexto dos desastres naturais no Brasil, considera-se situação de emergência o "reconhecimento legal pelo poder público de situação anormal, provocada por desastre, causando danos suportáveis à comunidade afetada (BRASIL, 2007, p. 9).

Já o estado de calamidade pública se configura como o:

Reconhecimento legal pelo poder público de situação anormal, provocada por desastre, causando sérios danos à comunidade afetada, inclusive à incolumidade ou à vida de seus integrantes (BRASIL, 2007, p. 9).

Não existe ainda uma concordância internacional quanto a um padrão de classificação de desastres e há certas divergências entre os especialistas acerca dos critérios e métodos mais adequados para isso.

No Brasil, a Instrução Normativa oㅡ 01, de 24 de agosto de 2012, do Ministério da Integração Nacional instituiu a Classificação Brasileira de Desastres Naturais (COBRADE). Ela foi estruturada com base na classificação utilizada pelo Banco de Dados Internacional de Desastres (EM-DAT) do Centro para Pesquisa sobre Epidemiologia de Desastres (CRED) da Organização Mundial de Saúde (OMS/ONU). Alguns dos desastres típicos do contexto brasileiro foram também incluídos (BRASIL, 2012b).

Apresenta-se a seguir, no quadro 2, a COBRADE, considerando seus grupos e subgrupos. 


\begin{tabular}{|l|l|}
\hline \multirow{4}{*}{ 1. Geológico } & \multicolumn{1}{|c|}{ SUBGRUPO } \\
\hline \multirow{5}{*}{ 2. Hidrológico } & 1. Terremoto \\
\cline { 2 - 2 } & 2. Emanação vulcânica \\
\cline { 2 - 2 } & 3. Movimento de massa \\
\cline { 2 - 2 } & 4. Erosão \\
\hline \multirow{2}{*}{ 3. Meteorológico } & 1. Inundações \\
\cline { 2 - 2 } & 2. Enxurradas \\
\cline { 2 - 2 } & 3. Alagamentos \\
\hline \multirow{4}{*}{ 4. Climatológico } & 1. Sistemas de grande escala/Escala regional \\
\cline { 2 - 2 } 5. Biológico & 2. Tempestades \\
\cline { 2 - 2 } & 3. Temperaturas extremas \\
\hline
\end{tabular}

QUADRO 2 - CLASSIFICAÇÃO DOS GRUPOS E SUBGRUPOS DOS DESASTRES NATURAIS (COBRADE)

Fonte: Brasil (2012b).

A década de 2000 registrou um aumento da frequência dos desastres naturais no Brasil, considerando-se eventos como estiagem e seca, inundação brusca e alagamento, inundação gradual, vendaval ou ciclone, tornado, granizo e geada. Segundo o CEPED/UFSC, embora se reconheça a fragilidade do sistema de defesa civil em manter seus registros atualizados, é razoável supor que: ou houve um aumento do número de ocorrências, ou está havendo uma maior organização para a realização dos registros, ou até mesmo que as duas situações coexistam durante o período de análise para elaboração do Atlas Brasileiro de Desastres Naturais (UNIVERSIDADE FEDERAL DE SANTA CATARINA, 2012).

O atlas traz um mapeamento completo dos desastres naturais ocorridos no Brasil nas décadas de 90 e 2000. Nesse período, o maior número de registros (16.944) está relacionado às secas e estiagens. Os eventos que provocam o maior número de impactos na população, considerando número de pessoas afetadas e óbitos são as inundações, enxurradas e deslizamentos. Nos últimos anos, o país tem sido testemunha de inúmeras tragédias dessa natureza (UNIVERSIDADE FEDERAL DE SANTA CATARINA, 2012).

Essa realidade pode ser em parte explicada pela ausência de políticas públicas capazes de garantir moradias em número suficiente no Brasil, especialmente na 
década de 50, quando se acelerou o processo de urbanização do país. Com isso, uma parcela da população pobre, sem condições de pagar por moradias disponíveis no mercado imobiliário, passou a se dirigir para regiões restritas à ocupação legal, por serem áreas de risco ou por questões de preservação ambiental. Considerando que tais regiões eram normalmente aquelas de acentuado declive ou situadas à beira de córregos e rios, a vulnerabilidade das populações que ali se instalaram tornou-se elevadíssima, tendo em vista as possibilidades de inundações, enxurradas e deslizamentos de encostas. Ainda, quando se consideram as mudanças climáticas, há uma perceptível elevação dessa vulnerabilidade (BERTONE; MARINHO, 2013).

Sobre os danos humanos causados por inundações bruscas e alagamentos nas décadas de 90 e 2000, por região, tem-se que Sudeste, Sul e Nordeste, respectivamente, registram os maiores números de afetados. Esse tipo de desastre é responsável também por um grande número de pessoas desalojadas. As 1.069 mortes ocasionadas nesse período por esse tipo de desastre natural, estão assim distribuídas por região: Norte, $5 \%$. Nordeste, 21\%. Centro-Oeste, 1\%. Sudeste, $51 \%$ e Sul, 22\% (UNIVERSIDADE FEDERAL DE SANTA CATARINA, 2012).

Em 2008, setenta e oito mil pessoas ficaram desalojadas ou desabrigadas e 135 perderam suas vidas na região do Vale do Itajaí, por causa de inundações e deslizamentos, no pior desastre natural do Estado de Santa Catarina. Em 2010, 97 municípios nos Estados de Pernambuco e de Alagoas, foram atingidos pela cheia do Rio Mundaú, que desabrigou ou desalojou mais de 150 mil habitantes e provocou a morte de 47 pessoas. Em fevereiro de 2015, o estado do Acre foi assolado por fortes chuvas que causaram o transbordamento de rios em cidades como Rio Branco e Basileia. Em julho do mesmo ano os estados do Rio Grande do Sul e Santa Catarina também foram castigados por cheias de rios em decorrência de um volume de chuva bastante acima do esperado.

Entretanto, o maior desastre natural do país em número de mortos ocorreu no ano de 2011. Os deslizamentos e enxurradas na Região Serrana do Estado do Rio de Janeiro deixaram novecentas e doze pessoas mortas, além de trezentos e cinquenta desaparecidas e quarenta e cinco mil desabrigadas e desalojadas. Considerado como um megadesastre esse foi um evento de dimensões catastróficas na história 
do Brasil (BERTONE; MARINHO, 2013; BRASIL, 2012b). Esse desastre natural somou-se a muitos outros ocorridos no ano de 2011, trazendo impactos significativos para a sociedade brasileira de maneira geral.

No ano de 2011, ocorreram 795 desastres naturais no país, que causaram 1.094 mortes e afetaram 12.535.401 pessoas. A região sudeste foi a que sofreu o maior impacto pelo poder de destruição desses desastres em 2011, sendo que a quantidade de óbitos que foi identificada nessa região é 7,29 vezes maior do que a que foi verificada nas outras quatro regiões juntas. Muito dessa situação deve-se ao ocorrido na Região Serrana do Rio de Janeiro, conforme já mencionado (BRASIL, 2012b).

Em se tratando especificamente das inundações e enxurradas, boa parte do problema encontra explicação no fato de que a ocupação do solo nas cidades se deu em grande medida, junto às regiões ribeirinhas. Com o passar do tempo e o aumento da impermeabilização do solo em função do asfalto e construções, houve uma facilitação da ocorrência de enchentes e a consequente ampliação dos casos de inundações e alagamentos. A alteração na cobertura vegetal em áreas rurais contribui também para a intensificação do problema ao acarretar a modificação da dinâmica das águas na bacia e dos condicionantes do ciclo hidrológico. Em decorrência, os rios são impactados quanto à quantidade e a qualidade da água e ainda sofrem o chamado assoreamento (BERTONE; MARINHO, 2013).

O problema dos deslizamentos, por sua vez, está baseado na ocupação inadequada das chamadas áreas de risco geológico potencial. A ausência de infraestrutura urbana, marca registrada dos assentamentos precários em áreas íngremes, que não contam com sistemas adequados de drenagem, aliada à ausência de taludes e contenções em cortes e aterros instáveis, à fragilidade das construções e aos inúmeros depósitos de lixo que existem nas encostas, acabam por deixar essas áreas ainda mais vulneráveis, tornando-as suscetíveis a deslizamentos, especialmente nas épocas de chuvas intensas e prolongadas (BERTONE; MARINHO, 2013).

Mas nem por isso, os terrenos legalmente ocupados deixam de oferecer riscos de deslizamentos, já que, de forma geral, o conhecimento adequado do comportamento do meio físico, parece ainda não ter sido incorporado a planos diretores urbanos, leis 
de uso e ocupação do solo ou ao processo de licenciamento dos novos parcelamentos do solo (BERTONE; MARINHO, 2013).

Considerando esse histórico de desastres naturais de grande magnitude ocorridos no Brasil nos últimos anos, o governo federal tem buscado a implantação de diversas ações visando à prevenção e resposta a desastres de forma mais efetiva. Observa-se, nesse sentido, a criação do Centro Nacional de Monitoramento e Alertas de Desastres Naturais (CEMADEN), em 2011, vinculado ao Ministério de Ciência, Tecnologia e Inovação (BRASIL, 2012a).

O CEMADEN atua de forma integrada ao Centro Nacional de Gerenciamento de Risco e Desastres (CENAD), vinculado à Secretaria Nacional de Defesa Civil. Além disso, pode-se mencionar a Força Nacional de Apoio Técnico de Emergência, organismo interministerial criado em 2012 e composto por 50 especialistas, sendo 35 geólogos e 15 hidrólogos, alocados em áreas consideradas de alto risco de desastres (BERTONE; MARINHO, 2013; BRASIL, 2012a)

Dados do Ministério do Planejamento revelam que os investimentos governamentais na resposta a desastres aumentaram significativamente entre 2004 e 2010, passando de 130 milhões para 3 bilhões e 45 milhões de reais (BERTONE; MARINHO, 2013).

Como resultado do trabalho de um grupo especial constituído em 2011, pelo governo federal, foi elaborado o Plano Nacional de Gestão de Riscos e Resposta a Desastres (PNGRD). Na mesma data de seu lançamento, 08 de agosto de 2012, foi inaugurado o CENAD. Era previsto o investimento de $\mathrm{R} \$ 18,8$ bilhões para a implantação do plano, até o final de 2014 (BRASIL, 2013).

Assim, são muitos os órgãos federais que atuam nas diferentes fases de gestão dos desastres naturais no Brasil, sendo que a estrutura ainda se complementa pela atuação indireta de outras várias instituições. Normalmente tais catástrofes geram graves consequências locais, mas muitas vezes também regionais, implicando na necessidade de atuação de uma rede governamental que seja capaz de agir em diferentes frentes (BERTONE; MARINHO, 2013).

A Lei Federal no 12.608, de 10 de abril de 2012 é a que institui a Política Nacional de Proteção e Defesa Civil (PNPDEC) e dispõe sobre o Sistema Nacional de Proteção 
e Defesa Civil (SINPDEC) e o Conselho Nacional de Proteção e Defesa Civil (CONPDEC) (ESPÍRITO SANTO, 2014).

A referida lei estabelece a necessidade de criação dos Sistemas Estaduais de Proteção e Defesa Civil (SIEPDECs), cuja gestão é de responsabilidade dos governos estaduais, e é exercida pelas Coordenadorias Estaduais de Proteção e Defesa Civil (CEPDECs) em seu nome. Essas são responsáveis pelo acompanhamento dos órgãos de Defesa Civil dos municípios. Neles, devem existir as Coordenadorias Municipais de Proteção e Defesa Civil (COMPDECs). De acordo com dados da FGV, $70 \%$ dos municípios brasileiros possuem COMPDECs formalizadas. Existem também as Coordenadorias Regionais de Proteção e Defesa Civil (REPDECs). No Espírito Santo, o Decreto no 3.430-R, de 06 de novembro de 2013, regulamenta a gestão do SIEPDEC (ESPíRITO SANTO, 2014).

A PNPDEC estabelece cinco tipos de ações ou fases distintas para a gestão de riscos e desastres naturais: Prevenção, Mitigação, Preparação, Resposta e Recuperação. É preciso destacar o aspecto cíclico da dinâmica dessas etapas, que não devem, portanto, ser concebidas de forma linear. A figura 7 apresenta 0 esquema cíclico de tais ações.

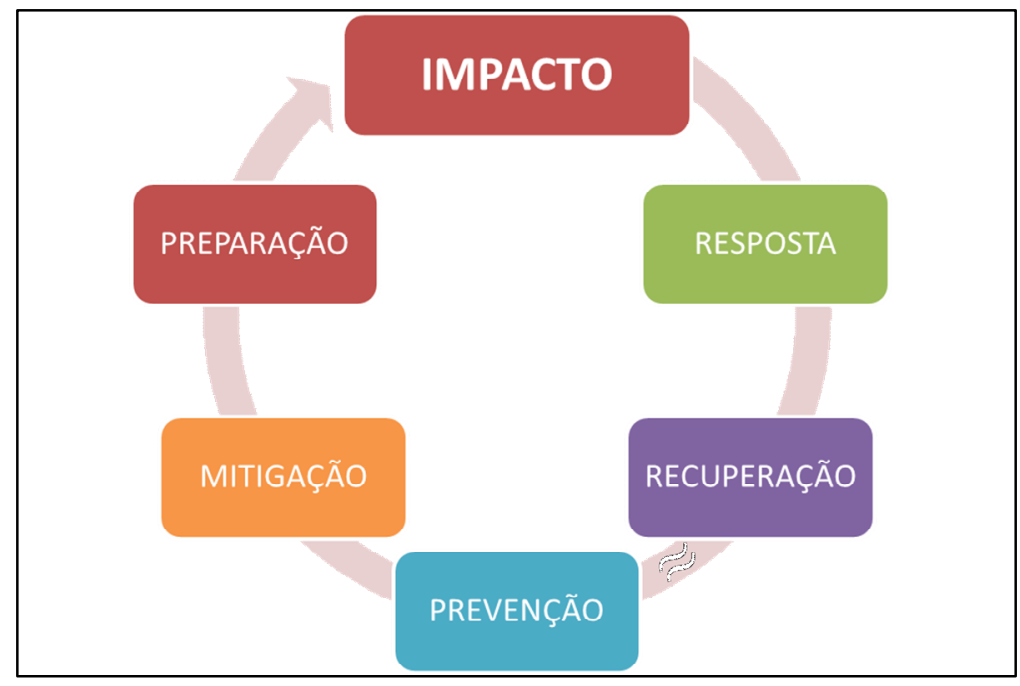

FIGURA 7 - DINÂMICA DOS DESASTRES

Fonte: Shadeck (et. al., 2013).

A prevenção se configura como o conjunto de ações que visam a evitar que o desastre aconteça e abrange duas linhas principais: a avaliação de riscos de desastres e a redução de riscos de desastres. Essa etapa ocorre em períodos de 
normalidade, quando ainda não existe o evento de desastre, apenas seu risco. A prevenção representa, portanto, a primeira fase da administração de um desastre.

Avaliações de risco caracterizam-se como o estudo das ameaças de desastres que podem atuar sobre determinada área, bem como do grau de vulnerabilidade desses sistemas considerados sensíveis. A redução de riscos, por sua vez, consiste das ações envolvendo medidas não estruturais e medidas estruturais para diminuir a vulnerabilidade dos sistemas (SHADECK et.al., 2013)

Por mais que sejam tomadas ações no sentido da redução de riscos de desastres, admite-se que sempre haverá o chamado risco residual, ou seja, as ações de redução não são capazes de levar o nível de risco a zero. Por isso, existem as ações de mitigação, a segunda fase da gestão de desastres, que visam a tratar o risco residual e minimizar a magnitude de impactos de eventos extremos, diminuindo, com isso, a intensidade de suas consequências. A utilização de sistemas de monitoramento de eventos naturais encontra-se no rol das ações de mitigação (SHADECK et.al., 2013).

A fase de preparação se relaciona às ações voltadas para a melhoria da capacidade da comunidade, o que inclui indivíduos, organizações governamentais e organizações não governamentais, para atuação diante de situações de desastre natural (OLIVEIRA, 2010). É a terceira fase da administração do desastre. Considerando as informações advindas das atividades de monitoramento e a iminência do desastre, as ações de preparação devem ser iniciadas para que se poupe vidas e se reduza danos e prejuízos (SHADECK et.al., 2013).

A resposta constitui uma série de ações com o objetivo de prestar socorro e auxílio às pessoas atingidas, reduzir os danos e prejuízos e garantir o funcionamento dos sistemas essenciais da comunidade (OLIVEIRA, 2010). Trata-se da situação mais imediata ao impacto, onde se dá o desenvolvimento de atividades de assistência à população vitimada, por meio de atividades logísticas, assistenciais, e de promoção da saúde. Busca-se também promover a estabilização do quadro geral para que se evite um agravamento da situação (ESPÍRITO SANTO, 2014). 
A reconstrução é a última fase da gestão do desastre e consiste em ações voltadas para reconstruir a comunidade atingida, com vistas ao retorno a uma condição de normalidade, buscando continuamente a minimização de novos desastres.

Conforme já mencionado, o foco desta pesquisa está nas ações de resposta aos desastres naturais. Especificamente sobre elas, é preciso que se reconheça a importância dos planos de contingência. Tais planos necessitam prever a composição geral do grupo de organizações envolvidas na resposta aos desastres naturais, bem como as respectivas responsabilidades de cada uma delas. O Estado do Espírito Santo foi um dos pioneiros do país na construção de seu Plano Estadual de Proteção e Defesa Civil (ESPÍRITO SANTO, 2014).

Entretanto, apesar da existência desse planejamento, muitos problemas ainda ocorrem no momento da execução das ações de resposta propostas nos planos, sendo que questões relacionadas a comando e controle são pontos bastante centrais e muitas vezes deficientes, nesses contextos (OLIVEIRA, 2010).

Nesse sentido, tem sido bastante utilizada pelos órgãos governamentais responsáveis, uma ferramenta gerencial padronizada para responder aos desastres, denominada Sistema de Comando em Operações (SCO), conforme já mencionado. O SCO possui, entre outros objetivos, permitir que as esferas federal, estadual e municipal atuem de maneira integrada com o setor privado e também com organizações não governamentais.

O SCO baseia-se nos princípios centrais da Administração, tendo como funções básicas o planejamento, a organização, a direção (liderança) e o controle, configurando-se como uma ferramenta gerencial para tratamento de situações críticas. Na conceituação de Oliveira (2010, p. 23) o SCO é "uma ferramenta gerencial (modelo) de concepção sistêmica e contingencial, que padroniza as ações de resposta em situações críticas de qualquer natureza ou tamanho."

Conforme destaca o autor, existe uma importante diferença entre emergências e situações críticas. As emergências são situações que exigem intervenções rápidas, mas que podem ser atendidas pelos recursos disponíveis, sem a necessidade de procedimentos extraordinários. Já as situações críticas exigem, além de uma 
intervenção imediata, também uma postura não rotineira para o gerenciamento integrado das ações de resposta.

As situações críticas, ou de crise, são essencialmente de alto risco, dinâmicas, complexas e confusas. OLIVEIRA (2010) assim descreve tal caracterização:

\begin{abstract}
Alto risco: os riscos decorrentes de situações críticas são elevados e a possibilidade de que resultados indesejados se concretizem é sempre grande. O risco elevado pode representar lesões, mortes, pessoas desabrigadas, desalojadas, danos a propriedade ou ao meio ambiente.

Dinâmicas: os cenários se modificam com muita rapidez, às vezes de maneira surpreendente, em função da interação complexa de múltiplos fatores tais como o clima, a temperatura, o vento, a luminosidade, 0 comportamento das pessoas, etc.

Complexas: situações críticas são complexas porque envolvem situações de elevada complexidade (resgates técnicos, controle de derramamento de produtos perigosos, evacuação de populações, triagem e socorro de múltiplas vítimas, gerenciamento de crises policiais) e também porque exigem a intervenção de múltiplas organizações com responsabilidades e jurisdições diferenciadas.

Confusas: situações críticas são confusas porque a falta de informações faz com que o cenário pareça fragmentado, surgem deficiências de comunicação entre os envolvidos, sobrecarga no comando da operação, prioridades e objetivos comuns nem sempre são estabelecidos e os recursos disponíveis não são compartilhados de forma adequada (OLIVEIRA, 2010, p. 21)
\end{abstract}

Considerando tais características das situações críticas é que se busca, por meio do SCO, a utilização de procedimentos gerenciais padronizados que permitam uma melhor utilização de recursos, a otimização de resultados e a maior segurança de todos os envolvidos em ações de resposta a desastres.

Dessa forma, o SCO é baseado em uma cadeia de comando, ou seja, em uma linha ininterrupta de autoridade que liga as pessoas atuantes no sistema. Tal comando pode ser do tipo único, quando apenas uma pessoa comanda todo o sistema, representando uma única organização, ou do tipo unificado, onde existe uma abordagem mais cooperativa, em que representantes de diferentes organizações envolvidas nas ações de resposta atuam de forma conjunta.

A estrutura organizacional padronizada de um SCO está destacada na figura 8. Em sua implantação pode ocorrer certa flexibilização, quando apenas algumas das funções são ativadas em função dos objetivos da operação, especificamente (OLIVEIRA, 2010). 


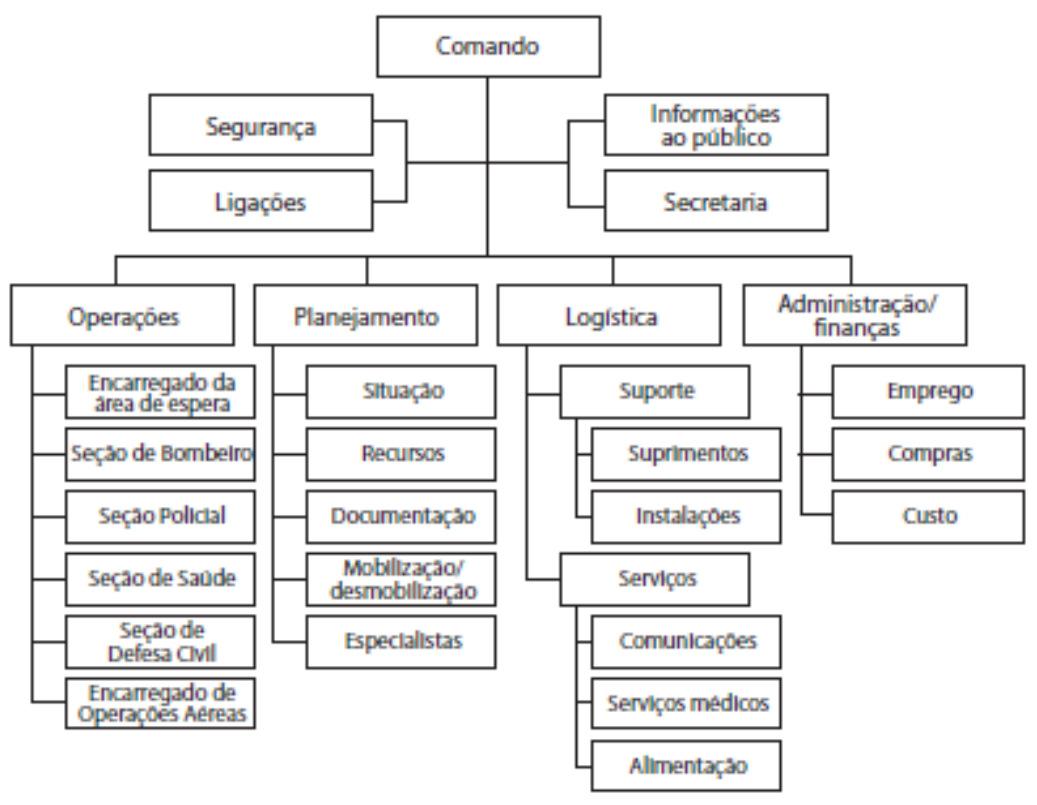

FIGURA 8 - ESTRUTURA ORGANIZACIONAL PADRÃO DO SCO Fonte: Oliveira (2010).

O sistema prevê o gerenciamento integrado de informações e inteligência, visando à obtenção, julgamento, processamento útil e compartilhamento de informações com outros. Nas situações de menor complexidade, recomenda-se o uso de formulário padronizado, cuja nomenclatura dentro do sistema é SCO 201, para coleta e consolidação de dados iniciais de inteligência. Já em momentos de maior complexidade e repercussão, pode-se fazer necessária uma unidade de situação, ligada diretamente ao planejamento, com a finalidade de integrar informações, produzir inteligência e manter atualizados os quadros de situação. Durante uma eventual troca de comando, a transmissão de informações necessárias deve ser realizada por meio de formulário padronizado, preenchido pelo próprio comando (OLIVEIRA, 2010).

Atualmente, o Corpo de Bombeiros Militar do Estado do Espírito Santo (ES) também faz uso do SCO nos processos de resposta a desastres naturais, conforme ocorreu nas fortes chuvas de dezembro de 2013. A seguir, apresenta-se um panorama sucinto da situação relativa aos desastres naturais no estado. 


\subsubsection{Desastres Naturais no ES}

O ES foi um dos estados pioneiros na elaboração do PEPDEC, (ESPÍRITO SANTO, 2014) instituído pelo Decreto Estadual № 3.140-R, de 30 de outubro de 2012, atualmente em sua quarta atualização.

Em grande medida, os processos geradores de desastres naturais no ES estão relacionados a fatores bastante semelhantes aos ocorridos no restante do Brasil. Planejamento urbano deficiente e crescimento rápido e desordenado das cidades, em sua maioria iniciado às margens de rios, são alguns exemplos. A deficiência na drenagem urbana associada à existência de resíduos sólidos com disposição irregular estão também entre os fatores que aumentam a vulnerabilidade do estado a desastres naturais (ESPÍRITO SANTO, 2010; 2014).

O ES possui relevo dividido em duas principais regiões: uma planície litorânea e os planaltos, configurados como zonas montanhosas, onde fluem numerosos cursos d'água nascidos na própria região pelo elevado volume de precipitação ali localizado. As precipitações elevadas possuem como principal efeito desastroso os deslizamentos que normalmente são responsáveis pelos danos humanos mais graves, levanto até mesmo à morte de pessoas.

Cinquenta e oito municípios do ES, eleitos em prioridade pela Defesa Civil em função de seu histórico de desastres, já possuem o mapeamento de risco geológico. Trata-se de parte de um projeto coordenado pelo Serviço Geológico Nacional (CPRM), em todo o país e envolve parcerias com Governo Federal para o diagnóstico e mapeamento das áreas de risco considerado alto e muito alto. $\mathrm{O}$ objetivo é criar uma interface geográfica unificada, disponível à população para consulta, conforme estabelece a PNPDEC. A realização dessa tarefa decorre de parceria com o Sistema Integrado de Bases Geoespaciais do Espírito Santo (GEOBASES), pertencente ao Instituto Capixaba de Pesquisa Assistência e Extensão Rural (INCAPER) (ESPÍRITO SANTO, 2014).

Desde 2012 o ES também possui um Atlas de Vulnerabilidade às Inundações, porém apenas para as aquelas do tipo gradual. $O$ documento foi elaborado a partir de metodologia inicialmente desenvolvida pela Agência Nacional de Águas (ANA), 
de forma participativa, envolvendo a Defesa Civil Estadual e os municípios, por meio das COMPDECs. Importante destacar que, dessa maneira, o Atlas incorpora o conhecimento que as comunidades locais possuem acerca do comportamento das inundações dos rios de cada região, como áreas inundáveis, frequência e grau de impacto (ESPÍRITO SANTO, 2013, 2014).

Em termos de monitoramento e alerta, o ES conta com o INCAPER e o CEMADEN como principais fontes de informações meteorológicas. O INCAPER reúne informações de diferentes instituições que atuam com meteorologia e recursos hídricos no estado, subsidiando a Defesa Civil com informações e alertas meteorológicos. O CEMADEN atua em todo o território nacional com um sistema de previsão de ocorrência de desastres naturais. No ES, 52 municípios são monitorados pelo CEMADEN, correspondendo a aproximadamente $40 \%$ do estado (ESPÍRITO SANTO, 2014).

Um estudo realizado pela Defesa Civil Estadual sobre os dados relativos aos 898 registros de desastres naturais ocorridos no ES entre os anos de 2000 e 2013 levaram à conclusão de que são sete os tipos de desastres mais recorrentes no estado: inundações, enxurradas, estiagem, vendavais, granizo, deslizamentos e erosão marinha (ESPÍRITO SANTO, 2010, 2014). O quadro 3, a seguir, apresenta uma descrição sucinta de cada um desses tipos de desastres naturais.

\begin{tabular}{|c|c|}
\hline TIPO DE DESASTRE & DESCRIÇĀO \\
\hline INUNDAÇÃO GRADUAL & $\begin{array}{l}\text { Transbordamento paulatino de água da calha normal de rios e lagos, } \\
\text { ou acumulação de água por drenagem deficiente em áreas que não } \\
\text { são habitualmente submersas. }\end{array}$ \\
\hline ENXURRADA & $\begin{array}{l}\text { Possui causas e efeitos semelhantes à inundação gradual, porém } \\
\text { advém de escoamentos superficiais com grande velocidade e energia, } \\
\text { resultante de fortes chuvas. }\end{array}$ \\
\hline ESTIAGEM & $\begin{array}{l}\text { Período prolongado de baixa pluviosidade ou sua ausência, em que a } \\
\text { perda de umidade do solo é superior à sua reposição. }\end{array}$ \\
\hline VENDAVAL & $\begin{array}{l}\text { Deslocamento violento de uma massa de ar. Forma-se, normalmente, } \\
\text { pelo deslocamento de ar de área de alta para baixa pressão. }\end{array}$ \\
\hline GRANIZO & $\begin{array}{l}\text { Precipitação sólida de grânulos de gelo, transparentes ou translúcidos, } \\
\text { de forma esférica ou irregular, raramente cônica, de diâmetro igual ou } \\
\text { superior a } 5 \mathrm{~mm} \text {. }\end{array}$ \\
\hline
\end{tabular}


(conclusão)

\begin{tabular}{|l|l|}
\hline DESLIZAMENTOS & $\begin{array}{l}\text { Fenômeno provocado pelo Escorregamento de materiais sólidos, como } \\
\text { solos, rochas, vegetação e/ou material de construção ao longo de } \\
\text { terrenos inclinados, denominados encostas, vertentes ou escarpas. }\end{array}$ \\
\hline EROSÃO MARINHA & $\begin{array}{l}\text { Resultado do movimento das águas oceânicas que atuam sobre as } \\
\text { bordas litorâneas, modelando o relevo de forma destrutiva. Esse } \\
\text { movimento pode, também, modelar o relevo de forma construtiva, } \\
\text { resultando em acumulação marinha e, consequentemente, dando } \\
\text { origem a praias, restingas, recifes e tômbulos. }\end{array}$ \\
\hline
\end{tabular}

QUADRO 3 - DESASTRES NATURAIS RECORRENTES NO ES ENTRE 2000 E 2013 Fonte: Espírito Santo (2014).

Dentre esses principais tipos de desastres, as estiagens costumam atingir o ES com bastante frequência, sendo o segundo tipo de desastre com maior incidência, correspondendo a 77 registros no período analisado. Em termos de perdas humanas, as estiagens costumam ser menos catastróficas, porém ainda capazes de trazer inúmeros prejuízos econômicos e sociais, especialmente pelos problemas causados à produção agrícola de forma geral. Mas são as enxurradas as responsáveis pelo maior número de ocorrências, com 473 registros. Elas costumam possuir um efeito devastador que vai além da ação direta da água, já que provocam também deslizamentos de terra (ESPÍRITO SANTO, 2014).

Conforme já mencionado, as fortes chuvas ocorridas em dezembro de 2013, em um período de apenas 15 dias, afetaram fortemente a população do $\mathrm{ES}$, algo que não se via desde 1979. O município de Rio Bananal foi um dos primeiros e mais fortemente atingidos, conforme se pode observar pela fotografia 1.

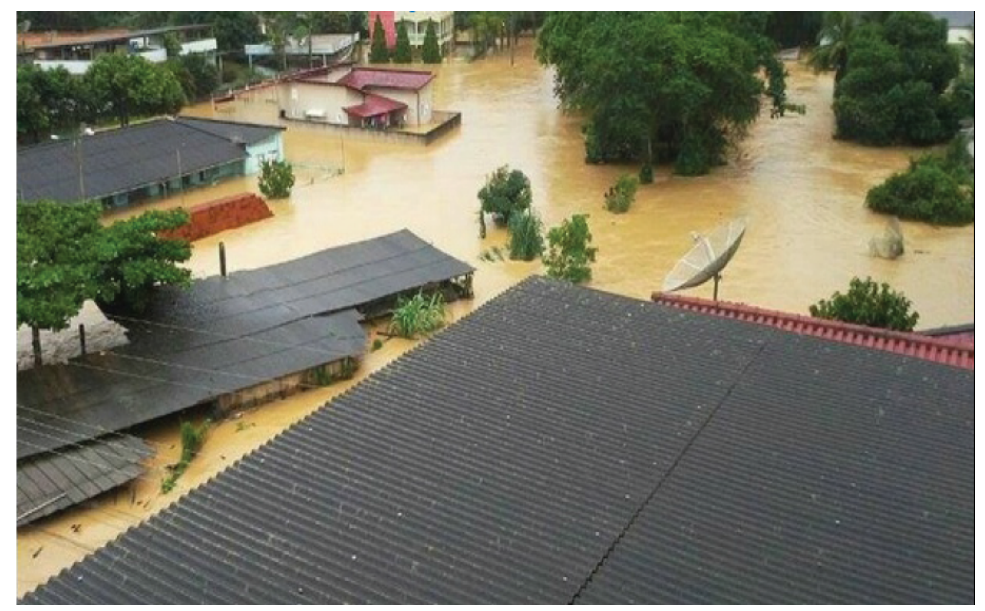

FOTOGRAFIA 1 - INUNDAÇÃO NO MUNICÍPIO DE RIO BANANAL DEZEMBRO DE 2013

Fonte: Espírito Santo (2014). 
A partir da análise da observação dos dois próximos gráficos (gráfico 1e gráfico2), é possível perceber o grande impacto que as chuvas de 2013 trouxeram ao estado, também em termos de desabrigados, desalojados e, especialmente, em número de mortes.

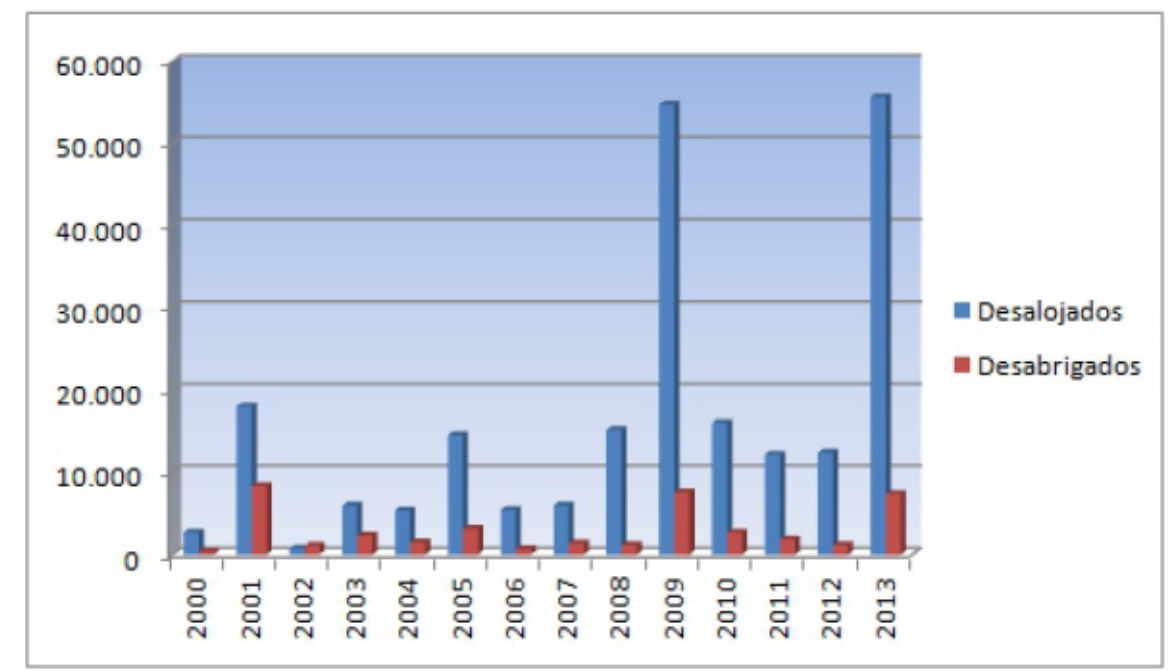

GRÁFICO 1 - NÚMERO DE PESSOAS DESABRIGADAS E DESALOJADAS EM DESASTRES NO ES - 2000 A 2013

Fonte: CEPDEC/ES apud Espírito Santo (2014).

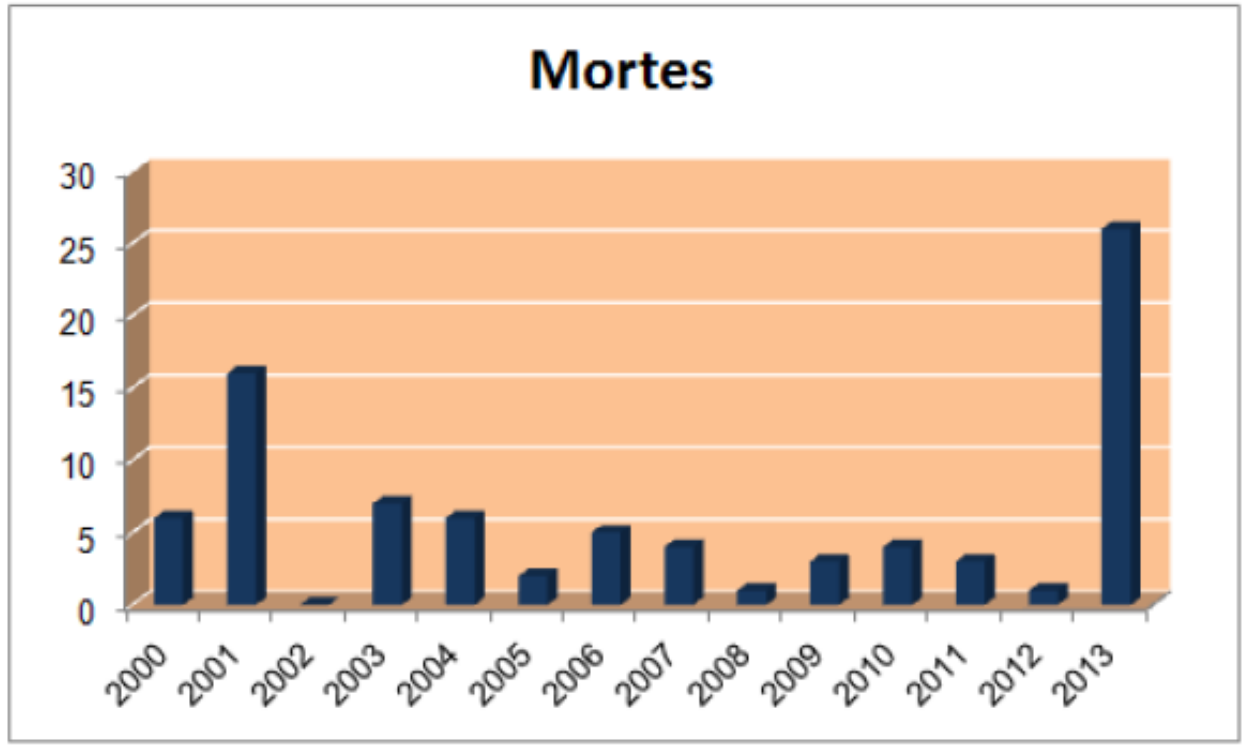

GRÁFICO 2 - NÚMERO DE PESSOAS MORTAS EM DESASTRES NO ES - 2000 A 2013 Fonte: CEPDEC/ES apud Espírito Santo (2014).

As 24 mortes ocorridas em dezembro de 2013 não puderam ser evitadas apesar de todos os esforços da Defesa Civil Estadual e das ações de prevenção e monitoramento de vulnerabilidades em andamento. A fotografia 2 mostra um deslizamento ocorrido no Bairro São Marcos, no município de Colatina, em 24 de dezembro de 2013, onde sete pessoas perderam a vida. 


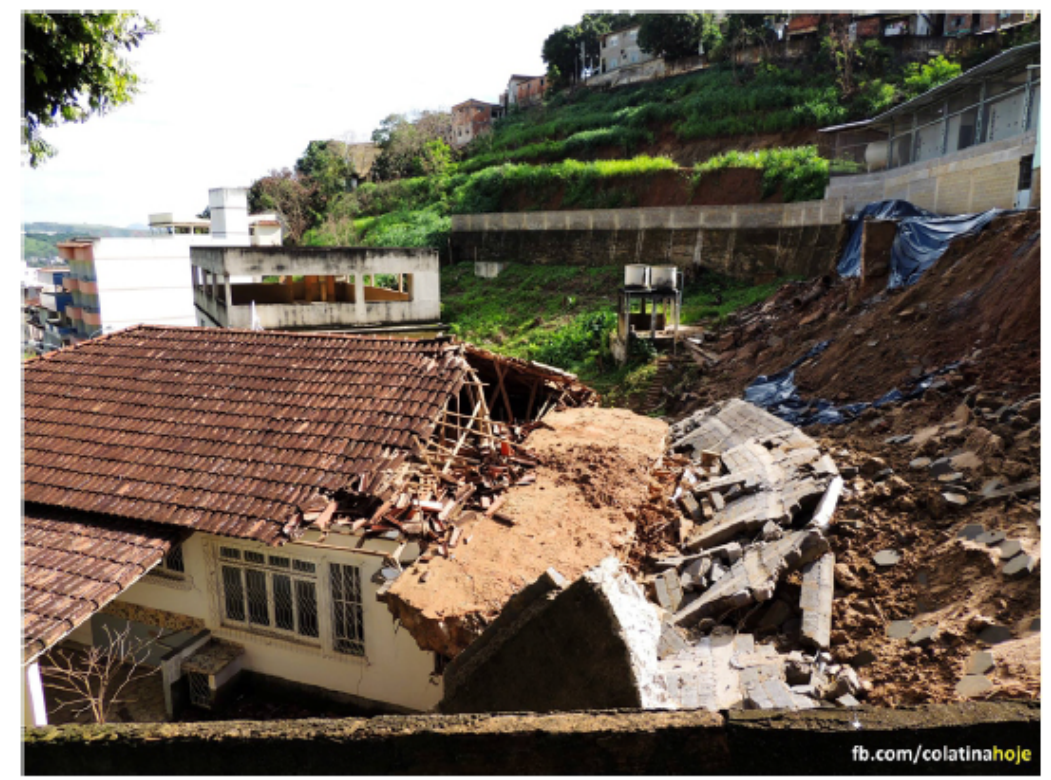

FOTOGRAFIA 2 - DESLIZAMENTO EM COLATINA - DEZEMBRO DE 2013 Fonte: fb.com/colatinahoje apud Espírito Santo (2014).

Entre os 78 municípios capixabas, 55 registraram situação de emergência no período, conforme se pode observar no mapa 1 , a seguir.

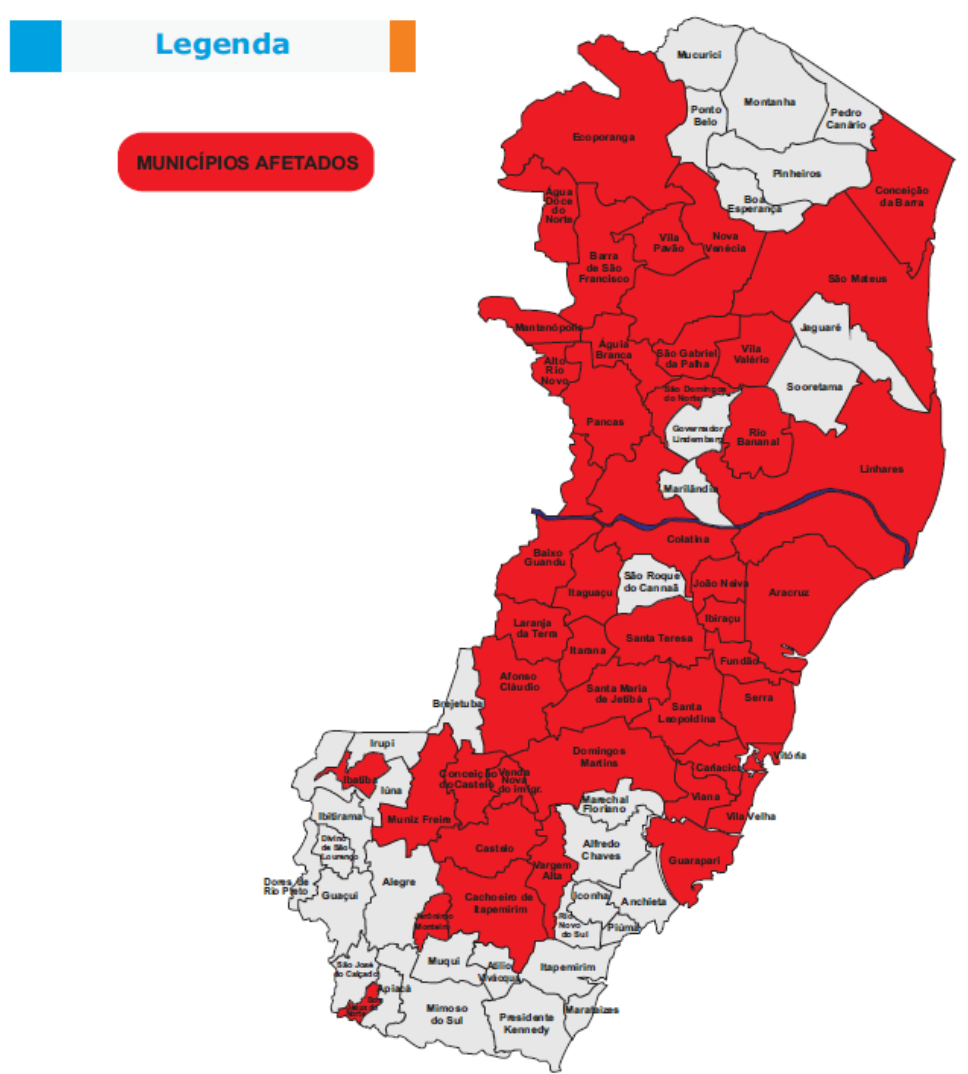

MAPA 1 - MUNICÍPIOS AFETADOS PELAS ENXURRADAS DE DEZEMBRO DE 2013 NO ES Fonte: Espírito Santo (2014). 
O Decreto Estadual no 3.140-R, de 30 de outubro de 2012 constituiu o Comitê Estadual de Combate às Adversidades Climáticas no ES. Trata-se de um grupo executivo composto por representantes de diferentes instituições do estado, cuja função principal é atuar em ações de prevenção e resposta a desastres (ESPÍRITO SANTO, 2014).

O Comitê deve atuar de maneira integrada, sob o controle e a coordenação da CEPDEC e da Casa Militar. Cada um dos órgãos componentes administra seus recursos, a partir da utilização de sua infraestrutura, e presta informações acerca de suas ações aos órgãos coordenadores. São os seguintes os órgãos que compõem o Comitê no ES, retratados na figura 9 :

- Secretaria da Casa Militar (SCM);

- Secretaria de Estado de Assistência Social e Direitos Humanos (SEADH);

- Secretaria de Estado da Saúde (SESA);

- Serviço de Atendimento Móvel de Urgência (SAMU 192);

- Secretaria de Estado da Educação (SEDU);

- Secretaria de Estado da Agricultura, Abastecimento e Pesca (SEAG);

- Instituto Capixaba de Pesquisa, Assistência Técnica e Extensão Rural (INCAPER);

- Instituto de Defesa Agropecuária e Florestal (IDAF);

- Secretaria de Estado de Saneamento, Habitação e Desenvolvimento Urbano (SEDURB);

- Secretaria de Estado do Meio Ambiente (SEAMA);

- Instituto Estadual de Meio Ambiente e Recursos Hídricos (IEMA);

- Superintendência Estadual de Comunicação (SECOM);

- Secretaria de Estado dos Transportes e Obras Públicas (SETOP);

- Departamento de Estradas de Rodagem (DER);

- Companhia Espírito Santense de Saneamento (CESAN);

- Autarquias ou Empresas Municipais de Saneamento;

- Polícia Militar do Estado do Espírito Santo (PMES);

- Corpo de Bombeiros Militar do Estado do Espírito Santo (CBMES); 
- Coordenadoria Estadual de Proteção e Defesa Civil (CEPDEC);

- Agência Estadual de Recursos Hídricos (AGERH);

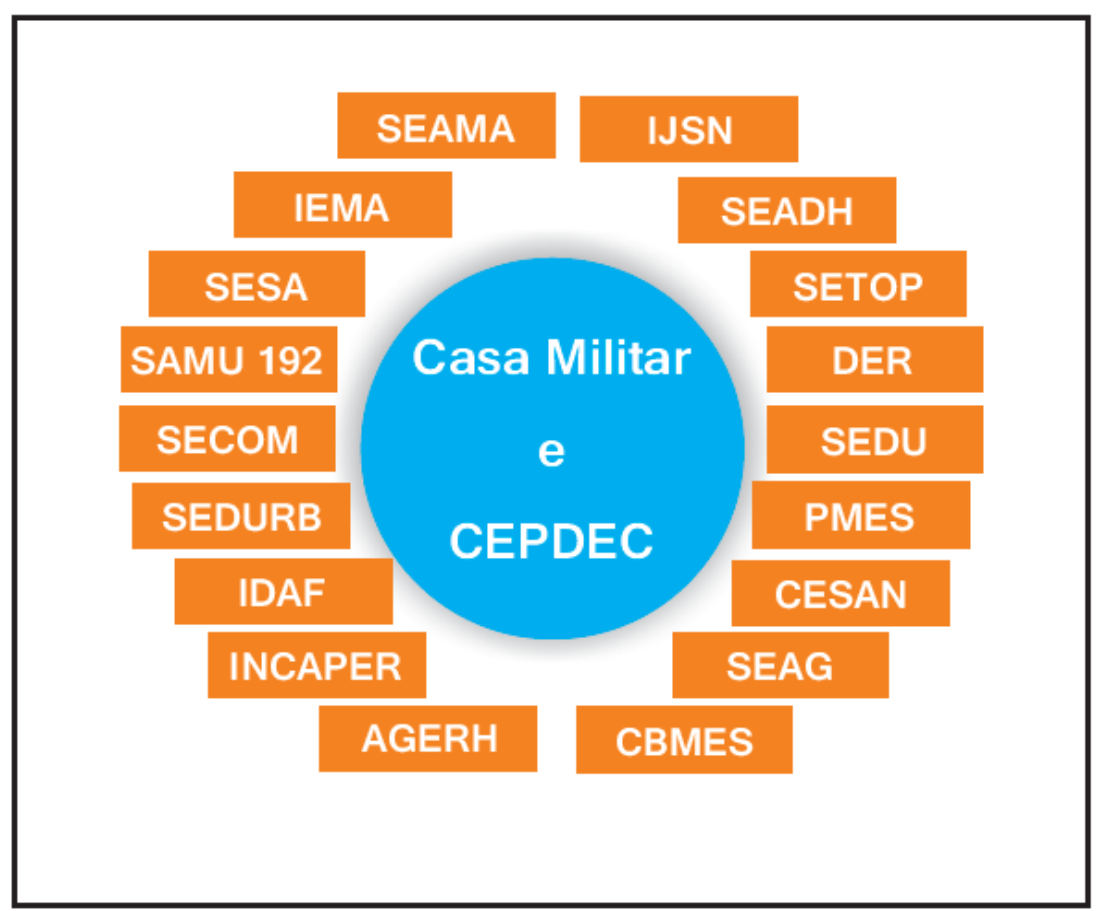

FIGURA 9 - ÓRGÃOS COMPONENTES DO COMITÊ ESTADUAL DE COMBATE ÀS ADVERSIDADES CLIMÁTICAS - ES

Fonte: Espírito Santo (2014).

Cada um dos órgãos possui atribuições claramente definidas para as fases de prevenção, preparação e resposta a desastres naturais, devidamente detalhadas no PEPDEC. Grupos de voluntários também são admitidos nessas ações, mediante celebração prévia de Termo de Cooperação Técnica, para adesão ao programa de voluntariado da CEPDEC. Atualmente, o programa prevê apenas convênios com pessoas jurídicas, como associações, institutos, empresas e organizações não governamentais.

Conforme tratam Beagrie (2009), Majchrzak, Jarvenpaa e Hollingshead (2007), Quarantelli (1993; 1995) e Voorhees (2008), a participação de grupos emergentes de voluntários é bastante comum em ações de resposta a desastres naturais e sua contribuição necessita ser considerada quando do planejamento de tais ações. É sobre essas questões que trata mais especificamente a próxima seção. 


\subsection{OS GRUPOS EMERGENTES NA RESPOSTA A DESASTRES NATURAIS}

A perspectiva utilizada na presente pesquisa parte da análise dos grupos emergentes na resposta a desastres naturais a partir de sua concepção como redes sociais. A caracterização mais detalhada de tais grupos está realizada mais a frente, nesta mesma seção, mas de maneira geral, pode-se considerar que esses grupos são, em suma, formados por pessoas que resgatam antigos relacionamentos e/ou estabelecem novos laços entre si, com a finalidade de desenvolvimento de ações específicas, atendimento de demandas e resolução de problemas na resposta a desastres, para além da ação das instituições oficiais envolvidas (QUARANTELLI, 1993; 1995).

Assim, compreende-se ser adequada a sua concepção como redes sociais, conforme discussões anteriores realizadas aqui, e, mais especificamente, de acordo com as conceituações de Marin e Wellman (2010) e Wasserman e Faust (2009), apresentadas na seção 2.5. Nesse sentido, as abordagens teóricas desenvolvidas a seguir permitem contextualizar e caracterizar as redes sociais atuantes em situações e resposta a desastres naturais.

Tem havido um aumento significativo das pesquisas acerca da fase de resposta a desastres, muito em decorrência do reconhecimento de que ações de resposta pobres ou inadequadas podem levar a catástrofes humanitárias ainda maiores do que aquelas já provocadas pelo próprio desastre (PAN; PAN; LEIDNER, 2012).

Conforme já mencionado na seção 3.1.1, o modelo tradicional e hierárquico de comando e controle, baseado no SCO é preconizado pelas instituições governamentais envolvidas nas atividades de resposta a desastres naturais no Brasil, tendo sido utilizado pela Defesa Civil Estadual, durante as ações de resposta ao desastre natural ocorrido no ES em dezembro de 2013.

Quarantelli (1993) destaca que esse reconhecimento dos padrões burocráticos de ação, parte de um pressuposto que considera que as respostas organizacionais aos desastres necessitam de tomadas de decisão centralizadas no topo das estruturas hierárquicas das instituições envolvidas, envolvendo assim, ações de comando e controle. 
Majchrzak, Jarvenpaa e Hollingshead (2007) também destacam que o modelo burocrático de ação, baseado em cadeias de comando, hierarquia e controle, continua sendo a abordagem mais comumente utilizada na coordenação da resposta organizacional a desastres de grande magnitude. Entretanto, segundo os mesmos autores, tal abordagem não é suficientemente adequada para acomodar uma situação de crise multidimensional típica dos grandes desastres.

É nesse sentido que Beagrie (2009) aponta que, na prática, as ações desenvolvidas no período mais imediato após o desastre raramente seguem tais padrões. As decisões são variadas, pluralísticas e tendem a ser descentralizadas aos níveis hierárquicos mais baixos das cadeias de comando organizacionais.

Para a autora, a incerteza, diversidade, baixa formalidade e descentralização são características estruturais típicas dos contextos de tomada de decisão pósdesastres. A improvisação é, por conseguinte, uma característica presente nas formas de respostas nesses contextos, em especial pelas condições sempre atípicas e diferenciadas de cada um deles.

De acordo com os estudos realizados por Quarantelli (1993), desde o aparecimento da literatura específica no final da década de 50 , os desastres vêm sendo caracterizados como fenômenos emergentes. Além disso, parece haver certos padrões de comportamentos sociais emergentes nos contextos pós-desastre, conforme já mencionado.

É preciso considerar a emergência tanto de novas formas de ação pelas organizações formais, quanto de novos grupos de atuação, como um processo natural num contexto pós-desastre. Sendo assim, é necessário incluir as possibilidades de surgimento de padrões emergentes de atuação, quando do planejamento da gestão de desastres (QUARANTELLI, 1993).

Voorhees (2008) destaca, inclusive, que a gestão de emergências deve incluir previsões para o gerenciamento de grupos emergentes de voluntários. Segundo o autor, falhas nesse planejamento podem desperdiçar o recurso valioso que é a ação dos voluntários, além de dificultar o esforço oficial de socorro. O planejamento deve conceber ações para como e quando utilizar os grupos de voluntários, caso eles apareçam. 
Em muitas situações, a falta de planejamento anterior ao desastre aliada às inúmeras demandas surgidas no pós-desastre, fazem com que a capacidade da comunidade para lidar com a situação seja excedida, contribuindo para a emergência de inúmeros grupos e ações não planejadas.

Nessa linha de percepção do fenômeno, Quarantelli e Dynes (1977) há algum tempo, vem chamando bastante atenção para a ideia de que os grupos, e não os indivíduos, têm sido a unidade básica de análise nos estudos sobre desastres, o que pode conduzir a questões bastante importantes e até mesmo fundamentais tanto do ponto de vista teórico quanto metodológico.

Nos contextos dinâmicos e turbulentos dos desastres, o formato em rede tem sido apontado como uma estrutura adequada para se atuar nos processos de resposta. São necessárias respostas rápidas e ao mesmo tempo flexíveis, além da execução de tarefas complexas em um curtíssimo espaço de tempo, condicionada ainda a inúmeros fatores adversos. Assim, diferentes grupos de atores normalmente se inserem nessa rede de resposta, como as organizações formais, as organizações sem fins lucrativos, além da sociedade civil de forma geral. Foi o que observaram Nolte e Boenick (2013) em sua análise do caso do terremoto no Haiti ocorrido em 2010:

A natureza do conjunto de atores é dependente da natureza do desastre.
No caso do Haiti, o país contou, em grande medida, com ajuda
internacional. Diferentes redes existiram durante a resposta ao terremoto do
Haiti, sendo que a maior delas era formada por variados clusters de ajuda
humanitária, coordenados pela ONU (NOLTE; BOENIGK, 2013, p. 150,
tradução nossa) Justi Junior e outros (2012) em seu trabalho de análise da rede interorganizacional de entidades formais envolvidas na gestão de uma enchente ocorrida na cidade de São José dos Campos, SP, apontam que o estudo das redes envolvidas em situações de gerenciamento de crises, como é o caso dos desastres naturais, pode abrir caminhos importantes para um melhor gerenciamento da tomada de decisão, especificamente no que diz respeito aos processos de comunicação e cooperação entre as entidades envolvidas nessas situações.

Sobre a importância das redes atuantes em desastres naturais, um bom exemplo é o trabalho de Barraket e outros (2013). Apesar de possuírem como foco de sua pesquisa a caracterização do voluntariado individual, os autores apontam para a 
importância dos relacionamentos estabelecidos pelos voluntários antes, durante e após a sua atuação na resposta ao desastre.

O Disasters Research Center (DRC), da Universidade de Delaware, nos Estados Unidos, desenvolveu uma tipologia para a caracterização dos tipos de resposta organizada aos desastres. Considerando-se tal tipologia, existem quatro tipos diferentes de organizações que atuam na resposta aos desastres: as organizações estabelecidas, as organizações expandidas, as organizações estendidas e os grupos emergentes (QUARANTELLI, 1993; RODRIGUEZ; TRAINOR; QUARANTELLI, 2006). Esses últimos, conforme mencionado, são o foco da presente pesquisa, concebidos como redes sociais, e analisados a partir do caso das chuvas de dezembro de 2013 no ES.

Assim, de acordo com a tipologia mencionada, em primeiro plano existem as organizações estabelecidas, aquelas que atuam formalmente e cumprem suas tarefas regulares, conforme suas estruturais normais. São exemplos: o corpo de bombeiros, a defesa civil, e demais instituições policiais civis e militares.

Em segundo lugar têm-se as chamadas organizações expandidas, aquelas que além de suas tarefas tradicionais, realizam certas alterações e expansões em suas estruturas normais de atuação. Organismos como a Cruz Vermelha e outras voltadas para a assistência social humanitária são exemplos. Fazem suas tarefas habituais, mas normalmente desenvolvem diferentes estruturas para suas finalidades.

As chamadas organizações estendidas são as do terceiro tipo. São aquelas que mantêm suas estruturas tradicionais, porém passam a desenvolver atividades não regulares ou não tradicionais, durante um desastre. É o caso, por exemplo, de uma construtora que se envolve em atividades de remoção de restos de demolição, após um terremoto. Sua estrutura se mantém inalterada, porém passa a desenvolver tarefas não rotineiras, diferentes de seu escopo original.

Os grupos emergentes são o quarto e último tipo e caracterizam-se como coletividades que não existiam antes do desastre. Trata-se de entidades sociais que desenvolvem uma nova estrutura para dar condições à execução de novas atividades. Um time informal de busca e resgate é um exemplo bastante típico desse 
formato emergente de grupo social em situações de pós-desastre. Os grupos emergentes, mesmo sendo de existência transitória, podem ser considerados cruciais, pois se responsabilizam pela execução de tarefas e o desenvolvimento de determinadas estruturas que os grupos ou organizações já estabelecidos poderiam não ser capazes de realizar naquele momento, mesmo se conseguissem ampliar suas estruturas de atuação (BEAGRIE, 2009; QUARANTELLI, 1993, 1995).

Barraket e outros (2013), baseando-se em Stallings e Quarantelli lembram ser importante distinguir entre pessoas que se voluntariam individualmente para ajudar nas ações de resposta e aqueles que formam grupos de cidadãos que atuam nas lacunas percebidas nesses contextos. Beagrie (2009) destaca que tais grupos são também conhecidos como grupos emergentes de cidadãos, organizações emergentes, grupos improvisados, grupos espontâneos ou grupos temporários ad hoc.

No contexto internacional, existem pesquisas acerca da atuação de tais grupos em resposta a desastres como o Furacão Katrina, em 2005, em Nova Orleans, EUA (MAJCHRZAK, JARVENPAA E HOLLINGSHEAD, 2007); os ataques terroristas de 11 de setembro de 2001 em Nova York, EUA; o Tsunami na Indonésia em 2004 e os incêndios na Austrália em 2009 (BARRAKET et.al. 2013; BEAGRIE, 2009).

Os grupos emergentes são efêmeros e também informais. Assim, muitas de suas características permanecem em constante transformação durante toda sua existência, como seus limites, seus membros, sua liderança, a natureza das tarefas e a divisão do trabalho. Isso torna bastante desafiadora a tarefa de sua investigação e compreensão (BEAGRIE, 2009).

Uma caracterização bastante semelhante vem de Majchrzak, Jarvenpaa e Hollingshead (2007) quando, baseados em pesquisas anteriores, apontam que tais grupos emergentes possuem limites fluidos e não muito claros. Além disso, a forma de adesão é fugaz e também incerta, e a liderança é bastante fluida e dispersa. As definições de atribuições e tarefas são altamente instáveis e as condições ambientais mudam continuamente. A dispersão geográfica entre os membros do grupo podem dificultar a comunicação. $O$ aprendizado decorre de aprender fazendo, ao invés de surgir de decisões baseadas em planejamento. Assim, a resolução de problemas se apresenta muito mais como resultado de improvisações. 
Essas características, aliadas à lógica da emergência, marcante na estruturação e atuação de tais grupos, reforçam ainda mais a sua concepção como redes sociais. Nas palavras dos referidos autores:

Como grupos emergentes de resposta aprendem fazendo, a coordenação torna-se oportunística, com líderes emergentes, normas emergentes, princípios de coordenação emergentes e canais de coordenação emergentes (MAJCHRZAK, JARVENPAA E HOLLINGSHEAD, 2007, p. 151, tradução nossa).

Como tais grupos atuam em situações críticas, buscam uma forma de coordenação que seja minimamente aceitável, que leve a ações rápidas, mesmo que outras mais efetivas sejam possíveis, mas demandem mais tempo e recursos.

De acordo com Quarantelli (1995) existem três condições básicas essenciais para que ocorra a emergência de tais grupos nas situações de desastres naturais. Seriam elas: a existência de uma condição social de suporte, de relacionamentos sociais relevantes antes da ocorrência do desastre e de determinados recursos específicos necessários à ação coletiva.

A ideia de condição social de suporte refere-se à existência de normas, valores e crenças partilhados entre os participantes e que de alguma forma os levam a compreensão de que é necessária uma ação coletiva naquele momento. Os relacionamentos sociais preexistentes, e facilitadores do processo, normalmente estão atrelados a laços familiares, de amizade, vínculos religiosos ou até mesmo de vizinhança. Os recursos específicos de que trata a terceira condição, são relativos não apenas à existência de fontes materiais e humanas para a execução das tarefas, como também de conhecimento relevante a ser aplicado na situação.

Em algumas ocorrências, a emergência de grupos que atuem coletivamente nas respostas a desastres pode ser compreendida como algo indesejado e até mesmo ruim para o processo. Algumas pesquisas sobre desastres naturais sustentam tal argumento, conforme destaca Quarantelli (1995). Isso se deve, muitas vezes, à crença de que algo que não tenha sido planejado e testado previamente, não pode ser bom, ou não pode dar certo em uma situação prática.

Assim, não é incomum a existência de conflitos entre as organizações formais e os grupos emergentes, quando passam a atuar conjuntamente numa rede de resposta. A coordenação dos grupos emergentes pode criar dificuldades para as organizações 
oficiais, levando a distrações e perda de tempo. Existe uma preocupação das organizações oficiais especialmente do ponto de vista da segurança e da proteção dos envolvidos na resposta ao desastre. É preciso, contudo, criar mecanismos para que se alcance sinergia nas atividades conjuntas dos dois tipos de organização, e esse permanece ainda como um grande desafio (BEAGRIE, 2009).

Existe uma relação direta entre a magnitude do desastre e a existência de organizações estendidas e de grupos emergentes envolvidos nas ações de resposta. Assim, considera-se que quanto maior a existência desses formatos de organização na resposta, mais severo e catastrófico terá sido o desastre (QUARANTELLI, 1993).

É essencial mencionar ainda que as ações coletivas desencadeadas de diversas formas nos contextos de resposta a desastre têm encontrado nas novas TICs um apoio fundamental. Elas têm atuado, por exemplo, como plataformas de comunicação para sobreviventes ou por pessoas que têm a intenção de prestar ajuda às vítimas. Nesse contexto, novos papeis e funções têm surgido à medida que as pessoas têm procurado a atuação online, para oferecer, buscar ou intermediar informações (PALEN et al., 2007).

Os estudos de Vieweg (et al., 2008) apontam para a existência de um fenômeno emergente e largamente distribuído de ação coletiva em comunidades altruísticas, voltadas para a solução de problemas em contextos pós-desastre e que tem sido, em grande medida, suportadas pelas novas TICs, especialmente por mídias sociais, como o Facebook.

Assim, as novas TICs têm colaborado de maneira fundamental com duas questões centrais nos processos de resposta a desastre: os fluxos de informação e a gestão das redes envolvidas. Num contexto mutável, onde são necessárias decisões rápidas, as informações precisam ser atualizadas constantemente. Além disso, a existência de sobrecarga de informações, de fontes restritas de informação e de questões como atrasos e incorreções são problemas com os quais os tomadores de decisão precisam lidar constantemente (PAN; PAN; LEIDNER, 2012).

Em seus estudos acerca de redes interorganizacionais de resposta a desastres, Pan, Pan e Leidner (2012) concluíram que o fluxo de informações está diretamente 
relacionado aos relacionamentos sociais existentes nas redes de atuação na resposta aos desastres. Nos contextos de crise, como os desastres naturais de grande magnitude, se faz necessária uma grande capacidade para contar com laços relacionais já existentes, mas também estabelecer novos laços de maneira rápida e consistente, de maneira a garantir um fluxo de informações adequado à necessidade do momento.

É nesse ponto que os argumentos de Quarantelli $(1993,1995)$ e Pan, Pan e Leidner (2012) encontram grande convergência. Segundo esses últimos, a informação, nos contextos de desastres, necessita mover-se rapidamente e através de uma variada gama de fontes. Entretanto, os canais de informação existentes nas estruturas formais de atuação são, não raro, muito lentos, desconectados e até mesmo inadequados para dar conta das necessidades existentes. Então, como resultado dessa realidade, outras formas de redes de resposta necessitam ser consideradas para que o fluxo de informações possa ser melhorado (PAN; PAN; LEIDNER, 2012).

$\mathrm{Na}$ mesma direção apontam Palen e outras (2007) quando descrevem as novas TICs como possibilidades para a viabilização de atividades não previstas, para o surgimento de novos grupos de atuação, e para o seu respectivo alinhamento com as organizações formais de resposta. Segundo as autoras:

[...] além da atenção às atividades formais de resposta - aquelas desenvolvidas pelas equipes de emergência para avaliar e gerenciar as crises e executar buscas e resgates - os usos de TICs que não foram anteriormente previstos estão emergindo agora. Especificamente, o papel exercido por membros do público em geral em desastres - um papel que sempre se caracterizou como um dos de alto envolvimento por parte dos sociólogos ao longo da história de quase um século de pesquisas sobre desastres - está se tornando mais visível, ativo e de posse de um alcance maior do que nunca se viu antes (PALEN et.al., 2007, p.727, tradução nossa).

Além disso, Palen e outras (2007) contextualizam a atuação dos grupos emergentes a partir da situação imediatamente após o ataque terrorista de 11 de setembro de 2001, nos Estados Unidos. Indivíduos e grupos locais se reuniram em forma de organizações temporárias e emergentes e atuaram em esforços improvisados de resgate e socorro imediato às vítimas. Moradores dos arredores providenciavam abrigo, roupas, cobertores e alimentação. As próprias vítimas, na medida de suas possibilidades, atuavam como voluntários. Congregações religiosas ajudavam prestando serviços de cuidado a crianças enquanto os pais saíam para providenciar 
o andamento burocrático do recebimento de suas apólices de seguros. Apenas para citar alguns exemplos.

Tais situações que fogem completamente da rotina, necessitam também de abordagens diferenciadas para sua análise, que sejam capazes de abarcar suas peculiaridades e dinamismos. É em razão disso que Varda e outros (2008) consideram que os modelos investigativos tradicionais em ciências sociais não são adequados para os contextos de desastres.

Desastres tem a habilidade de sacudir uma infraestrutura social inteira, transformando o que sabemos acerca de como as pessoas se relacionam, de como as organizações se comportam, e o sistema de suporte social e de recursos sociais, em novas questões que, se compreendidas, podem impactar significativamente na habilidade da sociedade de lidar com as consequências dos desastres (VARDA et al., 2008, p.13, tradução nossa )

Sendo assim, baseando-se no ocorrido após o Furacão Katrina em 2005, os autores propõem um modelo específico para o estudo das redes nessas situações.

O modelo está baseado numa estrutura que considera quatro parâmetros básicos, denominados In/Out/Seeker/Provider (IOSP), numa tradução livre Dentro/Fora/Buscador/Provedor. Optou-se por manter a utilização da sigla IOSP, bem como dos termos originais em inglês, para se tratar do modelo deste ponto em diante.

A aplicação dessa estrutura de investigação dos atores pode se dar em diversas fases da gestão de desastres, incluindo a mitigação, a resposta e a reconstrução. A figura 10 apresenta a descrição sucinta do modelo, onde podem ser observados os principais papeis e atributos dos atores num contexto pré e pós-desastre.

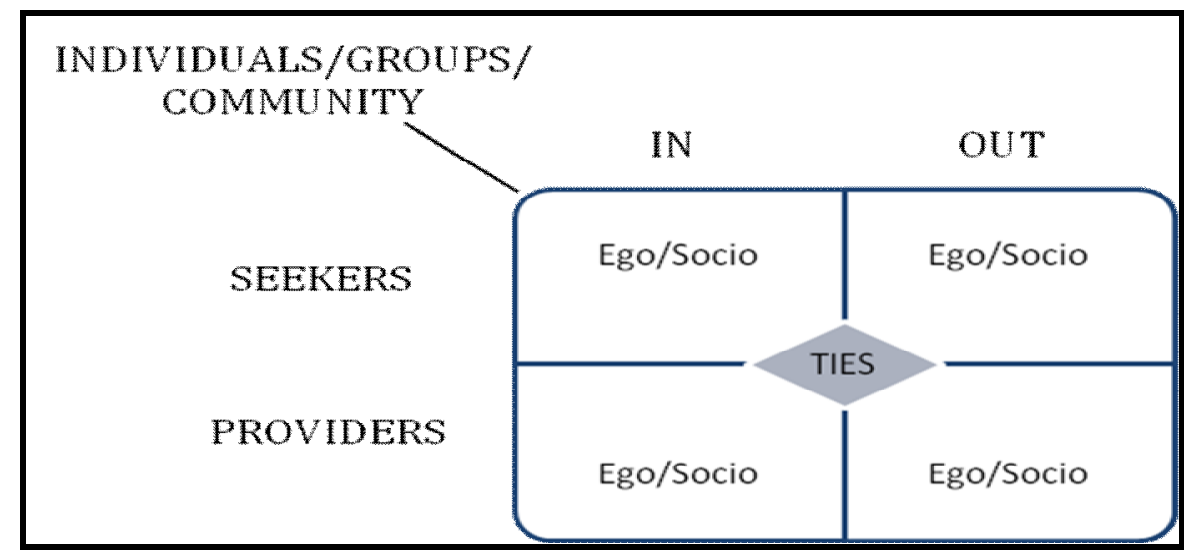

FIGURA 10 - ATORES DE REDES SOCIAIS EM CONTEXTOS DE DESASTRES MODELO IN/OUT/SEEKER/PROVIDER (IOSP)

Fonte: Varda e outros (2008) 
Como se observa na figura os atores podem ser indivíduos, grupos ou comunidades existentes na rede social. O eixo vertical descreve os papeis desempenhados por esses diferentes atores num contexto pré e pós-desastre. Nesse sentido, os atores podem ser provedores, ou seja, prestadores de serviços ou podem estar em busca de determinado serviço, apesar de em alguns casos o mesmo ator poder desempenhar os dois papeis dependendo de seus laços relacionais.

O eixo horizontal denota a localização espacial do ator, se dentro ou fora da área do desastre. Entretanto, como um contexto de desastre pode possuir fronteiras não muito claras e também como um ator pode se mover continuamente para dentro ou para fora da área afetada, mais uma vez o mesmo ator pode fazer parte dos dois quadrantes.

Do ponto de vista de ambos os eixos, as redes podem ser estudadas tanto como redes ego, quanto como redes inteiras. Isso dependerá da estrutura das questões de pesquisa a serem respondidas.

Assim, Varda e outros (2008) definem da seguinte forma os quadrantes:

Quadrante 1: In/Seekers: Membros da rede que estão localizados na área do desastre e que estão em busca de algo na rede. O exemplo mais típico desse tipo de ator são vítimas do desastre buscando assistência humanitária.

Quadrante 2: Out/Seekers: Membros da rede que estão localizados fora da área do desastre e que estão em busca de algo na rede. Podem se tratar, por exemplo, de organizações que estão em busca de recursos para prestar assistência aos desabrigados do desastre.

Quadrante 3: In/Providers: Membros da rede que estão localizados na área do desastre, buscando prestar algum tipo de serviço ou assistência a outros membros da rede. Nesse caso, tem-se o exemplo de profissionais atuando no resgate de vítimas, em busca de recursos logísticos para providenciar seu transporte para fora da área atingida.

Quadrante 4: Out/Providers: Membros da rede que estão localizados fora da área do desastre, prestando algum tipo de serviço ou assistência a outros membros da rede. 
É o caso, por exemplo, de hospitais que estão tratando das vítimas depois que elas deixaram a região do desastre.

Assim, a estrutura proposta por Varda e outros (2008) pode, em primeiro plano, auxiliar na identificação dos limites da rede. Além disso, permite um alinhamento das perguntas de pesquisa às unidades e aos níveis de análise inseridos no modelo, além do alcance de uma maior objetividade na definição das etapas metodológicas e dos instrumentos de coleta de dados da pesquisa.

Essa proposição de Varda e outros (2008) encerra o referencial teórico da pesquisa. A próxima seção está dedicada a apresentar a escolha metodológica que foi utilizada para o seu desenvolvimento, tendo em vista os objetivos (geral e específicos) aqui propostos.

Para um fechamento do referencial teórico, são esclarecidas as razões de ser dos conceitos apresentados nos capítulos 2 e 3 , ou seja, quais as contribuições diretas para os objetivos definidos na pesquisa. O quadro 4 demonstra essas contribuições, considerando os objetivos e as seções específicas do referencial teórico.

\begin{tabular}{|c|c|}
\hline OBJETIVOS ESPECÍFICOS & RELAÇÃO COM O REFERENCIAL TEÓRICO \\
\hline $\begin{array}{l}\mathrm{OE}_{1:} \text { Descrever o surgimento de uma } \\
\text { organização estruturada na forma de rede } \\
\text { social no caso específico da resposta às chuvas } \\
\text { de dezembro de } 2013 \text { no ES, bem como as } \\
\text { atividades por ela desenvolvidas. }\end{array}$ & $\begin{array}{l}\text { 2.2 Sociedade da informação: aproximações } \\
\text { relevantes para o contexto da pesquisa. } \\
2.3 \text { Inteligência coletiva: um fenômeno complexo } \\
\text { 2.8 Comunicação e mediação da informação nas } \\
\text { redes sociais } \\
\text { 3.1 Desastres Naturais no Brasil } \\
\text { 3.2 Os grupos emergentes na resposta a } \\
\text { desastres naturais }\end{array}$ \\
\hline $\begin{array}{l}\mathrm{OE}_{2:} \text { Identificar os fenômenos de comunicação } \\
\text { e mediação da informação existentes nessa } \\
\text { rede social. }\end{array}$ & $\begin{array}{l}\text { 2.2 Sociedade da informação: aproximações } \\
\text { relevantes para o contexto da pesquisa. } \\
\text { 2.5 Alguns fundamentos sobre redes } \\
\text { 2.6 A análise de redes sociais - ARS. } \\
\text { 2.8 Comunicação e mediação da informação nas } \\
\text { redes sociais }\end{array}$ \\
\hline $\begin{array}{l}\mathrm{OE}_{3:} \text { Identificar o relacionamento dessa rede } \\
\text { social, com as organizações estabelecidas para } \\
\text { a gestão de desastres no ES, especialmente } \\
\text { com a Defesa Civil Estadual. }\end{array}$ & $\begin{array}{l}\text { 2.7 Sobre estruturas burocráticas e redes } \\
\text { 3.1 Desastres Naturais no Brasil } \\
\text { 3.2 Os grupos emergentes na resposta a } \\
\text { desastres naturais }\end{array}$ \\
\hline
\end{tabular}


(conclusão)

$\mathrm{OE}_{4:}$ Realizar uma análise comparativa entre as estruturas de ação da Defesa Civil Estadual e da rede social de apoio às vítimas das chuvas de dezembro de 2013 no ES.

$\mathrm{E}_{5}$. Mapear a topologia dessa rede social, identificando e analisando algumas de suas propriedades a partir da Análise de Redes Sociais.

QUADRO 4 - RELAÇÖES DOS OBJETIVOS DA PESQUISA COM AS SEÇŌES DO REFERENCIAL TEÓRICO.

Fonte: A autora.

A relação apresentada considerou a mobilização e utilização dos conceitos quando da elaboração dos instrumentos de pesquisa, da coleta, análise e discussão dos resultados e da realização das conclusões.

Além disso, os conceitos também se encontram conectados entre si, numa teia teórica que possibilita o aprofundamento de reflexões e a construção dos pressupostos básicos para a pesquisa. Os pontos de contato entre os conceitos estão apontados no próprio texto, quando se menciona, ao longo das discussões realizadas, seções anteriores em que determinados pontos já foram abordados, ou seções posteriores, onde alguns aspectos estão retomados. 


\section{PERCURSO METODOLÓGICO DA PESQUISA}

Considerando o objetivo geral proposto nesta tese, bem como seus objetivos específicos e pressupostos, este capítulo apresenta as opções adotadas para o planejamento da pesquisa, além dos métodos utilizados para 0 seu desenvolvimento. A seguir estão detalhados: a delimitação do estudo, a classificação da pesquisa, bem como as formas de coleta, tratamento, análise e apresentação dos dados.

Um aspecto central para a compreensão do delineamento metodológico a seguir apresentado, é que o estudo voltou-se essencialmente para a ação dos chamados grupos emergentes, concebidos como redes sociais, atuantes em processos de resposta a um desastre natural. Conforme a tipologia proposta por Quarantelli (1993, 1995), tais grupos são um dos quatro formatos organizacionais de ação em situações de desastres, tendo sido caracterizados na seção anterior.

Embora em alguns pontos a rede possa vir a abarcar relacionamentos com indivíduos pertencentes a instituições formais, expandidas ou estendidas que povoam o contexto em análise, bem como com outros grupos não diretamente envolvidos, mas simplesmente interessados em informações sobre a resposta, o enfoque é dado ao surgimento e à estruturação de formatos improvisados de ação, emergentes na sociedade civil, em que uma rede se estrutura a partir do impacto social causado por um desastre natural.

\subsection{DELIMITAÇÃO DO ESTUDO E TIPO DE PESQUISA}

A pesquisa possui natureza exploratória. Para o alcance dos objetivos da pesquisa, compreendeu-se o estudo de caso como uma opção apropriada, considerando o que 
destaca Yin (2005). De acordo com o autor, o estudo de caso é considerado uma opção estratégica adequada em investigações sobre acontecimentos contemporâneos em que as questões de pesquisa se iniciam com "como" e "por que". Sua aplicação é indicada em contextos em que não se pode controlar os eventos comportamentais envolvidos.

Além disso, Braga (2007) afirma que o estudo de caso é uma das metodologias consideradas mais adequadas às pesquisas exploratórias. O caso pode ser um objeto ou processo teórico, empírico ou ambos. No mínimo é um fenômeno específico no tempo e no espaço (CALAZANS, 2007).

Do ponto de vista específico da Análise de Redes Sociais (ARS), a abordagem exploratória considera que o padrão de relacionamentos em uma rede social tem a capacidade de revelar estruturas e comportamentos sociais, sendo, portanto, algo bastante significativo para a investigação proposta (DE NOOY; MRVAR; BATAGELJ, 2005). Além disso, a ARS exploratória, como definida por De Nooy; Mrvar; Batagelj, (2005) investiga primordialmente dois tipos de fenômenos estruturais nas redes: a constituição de subgrupos coesos e a atuação de intermediários nos fluxos de informação na rede.

Assim, trata-se de um estudo de caso que tem como unidade de análise um grupo estruturado na forma de rede social que atuou durante as ações de resposta às fortes chuvas ocorridas no Estado do Espírito Santo - ES em dezembro de 2013.

Ao se considerar as participações da sociedade civil por meio de um perfil criado no Facebook (denominado Apoiadores: Rede de Apoio Social às Vítimas das Chuvas no Espírito Santo), bem como a atuação de todos os voluntários que participaram tanto da articulação das demandas, quanto da doação, separação, organização e envio dos donativos às vítimas, tem-se uma rede de grandes proporções, em todo 0 ES. Estima-se, segundo dados da imprensa local, que por dia, chegava-se a uma média de mais de 1000 voluntários na Praça do Papa, em Vitória - ES (local onde eram recebidas, e separadas as doações), envolvidos em atividades que duraram aproximadamente oito dias. O perfil criado no Facebook atingiu o patamar de quinze mil curtidas apenas quatro dias após a sua criação (APOIADORES, 2013). 
Considerando o caráter inacabado e em constante rearranjo das redes e, consequentemente, seus fluidos limites e fronteiras, essa tarefa de delimitação de uma rede é bastante trabalhosa, e imprecisa, conforme já mencionado. Entretanto, foi necessário criar critérios para a delimitação da rede estudada de forma a deixar claro o escopo da pesquisa e proporcionar condições para a definição adequada do seu percurso metodológico. Nesse sentido, para que se pudesse atingir os objetivos propostos, dentro do tempo e com os recursos disponíveis, optou-se por uma delimitação da rede que considerou dois aspectos centrais: as atividades desenvolvidas pelos atores e o tipo de organização ao qual pertenciam.

Assim, buscou-se em primeiro lugar, mapear a rede em estudo identificando os relacionamentos estabelecidos por atores envolvidos apenas em atividades de articulação e coordenação voltadas para a viabilização da arrecadação, organização e transporte dos donativos para as cidades afetadas, conforme descritas a seguir:

- Contatos com Prefeituras, Corpo de Bombeiros, Cruz Vermelha ou Defesa Civil para levantamento de necessidades de donativos;

- Administração do perfil dos Apoiadores no Facebook;

- Contatos com Empresas Privadas ou pessoas físicas para solicitação de donativos ou viabilização de recursos como caminhões, aviões, embalagens, lanches para os voluntários;

- Coordenação de atividades de recebimento, separação, organização ou embalagem de donativos recebidos na Praça do Papa;

- Articulação com as instituições envolvidas nas ações de apoio às vítimas, visando à organização e à continuidade do andamento das atividades;

- Contatos com Prefeituras Municipais para viabilização da chegada dos donativos às cidades afetadas;

- Acompanhamento das viagens de caminhão/avião com donativos para as cidades afetadas;

- Idas às cidades afetadas nos caminhões/aviões para entrega dos donativos. 
Não estão incluídos, portanto, atores que se envolveram exclusivamente em atividades operacionais mais diretamente voltadas ao manuseio dos donativos, como: recebimento, separação, embalagem e carregamento de caminhões e/ou aviões. Nem aqueles que apenas fizeram doações.

Também não estão incluídos no escopo deste trabalho, os relacionamentos estabelecidos entre pessoas por meio do perfil criado no Facebook. Compreendeuse pelas investigações feitas sobre o conteúdo do perfil, que as interações ali realizadas não se dedicaram, em sua enorme maioria, à viabilização das atividades acima descritas. Boa parte das interações foi realizada por pessoas simpatizantes da ação, que desejavam fazer doações ou saber apenas sobre pontos de coleta de donativos. Muitos comentários exaltavam e elogiavam as atividades desenvolvidas e outros prestavam esclarecimentos sobre a situação das chuvas em determinados locais do ES.

Assim, apesar do perfil no Facebook ter possuído um papel importante para o desenvolvimento das atividades de apoio às vítimas, (que será demonstrado no capítulo 5, na análise de resultados), de terem existido muitas "curtidas" e também diversas participações de pessoas físicas, não se pode afirmar que foram realizadas por pessoas que se adequavam ao perfil aqui delimitado. É nesse sentido que se decidiu não incluir tais interações no escopo desta pesquisa.

Considerando que o foco da análise do estudo aqui apresentado encontra-se nos grupos emergentes (QUARANTELLI, 1995) na sociedade civil, o segundo critério de delimitação da rede analisada é que ela considera apenas um nível de atores pertencentes às chamadas organizações estabelecidas, expandidas ou estendidas (QUARANTELLI, 1995) como Defesa Civil Estadual, CBMES, Prefeituras Municipais, Cruz Vermelha, Empresas Privadas, dentre outras. Quando os atores da sociedade civil indicaram, por meio dos questionários, contatos nesses outros tipos de organização, a rede foi traçada apenas até esse limite, ou seja, não foram enviados questionários aos atores pertencentes a esses tipos de organizações. Assim, foram enviados questionários apenas aos atores pertencentes ao grupo emergente na sociedade civil e ONGs.

O levantamento de dados em campo ocorreu entre os dias 25 de setembro de 2014 e 29 de junho de 2015, conforme detalhamento apresentado na próxima seção. 


\subsection{COLETA DE DADOS}

De acordo com Yin (2005) um dos princípios essenciais à coleta de dados em estudos de caso é a utilização de várias fontes de evidência, necessitando, para sua análise, de uma perspectiva que promova a sua triangulação. Essa utilização variada de fontes de evidência permite ao pesquisador o desenvolvimento de linhas convergentes de investigação, consolidando um estilo corroborativo de pesquisa, capaz de trazer resultados mais convincentes e acurados. Ao mesmo tempo, é necessária a estruturação prévia de proposições teóricas que possam conduzir a coleta e a análise de dados.

Ainda conforme destaca Yin (2005), procedimentos de coleta de dados em estudo de caso não seguem uma rotina, por isso o estudo de caso é tão desafiador. Não há padrões pré-estabelecidos, mas sim uma contínua interação entre as questões teóricas estudadas e os dados que estão sendo coletados.

É nesse sentido, que a coleta de dados do presente estudo de caso esteve baseada em fontes diferenciadas de evidência. Foram elas: entrevistas, questionários, levantamento de dados no perfil dos Apoiadores no Facebook, além de levantamentos não estruturados.

Especificamente sobre as entrevistas, Yin (2005) destaca que essas são uma das mais importantes fontes de informações para um estudo de caso. Dentre as diversas formas de entrevistas que podem ser realizadas em estudos de caso, optou-se aqui por aquelas conduzidas de forma espontânea. Esse formato de entrevista permite tanto indagar aos respondentes sobre os fatos, quanto pedir a opinião deles sobre determinados eventos. Auxiliando de maneira mais próxima, o respondente assume o papel de informante-chave, figura sempre muito importante para o sucesso de um estudo de caso.

Essas pessoas não apenas fornecem ao pesquisador do estudo percepções e interpretações sob um assunto, como também podem sugerir fontes nas quais se pode buscar evidências corroborativas - e pode-se iniciar a busca a essas evidências (YIN, 2005, p. 112).

Assim, a primeira entrevista, de natureza semi estruturada, foi realizada com a principal informante-chave da pesquisa, a iniciadora da rede em estudo, que será a 
partir daqui tratada como A01. O primeiro contato com essa entrevistada se deu em dezembro de 2013 no momento em que as atividades de apoio às vítimas por parte do grupo da sociedade civil, ainda estavam acontecendo. À época do ocorrido, a pesquisa ainda se encontrava em delineamentos bastante iniciais. Não estavam definidos os objetivos, o objeto de estudo, nem mesmo havia sido traçado o percurso metodológico. Contudo, já se encontrava definido o tema geral da pesquisa.

Foi por essa razão que em dezembro de 2013, ao se saber do desenrolar das atividades de apoio às vítimas por meio da mídia impressa e televisiva, buscou-se uma aproximação com o que poderia ser um possível objeto de estudo, por meio de visita à Praça do Papa, em Vitória, capital do ES (local onde estavam sendo arrecadados os donativos), no dia 20 de dezembro de 2013. Nesta aproximação, um dos objetivos era identificar informantes para a pesquisa, que tivessem tido envolvimento com as atividades do grupo emergente desde o seu início.

Essa busca por informantes-chave ocorreu de maneira informal, por meio de abordagens feitas a algumas pessoas no local, onde se perguntava sobre quem seriam as "lideranças do movimento". Conseguiu-se obter alguns nomes, mas apenas foi possível contato com A01 naquele momento. Obteve-se o número de telefone da informante para a realização de um possível contato posterior, assim que os objetivos da pesquisa estivessem mais bem delineados, quando se compreendeu que esse contato seria mais proveitoso.

Foi em abril de 2014 o primeiro contato telefônico com A01, de natureza exploratória, quando foi possível identificar seu protagonismo na animação da rede, seu conhecimento detalhado sobre as atividades desenvolvidas, sua atuação durante todos os dias em que as ações foram realizadas e seu interesse em colaborar com a pesquisa. Decorreu daí a escolha de A01 como um dos informantes-chave para a pesquisa.

Conforme destacado por Yin (2005), a realização da entrevista com A01 foi essencial ao planejamento e desenvolvimento do próprio percurso metodológico do estudo de caso, na medida em que permitiu identificar outros atores importantes ao processo, delinear os conteúdos de outro instrumento de coleta de dados utilizado (o 
questionário), além de levantar aspectos temporais, percepções e sentimentos acerca da atuação do grupo em análise.

A entrevista foi agendada em um segundo contato telefônico com A01 e realizada na Universidade Federal do Espírito Santo - UFES, no dia 25 de setembro de 2014, na sala de trabalho da pesquisadora. A entrevista teve duração de aproximadamente 3 horas. Toda a entrevista foi gravada com o consentimento da entrevistada, tendo sido transcrita em sua íntegra para posterior análise.

A entrevista teve roteiro semi-estruturado, onde as questões objetivaram contemplar as seguintes finalidades principais $\left(E_{A 1}\right.$ a $\left.E_{A 4}\right)$ :

$E_{A 1}$ : Proporcionar melhores indicativos para a definição dos limites e das características da rede a ser analisada;

$\mathrm{E}_{\mathrm{A} 2}$ : Detalhar aspectos relacionados ao surgimento da rede, suas motivações, objetivos iniciais e forma de atuação;

$E_{A 3}$ : Identificar quais as principais ações e como elas foram desenvolvidas pela rede durante as fortes chuvas de 2013 no ES;

$\mathrm{E}_{\mathrm{A4}}$ : Levantar as organizações estabelecidas, expandidas e estendidas com as quais os membros da rede se relacionaram.

Foram seguidas as recomendações de Yin (2005), quanto à importância de tomar precauções para que a pesquisa não se torne excessivamente dependente de um informante-chave. Assim, conforme já mencionado, outras fontes de evidência como os questionários e os conteúdos disponíveis no perfil Apoiadores no Facebook, foram também utilizadas, além de terem sido entrevistados outros informanteschave. Tais precauções visaram a corroborar qualquer interpretação dada por essa primeira informante-chave e também criar oportunidades para verificação de provas contrárias a essas interpretações.

Assim, uma entrevista semi estruturada foi também realizada com o Comandante Geral do CBMES, Coronel Carlos Marcelo D'Isep Costa, que à época da ocorrência do caso em análise era o Coordenador da Defesa Civil Estadual, para levantamento de informações acerca da atuação da Defesa Civil nas ações de resposta às chuvas no ES em dezembro de 2013. 
A entrevista com esse informante foi agendada por telefone, quando os objetivos do estudo foram esclarecidos ao entrevistado. Foi realizada no dia 14 de maio de 2015, no gabinete do comandante, na sede do CBMES, localizada na Enseada do Suá, em Vitória - ES. A entrevista durou aproximadamente uma hora e trinta minutos e também foi gravada, com o consentimento do comandante, para posterior transcrição e análise. A entrevista também possuiu roteiro semi-estruturado, onde as questões objetivaram contemplar as seguintes finalidades principais ( $E_{B 1}$ a $\left.E_{B 5}\right)$ :

$\mathrm{E}_{\mathrm{B} 1}$ : Detalhar a estrutura do planejamento e da execução das ações de resposta a desastres naturais protagonizadas pela Defesa Civil do Estado do Espírito Santo;

$\mathrm{E}_{\mathrm{B} 2:}$ Identificar a percepção da Defesa Civil Estadual quanto à atuação do grupo emergente em estudo;

$\mathrm{E}_{\mathrm{B} 3:}$ Identificar em que medida as ações planejadas pela Defesa Civil Estadual puderam ser efetivamente executadas na ocasião;

$\mathrm{E}_{\mathrm{B} 4:}$ Descrever as características do processo decisório do âmbito da Defesa Civil Estadual, em ações de resposta a desastres naturais.

A Equipe da Defesa Civil Estadual, voltada especificamente à coordenação dos processos de prevenção e resposta a desastres também foi entrevistada, no dia 19 de maio de 2015. A equipe é composta por três profissionais vinculados ao CBMES, sendo esses: Major Anderson A. Guerim Pimenta, Sub-tenente Jocirley Bubach Andreatti e Erica Ayme Rocha. Os três participaram das ações de resposta às chuvas de 2013. Da mesma forma que as anteriores, a entrevista foi agendada por telefone, quando se esclareceu sobre os objetivos da entrevista. Tratou-se de uma entrevista semi estruturada, realizada de forma coletiva, ou seja, simultaneamente com os três participantes e cada um dos profissionais teve a oportunidade de responder às questões, conforme suas atividades e sua participação à época do ocorrido. A entrevista durou aproximadamente uma hora e trinta minutos. Os dados coletados foram transcritos para posterior análise. À semelhança das anteriores, essa entrevista também possuiu roteiro semi-estruturado, onde as questões objetivaram contemplar as seguintes finalidades principais $\left(E_{C 1}\right.$ a $\left.E_{C 5}\right)$ :

$\mathrm{E}_{\mathrm{C1}}$ : Identificar a dimensão do desastre ocorrido em dezembro de 2013 em relação à capacidade de resposta da Defesa Civil Estadual à época; 
$\mathrm{E}_{\mathrm{C2} \text { : }}$ Identificar a percepção da Defesa Civil Estadual quanto à atuação do grupo emergente em estudo;

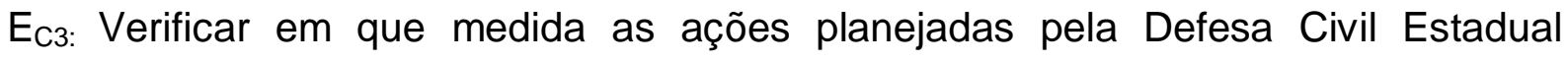
puderam ser efetivamente executadas na ocasião;

$\mathrm{E}_{\mathrm{C} 4:}$ Compreender como se deu a interação entre a Defesa Civil Estadual e o grupo emergente em estudo;

$E_{C 5:}$ Levantar como a Defesa Civil Estadual trata as contribuições de grupos voluntários em situações de gestão de desastres naturais.

Os questionários (APÊNDICE A), por sua vez, foram utilizados para a coleta dos dados mais específicos para levantamento da estrutura da rede e também para evidenciação de motivações dos atores, formas de comunicação utilizadas e conteúdos informacionais trocados. Foram aplicados aos atores da rede, conforme o perfil delimitado para a pesquisa, apresentado na seção 4.1, utilizando-se a técnica conhecida como bola de neve (snowball). Como destacam Varda e outros (2008), trata-se de uma técnica bastante comum na coleta de dados sobre redes. Nela, um respondente inicial (A01 no caso desta pesquisa) é questionado acerca de seus relacionamentos na rede. Esses, por sua vez, são abordados para que respondam sobre seus próprios relacionamentos e assim, sucessivamente, até que se consiga mapear as linhas de conexão e os atores participantes da rede inteira.

No dia 27 de abril de 2015, foi realizado o pré-teste do questionário utilizando-se a plataforma digital denominada SurveyMonkey. Foi enviado para o email do ator inicial A01 - o mesmo com quem foi realizada a primeira entrevista - o link para o preenchimento do questionário e solicitado que retornasse com suas observações acerca de sua impressão sobre 0 instrumento, incluindo dificuldades de preenchimento e sugestões de alterações nas questões apresentadas.

Considera-se que o pré-teste foi bem sucedido, tendo sido realizadas no questionário as modificações necessárias, para que em seguida pudesse ser enviado aos demais participantes da rede.

Assim, a partir das indicações fornecidas pelo ator inicial (A01) foram alcançados os demais participantes da rede, que responderam a questionários disponibilizados em 
plataforma de Internet (SurveyMonkey). Essa fase da coleta de dados teve início em 05 de maio de 2015 e terminou em 29 de junho de 2015. Todos os respondentes, antes de receberem o link para o questionário, foram contatados por telefone ou por meio do Facebook (conforme as indicações fornecidas pelos respondentes anteriores), onde recebiam esclarecimentos sobre a pesquisa e eram convidados a participar.

Nesses contatos realizados, as pessoas eram também convidadas a colaborar com dados complementares, apresentando uma impressão geral sobre as ações desenvolvidas pela rede de apoio às vítimas e, mais especificamente, sobre a sua participação, em um formato de levantamento não estruturado. Visou-se buscar alguns dados adicionais que pudessem trazer mais profundidade às respostas do questionário. O êxito dessa tarefa variou muito em função da disponibilidade do respondente em colaborar.

Assim, embora tenha se buscado esse levantamento com todos os respondentes, os dados que puderam ser considerados mais relevantes para os objetivos da pesquisa, vieram apenas dos contatos realizados com A08 e A19, ocorridos nos dias 21 e 22 de maio de 2015, respectivamente. Assim, os dados coletados na entrevista realizada com A01 foram complementados por aqueles obtidos no contato com esses dois atores.

Conforme já se pode observar, a codificação dos atores foi realizada a partir de letras, conforme a nomenclatura apresentada no quadro 5 , já que se optou por preservar as identidades dos participantes da rede. Às letras, foram sendo adicionados números sequenciais para a identificação de cada um dos atores, conforme o segmento a que pertenciam. 


\begin{tabular}{|l|l|}
\hline NOMENCLATURA & DESCRIÇÃO DE PERTENCIMENTO DO ATOR \\
\hline A & Grupo emergente na sociedade civil \\
\hline CV & Cruz Vermelha \\
\hline DCE & Defesa Civil Estadual \\
\hline DCM & Defesas Civis Municipais \\
\hline E & Empresas Privadas \\
\hline ONG & Organização Não Governamental \\
\hline PM & Prefeituras Municipais \\
\hline POL & Polícia Militar \\
\hline
\end{tabular}

QUADRO 5 - NOMENCLATURA PARA IDENTIFICAÇÃO DOS ATORES DA REDE ANALISADA

Fonte: A autora.

Todos os respondentes, sem exceção, concordaram expressamente em participar da pesquisa. O preenchimento do questionário só era realizado se os respondentes concordassem em participar, por meio de um click em "aceito participar da pesquisa", no Termo de Consentimento Livre e Esclarecido, constante no APÊNDICE A. O referido termo era a parte inicial do questionário.

A coleta de dados era interrompida quando se identificava um ator que não pertencia à sociedade civil ou ONG, ou quando não houve resposta por um desses atores da sociedade civil.

Utilizando a própria ferramenta SurveyMonkey, lembretes em intervalos semanais eram enviados aos participantes que ainda não haviam respondido o questionário. Em alguns casos, foram necessários também novos telefonemas, nos quais se solicitava mais uma vez a participação na pesquisa.

Apesar desses esforços, algumas pessoas mesmo tendo sido contatadas mais de uma vez, não responderam o questionário. Além disso, houve outro fator limitador da pesquisa que contribuiu para a redução do número de respondentes. Em função do tempo decorrido desde o desastre natural de 2013, muitas pessoas não possuíam mais os contatos de seus relacionamentos na rede, como telefone ou email. Ou, em outras situações, os contatos fornecidos não estavam corretos, em função de mudanças variadas como de emprego ou de telefone pessoal. Nesses casos, a partir do nome completo fornecido, foram realizadas buscas na Internet, principalmente em sites de redes sociais, na tentativa de conseguir alguma forma de 
contato com a pessoa indicada. Algumas dessas tentativas foram bem sucedidas, porém outras fracassaram.

Assim, nem todos os indivíduos que se adequavam ao perfil da pesquisa, responderam o questionário, o que, de certa forma, tornou-se um desafio para o mapeamento da rede, que certamente não está mapeada em sua integralidade. Do total de vinte e quatro pessoas que se adequaram ao perfil de respondentes (sociedade civil e ONGs), não foi possível obter a resposta de onze. Nesses casos, os relacionamentos considerados para essas pessoas, foram aqueles apontados pelos demais respondentes. Os treze respondentes estão identificados por meio dos seguintes códigos: A01, A03, A07, A08, A11, A15, A17, A18, A19, A20, A21, ONG02 e ONG03.

O questionário está apresentado em sua íntegra no APÊNDICE A e foi estruturado em duas partes principais. A primeira se destinava a caracterizar o respondente e incluía questões para levantamento de: nome completo; telefone; email para contato; a que instituição pertencia em dezembro de 2013; as principais motivações para ter atuado no apoio às vítimas; a data em que começou a sua participação; as atividades nas quais se envolveu; as dificuldades que enfrentou no desenvolvimento dessas atividades e com quantas pessoas aproximadamente manteve contato na ocasião.

A segunda parte referia-se a levantamentos acerca dos relacionamentos que o respondente estabeleceu no desenvolvimento das atividades de apoio às vítimas. Tratava-se de um conjunto de questões que se repetia para cada novo contato que o respondente desejasse indicar. As questões eram voltadas para o levantamento de: nome completo, telefone e email do contato; a que organização ele pertencia; o sentido das informações trocadas nessa relação; o número de vezes que estabeleceu contato com essa pessoa durante o desenvolvimento das atividades; como eram feitos tais contatos; se já existia um relacionamento com essa pessoa antes de dezembro de 2013; se já conhecia essa pessoa, de onde a conhecia; quais foram as principais informações trocadas com essa pessoa e qual a frequência do contato com essa pessoa atualmente.

A partir de tais questões, objetivou-se identificar os seguintes aspectos principais $\left(Q_{1}\right.$ a $\left.Q_{6}\right)$ : 
$Q_{1}$ : Identificar os atores participantes da rede, seus relacionamentos e atividades que desenvolveram;

$\mathrm{Q}_{2}$ : Identificar quais desses relacionamentos eram anteriores à rede em estudo;

$\mathrm{Q}_{3}$ : Identificar o tipo de informação que o ator enviava e para quem;

Q4: Identificar o tipo de informação que o ator recebia e de quem;

$Q_{5}$ : Mapear os meios de comunicação através dos quais recebia e enviava informações a seus relacionamentos na rede;

Q6: Identificar as motivações dos atores para participação na rede.

Considerando então a delimitação do estudo, bem como as limitações evidenciadas anteriormente, a partir dos questionários foi possível o mapeamento da estrutura de uma rede que revelou apenas o núcleo dos atores atuantes nas ações de apoio às vítimas. É essa a rede aqui estudada e que foi nomeada como "Núcleo de Apoiadores". Nela, as interações comunicacionais relacionadas à articulação das demandas por donativos para as vítimas da chuva de 2013 é o tipo de laço relacional considerado.

Também como fonte de evidência de dados, utilizados principalmente na descrição do surgimento da rede, na caracterização de seus objetivos e das atividades por ela desenvolvidas, foram utilizados alguns dos posts realizados no perfil "Apoiadores" no Facebook. Durante a entrevista com A01, a respondente "liberou o acesso" a algumas informações restritas sobre o perfil, por meio de um recurso do próprio Facebook. Assim, foi possível a partir daquele momento, visualizar o alcance de cada um dos posts realizados, bem como as estatísticas de acesso ao perfil. Isso possibilitou uma compreensão mais clara sobre o papel e o impacto da utilização do Facebook como ferramenta de comunicação entre o núcleo e a periferia da rede em análise.

O Facebook é tratado no âmbito da tese como um site de rede social (SRS), nos termos do que propõe Recuero (2009), conforme apresentado na seção 2.8. Além disso é utilizado o termo perfil, para designar o conjunto de todos os conteúdos existentes no Facebook sobre os Apoiadores, e o termo post, para as mensagens 
não dirigidas divulgadas no perfil, baseando-se na descrição de funcionalidades do Facebook de Bohn e outros (2014), também apresentada na seção 2.8.

Esse perfil é compreendido no âmbito da pesquisa como uma zona de mediação, no sentido do que propõe Marteleto (2010) acerca da mediação da informação em redes sociais, conforme apresentado na seção 2.8. Para sua definição como uma fonte adequada para a coleta de dados, foi considerada especialmente a dimensão de produção de sentidos dessa zona de mediação, "que se visualiza quando os elementos interativos, comunicacionais, informacionais e cognitivos clareiam uma zona de encaminhamento das ações individuais e coletivas" (MARTELETO, 2010, p. 39). Assim, foram selecionadas algumas informações divulgadas no perfil, que pudessem levar a uma melhor compreensão de como as ações da rede tomaram corpo e foram desenvolvidas, evidenciando pontos importantes para a caracterização da ação coletiva em estudo.

A seguir no quadro 6 estão apontadas as formas de coletas de dados utilizadas na pesquisa, bem como as finalidades de cada uma delas.

(continua)

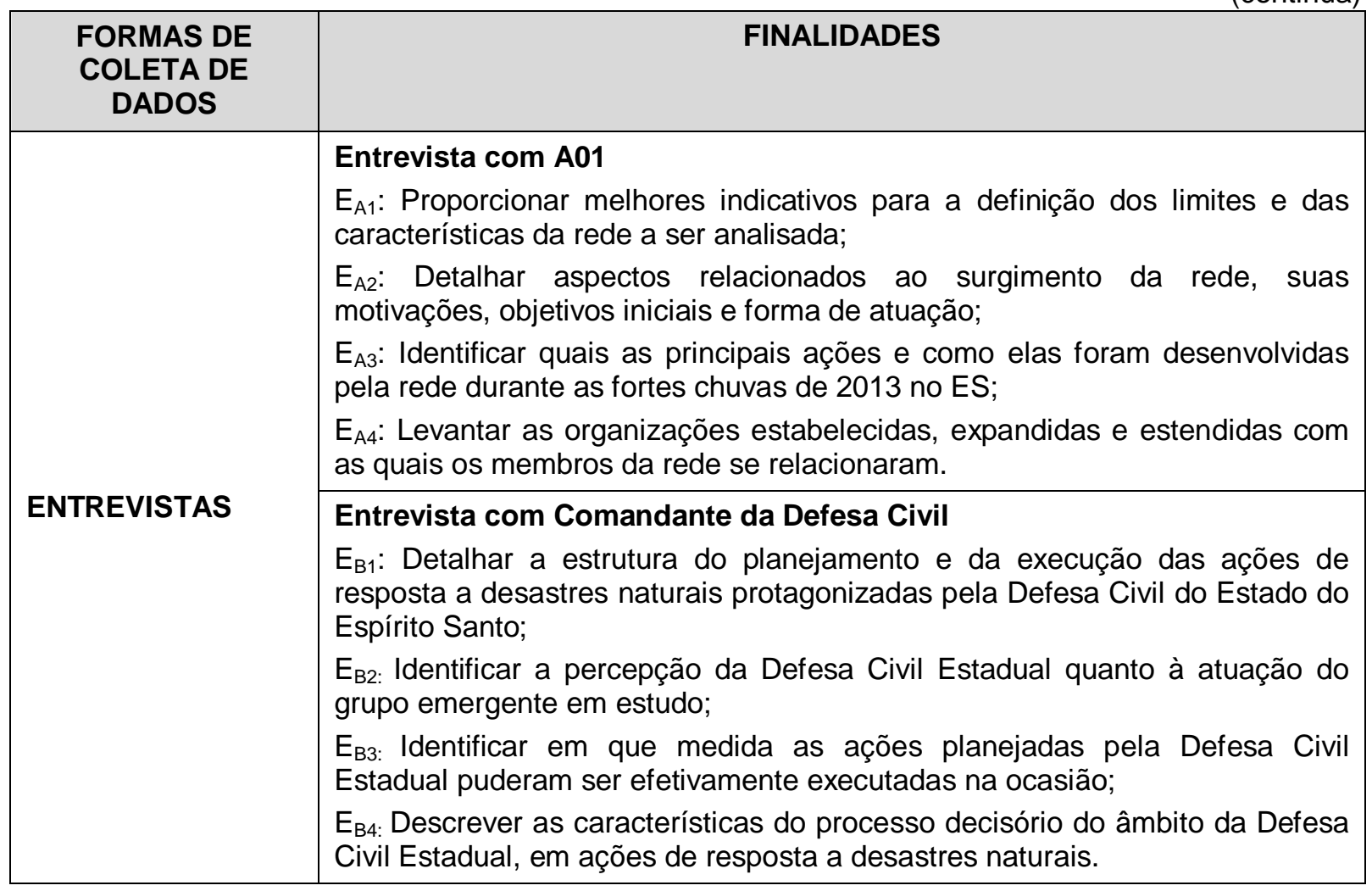


(conclusão)

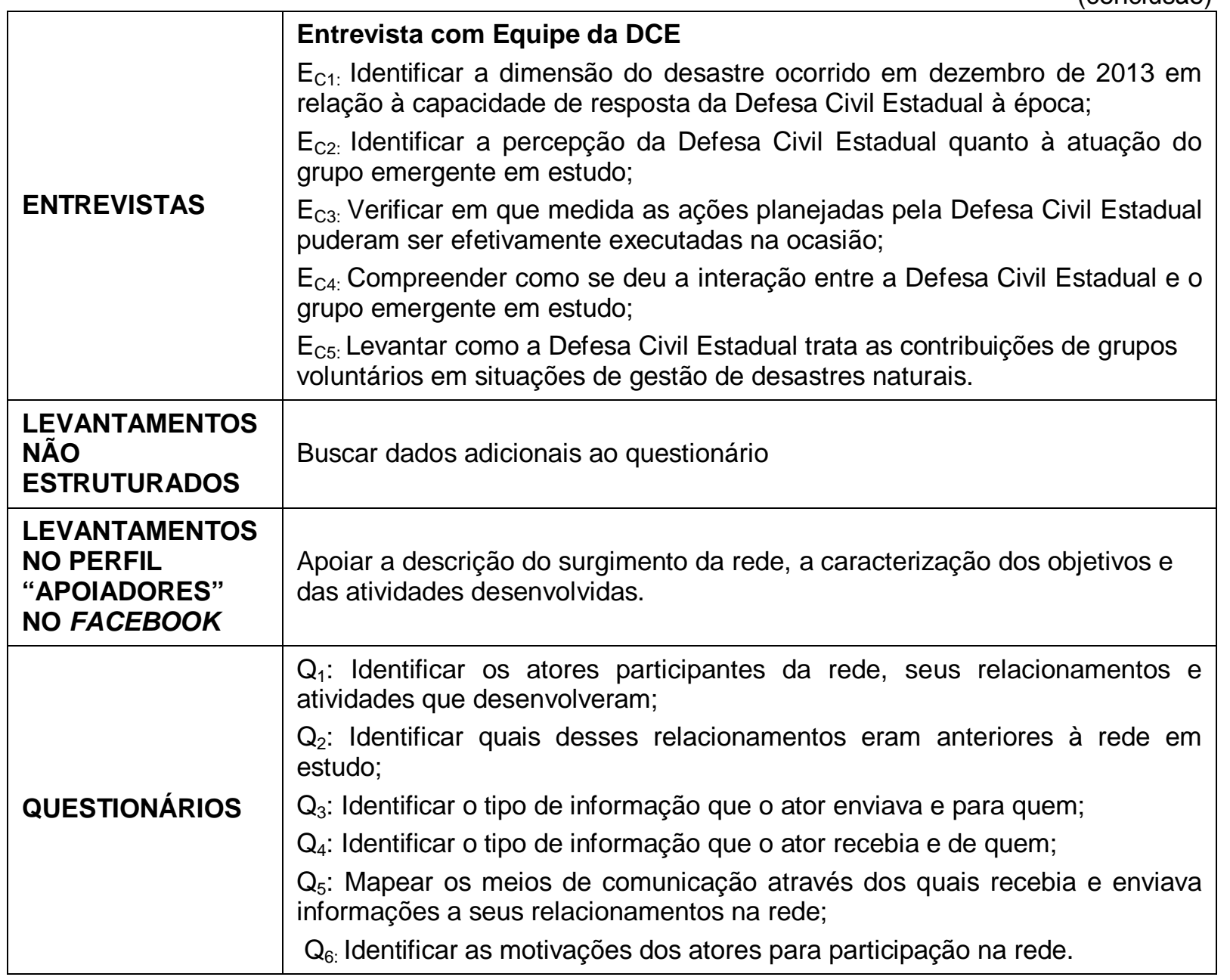

QUADRO 6 - FORMAS DE COLETA DE DADOS DA PESQUISA E SUAS FINALIDADES

Fonte: A autora.

\subsection{TRATAMENTO, APRESENTAÇÃO E ANÁLISE DE RESULTADOS}

Os dados coletados foram tratados de formas diferenciadas, conforme o instrumento utilizado. A primeira dessas formas refere-se aos dados das entrevistas que foram transcritas em sua íntegra para posterior análise de seu conteúdo. Os dados coletados nas entrevistas contribuíram de forma direta, para o alcance de objetivos da pesquisa, conforme pode ser observado a partir do quadro 7 , apresentado ao final deste capítulo. 
A partir de visitas ao perfil Apoiadores no Facebook também foi possível coletar dados sobre as atividades desenvolvidas pela rede e a evolução de tais atividades ao longo do tempo. As publicações realizadas no perfil foram analisadas, principalmente, do ponto de vista de sua contribuição para identificar origens e motivações da rede e mapear as atividades por ela desenvolvidas.

A segunda forma de tratamento de dados se relaciona aos que foram obtidos a partir dos questionários. Eles foram extraídos do SurveyMonkey e utilizados, em parte, para a caracterização da rede sob diferentes aspectos, tendo sido tabulados e apresentados em quadros e tabelas, conforme poderá ser observado a partir da próxima seção.

A outra parte dos dados do questionário, utilizados especificamente na ARS, foi tabulada em planilhas utilizando o software Excel e organizada em arquivos específicos, em adequação à sua utilização pelo software Pajek. Para a aplicação da ARS, especificamente, foram utilizadas as quatro atividades sequenciais e cíclicas que compõem a análise exploratória de redes sociais, de acordo com Nooy, Mrvar e Batagelj (2005).

A primeira delas foi a definição da rede, que é consequência do recorte dado à pesquisa, conforme apresentado na seção 4.2. A segunda foi a manipulação da rede, quando se realiza a seleção de sub-redes ou a extração de determinadas partes da rede escolhidas por serem identificadas como capazes de levar a uma análise significativa e apurada da rede. A terceira atividade foi a determinação de características estruturais, que envolve a identificação de subgrupos coesos e estruturas de intermediação de relacionamentos. A inspeção visual, como quarta atividade, foi facilitadora das percepções acerca das características específicas da rede em estudo. Foram utilizados os instrumentos de representação gráfica para essa finalidade.

Conforme já mencionado, o formato dos dados foi adequado à utilização do software Pajek, específico para ARS. A visualização da rede foi realizada por meio de grafos. O Pajek permitiu o delineamento das principais características estruturais da rede em questão. 
Apesar da ARS se sustentar em um arcabouço matemático e estatístico, em sua aplicação, as abordagens quantitativa e qualitativa são entendidas como interdependentes. Assim sendo não devem ser visualizadas em oposição uma à outra, mas sim, de forma complementar (MARTELETO; TOMAÉL, 2005). Dessa forma, além das medidas quantitativas que foram realizadas por meio da utilização do Pajek, a abordagem qualitativa também foi aplicada continuamente aos dados, à luz das reflexões teóricas apresentadas.

Especificamente sobre a análise dos dados, Yin (2005) destaca que tal tarefa em estudos de caso não segue fórmulas ou receitas fixas, dependendo muito mais do próprio estilo de pensar que o pesquisador possui, aliado à suficiente apresentação de evidências e à análise cuidadosa de interpretações alternativas. Ainda assim, o autor apresenta algumas estratégias gerais importantes para a fase de análise da pesquisa, sendo uma das mais destacadas, aquela que se baseia nas proposições teóricas que levaram ao estudo de caso.

De acordo com o autor:

Evidentemente, a proposição ajuda a por em foco certos dados e ignorar
outros (um bom teste para isso seria decidir quais dados devem ser
mencionados se você tiver apenas cinco minutos para sustentar uma
proposição em seu estudo de caso). Ela também ajuda a organizar todo o
estudo de caso e a definir explanações alternativas a serem examinadas
(Yin, 2005, p. 133). Além de dar forma ao plano de coleta de dados, as proposições teóricas norteiam os objetivos e o projeto originais do estudo, refletindo, inclusive, as revisões feitas na literatura sobre o assunto. A observação dessas relações estabelecidas dentro do estudo de caso aqui proposto pode ser realizada a partir de dois quadros apresentados nesta tese: (a) o quadro 4, já apresentado ao final da seção 3.2, onde é possível perceber as relações existentes entre os objetivos específicos e a revisão de literatura realizada sobre os diferentes assuntos; (b) o quadro 7 a seguir, que relaciona os pressupostos da pesquisa ao seus objetivos específicos e aos aspectos metodológicos relacionados e que serviu como principal elemento norteador na apresentação e análise dos resultados. 
(continua)

\begin{tabular}{|c|c|c|}
\hline $\begin{array}{l}\text { PRESSUPOSTOS SOBRE AS } \\
\text { REDES SOCIAIS DE RESPOSTA A } \\
\text { DESASTRES NATURAIS }\end{array}$ & $\begin{array}{l}\text { OBJETIVOS } \\
\text { ESPECÍFICOS }\end{array}$ & $\begin{array}{l}\text { ASPECTOS } \\
\text { METODOLÓGICOS } \\
\text { RELACIONADOS }\end{array}$ \\
\hline $\begin{array}{l}P_{1} \text { : Inserem-se no âmbito da Ciência } \\
\text { da Informação como um fenômeno } \\
\text { não clássico, cuja organização e } \\
\text { animação encontram significativo } \\
\text { suporte nas novas TICs. }\end{array}$ & $\begin{array}{l}\mathrm{O}_{\mathrm{E} 1:} \text { Descrever } 0 \\
\text { surgimento de uma } \\
\text { organização estruturada } \\
\text { na forma de rede social } \\
\text { no caso específico da } \\
\text { resposta às chuvas de } \\
\text { dezembro de } 2013 \text { no ES, } \\
\text { bem como as atividades } \\
\text { por ela desenvolvidas. } \\
\mathrm{O}_{\mathrm{E} 2 \text { : Identificar os }} \\
\text { fenômenos de } \\
\text { comunicação e mediação } \\
\text { da informação existentes } \\
\text { nessa rede social. }\end{array}$ & $\begin{array}{l}\text { Levantamento de dados por } \\
\text { meio de questionários, mais } \\
\text { especificamente na finalidade: } \\
\mathrm{Q}_{5} \text {. } \\
\text { Levantamento de dados por } \\
\text { meio de entrevistas, mais } \\
\text { especificamente na finalidade: } \\
\text { E}_{\mathrm{A} 2 \text {. }} \\
\text { Levantamento de dados } \\
\text { existentes no perfil dos } \\
\text { Apoiadores no Facebook. } \\
\text { Levantamentos não } \\
\text { estruturados com A08 e A19. }\end{array}$ \\
\hline $\begin{array}{l}\mathrm{P}_{2}: \mathrm{A} \text { comunicação se apresenta } \\
\text { como elemento regulador e essencial } \\
\text { à sua auto-organização, a partir da } \\
\text { qual se tornam possíveis a } \\
\text { articulação das multilideranças e a } \\
\text { coordenação de diferentes ações. }\end{array}$ & $\begin{array}{l}\mathrm{O}_{\mathrm{E2}} \text { : Identificar oS } \\
\text { fenômenos de } \\
\text { comunicação e mediação } \\
\text { da informação existentes } \\
\text { nessa rede social. } \\
\mathrm{O}_{\mathrm{E5} \text { : Mapear a topologia }} \\
\text { dessa rede social, } \\
\text { identificando e analisando } \\
\text { algumas de suas } \\
\text { propriedades pela ARS. }\end{array}$ & $\begin{array}{l}\text { Levantamento de dados por } \\
\text { meio de questionários, mais } \\
\text { especificamente nas } \\
\text { finalidades: } Q_{3} \text { e } Q_{4} \text {. } \\
\text { Utilização da abordagem da } \\
\text { Análise de Redes Sociais. }\end{array}$ \\
\hline $\begin{array}{l}P_{3} \text { : Em seu âmbito, a mediação da } \\
\text { informação possui características } \\
\text { diferenciadas em relação a algumas } \\
\text { conceituações mais usuais da } \\
\text { Ciência da Informação. }\end{array}$ & $\begin{array}{l}\mathrm{O}_{\mathrm{E} 2} \text { : Identificar OS } \\
\text { fenômenos de } \\
\text { comunicação e mediação } \\
\text { da informação existentes } \\
\text { nessa rede social. } \\
\text { O }_{\mathrm{E} 5:} \text { Mapear a topologia } \\
\text { dessa rede social, } \\
\text { identificando e analisando } \\
\text { algumas de suas } \\
\text { propriedades a partir da } \\
\text { Análise de Redes Sociais. }\end{array}$ & $\begin{array}{l}\text { Levantamento de dados por } \\
\text { meio de questionários, mais } \\
\text { especificamente nas } \\
\text { finalidades: } Q_{3} \text { e } Q_{4} \text {. } \\
\text { Utilização da abordagem da } \\
\text { Análise de Redes Sociais. }\end{array}$ \\
\hline $\begin{array}{l}\mathrm{P}_{4}: \quad \text { Em seu processo de } \\
\text { estruturação, os atores contam com } \\
\text { laços relacionais pré-existentes, mas } \\
\text { também estabelecem novos laços de } \\
\text { forma dinâmica. }\end{array}$ & $\begin{array}{l}\text { OE5: Mapear a topologia } \\
\text { dessa rede social, } \\
\text { identificando e analisando } \\
\text { algumas de suas } \\
\text { propriedades a partir da } \\
\text { Análise de Redes Sociais }\end{array}$ & $\begin{array}{l}\text { Levantamento de dados por } \\
\text { meio de questionários, mais } \\
\text { especificamente nas } \\
\text { finalidades: } Q_{1}, Q_{2} \text {. } \\
\text { Levantamento de dados por } \\
\text { meio de entrevistas, mais } \\
\text { especificamente na finalidade: } \\
\text { E }_{\mathrm{A} 2} \text {. } \\
\text { Utilização da abordagem da } \\
\text { Análise de Redes Sociais. }\end{array}$ \\
\hline
\end{tabular}


(conclusão)

$\mathrm{P}_{5}$ : As estruturas usuais do Estado para a resposta a desastres naturais possuem como princípios o comando, o controle e a hierarquia. Por outro lado, a estruturação em rede, representada pelos grupos emergentes no pós-desastre natural, possui natureza autônoma, voluntária e solidária, cujas características denotam aproximações com a racionalidade substantiva.

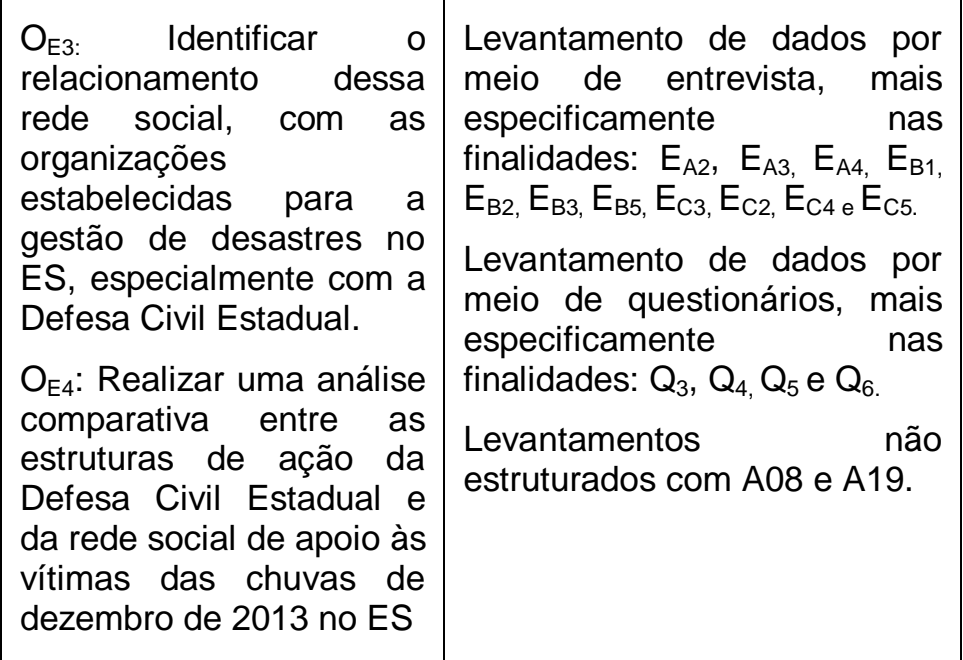

QUADRO 7 - PRESSUPOSTOS DA PESQUISA, OBJETIVOS ESPECÍFICOS E ASPECTOS METODOLÓGICOS RELACIONADOS

Fonte: A autora.

Em resumo, o quadro 8 destaca de forma sucinta as escolhas metodológicas realizadas para o desenvolvimento da pesquisa, (anteriormente abordadas nesta seção) com enfoque em cada um dos principais componentes do percurso metodológico.

\begin{tabular}{|l|l|}
\hline \multicolumn{1}{|c|}{ COMPONENTES } & \multicolumn{1}{c|}{ ESCOLHAS METODOLÓGICAS } \\
\hline 1) Forma de abordagem do problema & $\begin{array}{l}\text { Pesquisa exploratória } \\
\text { Abordagem quantitativa e qualitativa }\end{array}$ \\
\hline 2) Estratégia de Pesquisa & $\begin{array}{l}\text { Estudo de caso único } \\
\text { 4) Unidade de análise } \\
\text { dede social de apoio às vítimas da chuva de } \\
\text { dezembro de 2013 no ES: Núcleo de Apoiadores }\end{array}$ \\
\hline 5) Fontes de coleta de dados & $\begin{array}{l}\text { Entrevistas } \\
\text { Questionários } \\
\text { Levantamentos não estruturados } \\
\text { Perfil "Apoiadores" no Facebook. }\end{array}$ \\
\hline $\begin{array}{l}\text { 6) Tratamento e Análise de dados coletados em } \\
\text { campo }\end{array}$ & $\begin{array}{l}\text { Transcrição das entrevistas } \\
\text { Tabulação dos dados dos questionários dos dados constantes no perfil } \\
\text { "Apoiadores" no Facebook } \\
\text { Análise de Redes Sociais com a utilização do } \\
\text { software Pajek. } \\
\text { Baseando-se nas proposições teóricas que } \\
\text { levaram ao estudo de caso }\end{array}$ \\
\hline 7) Discussão dos resultados & $\begin{array}{l}\text { Considerando pressupostos e objetivos } \\
\text { propostos. } \\
\text { À luz das reflexões teóricas apresentadas }\end{array}$ \\
\hline
\end{tabular}

QUADRO 8 - RESUMO DA ESTRATÉGIA DE PESQUISA PROPOSTA

Fonte: adaptado de Neto, Barbosa e Cendón (2006).

Diante do exposto, passa-se no próximo capítulo, à apresentação e análise dos dados coletados. 


\section{APRESENTAÇÃO E DISCUSSÃO DOS RESULTADOS}

A apresentação e a discussão dos resultados obtidos por meio dos instrumentos de coleta de dados estão estruturadas com base nos pressupostos adotados, considerando suas relações com o alcance dos objetivos e com a definição dos aspectos metodológicos propostos para o estudo.

Nas seções deste capítulo são apresentados e analisados os dados coletados a partir de entrevistas, questionários, levantamentos não estruturados e no perfil "Apoiadores" no Facebook, de acordo com o esquema apresentado no quadro 7, do capítulo anterior. Nesse sentido, o referido quadro foi a base essencial para a estruturação da apresentação e análise dos resultados.

Conforme o mesmo quadro, foram realizadas também análises a partir do método de ARS que estão ilustradas em grafos específicos, a partir dos quais podem ser visualizadas características e propriedades estruturais relevantes da rede em estudo.

\subsection{O SURGIMENTO E A ORGANIZAÇÃO DA REDE}

Esta seção relaciona-se ao primeiro pressuposto $\left(P_{1}\right)$ da pesquisa que considera que "as redes sociais atuantes em ações de resposta a desastres naturais, inseremse no âmbito da Ciência da Informação como um fenômeno não clássico, cuja organização e animação encontram significativo suporte nas novas TICs."

Além disso, estão presentes nesta seção, conexões importantes com o alcance de dois dos objetivos específicos propostos:

$\mathrm{O}_{\mathrm{E} 1:}$ Descrever o surgimento de uma organização estruturada na forma de rede social no caso específico da resposta às chuvas de dezembro de 2013 no ES, bem como as atividades por ela desenvolvidas. 
$\mathrm{O}_{\mathrm{E} 2}$ : Identificar os fenômenos de comunicação e mediação da informação existentes nessa rede social.

A entrevista realizada com a informante-chave aqui denominada A01 teve como uma das finalidades o detalhamento de aspectos relacionados ao surgimento da rede, suas motivações, objetivos iniciais e formas de atuação $\left(E_{A 2}\right)$. Além disso, também permitiu identificar quais as ações e como elas foram desenvolvidas pela rede durante as fortes chuvas de dezembro de 2013 no $E S\left(E_{A 3}\right)$. Os dados coletados por meio dos levantamentos não estruturados com A19 e A08 também estão aqui apresentados, de forma complementar à entrevista com A01.

Os questionários foram aqui utilizados especificamente em sua finalidade de mapear os mecanismos de comunicação por meio dos quais o respondente recebia e enviava informações a seus relacionamentos $\left(Q_{5}\right)$. Por meio dos questionários conseguiu-se ainda, identificar os atores participantes da rede, seus relacionamentos e atividades que desenvolveram $\left(Q_{1}\right)$.

O grafo que ilustra a topologia da rede analisada também consta da apresentação dos dados, permitindo a visualização da estrutura dos conexões que puderam ser mapeadas.

Alguns exemplos de informações divulgadas no perfil Apoiadores no Facebook auxiliam, especificamente, sobre a investigação da relevância dessa tecnologia na organização e na consolidação da ação coletiva desenvolvida pela rede. Sendo assim, passam a ser apresentados os dados oriundos dessas diferentes fontes de coleta.

\subsubsection{Como tudo começou e o papel do Facebook}

De acordo com A01, a rede de apoio às vítimas das chuvas começou a ganhar forma a partir de um chat entre alguns amigos, por intermédio do Facebook, onde discutiram de que forma poderiam ajudar na situação catastrófica que se abatia 
sobre o ES. Foi dessa primeira e breve discussão que surgiram as sementes para a estruturação das atividades da rede.

[...] na ante véspera teve uma grande chuva em Vitória. Foi quarta, bloqueou várias vias, eu fiquei presa na Marechal Campos, todo mundo parado ou o carro morrendo. [...] Bom, teve esse dia, então eu pensei, a coisa está séria. Tinha havido algumas chuvas pelo interior do Estado, mas isso começou a chegar perto, acho que isso foi marcante. $E$ no dia seguinte, eu não lembro se foi nessa cronologia exata, mas, eu acho que no dia seguinte eu acordei com uma mensagem de lamentação no Facebook, do tipo: "Ah, não sei o que lá...o que está acontecendo... Meu Deus, que pena... não sei que..." Aí aquilo me grilou, porque assim, vem cá, lamentando? Porque não faz alguma coisa? Aí eu falei, vamos fazer alguma coisa. [...] Então eu comecei a conversar. Puxa, vamos fazer alguma coisa! Aí chamei algumas pessoas no Facebook para uma conversa [...] (TRECHO EXTRAÍDO DA ENTREVISTA COM A01).

De acordo com A01, após essa conversa inicial, duas ações paralelas foram os primeiros passos dados por aqueles que se prontificaram a iniciar a ajuda. Uma delas foi a criação de um perfil no Facebook para recebimento de demandas e divulgação de informações de utilidade pública, acerca dos desdobramentos do desastre natural em curso. Isso foi feito em 19 de dezembro de 2013, o mesmo dia em que ocorreu o chat.

[...] Nessa reunião de manhã apareceu a ideia de criar uma página no Facebook. Nove horas da manhã, todo mundo no chat, conversando, e então surgiu a ideia: vamos fazer a página no Facebook. Por ali a gente mobiliza. Então fomos tentando dividir tarefas. Um ficava com isso, o outro cuidava daquilo [...] (TRECHO EXTRAÍDO DA ENTREVISTA COM A01).

O perfil foi intitulado "Apoiadores - Rede de Apoio Social às Vítimas das Chuvas no ES". A descrição ali contida aponta como sua finalidade "articular as demandas das vítimas das chuvas no Espírito Santo com as iniciativas de ONGs, empresas, grupos e pessoas interessadas em ajudar". Em seus primeiros quatro dias de funcionamento, o perfil no Facebook já possuía mais de dez mil curtidas. Em 2015 são mais de quinze mil. A seguir estão apresentadas as fotos do perfil - figura 11 - e a foto de capa - fotografia 3 , nesta sequência. 


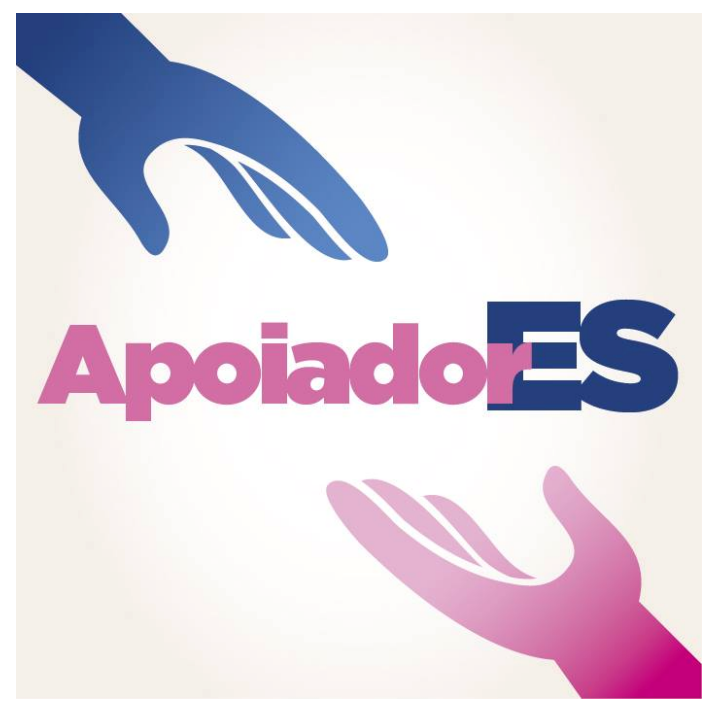

FIGURA 11 - FOTO DO PERFIL DOS APOIADORES NO FACEBOOK Fonte: Apoiadores (2013).

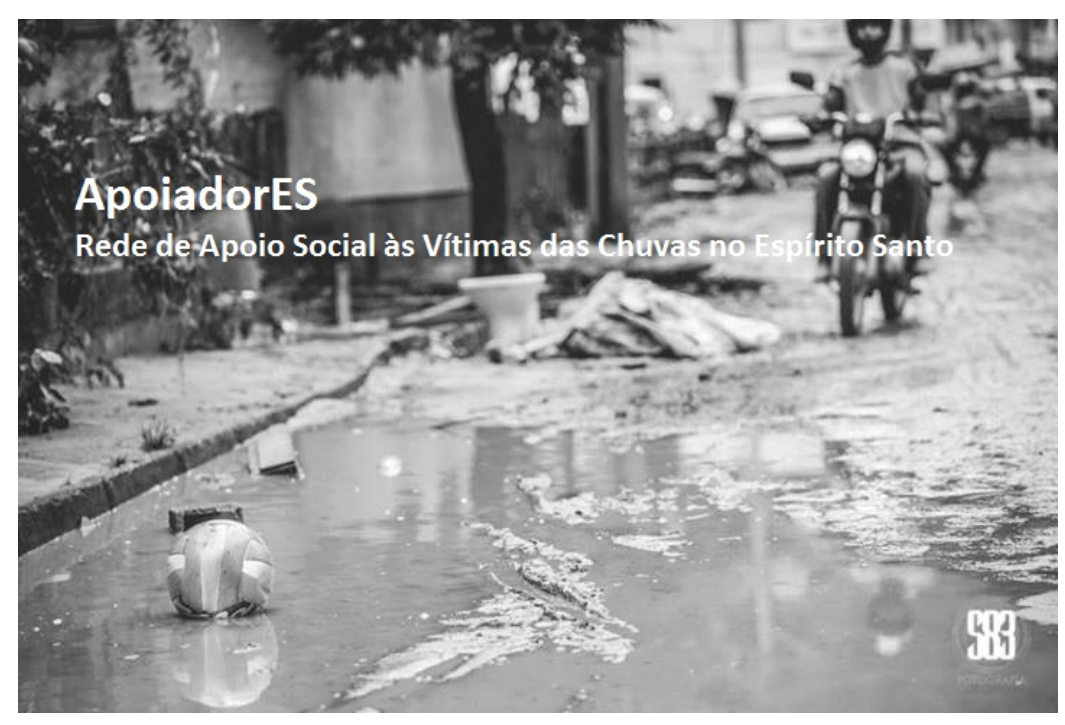

FOTOGRAFIA 3 - FOTO DE CAPA DOS APOIADORES NO FACEBOOK Fonte: Apoiadores (2013).

A observação do conteúdo dos posts existentes no perfil dos Apoiadores no Facebook permite verificar que durante todo o período em que a rede se manteve ativa, ou seja, entre 19 e 28 de dezembro de 2013, o perfil funcionou como espaço para divulgação de informações de utilidade pública sobre a situação do Estado, incluindo: pontos de arrecadação de donativos, situação de alagamento nas estradas, boletins de previsão do tempo, solicitação de donativos específicos (conforme informações recebidas dos pontos de coleta), dados sobre as entregas de donativos já realizadas, estatísticas de pessoas desabrigadas, desalojadas e óbitos, além de muitas outras. A seguir, nas figuras 12, 13 e 14 estão apresentados 3 posts 


\section{que foram selecionados com a finalidade de exemplificar tais divulgações de informação:}

Apoiadores: Rede de Apoio Social às Vítimas das

Chuvas no Espírito Santo

24 de dezembro de 2013

Segundo o Corpo de Bombeiros no momento, os municípios com situação mais crítica são Santa Leopoldina, Santa Maria de Jetibá, Itaguaçu e Barra de São Francisco. \#chuvasnoES

\begin{tabular}{|c|l|}
\hline 4.904 pessoas alcançadas & Opção para Impulsionar indisponivel \\
\hline Curtir Comentar $\quad$ Compartilhar \\
\hline
\end{tabular}

FIGURA 12 - POST SOBRE MUNICÍPIOS EM SITUAÇÃO CRÍTICA Fonte: Apoiadores (2013).

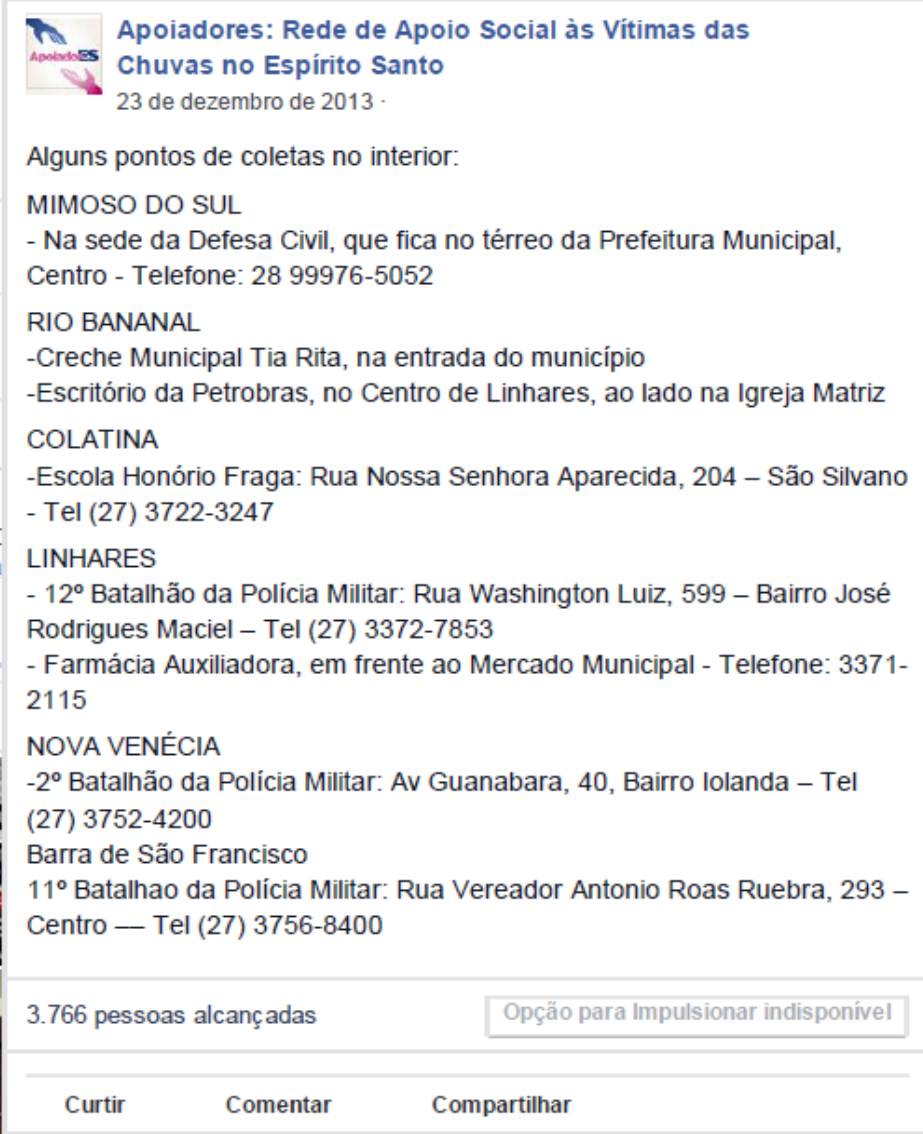

FIGURA 13 - POST SOBRE PONTOS DE COLETA NO INTERIOR Fonte: Apoiadores (2013). 
Apoiadores: Rede de Apoio Social às Vítimas das

Chuvas no Espírito Santo

23 de dezembro de 2013

APOIADORES: Segue a lista do que foi distribuído hoje (23/12) em doações para os municípios capixabas (parcial em toneladas)

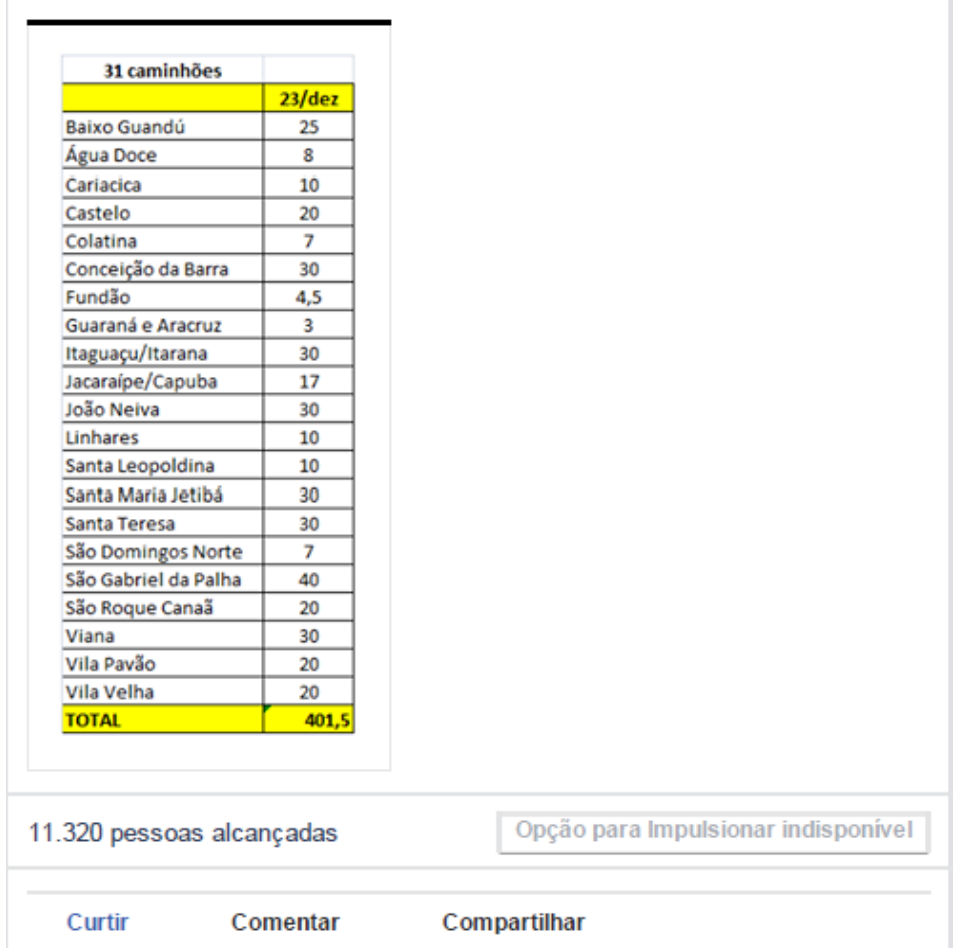

FIGURA 14 - POST SOBRE LISTA DE ENTREGA DE DOAÇÕES EM 23/12/2013 Fonte: Apoiadores (2013).

O perfil também foi um suporte significativo para as ações desenvolvidas por voluntários nos pontos de coleta, pois, por meio das informações ali divulgadas os doadores poderiam saber o que era mais necessário em determinado momento, interessados eram convidados a fornecer alimentação para os voluntários e empresas de transporte e logística eram chamadas a contribuir voluntariamente com caminhões e motoristas, para o envio dos donativos para o interior, dentre outras questões. Além disso, voluntários em diferentes áreas eram convidados a participar. As figuras destacadas a seguir, 15, 16 e 17 ilustram exemplos dessas ações. 


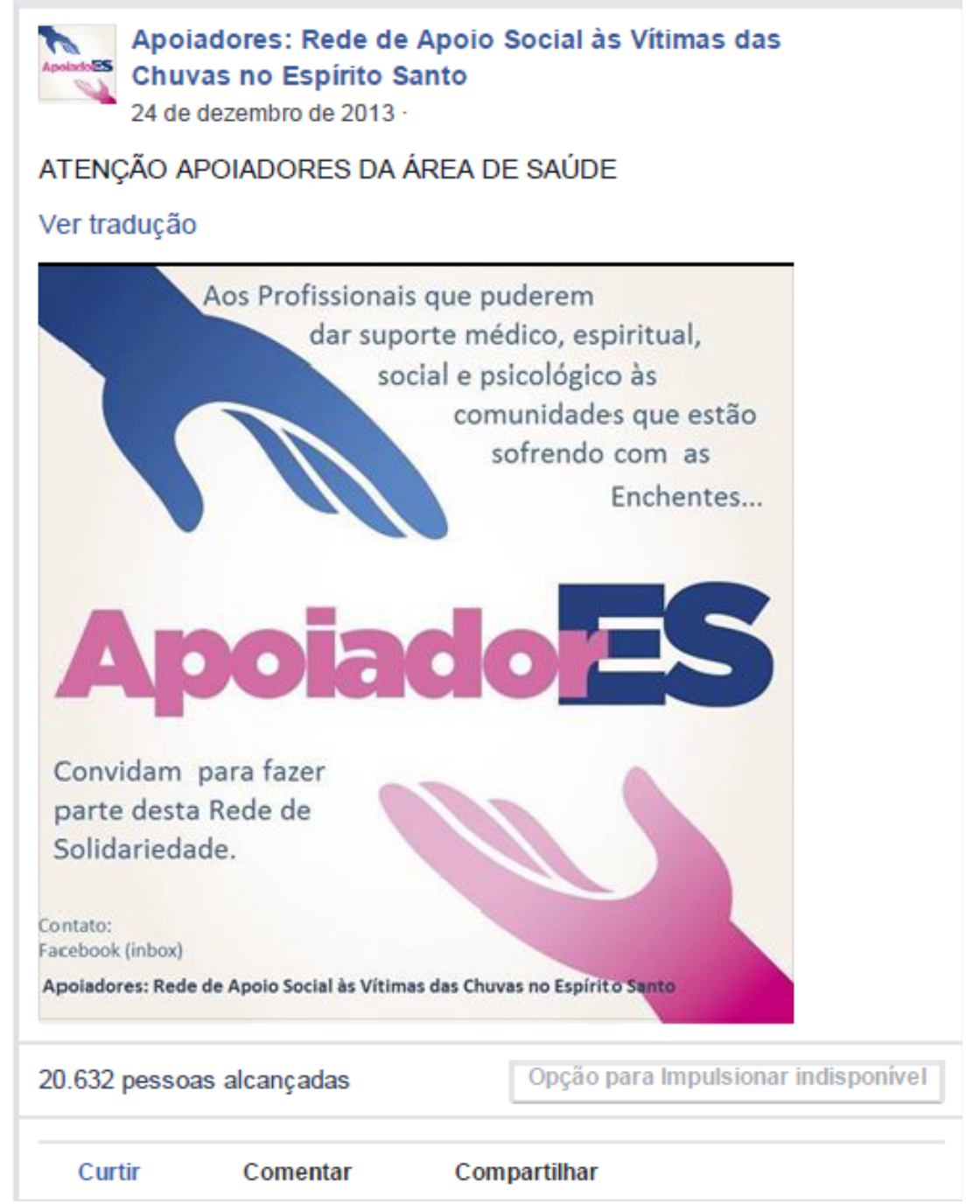

FIGURA 15 - POST CONVIDANDO VOLUNTÁRIOS NA ÁREA DE SAÚDE Fonte: Apoiadores (2013).

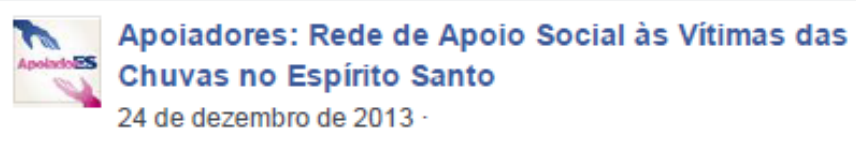

DOAÇÕES PRAÇA DO PAPA: As doações poderão ser feitas hoje até 17 hs e depois somente do dia $26 / 12$ pela manhã em diante.

Os trabalhos lá se encerrarão às $17 \mathrm{hs}$ de hoje e serão retomados dia 26/12 pela manhã

\begin{tabular}{|c|c|}
\hline 8.356 pessoas alcançadas & Opção para Impulsionar indisponível \\
\hline Comentar & artilhar \\
\hline
\end{tabular}

FIGURA 16 - POST SOBRE SUSPENSÃO DE ATIVIDADES NA PRAÇA DO PAPA DURANTE O DIA DE NATAL

Fonte: Apoiadores (2013). 


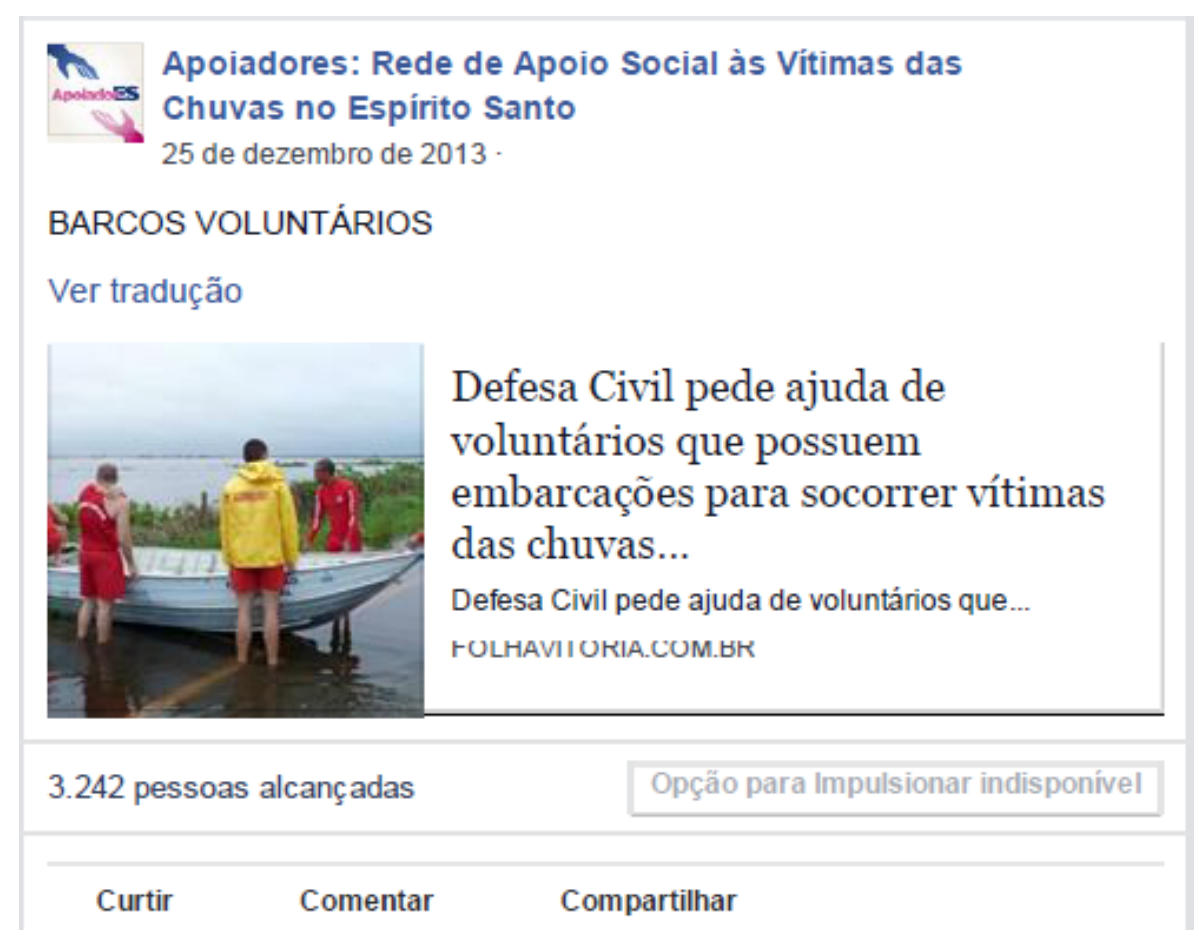

FIGURA 17 - POST SOBRE PEDIDO DO CORPO DE BOMBEIROS PARA VOLUNTÁRIOS COM EMBARCAÇÕES

Fonte: Apoiadores (2013).

Pelo exposto até aqui, pode-se observar que o Facebook possuiu uma significativa contribuição tanto no processo de mobilização inicial da rede, quanto durante o desenvolvimento das ações. Considerando o que aponta Castells (1999), evidenciase assim, sobre a rede em análise, o reflexo do caráter típico da sociedade da informação, que apresenta a tecnologia e a informação como partes integrantes tanto dos processos produtivos quanto das relações sociais.

Diante dos dados apresentados, observa-se, conforme destaca Recuero (2009) a Internet como suporte a uma forma de organização social que se estruturou por meio de um site de rede social. Por intermédio de trocas comunicacionais nesse site buscou-se uma mobilização em prol do auxílio às vítimas das chuvas.

O uso de sites de redes sociais como o Facebook, como suporte em ações coletivas voltadas para a solução de problemas em contextos pós-desastre, como a que aqui se observou, é amplamente apontada nos estudos Vieweg (et al., 2008).

Nas palavras de Di Felice (2007) trata-se de um social tecnológico, onde novos dispositivos de comunicação e programas de computador apresentam-se como objetos materiais em torno dos quais existem grupos humanos em uma ação 
coletiva complexa. Pelos dados apresentados até aqui, pode-se compreender a importante infraestrutura informacional representada pelo Facebook, que se constituiu como verdadeiro suporte para a estruturação e consolidação dos objetivos coletivos definidos pela rede.

Ao lado do Facebook, outras tecnologias como a telefonia móvel e o Whatsapp possuíram um papel fundamental na troca de informações entre os atores da rede em análise, conforme será mais bem discutido, adiante.

\subsubsection{As atividades desenvolvidas pela rede}

Voltando a tratar mais especificamente da entrevista com A01, pode-se verificar que dentre as pessoas participantes da rede, uma delas, A15, possuiu maior destaque no gerenciamento do perfil no Facebook. Além disso, a entrevistada destacou que a inserção de A15 nessa tarefa se deveu, em grande medida, a sua experiência anterior na área de comunicação. Essa questão é um ponto bastante interessante destacado por A01. Muitos dos participantes da rede acabaram assumindo determinadas "funções" em razão de seus conhecimentos, habilidades e experiências adquiridas anteriormente em suas atividades profissionais, ou de seus relacionamentos e capacidade de acionar suas próprias redes pessoais para viabilizar as ações. $O$ trecho a seguir retrata mais claramente a visão de A01, nesse sentido, quando escolheu algumas pessoas em sua rede no Facebook para iniciar o chat.

[...] Então chamei algumas pessoas no Facebook para uma conversa. Eu tive critério, eu tenho uma boa rede de relacionamentos, então eu fui pegando pessoas chave. E eu fui atrás de pessoas que tinham poder de articulação, ou que tinham poder financeiro, ou que ocupam uma posição importante, ou que podiam chamar ou cutucar alguém e fui chamando essas pessoas para esse bate papo no chat do Facebook. [...] o grande problema quando acontece isso, uma tragédia e tudo o mais, é que fica todo mundo igual maluco, perdido. E então eu usei também um critério técnico, as pessoas que tinham capacidade de organização, que poderiam divulgar. E então pensei em pessoas de marketing e também de TV, então chamei algumas pessoas com esse envolvimento que tinham esse engajamento pra poder participar. 
No seguinte trecho, A01 relata o exemplo específico de A15 e de como seus conhecimentos, habilidades e experiência anterior na área de comunicação, puderam ser úteis nas atividades que desenvolveu na rede.

[...] ao mesmo tempo apareceu uma pessoa fundamental que foi a $A 15$ que é da área de MKT, trabalha na Agência X, que assumiu as postagens. A15 foi a voz no Facebook a maioria do tempo, mas tinha outras pessoas postando também. [...] Então ela recebia as informações da gente: preciso de caminhão, preciso disso [...] A15 é a mais chave de todas aqui em relação à gestão da página. Todos postavam, mas quem mais postou foi ela. E isso foi chave para que o grupo conseguisse tamanha adesão. (TRECHO EXTRAÍDO DA ENTREVISTA COM A01).

No mesmo sentido, A08, que não participou do chat no Facebook - tendo em vista que não conhecia A01 antes das ações de dezembro - informou que sua formação como técnico em logística foi fator determinante para sua contribuição durante a ação coletiva. Segundo o ator, o fato de possuir essa formação foi o principal fator que o fez pensar que pudesse ser de grande ajuda, quando soube da ação que estava acontecendo na Praça do Papa. Assim, ele se dirigiu ao local e se ofereceu para ajudar no que fosse preciso, destacando que possuía conhecimentos na área de logística.

A19, por sua vez, informou que na ocasião das chuvas de 2013, atuava prestando serviços de manutenção de caminhões para diferentes empresas da área de transporte e logística e que não conhecia anteriormente as pessoas que já estavam se articulando na Praça do Papa. Esse ator destacou que, quando chegou até a Praça e se juntou ao Núcleo de Apoiadores, já havia passado alguns dias no interior do estado, entregando donativos que havia comprado e também arrecadado entre seus contatos. Assim, ele pode trazer informações importantes sobre a situação de alguns municípios no interior do Estado, bem como agregar à rede, seus contatos pré-existentes, principalmente com empresas transportadoras, como poderá ser observado a partir da visualização do grafo representativo do Núcleo de Apoiadores.

Este outro trecho da entrevista com A01 também deixa claro que, além da sua percepção acerca das habilidades das pessoas que foram acionadas, houve também um processo espontâneo de acomodação das pessoas em determinadas atividades, por se sentirem à vontade naquelas tarefas.

[...] E o negócio foi institucionalizando, naturalmente, cada um já tava fazendo alguma coisa e a gente foi e começou a conversar e a se inteirar e 
concluiu que cada um estava fazendo o que estava fazendo, e estava fazendo bem feito. Por que cada um já assumiu aquela tarefa porque já se sentiu confortável. Eu fazia a articulação entre a Defesa Civil Estadual, os municípios, as defesas civis, os secretários para ver o que tinha. E tinha os contatos com alguns pontos, com os doadores e tudo o mais.[...] Mas assim, o que eu fazia de mais forte era conseguir organizar os carregamentos, por exemplo, eu ficava focada na articulação, então cada um foi absorvendo de acordo com sua competência, é uma liderança reconhecida [...] (TRECHO EXTRAÍDO DA ENTREVISTA COM A01).

Estes trechos da entrevista de A01 e os dados fornecidos por A08 e A19 refletem o que propõe Quarantelli (2005) acerca das condições básicas essenciais para que ocorra a emergência de grupos de suporte nas ocorrências de desastres naturais. Segundo o autor, a existência de determinados recursos específicos necessários à ação coletiva é fundamental para a emergência de grupos dessa natureza. Tais recursos referem-se não apenas à existência de fontes materiais e humanas para a execução das tarefas, como também de conhecimento relevante a ser aplicado na situação.

Os dados também permitem uma interessante conexão com o fenômeno emergente da inteligência coletiva, diretamente imbricado na lógica das redes sociais. Especialmente a partir da abordagem proposta por Heylighen (2013) e Noubel (2006), é possível enxergar a ação colaborativa desenvolvida pela rede em análise, como um fenômeno de inteligência coletiva.

Percebe-se a existência de uma coordenação cognitiva (HEYLIGHEN, 2013) entre os agentes participantes da rede, em que cada um deles se acomodou no exercício de atividades que se conformavam mais diretamente a suas habilidades, conhecimentos e experiências pessoais específicas, numa soma de esforços que resultou na oferta de uma solução possível para parte dos problemas enfrentados em decorrência das chuvas.

Assim, os resultados obtidos foram decorrentes de ações desenvolvidas em grupo, a partir do acionamento de habilidades individuais, onde o todo se tornou maior do que a simples soma das partes. Foi possível observar, pelos trechos destacadas da entrevista com A01, que, apesar de ela mesma ter inicialmente buscado acionar pessoas que julgava possuir determinadas habilidades, conhecimentos e experiências interessantes para o trabalho a ser desenvolvido - ou seja, uma intervenção deliberada sobre essa composição de habilidades e competências dos atores - houve, com o desenrolar das atividades, a acomodação natural e 
espontânea dos atores em determinadas tarefas. Além disso, conforme os dados fornecidos por A08 e A19, novos atores, que não participaram da articulação inicial no chat, também foram se agregando ao núcleo da rede, e se acomodando em atividades conforme seus próprios conhecimentos e experiências.

Essas atividades desenvolvidas no âmbito da rede puderam ser mapeadas a partir da entrevista com A01. Foi possível identificar as principais atividades, principalmente relacionadas à articulação das demandas por donativos, junto aos diferentes envolvidos. Foram listadas e incluídas no questionário aplicado, para que se pudesse identificar o envolvimento dos respondentes em cada uma delas. $O$ resultado dessa questão específica do questionário, encontra-se no quadro 9 a seguir.

\begin{tabular}{|l|l|}
\hline \multicolumn{1}{|c|}{ ATIVIDADES } & \multicolumn{1}{|c|}{ ATORES ENVOLVIDOS } \\
\hline $\begin{array}{l}\text { Contatos com Prefeituras, Corpo de Bombeiros, Cruz } \\
\text { Vermelha ou Defesa Civil para levantamento de } \\
\text { necessidades de donativos. }\end{array}$ & A01, A03, A17, A18, A19 \\
\hline Administração do perfil Apoiadores no Facebook. & A01, A03, A11, A15, A18, ONG03 \\
\hline $\begin{array}{l}\text { Contatos com Empresas Privadas ou pessoas físicas para } \\
\text { solicitação de donativos ou viabilização de recursos. }\end{array}$ & $\begin{array}{l}\text { A01, A03, A07, A08, A17, A18, } \\
\text { A19, A21 }\end{array}$ \\
\hline $\begin{array}{l}\text { Coordenação de atividades de recebimento, separação, } \\
\text { organização ou embalagem de donativos recebidos. }\end{array}$ & A01, A06, A08, A19, A20 \\
\hline $\begin{array}{l}\text { Articulação com as instituições envolvidas nas ações de de } \\
\text { apoio às vítimas, visando à organização e à continuidade } \\
\text { das atividades. }\end{array}$ & $\begin{array}{l}\text { A01, A06, A08, A17, A18, A19, } \\
\text { A20, ONG3 }\end{array}$ \\
\hline $\begin{array}{l}\text { Recebimento, separação, organização ou embalagem de } \\
\text { donativos recebidos. }\end{array}$ & A07, A08, A17, A19, A20, A21 \\
\hline $\begin{array}{l}\text { Contatos com Prefeituras Municipais para viabilização da } \\
\text { chegada dos donativos às cidades afetadas }\end{array}$ & A01, A08, A17, A19, A21, ONG02 \\
\hline $\begin{array}{l}\text { Acompanhamento das viagens de caminhão/avião com } \\
\text { donativos para as cidades afetadas }\end{array}$ & A08, A19, A20, ONG02 \\
\hline $\begin{array}{l}\text { Idas às cidades afetadas nos caminhões/aviões para entrega } \\
\text { dos donativos }\end{array}$ & A08, A19, A20 \\
\hline
\end{tabular}

QUADRO 9 - ATIVIDADES E ATORES ENVOLVIDOS

Fonte: A autora

Observa-se que, de forma geral, cada um dos atores respondentes acabou por se envolver em diferentes atividades simultaneamente. Além disso, há inúmeras 
sobreposições, em que vários atores exerceram uma mesma atividade, evidenciando certo ruído, típico dos sistemas auto-organizados.

Conforme destaca Heylighen (2013) esse é um processo de divisão do trabalho de natureza auto-organizativa. Essa forma de divisão do trabalho é essencial à compreensão da inteligência coletiva na concepção do autor, em que a definição de tarefas prescinde de qualquer imposição ou definição a priori, pois ocorre de forma espontânea. Para o autor, a inteligência coletiva se configura intrinsecamente como um processo de auto-organização em que a divisão do trabalho se dá por uma busca natural dos agentes por atividades para as quais percebem maior habilidade e facilidade para o desenvolvimento, de maneira que a divisão ocorre de forma espontânea entre os indivíduos.

É nesse mesmo sentido que Lévy (1999) sustenta que os dispositivos técnicos que propagam a inteligência coletiva não são vistos como resultados de um planejamento elaborado por especialistas em um poder central. Percebe-se assim, seu caráter integrador, includente e participativo. Tal perspectiva leva também à percepção do caráter emancipador tanto da inteligência coletiva - defendido por Lévy (1999) - quanto das redes sociais - apontado por Franco (2012), Martinho e outros 2003 e Serva (1992). Essa possibilidade de emancipação ocorre no sentido de que os atores puderam buscar atuar em atividades nas quais melhor se acomodaram. Pode-se depreender, a partir dos resultados alcançados pela rede que 0 desenvolvimento e a conclusão das atividades se deram por meio do alinhamento entre os atores em função da perseguição de um objetivo comum (ajudar as vítimas das chuvas).

Essa ótica de espontaneidade e auto-organização da rede permite também uma aproximação com o pensamento de Serva (1992) acerca das redes como organizações alternativas. Essas possuem na espontaneidade a mola mestra de sua criação e também de seu funcionamento, subvertendo os padrões clássicos da teoria organizacional. Tal pensamento se assemelha em grande parte à visão de Martinho e outros (2003) sobre as redes sociais, quando afastam da sua dinâmica a vinculação a papeis, regulamentos, cargos e departamentos.

Sob esse aspecto, emerge a possibilidade de reflexão sobre a oposição entre a concepção de organização como máquina e de organização como rede. Se 
estivesse sob consideração o funcionamento de uma organização burocrática, a partir da tradicional divisão e especialização do trabalho, usualmente corroborada num plano de cargos e salários, a situação constatada pela apresentação dos dados seria inadmissível. Entretanto, considerando o caráter espontâneo e autoorganizativo da divisão do trabalho na rede, além da necessidade de flexibilidade e dinamismo, tal realidade pode não causar tanto espanto. Enquanto divisões muito rígidas de tarefas podem levar a certo engessamento ou lentidão no desenvolvimento das atividades, certa "multifuncionalidade" pode proporcionar ritmo, flexibilidade e capacidade organizativa ao processo.

Conforme destaca Heylighen (2013), no contexto da inteligência coletiva emergente nas redes sociais, a acomodação da divisão e do fluxo do trabalho ocorre por meio de tentativa e erro, aonde as ações vão sendo constantemente avaliadas e modificadas num processo naturalmente auto-organizativo. Complementarmente, na visão de Morin (2005), a desordem e ruído são partes integrantes do próprio sistema, que, apesar do erro consegue se desenvolver e ampliar suas atividades, denotando uma capacidade auto-organizativa constante.

Além da criação do perfil dos Apoiadores no Facebook, a outra ação inicial desenvolvida foi o deslocamento para postos de coleta de donativos já instalados, de forma a iniciar as atividades de apoio na articulação das demandas, na organização de atividades, e no processo logístico, envolvendo especificamente o recebimento e alocação de donativos às vítimas.

Inicialmente, conforme relatou A01, os objetivos dos Apoiadores foram bastante modestos, se comparados aos resultados finais alcançados. As primeiras ideias de atuação eram: mapear e ampliar os pontos de arrecadação de donativos; levantar necessidades de doações para o município de Rio Bananal, que foi o primeiro a ser atingido fortemente pelas chuvas; divulgar as demandas das populações atingidas e os pontos de coletas de donativos já instalados e apoiar as atividades de logística do transporte de donativos dos diferentes pontos até o ponto central de coleta coordenado pela Defesa Civil.

[...] a ideia inicial era mapear as necessidades das pessoas e tentar mapear os pontos de coleta, que eram pouquinhos, ainda estava começando a história [...] quando eu chamei as pessoas para conversar, algumas outras ideias começaram a surgir: a gente podia também colocar uma pessoa trabalhando na parte logística, ajudar um pouco, dar algum suporte na parte 
de logística [...] logística era levar do ponto para centralizar em algum lugar.A gente ia mapear os pontos, a gente não sabia quais tinham ainda [...] Eu falei olha, vocês vejam essa parte aí e eu vou fazer contato com a Defesa Civil Estadual pra ver o que eles estão precisando e se tem algum ponto que a gente pode concentrar depois de coletar para mandar prá lá [...] porque aí a gente ficou sabendo do quarto batalhão da PM que estava centralizando, só que ele também não sabia o que fazer com isso. Eles poderiam levar pra lá, era um lugar que tinha um espaço maior, mas lá também não estava definido. $E$ aí alguém falou: tem um caminhão da Cruz Vermelha na Praça do Papa, aí eu falei: "estou indo lá agora que pode ser a solução. A gente encaminha todas as doações pra lá, separa, organiza lá e depois o pessoal manda." Aí chegamos lá, a gente viu que era uma ação da Cruz Vermelha com a TV Vitória, uma coisa que eles fizeram em parceria. A TV Vitória conseguiu o caminhão, a Cruz Vermelha estava mobilizando. Então eu cheguei lá e vi que o caos estava instaurado. Vi que tava tudo solto, uma falta de controle, uma bagunça, aí eu comecei a ficar agoniada. [...] eu comecei a fazer uns contatos, aí sabe aquele negócio que a gente não sabe como aconteceu a história? Eu fui lá só pra saber como direcionar os pontos que a gente tava começando a juntar, pra chegar lá na ponta [...] (TRECHO EXTRAÍDO DA ENTREVISTA COM A01).

As ações de recebimento, separação, organização, embalagem e envio de donativos estavam centralizadas na capital Vitória, em um galpão localizado na Praça do Papa. De acordo com A01, outros dois pontos menores de arrecadação coordenados pelos Apoiadores também foram importantes. Um deles localizado no Shopping Jardins, no bairro de Jardim da Penha, em Vitória, e outro em um Boliche localizado no bairro de Laranjeiras, no Município da Serra.

Os principais objetivos de atuação da rede também estão descritos no perfil dos Apoiadores no Facebook, em uma publicação de 19 de dezembro de 2013, que teve um alcance de mais de 20.000 pessoas, conforme a figura 18:

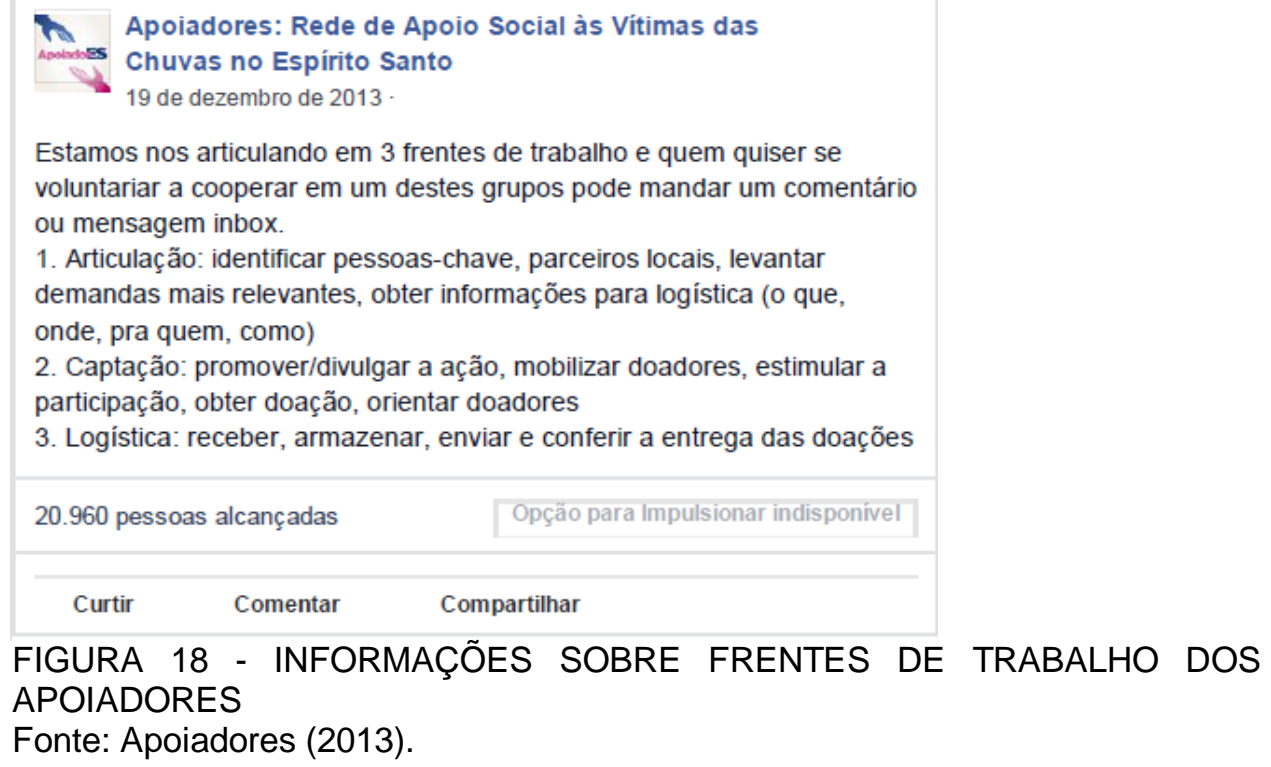


Entretanto, com o passar de pouquíssimo tempo, a atuação da rede foi significativamente ampliada. A01, durante a sua entrevista, mencionou informações que divulgou em seu perfil no Facebook, sobre essa questão e autorizou a sua utilização no trabalho. Assim, o conteúdo da publicação abaixo, realizada em 27 de dezembro de 2013, revela a percepção de A01, acerca da magnitude alcançada pelo movimento.

\begin{abstract}
Lembro claramente que na quinta-feira, dia 19/12, quando chamei alguns amigos, em um chat do Facebook, pensando em dar apoio às vítimas das chuvas, alguém comentou: mas o que meia dúzia de pessoas podem fazer? Criamos então o Apoiadores: Rede de Apoio Social às Vítimas das Chuvas no Espírito Santo. Nossa proposta desde o início era articular as demandas dos municípios, os órgãos responsáveis: bombeiros, Defesa Civil estadual e Municipais, Secretarias de Assistência Social, e principalmente: A POPULAÇÃO! Na sexta-feira, quando cheguei na Praça do Papa, onde já estava acontecendo uma ação promovida pela Rede Vitória, Cruz Vermelha e defesa Civil Municipal, que haviam conseguido um caminhão para levar donativos para Rio Bananal, é que nos demos conta do quanto aquilo era imprescindível! Graças a mobilização de todos, um caminhão tornou-se mais de 100 caminhões até o final do dia de ontem. Acabamos assumindo de fato a coordenação da distribuição de donativos para todo o estado, em parceria com a Defesa Civil Estadual e Municipal. Nós, um grupo de civis! Aquela meia dúzia de gatos pingados tornaram-se 13.750, com o alcance de mais de 760.000 pessoas, só na página dos Apoiadores! Hoje apoiaremos uma operação para esvaziar os donativos da Praça do Papa, enviando os donativos para o interior e realocando-os no Pavilhão de Carapina, sob o comando dos Corpo de Bombeiros Militar do ES I, que possui uma estrutura mais adequada para receber, armazenar e distribuir os donativos.

Continuaremos trabalhando em outras frentes e solicitamos a todos apoio para que continuem esse incrível trabalho! Parabéns a todos que se voluntariaram na triagem, carregamento e descarregamento de caminhões, fazendo donativos, cedendo caminhões, resgatando pessoas, e em tantas outras frentes de trabalho! O povo capixaba é o verdadeiro herói deste episódio, que ficará marcado em nossa história! Nós fizemos história! Nós mostramos do que somos feitos! Além de ajudar as pessoas que estavam precisando de nós, nós crescemos e nos tornamos ainda mais fortes e unidos! Certamente, nos tornamos um pouco melhor! Obrigado a todos e continuem contribuindo com a transformação de nosso estado! (POST EXTRAÍDO DO FACEBOOK DE A01).
\end{abstract}

De acordo com dados existentes no perfil dos Apoiadores, entre os dias 20 e 27 de dezembro de 2013 foram enviados aos municípios afetados 130 caminhões com um total de 1500 toneladas de donativos, incluindo alimentos, água, roupas, calçados, materiais de limpeza e higiene pessoal, além de brinquedos. De acordo com A01, A19 e A08, aviões e helicópteros também foram cedidos por empresas para a tarefa de transporte de pessoas e donativos. 
A08 em sua fala utilizou os termos "inteligência sobrenatural" e "lugar mágico" quando descreveu a sua percepção sobre a ação coletiva na Praça do Papa, demonstrando sua surpresa e admiração diante do que ali ocorreu.

A01 mencionou em vários momentos da entrevista, que não sabe explicar como as atividades tomaram tal proporção em tão pouco tempo. Segundo ela, não poderia ter imaginado que aquela mobilização inicial por meio do chat no Facebook iria resultar em algo tão "grandioso", nas palavras da entrevistada.

Uma possível consideração sobre essa questão é aquela que explica a conexão coletiva entre os agentes da rede, por meio de interações bottom-up, aonde a organização se dá de baixo para cima e leva o sistema a determinados comportamentos emergentes. Na concepção de Johnson (2003), isso explica, por exemplo, como formigas criam colônias e cidadãos criam comunidades. Nesse mesmo sentido, poderia explicar como o Núcleo de Apoiadores pode ter conseguido mobilizar, organizar e distribuir tantos recursos aos necessitados.

Para isso, é preciso pressupor, na rede analisada, a existência de determinados efeitos interdependentes combinados, nesse caso, viabilizados, em grande medida, pelas interações comunicacionais entre os agentes, que serão discutidas em maior profundidade na seção 5.2 .

\subsubsection{A topologia da rede em análise}

A partir das análises anteriores, torna-se ainda mais evidente a importância dos relacionamentos e das interações estabelecidas entre os atores da rede analisada. É preciso enfatizar que as atividades da rede só puderam ser concretizadas a partir dos relacionamentos estabelecidos entre diferentes personagens integrantes da sociedade civil organizada e desses com as chamadas organizações estabelecidas, expandidas e estendidas. 
O grafo 5 apresentado a seguir é resultante dos atores e relacionamentos que puderam ser mapeados a partir da coleta de dados por meio do questionário, consideradas as limitações já demonstradas na seção 4.2. Assim, identificados na cor amarela estão os atores que responderam o questionário. Os demais, na cor azul não responderam, seja porque estiveram fora da delimitação do estudo, ou, no caso dos atores "A", porque não puderam ser localizados ou realmente não retornaram com as respostas após contato.

Optou-se pelo desenho de arestas (laços não direcionados) e não de arcos (laços direcionados), em todos os grafos, considerando que a questão específica do questionário que solicitava aos respondentes que indicassem o sentido da informação (recebia, enviava ou ambos) para cada um de seus relacionamentos, teve praticamente $100 \%$ das respostas na terceira opção: ambos.

Considera-se esse resultado como uma evidência do que afirma Marteleto (2010) acerca da troca de informações em redes sociais, em que a visão diádica de uma zona de intercâmbio entre emissor e receptor de informação é considerada limitada.

Além do arquivo específico gerado para o desenho do grafo da rede, cuja extensão deve ser "net' no software Pajek, para que as partições pudessem ser evidenciadas, foi criado um arquivo específico, de extensão "clu" (que vem do inglês cluster), por meio do qual foi possível relacionar cada ator como tendo respondido ou não o questionário. O layout utilizado para o desenho da rede em todos os grafos apresentados é o Kamada-Kawai-livre, um algoritmo existente no Pajek, para a geração de layout automático no plano, onde cada posição no plano é possível.

O grafo 5 a seguir é então o desenho que resultou da combinação do arquivo net (rede) com o arquivo clu (partição) no Pajek, por meio da execução do comando Draw $>$ Network+First Partition. 


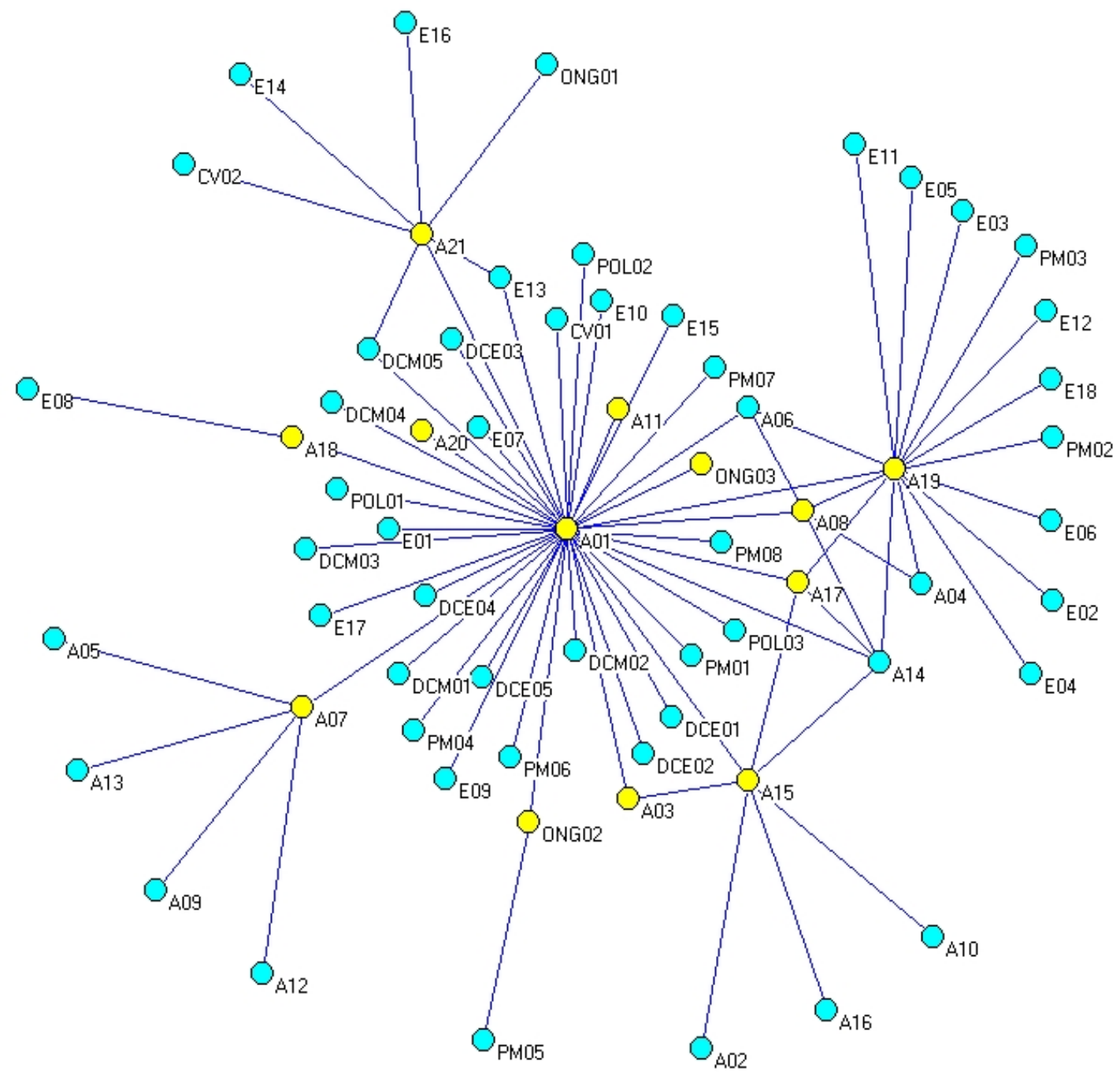

O Responderam ao questionário $\bigcirc$ Não responderam ao questionário

GRAFO 5 - NÚCLEO DE APOIADORES COM IDENTIFICAÇÃO DOS RESPONDENTES AO QUESTIONÁRIO

Fonte: A autora.

Pelas razões já esclarecidas no capítulo 4 que trata do percurso metodológico da pesquisa, a rede em análise foi denominada "Núcleo de Apoiadores".

No grafo 6 adiante estão consideradas as chamadas partições ou clusters definidos em função do tipo de instituição à qual pertenciam os atores desse núcleo, de acordo com a seguinte codificação e estrutura de cores, dispostas na tabela 3 : 
TABELA 3 - CÓDIGOS, CORES E NÚMERO DE ATORES EM CADA PARTIÇÃO DA REDE NÚCLEO DE APOIADORES

\begin{tabular}{clll}
\hline ÓDIGO & \multicolumn{1}{c}{ INSTITUIÇÃO } & \multicolumn{1}{c}{ COR } & NÚMERO DE ATORES \\
\hline A & Sociedade Civil & Amarelo & 21 \\
\hline CV & Cruz Vermelha & Verde & 02 \\
\hline DCE & Defesa Civil Estadual & Vermelho & 05 \\
\hline DCM & Defesa Civil Municipal & Roxo & 05 \\
\hline E & Empresas Privadas & Azul & 18 \\
\hline ONG & Organizações Não Governamentais & Rosa & 03 \\
\hline PM & Prefeitura Municipal & Branco & 08 \\
\hline POL & Polícia Militar & Laranja & 03
\end{tabular}

Fonte: A autora.

Assim, os vértices aparecem nas cores correspondentes à instituição à qual os atores pertencem. A codificação dos atores também foi realizada no sentido de permitir uma melhor visualização dessa segmentação na rede. Pode-se observar que os membros da sociedade civil aparecem em maior número, num total de 21 atores. Esses, juntamente com os representantes de ONGs (total de 3), representam o chamado grupo emergente, caracterizando-se como uma coletividade que não existia antes do desastre. O grupo emergente foi o foco principal do estudo aqui realizado, conforme já explicitado anteriormente.

Um número bastante significativo de atores com os quais os membros do grupo emergente na sociedade civil mantiveram contato foram os representantes de empresas privadas. Em sua enorme maioria eram transportadoras que cederam caminhões e motoristas para o transporte de donativos às cidades afetadas, como foi o caso de E02, E10, E11, E12, E17 e E18. Nesse rol, também estão outras empresas privadas como mineradoras, que emprestaram helicópteros e pilotos também para essa finalidade, a exemplo de E05 e E06. Essas, a partir da nomenclatura do Disasters Research Center (DRC), da Universidade de Delaware, nos Estados Unidos, (QUARANTELLI, 1993; RODRIGUEZ; TRAINOR; QUARANTELLI, 2006) podem ser classificadas como organizações estendidas, pois passaram a desenvolver atividades não regulares ou não tradicionais, em função do desastre.

Foram também mapeados na rede dois atores participantes de uma organização expandida, a Cruz Vermelha (CV). Essa organização, além de suas tarefas 
tradicionais, realizou também certas alterações e expansões em suas estruturas normais de atuação, em decorrência do desastre natural.

As chamadas organizações estabelecidas, ou seja, aquelas que atuaram formalmente no cumprimento de suas tarefas regulares, conforme suas estruturais normais, estão representadas na rede por membros da Defesa Civil Estadual (DCE), Defesas Civis Municipais (DCM), Polícia Militar (POL) e Prefeituras Municipais (PM).

Foi criado um novo arquivo de extensão .clu, considerando como partições as organizações representadas na rede. $O$ grafo 6 a seguir é o diagrama que resultou da combinação do arquivo net (rede) com esse arquivo clu (partição) no Pajek, por meio novamente da execução do comando Draw>Network+First Partition.

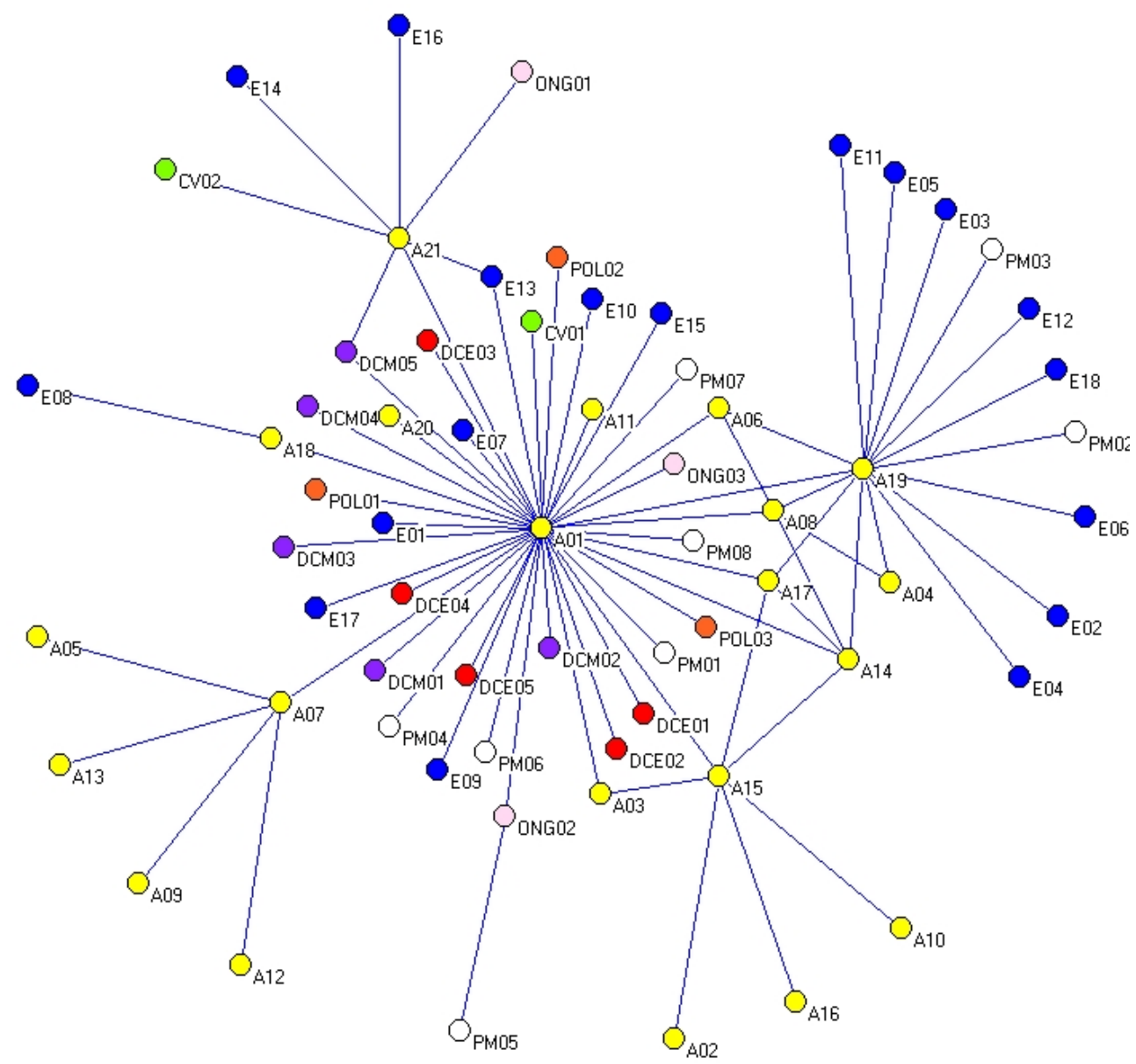

O Sociedade Civil O Cruz Vermelha O Defesa Civil Estadual O Defesa Civil Municipal - Empresas Privadas O Organizações Não Governamentais OPrefeituras Municipais O Polícia Militar

GRAFO 6 - NÚCLEO DE APOIADORES COM IDENTIFICAÇÃO DAS ORGANIZAÇÕES REPRESENTADAS NA REDE

Fonte: A autora. 
A rede em análise conta com 65 nós e 77 relacionamentos, considerando arestas não dirigidas. Conforme dados fornecidos pelo Pajek, em informações gerais sobre a rede, a densidade média é de $3,7 \%$, ou seja, entre todos os relacionamentos possíveis na rede, 3,7 \% estão presentes. O grau médio dos nós é de 2,4, o que significa dizer que os atores da rede possuem em média 2,4 relacionamentos com outros atores.

Conforme já mencionado, na realidade em estudo, foi necessária uma união de esforços entre membros do grupo emergente, mas também desses com os de outros atores pertencentes a organizações estabelecidas, expandidas e estendidas, para que pudessem realizar a contento todas as suas atividades. O próprio caráter de articulação de demandas, presente nas atividades da rede, traz em si a necessidade de interação com diferentes organizações, buscando, por exemplo, a mediação entre os chamados seekers e providers, ao se considerar a nomenclatura IOSP proposta por Varda e outros (2008).

Embora os próprios autores apontem como tal classificação pode ser bastante fluida em momentos de desastres, será considerado para efeito desta análise, os atores tipo "A" como out/providers (atuando fora da área do desastre como provedores de recursos às vítimas). Essa definição baseia-se no fato de Vitória, capital do ES, onde se localizaram as principais ações da rede, ter sido pouco atingida e poder ser tida como área fora do desastre, ao menos quando se analisa o ponto específico em que os donativos estavam sendo arrecadados e organizados. Além disso, os atores "A" tornam-se providers na medida em que viabilizaram a chegada dos donativos ao interior do estado.

Sob o mesmo critério, apenas a título de exemplo, os representantes das prefeituras e das defesas civis dos municípios do interior, podem ser considerados in/seekers, já que se situavam em regiões atingidas e, em seus relacionamentos na rede, estavam em busca de donativos para atender às demandas de suas respectivas populações. Os atores representativos de empresas privadas, por sua vez, podem ser tidos como providers, embora alguns in e outros out, considerando sua localização geográfica.

É nesse sentido que, de uma maneira geral, foi verificada a capacidade do grupo emergente em análise, de articular e mediar a comunicação entre diferentes seekers 
e providers no processo de resposta ao desastre, especialmente quando se analisam os relacionamentos estabelecidos por A01, A21 e A19. Na seção 5.2 algumas das medidas de análise obtidas da rede em estudo serão capazes de melhor demonstrar a situação específica desses e de outros atores nesse processo, como as análises de centralidade e dos papéis de intermediação.

\subsubsection{Os dispositivos de comunicação entre os atores}

Houve uma questão específica no questionário, sobre as diferentes formas de comunicação utilizadas pelos atores mapeados na rede. A questão buscou identificar quais dessas formas foram mais utilizadas, ao lado da opção do contato pessoal. As opções deveriam ser marcadas sobre cada um dos contatos indicados pelo respondente. Poderia ser escolhida mais de uma opção, considerando-se que uma mesma conexão poderia ser estabelecida por meio de variados mecanismos, considerando os diferentes momentos de interação ocorridos ao longo do desenvolvimento das atividades.

As opções existentes eram: pessoalmente, telefone fixo, telefone celular, Facebook, Whatsapp e outro. Nesse último caso, o respondente era convidado a especificar essa outra forma de comunicação. Os relacionamentos que representavam laços já registrados anteriormente foram excluídos para que se evitasse a duplicidade de dados. A partir da tabela 4 a seguir, pode-se observar os resultados da tabulação desta questão.

TABELA 4 - FORMAS DE COMUNICAÇÃO UTILIZADAS NOS RELACIONAMENTOS

\begin{tabular}{llc}
\hline \multicolumn{2}{c}{ Como você se comunicava com essa pessoa nesse período? } \\
\hline Opções de Resposta & Fração & Número de respostas \\
\hline Telefone celular & $73 / 77$ & 73 \\
\hline Pessoalmente & $45 / 77$ & 45 \\
\hline Whatsapp & $41 / 77$ & 41 \\
\hline Facebook & $21 / 77$ & 21 \\
\hline Telefone fixo & $2 / 77$ & 1 \\
\hline Outro (especifique) & $1 / 77$ &
\end{tabular}


O email foi a única forma de comunicação indicada na opção outro, presente em apenas um dos relacionamentos: entre ONG02 e PM05. Conforme se pode observar, o telefone celular se destaca como meio de comunicação mais utilizado, presente em 73 dos 77 relacionamentos. 0 Whatsapp também se apresentou como forma de comunicação bastante utilizada, aparecendo em terceiro lugar, presente em 41 dos 77 relacionamentos mapeados.

O contato pessoal, segunda forma de comunicação mais utilizada, existiu em 45 dos relacionamentos mapeados, especialmente naqueles estabelecidos entre os agentes da sociedade civil (atores cujo código começa com a letra A), que representaram 25 do total de relacionamentos onde existiram contatos pessoais. Isso se explica em função da maior proximidade física entre esses atores, já que, em sua maioria estiveram presentes no local de arrecadação de donativos, à exceção de A15 que se dedicou mais à alimentação de informações no perfil do Facebook.

Apesar do grande número de contatos pessoais identificados, fica também evidente a contribuição que as novas TICs (telefonia móvel, sites de redes sociais Facebook e aplicativos de relacionamento - Whatsapp) possuíram ao longo de todo o processo em análise, como importantes meios para viabilização da comunicação entre os agentes da rede estudada. Tais tecnologias contribuíram significativamente para viabilizar a troca de informações, especialmente entre as pessoas localizadas na capital Vitória e os agentes no interior.

Isso reforça o pensamento de Pan, Pan e Leidner (2012) quando afirmam que uma questão central relativa à contribuição das novas TICs aos processo de resposta a desastres, refere-se aos fluxos de informação e à gestão das redes envolvidas. Trata-se de um contexto adverso e mutável, onde as informações precisam fluir rapidamente e em atualização constante.

Evidencia-se também o destaque dado por Palen e outros (2007) às novas TICs que tem assumido papeis e funções diferenciadas na oferta, busca ou intermediação de informações em contextos de desastres naturais. As autoras tratam justamente da capacidade que tem as novas tecnologias para viabilizar atividades não previstas e para permitir o surgimento e o alinhamento de novos grupos de atuação com as organizações formais de resposta a desastres. Essa situação se torna evidente a partir dos dados aqui apresentados, em que membros do grupo emergente de 
resposta mantiveram relacionamentos com outras diferentes organizações por meio da utilização de novas TICs para a viabilização de variadas atividades que nem sequer estavam em seus planos, nem mesmo poucos dias antes de serem iniciadas. Tais atividades possuíram visibilidade, intensidade e alcance bem maiores que quaisquer outras desenvolvidas anteriormente com a mesma finalidade no ES.

Vieweg e outros (2008) também atribuem às novas TICs o papel de suporte a determinadas ações coletivas em contextos pós-desastre. Numa abordagem menos específica que o contexto dos desastres, mas não menos importante para a compreensão das questões aqui abordadas, Benkler (2006) também atribui grande relevância às novas TICs quando trata da chamada economia da informação em rede. Ao mesmo tempo pode-se buscar no pensamento de Braga (2009) e Rheingold (2012) a visão da inteligência coletiva como um fenômeno emergente possibilitado em grande medida pelas novas tecnologias digitais que permitem o surgimento de maneiras diferenciadas de organização social.

As novas TICs são também apontadas por Lévy (2011) como tendo um papel fundamental para a efetivação da comunicação entre os agentes em um contexto de inteligência coletiva, além de serem capazes de proporcionar a coordenação entre as inteligências individuais em tempo real, conferindo maior rapidez e agilidade no desenvolvimento da ação colaborativa.

\subsection{A COMUNICAÇÃO E A MEDIAÇÃO DA INFORMAÇÃO NA REDE}

Esta seção da análise de dados relaciona-se ao segundo $\left(P_{2}\right)$ e ao terceiro $\left(P_{3}\right)$ pressupostos da pesquisa. P2 considera que "a comunicação se apresenta como elemento regulador e essencial à sua auto-organização, a partir da qual se tornam possíveis a articulação das multilideranças e a coordenação de diferentes ações". P3 pressupõe que "no âmbito das redes sociais atuantes na resposta a desastres naturais, a mediação da informação possui características diferenciadas em relação a algumas conceituações mais usuais da Ciência da Informação" 
Ao mesmo tempo, as discussões aqui desenvolvidas permitem a compreensão de importantes pontos relacionados ao alcance de dois dos objetivos específicos propostos:

OE2: Identificar os fenômenos de comunicação e mediação da informação existentes nessa rede social.

OE5: Mapear a topologia dessa rede social, identificando e analisando suas propriedades a partir da Análise de Redes Sociais.

A entrevista com A01 foi importante para a definição da natureza das atividades realizadas pelo núcleo da rede, bem como das informações trocadas entre os atores que o compõem $\left(E_{A 3}\right)$, o que auxiliou bastante no desenvolvimento das opções de resposta utilizadas no questionário.

A partir dos dados coletados pela aplicação do questionário foi possível a identificação dos fluxos de informação existentes nos relacionamentos, considerando o sentido dos fluxos e a natureza das informações trocadas $\left(Q_{3}\right.$ e $\left.Q_{4}\right)$.

A ARS permitiu obter as métricas de análise consideradas adequadas aos objetivos da pesquisa, quais sejam: medidas de grau, centralidade de intermediação (betweenness), centralidade de proximidade (closeness) e identificação de papeis secundários de intermediação (brokerage roles). Além dessas, grafos indicativos da frequência das interações entre os agentes também estão apresentados.

\subsubsection{As informações trocadas na rede}

Conforme já apresentado no item 4.1, a partir da entrevista com A01 foi possível identificar a natureza das principais atividades desenvolvidas pelo Núcleo de Apoiadores. Percebe-se que em grande medida referem-se a ações de articulação entre as diferentes entidades envolvidas, o que em essência, representa diferentes necessidades de informação, além de necessidades de interação entre os agentes. 
Encontra-se a seguir, a descrição de tais atividades, conforme já apresentado na subseção 4.1.2:

- $\quad$ Contatos com Prefeituras, Corpo de Bombeiros, Cruz Vermelha ou Defesa Civil para levantamento de necessidades de donativos.

- Administração do perfil dos Apoiadores no Facebook.

- Contatos com empresas privadas ou pessoas físicas para solicitação de donativos ou viabilização de recursos.

- Coordenação de atividades de recebimento, separação, organização ou embalagem de donativos recebidos.

- Articulação com as instituições envolvidas nas ações de apoio às vítimas, visando à organização e à continuidade das atividades.

- Recebimento, separação, organização ou embalagem de donativos recebidos.

- Contatos com Prefeituras Municipais para viabilização da chegada dos donativos às cidades afetadas.

- Acompanhamento das viagens de caminhão/avião com donativos para as cidades afetadas.

- Idas às cidades afetadas nos caminhões/aviões para entrega dos donativos.

As informações fornecidas por A01 demonstraram que, para a consecução dessas atividades, as principais informações trocadas entre os atores eram relativas a determinados temas gerais. O termo "temas gerais de informação" reflete aqui conjuntos de informações variadas relacionadas a diferentes assuntos que tiveram espaço no âmbito das trocas comunicacionais realizadas no núcleo da rede. Tais temas gerais que puderam ser identificados são: necessidades de donativos, necessidades de voluntários, saída de caminhões para os municípios, pontos de coleta de donativos, necessidades de caminhões ou outros meios de transporte de donativos e divulgação de conteúdos no perfil do Facebook.

A partir dessa lista de temas gerais de informação foi criada uma das perguntas do questionário, voltada a identificar quais deles se fizeram presentes em cada um dos relacionamentos estabelecidos no Núcleo de Apoiadores. O quadro 10 apresenta os resultados das respostas a essa questão, onde cada " $x$ " representa a existência da troca de um determinado tipo de informação. 
(continua)

\begin{tabular}{|c|c|c|c|c|c|c|c|c|}
\hline \multirow[b]{2}{*}{ Ator } & \multirow[b]{2}{*}{ Relação } & \multicolumn{6}{|c|}{ TEMAS GERAIS DE INFORMAÇÃO TROCADOS NO NÚCLEO DE APOIADORES } & \multirow[b]{2}{*}{ QUANT } \\
\hline & & $\begin{array}{l}\text { Necessidade } \\
\text { de donativos }\end{array}$ & $\begin{array}{l}\text { Necessidade } \\
\text { de voluntários }\end{array}$ & $\begin{array}{l}\text { Saída de } \\
\text { caminhões } \\
\text { para os } \\
\text { municípios }\end{array}$ & $\begin{array}{l}\text { Pontos de } \\
\text { coleta de } \\
\text { donativos }\end{array}$ & $\begin{array}{l}\text { Necessidade } \\
\text { de caminhões } \\
\text { ou outros } \\
\text { meios de } \\
\text { transporte de } \\
\text { donativos }\end{array}$ & $\begin{array}{c}\text { Divulgação } \\
\text { de } \\
\text { conteúdos } \\
\text { no } \\
\text { Facebook }\end{array}$ & \\
\hline \multirow{40}{*}{ A01 } & A03 & $\mathrm{x}$ & & $\mathrm{x}$ & & & & 02 \\
\hline & A06 & $\mathrm{x}$ & $\mathrm{x}$ & $x$ & $x$ & $\mathrm{x}$ & & 05 \\
\hline & A07 & $\mathrm{x}$ & & & $\mathrm{x}$ & & & 02 \\
\hline & A08 & $\mathrm{x}$ & & & $\mathrm{x}$ & $\mathrm{x}$ & & 03 \\
\hline & A11 & $\mathrm{x}$ & & & & $x$ & & 02 \\
\hline & A14 & $x$ & $x$ & $x$ & $x$ & $x$ & & 05 \\
\hline & A15 & $x$ & $x$ & $x$ & $x$ & $x$ & $x$ & 06 \\
\hline & A17 & $x$ & $x$ & $x$ & $x$ & $x$ & $x$ & 06 \\
\hline & A18 & $x$ & & & $x$ & $x$ & & 06 \\
\hline & A19 & $x$ & & $x$ & & $x$ & & 03 \\
\hline & A20 & & $x$ & & & & & 01 \\
\hline & A21 & $x$ & $x$ & $x$ & $x$ & $x$ & & 05 \\
\hline & CV01 & $x$ & $x$ & & $x$ & $x$ & & 04 \\
\hline & DCE02 & & & $x$ & & $x$ & & 02 \\
\hline & DCE03 & $x$ & & & & & & 01 \\
\hline & DCE04 & $x$ & & $x$ & & $x$ & & 03 \\
\hline & DCE05 & $x$ & $x$ & $x$ & $x$ & $x$ & & 05 \\
\hline & DCE06 & $x$ & $x$ & $x$ & $x$ & $x$ & & 05 \\
\hline & DCM01 & $x$ & & $x$ & & & & 02 \\
\hline & DCM02 & $x$ & & $x$ & & $x$ & & 03 \\
\hline & DCM03 & $x$ & & $x$ & & & & 02 \\
\hline & DCM04 & $x$ & & & & $x$ & & 02 \\
\hline & DCM05 & $x$ & $x$ & $x$ & $x$ & $x$ & & 05 \\
\hline & E01 & $x$ & & & & $x$ & & 02 \\
\hline & E07 & & $x$ & $x$ & & & & 02 \\
\hline & E09 & $x$ & & & & $x$ & & 02 \\
\hline & E10 & & & $x$ & & & & 01 \\
\hline & E13 & $x$ & $x$ & $x$ & $x$ & $x$ & & 05 \\
\hline & E15 & $x$ & $x$ & $\mathrm{x}$ & $x$ & $x$ & & 05 \\
\hline & E17 & $x$ & & $x$ & & $x$ & & 03 \\
\hline & ONG02 & $x$ & & $x$ & & & & 02 \\
\hline & ONG03 & $x$ & $x$ & & $x$ & $x$ & & 04 \\
\hline & PM01 & & & $x$ & & & & 01 \\
\hline & PM04 & $x$ & & $x$ & & & & 02 \\
\hline & PM06 & $x$ & & $x$ & & & & 02 \\
\hline & PM07 & $x$ & $x$ & & $x$ & $x$ & & 04 \\
\hline & PM08 & $x$ & & $x$ & & $x$ & & 03 \\
\hline & POL01 & $x$ & & $x$ & & $x$ & & 03 \\
\hline & POL02 & $x$ & & & $x$ & & & 02 \\
\hline & POL 03 & $x$ & & & $x$ & & & 02 \\
\hline $\mathbf{A 0 3}$ & A15 & $x$ & $x$ & $\mathrm{x}$ & & & $x$ & 04 \\
\hline 10 & A05 & $x$ & $x$ & & & & & 02 \\
\hline AUT & A09 & $x$ & & $x$ & $x$ & & & 03 \\
\hline
\end{tabular}


(conclusão)

\begin{tabular}{|c|c|c|c|c|c|c|c|c|}
\hline \multirow{2}{*}{$\mathrm{A} 07$} & A12 & $x$ & $x$ & & & & & 02 \\
\hline & A13 & $x$ & $x$ & & & & & 02 \\
\hline \multirow{4}{*}{ A08 } & A04 & $x$ & $x$ & $x$ & & $x$ & & 04 \\
\hline & A06 & $x$ & $x$ & $x$ & $x$ & $x$ & & 05 \\
\hline & A14 & $x$ & & $x$ & & $x$ & & 03 \\
\hline & A19 & $x$ & & $x$ & & $x$ & & 03 \\
\hline \multirow{5}{*}{ A15 } & A02 & & & $x$ & & $x$ & & 02 \\
\hline & A10 & & $x$ & $x$ & & & & 02 \\
\hline & A14 & $x$ & $x$ & $x$ & $x$ & $x$ & $x$ & 06 \\
\hline & A16 & $x$ & $x$ & $x$ & $x$ & $x$ & $x$ & 06 \\
\hline & A17 & $x$ & $x$ & $x$ & $x$ & $x$ & $x$ & 06 \\
\hline A17 & A14 & $x$ & & & $x$ & $x$ & & 03 \\
\hline A18 & E08 & $x$ & $x$ & . & & & & 02 \\
\hline \multirow{14}{*}{ A19 } & A04 & $x$ & & $x$ & & $x$ & & 03 \\
\hline & A06 & $x$ & & $x$ & & $x$ & & 03 \\
\hline & A14 & $x$ & & $x$ & & $x$ & & 03 \\
\hline & A17 & $x$ & & $x$ & & $x$ & & 03 \\
\hline & E02 & $x$ & & $x$ & & $x$ & & 03 \\
\hline & E03 & $x$ & & $x$ & & $x$ & & 03 \\
\hline & E04 & $x$ & & $x$ & & $x$ & & 03 \\
\hline & E05 & $x$ & & $x$ & & $x$ & & 03 \\
\hline & E06 & $x$ & & $x$ & & $x$ & & 03 \\
\hline & E11 & $x$ & & $x$ & & $x$ & & 03 \\
\hline & E12 & & & $x$ & & $x$ & & 02 \\
\hline & E18 & $x$ & & $x$ & & $x$ & & 03 \\
\hline & PM02 & $x$ & & $x$ & & & & 02 \\
\hline & PM03 & $x$ & & & & $x$ & & 02 \\
\hline \multirow{6}{*}{ A21 } & CV02 & $x$ & $x$ & & $x$ & & & 03 \\
\hline & DCM05 & $x$ & $x$ & $x$ & $\mathrm{x}$ & $x$ & & 05 \\
\hline & E13 & $x$ & $x$ & $x$ & & & & 03 \\
\hline & E16 & $x$ & $x$ & $x$ & & & & 03 \\
\hline & E14 & $x$ & $x$ & & & & $x$ & 03 \\
\hline & ONG01 & $x$ & $x$ & $x$ & & & & 03 \\
\hline ONG02 & PM05 & $x$ & & $x$ & & & & 02 \\
\hline
\end{tabular}

QUADRO 10 - TEMAS GERAIS DE INFORMAÇÃO PRESENTES EM CADA UM DOS RELACIONAMENTOS DO NÚCLEO DE APOIADORES.

Fonte: A autora.

O quadro permite identificar o que se irá considerar como sendo a "densidade" dos relacionamentos estabelecidos, que considera a quantidade de temas tratados nesses relacionamentos. Serão destacadas os relacionamentos mais "densos" onde estiveram presentes 6 e 5 temas gerais de informação distintos.

São 5 os relacionamentos onde estiveram presentes todos os seis temas informacionais descritos: A01-A15; A01-A17; A15-A14; A15-A16 e A15-A17. Aquelas 
em que transitaram cinco dos seis temas informacionais foram em maior número: A01-A06; A01-A14; A01-A21; A01-DCE05; A01-DCE06; A01-DCM05; A01-E13; A01E15; A08-A06; A21-DCM05. Trata-se de relacionamentos que podem ser considerados bastante relevantes para os fluxos informacionais na rede, pela variedade de informações que por eles transitava.

Fica evidenciado que entre esses relacionamentos mais densos, possuem destaque aqueles estabelecidos entre atores da sociedade civil, como A01, A14, A15, A16, A17, A06 e A21, demonstrando uma articulação mais ampla por parte desses atores. Entretanto, pode-se dizer que A01 e A15 possuíram importância maior nesse sentido, pela quantidade de relacionamentos com grande variedade de temas informacionais, das quais participaram. Em se tratando de A01, isso talvez seja 0 reflexo de seu papel chave na articulação da rede. No caso específico de A15, isso pode ser decorrente de seu papel desempenhado na gestão de conteúdos no perfil do Facebook, conforme já discutido na seção 5.1. Era necessário que possuísse acesso a variados tipos de conteúdos, para as informações divulgadas no perfil sobre as diferentes atividades da rede, ao mesmo tempo em que também enviava informações captadas por intermédio do Facebook para os atores que estavam trabalhando na Praça do Papa.

Considerando o quadro 10, são possíveis algumas reflexões a partir do olhar de Saracevic (2009) sobre o contexto social específico da informação. Considera-se aqui a informação não apenas como mensagens processadas cognitivamente, mas também como motivações e intencionalidades dadas a priori. No caso específico em análise, as informações trocadas estavam intimamente relacionadas a um contexto social marcado pela solidariedade e pelo voluntariado voltados para o atendimento das demandas por donativos após o desastre natural.

Partindo-se do que sustenta Recuero (2012) quando afirma que a informação é o "alimento" da rede e possui o papel central de organizar a sua ação, o reconhecimento dos fluxos de informação na rede estudada é capaz de auxiliar na compreensão mais adequada dos relacionamentos, assim como da dinâmica das atividades desenvolvidas. 


\subsubsection{Algumas métricas de centralidade}

Conforme afirmam Martinho e outros (2003) a dinâmica de comunicação da rede se sustenta sobre a sua conectividade, ou seja, ao estabelecer relacionamentos numa rede social, os atores estão estabelecendo linhas de comunicação. Nesse sentido, as medidas de centralidade sobre os vértices na rede podem auxiliar na identificação dos atores que, em função de sua posição, possuem maior capacidade de acesso e disseminação de informações e até mesmo de exercer certo controle sobre os fluxos de informação.

Buscando verificar a importância relativa dos atores nas trocas de informação realizadas na rede, passa-se a seguir a algumas análises sobre a centralidade, incluindo a centralidade de grau, a centralidade de proximidade (closeness) e a centralidade de intermediação (betweenness). O tamanho dos vértices é proporcional ao valor do vetor criado para cada uma das medidas de centralidade.

Contudo, considerando-se a natureza do método bola de neve, aplicado à coleta de dados, é preciso realizar uma importante observação sobre as análises de centralidade aqui realizadas. Tendo em vista que A01 foi o ator inicial da rede, ele possui, naturalmente, a posição mais central no grafo, e é por isso que valores elevados de centralidade já são realmente esperados para ele. É nesse sentido que as análises a seguir procurarão demonstrar apenas os valores de centralidade para os demais atores do Núcleo de Apoiadores. Esta medida busca evitar influências desse enviesamento do método de coleta, sobre a análise dos dados.

A partir da análise da centralidade de grau dos atores podem ser realizadas algumas reflexões importantes sobre a sua participação nas trocas de informação realizadas na rede. No caso em análise, tanto como emissores, quanto como receptores de informação, já que não está sendo considerado o sentido da informação.

Assim, inicia-se com a apresentação da centralidade de grau, a partir do grafo 7. 0 cálculo foi realizado por meio do seguinte comando no Pajek: Network $>$ CreatVector $>$ Centrality $>$ Degree. 


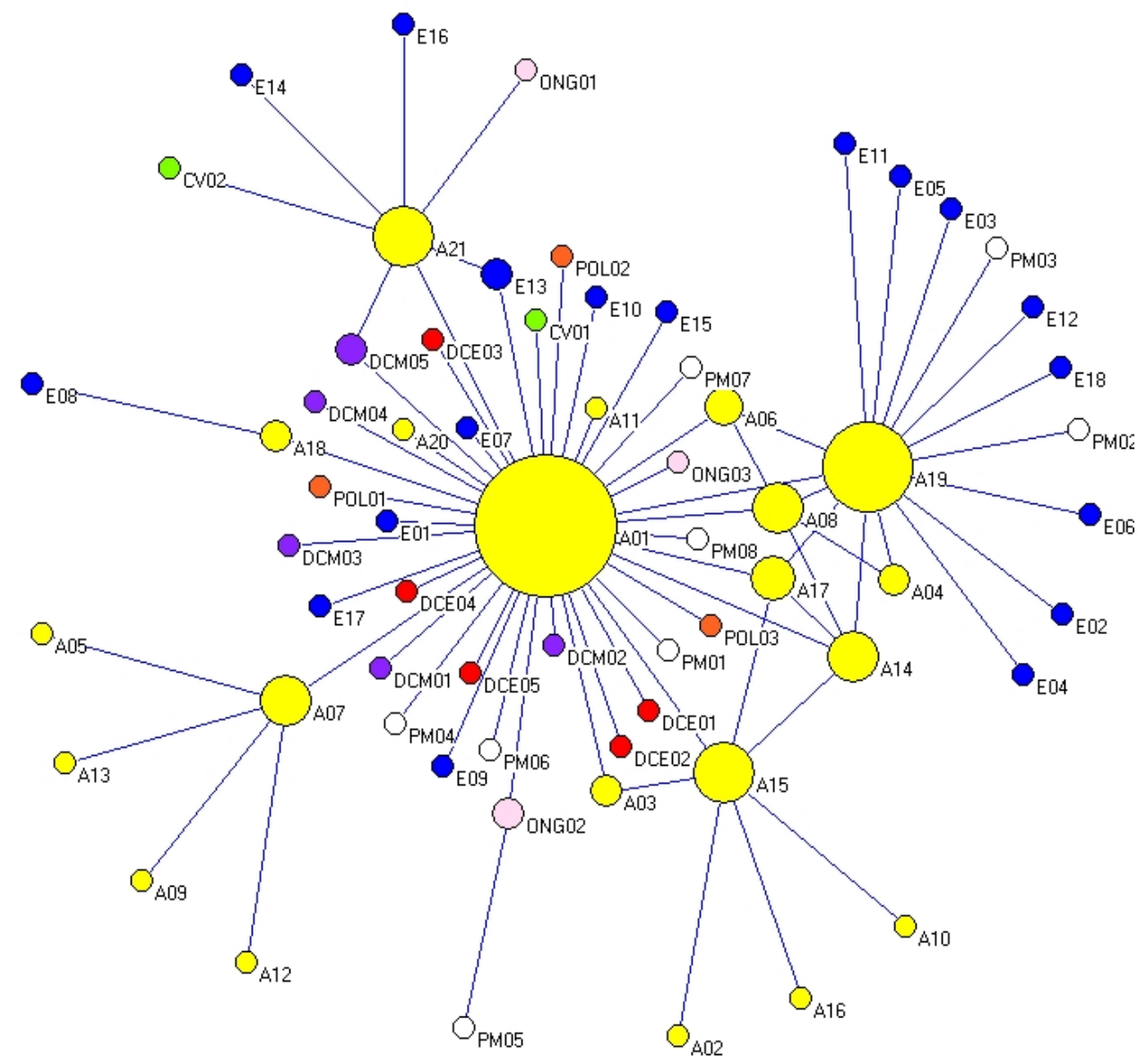

GRAFO 7 - CENTRALIDADE DE GRAU DOS ATORES DO NÚCLEO DE APOIADORES Fonte: A autora.

Considerando-se que o tamanho dos nós está desenhado de maneira proporcional ao grau de cada um dos atores, (e excluindo a análise de A01 pelas razões já explicitadas) pode-se observar que A19, A21, A15, A14, A08 e A07 são os que possuem o maior número de relacionamentos na rede. O número de laços de $\mathrm{A} 19$ é bastante considerável, 16. A tabela 5 a seguir apresenta os atores com os seis maiores valores de centralidade de grau localizados na rede em análise.

TABELA 5 -OS SEIS MAIORES VALORES DE CENTRALIDADE DE GRAU

\begin{tabular}{cc}
\hline Ator & Centralidade de Grau \\
\hline A19 & 16 \\
A21 & 07 \\
A15 & 07 \\
A07 & 05 \\
A14 & 05 \\
A08 & 05
\end{tabular}

Fonte: A autora 
A partir dos números da tabela percebe-se que os atores A19, A21, A15, A07, A14 e A08 são aqueles que na rede em análise possuíram maior capacidade de obtenção e disseminação de informação, considerando apenas os seus relacionamentos diretos. Para essa análise, parte-se do princípio de que, um maior número de fontes torna esse ator mais apto a acessar informação, conforme destacam De Nooy, Mrvar e Batagelj (2005).

Entretanto, não é apenas a quantidade de relacionamentos que indica a facilidade no acesso da informação, mas também a posição do relacionamento na estrutura da própria rede. Por exemplo, a propensão de um ator a estar localizado no caminho mais curto entre dois outros atores confere ao primeiro o poder de intermediação. É nesse sentido que a seguir encontra-se o cálculo do Betweenness. $O$ resultado pode ser visualizado a partir do grafo 8 a seguir. $O$ cálculo foi realizado por meio do seguinte comando no Pajek: Network>CreatVector>Centrality>Betweenness

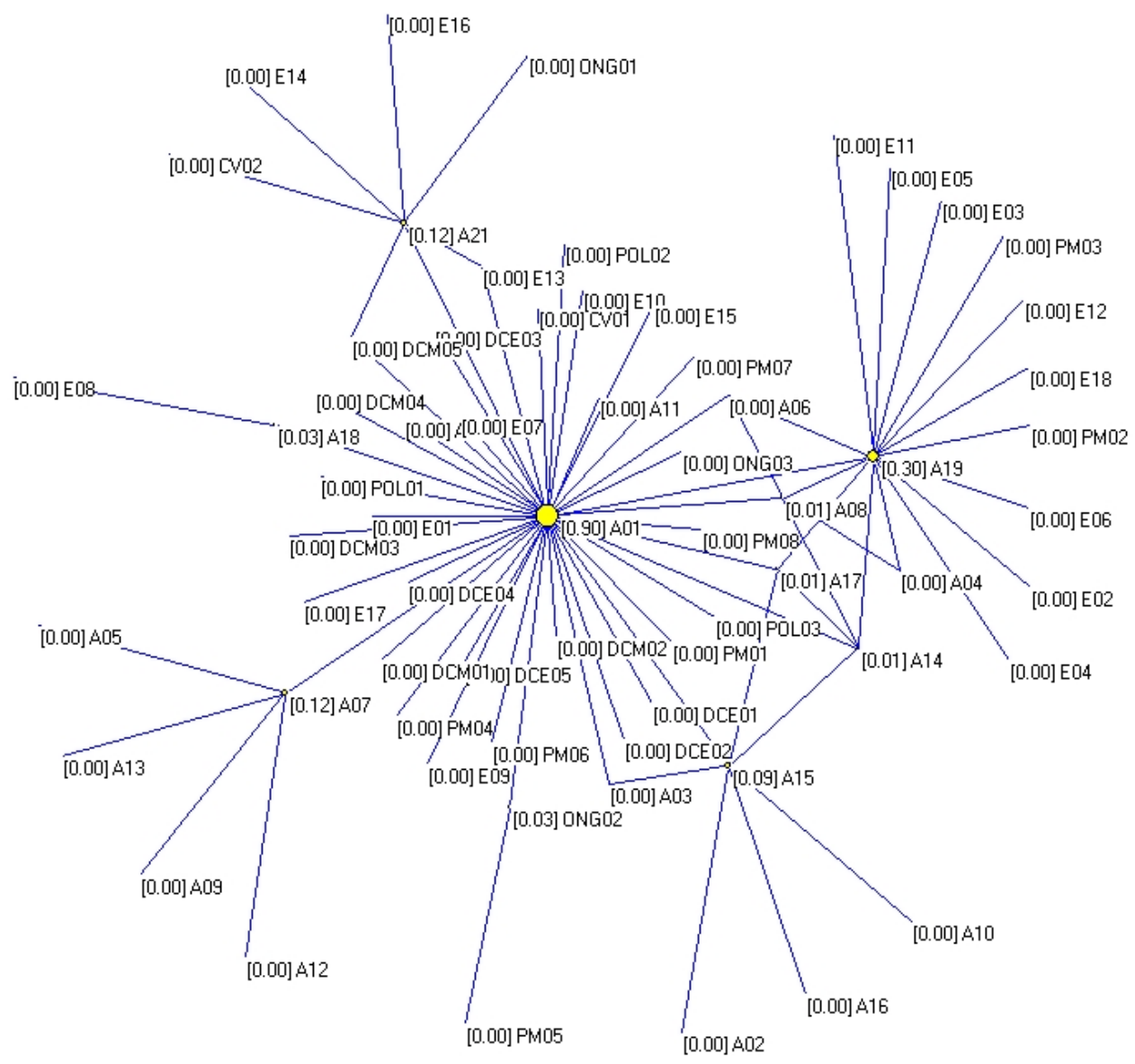

GRAFO 8 - CENTRALIDADE DE INTERMEDIAÇÃO DOS ATORES NO NÚCLEO DE APOIADORES Fonte: A autora. 
A inspeção visual do grafo permite destacar (excluindo-se A01 pelas razões já explicitadas) mais uma vez A19, mas também A21, A07 e A15 como atores com maior centralidade de intermediação, conforme destacado na tabela 6 a seguir.

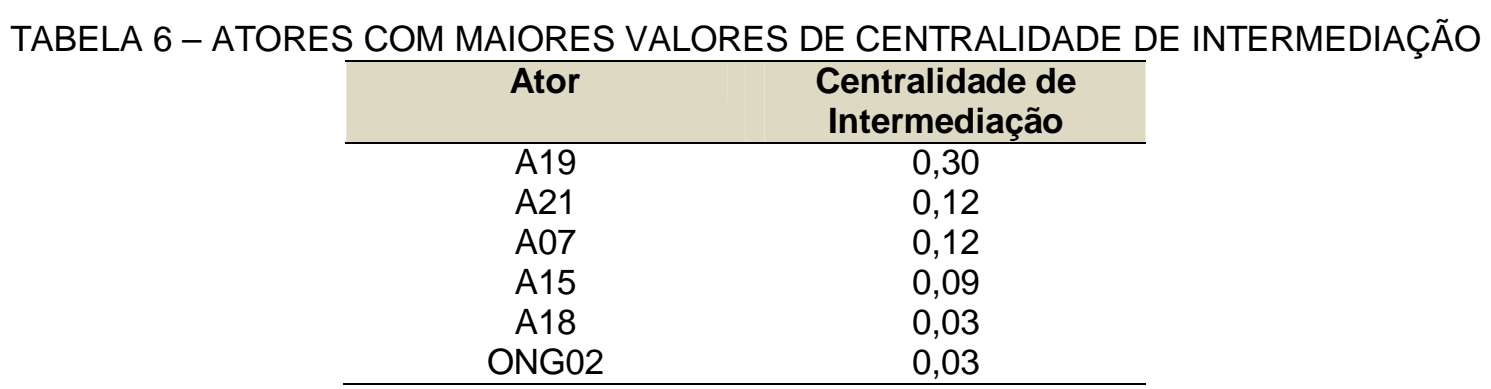

Fonte: A autora.

Destaque-se que, enquanto $A 07$ intermediou relacionamentos existentes apenas entre atores do grupo "A", A19, A21, A18 e ONG02 estiveram presentes em intermediações com atores representativos de outras partições na rede como Empresas, Prefeituras e Defesa Civil.

O caso específico de $\mathrm{A} 15$ merece uma observação importante que não se evidencia pela simples análise do grafo. A análise permite verificar apenas que A15 intermediou relacionamentos existentes entre atores do grupo A. Entretanto, como esse ator esteve em grande medida voltado para a divulgação de informações no perfil dos Apoiadores no Facebook, pode-se considerar que a sua grande contribuição esteve na intermediação entre o Núcleo de Apoiadores e aquilo que se pode chamar de periferia da rede, representada, em parte, pelas interações ocorridas no meio virtual.

Estes em destaque na tabela são vértices presentes em um maior número de caminhos geodésicos possíveis na rede (DE NOOY, MRVAR E BATAGELJ 2005). Pode-se inferir que os atores com maior centralidade de intermediação possuíram importante papel ou influência no controle das informações que circularam na rede, bem como do trajeto que elas puderam ou não percorrer.

Outra medida de centralidade é o índice de proximidade de um ator perante os outros. Isso significa dizer que tais atores são as pessoas cuja soma das distâncias das demais é a menor. 
A visualização do grau de proximidade dos atores pode ser realizada a partir do grafo 9, a seguir. O cálculo utilizou o seguinte comando no Pajek: Network>CreatVector>Centrality $>$ Closeness.

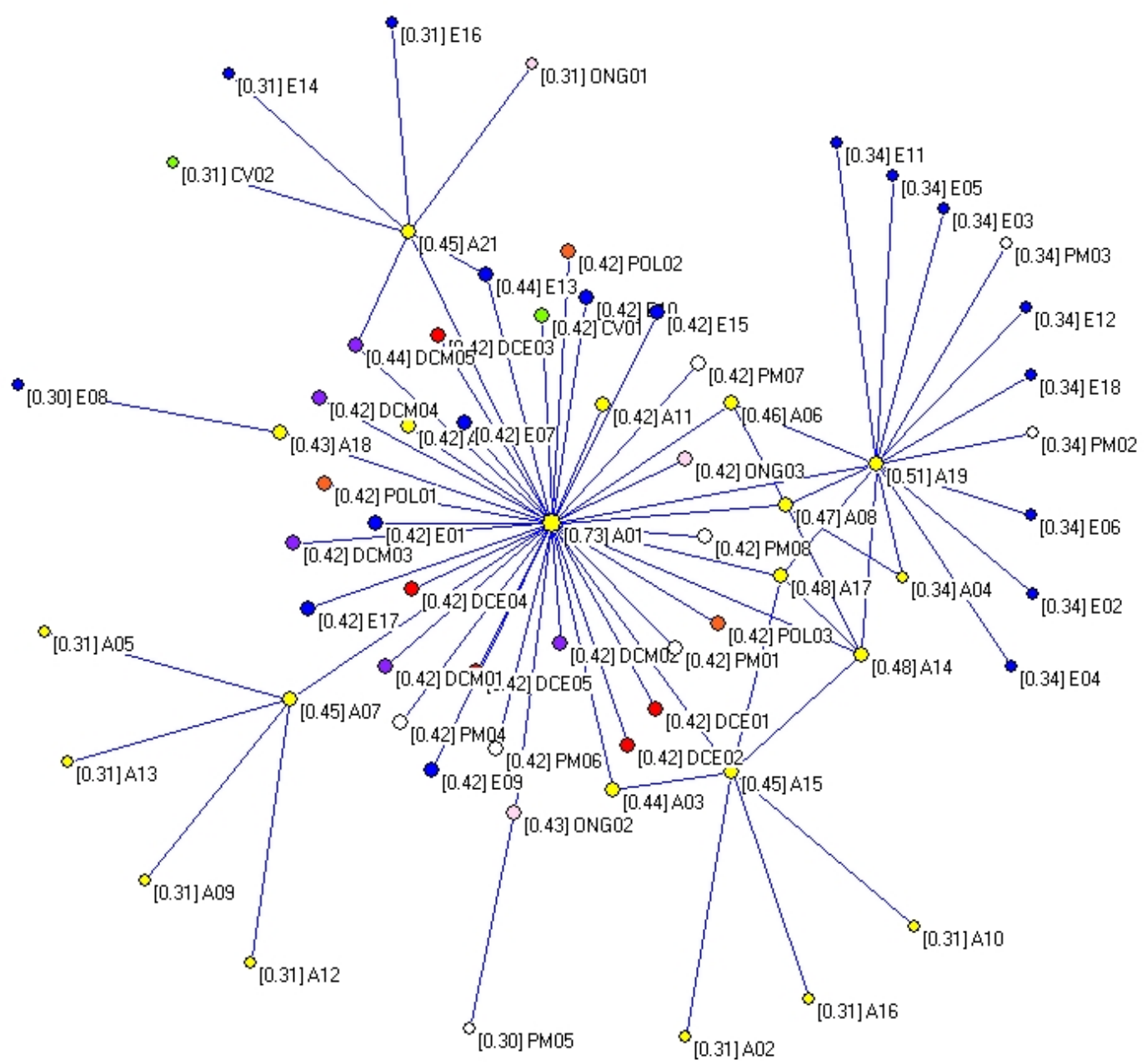

GRAFO 9 - CENTRALIDADE DE PROXIMIDADE DOS ATORES NO NÚCLEO DE APOIADORES Fonte: A autora

Nesse caso (excluindo-se mais uma vez A01 pelas razões já explicitadas) verifica-se que os atores A19, A14, A17, A08, A06 e A21 possuem os maiores valores de centralidade de proximidade na rede, conforme destacado na tabela 7 a seguir.

TABELA 7 - ATORES COM MAIORES VALORES DE CENTRALIDADE DE PROXIMIDADE

\begin{tabular}{cc}
\hline Ator & $\begin{array}{c}\text { Centralidade de } \\
\text { Proximidade }\end{array}$ \\
\hline A19 & 0,51 \\
A14 & 0,48 \\
A17 & 0,48 \\
A08 & 0,47 \\
A06 & 0,46 \\
\hline
\end{tabular}

Fonte: A autora 
Pressupõe-se que A19, A14, A17 e A08 são os atores que tiveram menor dificuldade, ou que realizaram um menor esforço para conseguir receber e enviar informações na rede, em função de sua maior proximidade com os demais.

É evidente a importância que possuiu o ator A19, presente com níveis mais elevados nos três tipos de centralidade analisados. Também se destacaram A14 e A08 que estiveram entre os cinco maiores valores de centralidade de grau e de proximidade e A21, A15 e A07 presentes ao mesmo tempo nos cinco maiores quantitativos na centralidade de grau e de intermediação.

É possível buscar uma aproximação da importância desses atores sobre o fluxo de informações na rede, com a lógica das multilideranças apontada por Franco (2012) e Martinho e outros (2013). Para esses autores, a informação pode ser considerada o elemento articulador das multilideranças, ao mesmo tempo em que viabiliza a coordenação das diferentes ações no âmbito da rede.

Uma característica essencial que emerge da existência das multilideranças na rede é a sua descentralização, demonstrada a partir da distribuição de poder no âmbito do sistema, de acordo com Martinho e outros (2003). Para os autores as redes são por natureza descentradas justamente por não se sustentarem em um único ponto de poder, mas no acionamento de diferentes relacionamentos.

$\mathrm{Na}$ visão desses autores, o surgimento de multilideranças na rede é decorrente do princípio da insubordinação, já que as decisões emergem de maneira cooperativa e compartilhada evidenciando uma desconcentração clara de poder entre os membros da coletividade. $O$ que se pode refletir a partir do que foi analisado até aqui é que essa inexistência de um poder hierárquico formal abre uma lacuna para que o poder emanado pela importância que determinados atores exercem sobre os fluxos de informação, possa explicar a existência de multilideranças na rede.

Ao se considerar os atores centrais destacados nas tabelas 2, 3 e 4 como aqueles que de uma maneira geral possuíram mais acesso à informação, foram mais importantes na garantia do fluxo da informação ou tiveram maiores oportunidades de disseminação da informação, encontram-se aí fundamentos para que possam ser considerados como lideranças na rede em análise. 
Assim, em se tratando de uma rede social voltada para a articulação e atendimento de demandas, pode-se compreender que os atores com maiores níveis de centralidade também foram aqueles que puderam atuar de forma mais decisiva para que as ações coletivas da rede tomassem corpo. Nesse sentido, compreende-se que a informação não apenas proporciona a articulação necessária entre as multilideranças, como também pode contribuir para a compreensão de quem são essas multilideranças.

\subsubsection{Os papeis de intermediação}

Os papeis de intermediação secundários desempenhados pelos diferentes atores são referentes à posição de um ator em relação a dois ou mais grupos.

Foi executado o comando Operations $>$ Network + Partition $>$ Brokerage roles, a partir do qual o Pajek realiza uma analise da rede, dos grupos definidos e dos relacionamentos entre os atores de cada grupo, executando a identificação algorítmica do número de vezes em que cada ator desempenha cada um dos cinco papéis de intermediação. Tem-se como resultado, cinco diferentes partições, uma para cada papel estrutural, que serão apresentadas a seguir. Uma vez que a rede não é dirigida, os papeis de representante e gatekeeper são os mesmos. Assim sendo, estão destacados na tabela 8 quatro colunas cujos valores correspondem à quantidade de papeis de intermediação desempenhada por cada um dos atores.

\begin{tabular}{|c|c|c|c|c|}
\hline Ator & Coordenador & $\begin{array}{l}\text { Intermediador } \\
\text { Itinerante }\end{array}$ & $\begin{array}{c}\text { Representante/ } \\
\text { Gatekeeper }\end{array}$ & $\begin{array}{c}\text { Elemento } \\
\text { de } \\
\text { ligação }\end{array}$ \\
\hline $\mathrm{A} 01$ & 112 & 110 & 334 & 646 \\
\hline A07 & 20 & - & - & - \\
\hline A08 & 08 & - & - & - \\
\hline $\mathrm{A} 14$ & 06 & - & - & - \\
\hline A15 & 34 & - & - & - \\
\hline A17 & 02 & - & - & - \\
\hline A18 & - & & 01 & - \\
\hline A19 & 14 & 58 & 60 & 32 \\
\hline A21 & - & 06 & 04 & 24 \\
\hline
\end{tabular}


A partir do quadro, desprezando-se o grande número de papeis desempenhados por A01, observa-se que os atores A15, A07 e A19, desempenharam os mais significativos papeis de coordenadores na rede, ou seja, tiveram um papel importante na intermediação da informação, entre os atores do grupo "A", ao qual pertencem. Para esclarecimentos sobre o conceito de coordenador, ver a figura 4 na subseção 2.6.1.

No desempenho do papel de intermediador itinerante, tem-se A19 como desempenhando 58 vezes o papel, sendo a maioria das vezes papeis desempenhados perante o grupo vinculado a empresas. Note-se que A19 também possui papel de coordenador, não tão significativo quanto A15 (34 coordenações) e A07 (20 coordenações).

A15 foi o maior coordenador, mas não atuou como intermediador itinerante, porteiro, nem elemento de ligação. Ou seja, intermediou o fluxo de informações no mesmo grupo. A07 também foi o segundo maior coordenador e também na atuou nos demais papeis.

A21 atuou como um significativo elemento de ligação entre os membros de distintos grupos, mas não atuou como coordenador e pouco atuou como intermediador itinerante e porteiro.

A19 atuou de forma significativa nos quatro papeis, sugerindo tratar-se de uma multiliderança, da mesma forma que o evidente papel de A01.

No sentido de perceber os atores mais importantes para a intermediação do fluxo de informações entre representantes de diferentes grupos participantes da rede, ou seja, atuantes como elemento de ligação entre os grupos de organizações estabelecidas, expandidas e estendidas, é importante analisar os atores que desempenharam tal papel. Ali se destacam, A01, A19 e A21, como tendo sido aqueles que exerceram intermediação entre atores de Prefeituras e Empresas, por exemplo, como se pode observar a partir da inspeção visual do sociograma do grafo 10. 


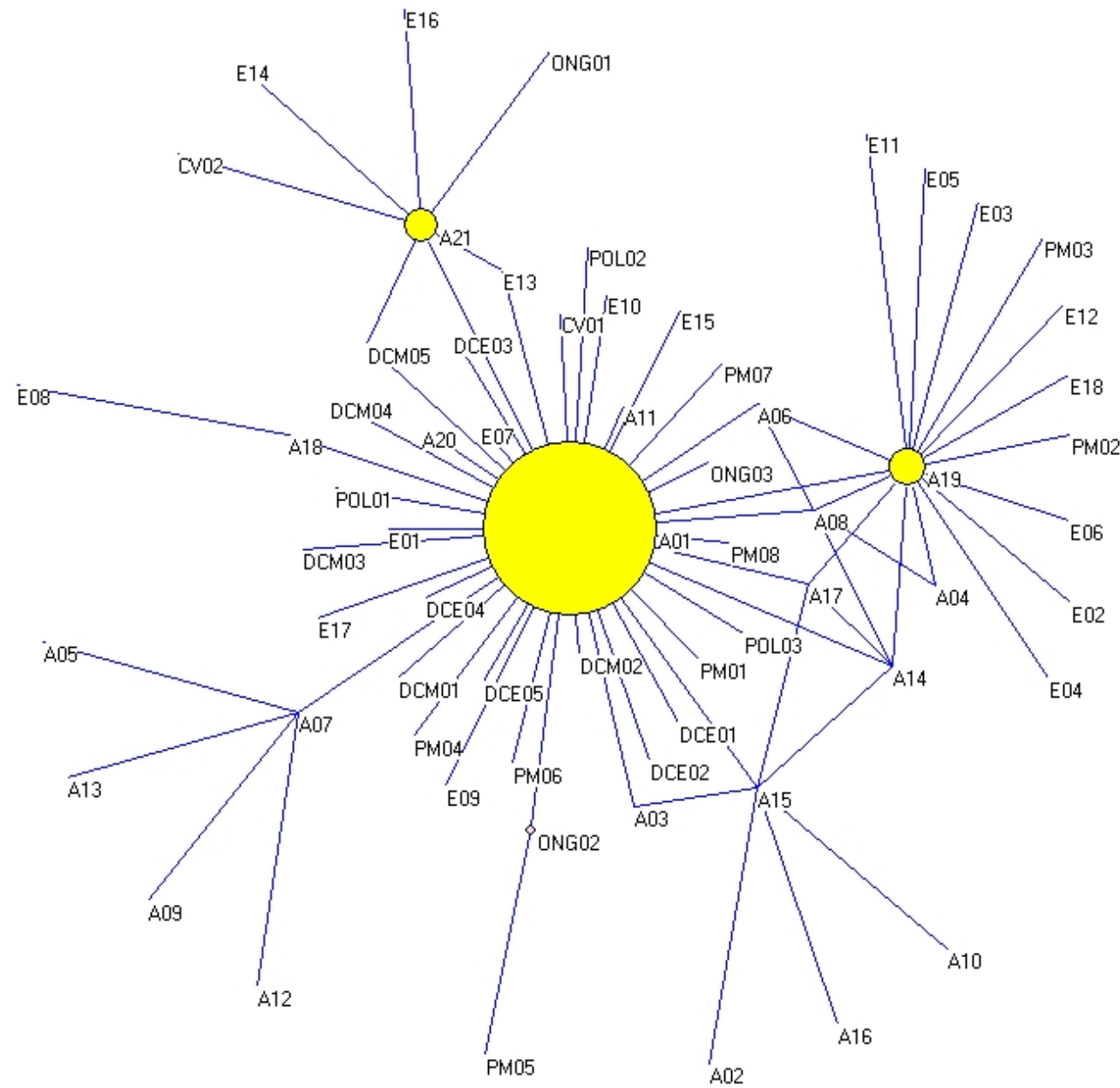

GRAFO 10 - QUANTIDADE DE PAPEIS DE ELEMENTOS DE LIGAÇÃO DESEMPENHADOS PELOS ATORES NO NÚCLEO DE APOIADORES

Fonte: A autora.

Observa-se que A21 possuiu importante papel na intermediação entre atores de ONGs, Empresas, Defesa Civil Municipal e Cruz Vermelha. Ao mesmo tempo, destaca-se A19 na intermediação entre agentes de Empresas Privadas e Prefeituras Municipais. A01, de forma tendenciosa, por ter sido o início da coleta de dados, apresentou expressivo valor também nesse papel de intermediação considerando que foi por inúmeras vezes o intermediário entre vários agentes de todos os tipos de organização presentes na rede. Observa-se assim, que a mediação da informação entre agentes de diferentes instituições esteve bastante concentrada nesses 3 atores do grupo $\mathrm{A}$.

Entretanto, é importante destacar que, em função da delimitação da pesquisa e da forma com que os dados foram coletados, não se pode afirmar que não tenha havido 
na realidade, interações diretas entre os agentes representantes de empresas, de prefeituras, defesa civil, e demais instituições presentes na rede. Considerando, por exemplo, a implementação da estrutura do PEPDEC durante as ações de resposta de dezembro de 2013, é bastante razoável supor que tenham existido interações diretas entre agentes do grupo DCM, do grupo DCE e do grupo PM. É preciso observar, contudo, que tais interações transcorrem no contexto de uma estrutura hierárquica de comando e controle, por linhas de comunicação formalmente definidas e não por meio de uma lógica de rede. Além disso, não se pode afirmar que tenham sido referentes aos mesmos conteúdos de informação que transitaram pelo Núcleo de Apoiadores, que se ateve exclusivamente às atividades voltadas para atendimento das demandas por donativos.

Dessa maneira, compreende-se que mesmo que as intermediações verificadas possam não ter sido necessariamente o caminho obrigatório da informação entre os agentes, tais relacionamentos existiram e podem ser considerados como relevantes para a consecução da ação coletiva desenvolvida na rede.

\subsubsection{Intensidade dos relacionamentos}

A intensidade dos relacionamentos entre os 24 membros da sociedade civil e os demais 41 membros mapeados, pode ser identificada com base nos dados obtidos do questionário, a partir da pergunta que solicitava informações sobre o número de vezes em que o respondente estabeleceu contato com um determinado ator da rede durante o desenvolvimento das atividades da rede. A tabela 9 apresenta os números obtidos.

TABELA 9 - QUANTIDADE DE CONTATOS POR RELACIONAMENTO

\begin{tabular}{lcc}
\hline $\begin{array}{c}\text { Quantas vezes você se } \\
\text { comunicou com essa pessoa? }\end{array}$ & Código de intensidade & $\begin{array}{c}\text { Relacionamentos nessa } \\
\text { quantidade }\end{array}$ \\
\hline Mais de 15 vezes & 5 & 30 \\
Entre 11 e 15 vezes & 4 & 04 \\
Entre 5 e 10 vezes & 3 & 23 \\
Entre 2 e 4 vezes & 2 & 19 \\
Uma única vez & 1 & 01 \\
\hline Fonte: A autora & &
\end{tabular}

Fonte: A autora 
O grafo 11 apresenta a visualização das diferentes intensidades de relacionamentos estabelecidos, onde existem quatro espessuras distintas para as linhas de relacionamento entre os atores, variando de 1 (para a menor intensidade) a 5 (para a maior intensidade), conforme a tabela 9 . 0 grafo foi gerado por meio do comando existente na janela draw de desenho da rede no Pajek: Options $>$ Lines $>$ DiferentWidths.

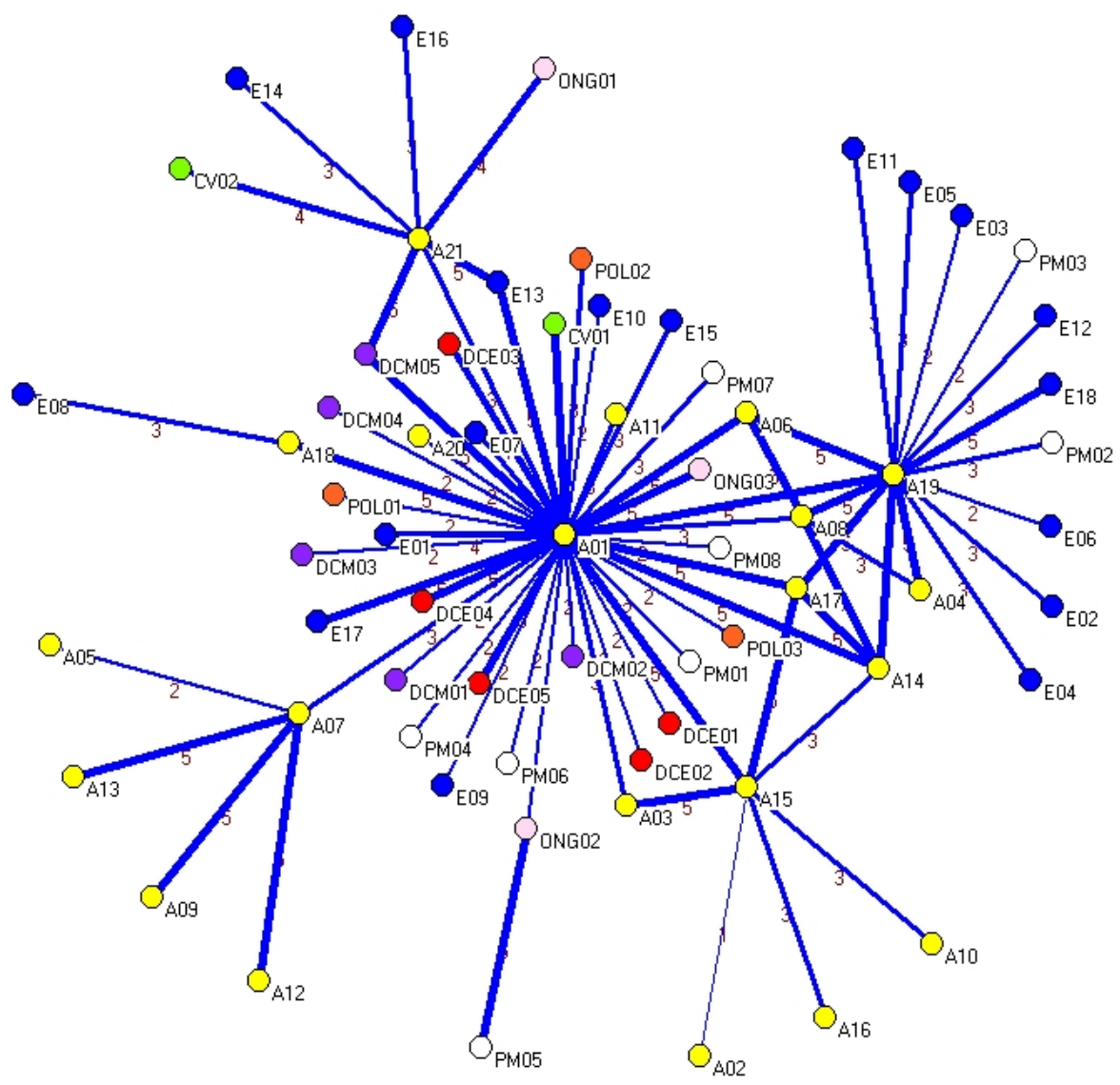
O Sociedade Civil O Cruz Vermelha
O Defesa Civil Estadual
ODefesa Civil Municipal
- Empresas Privadas
O Organizações Não Governamentais
O Prefeituras Municipais
O Polícia Militar

GRAFO 11 - INTENSIDADES DOS RELACIONAMENTOS NO NÚCLEO DE APOIADORES Fonte: A autora.

Para uma melhor percepção da intensidade de interações, foi traçado o sociograma do grafo 12. Apresenta apenas os relacionamentos com intensidade superior a 3 , restando, portanto, apenas os laços de peso 4 e 5 . Foi utilizando o seguinte comando no Pajek: Network>CreateNew Network>Transform $>$ Remove $>$ Lines with value $>$ Lower than 4. 


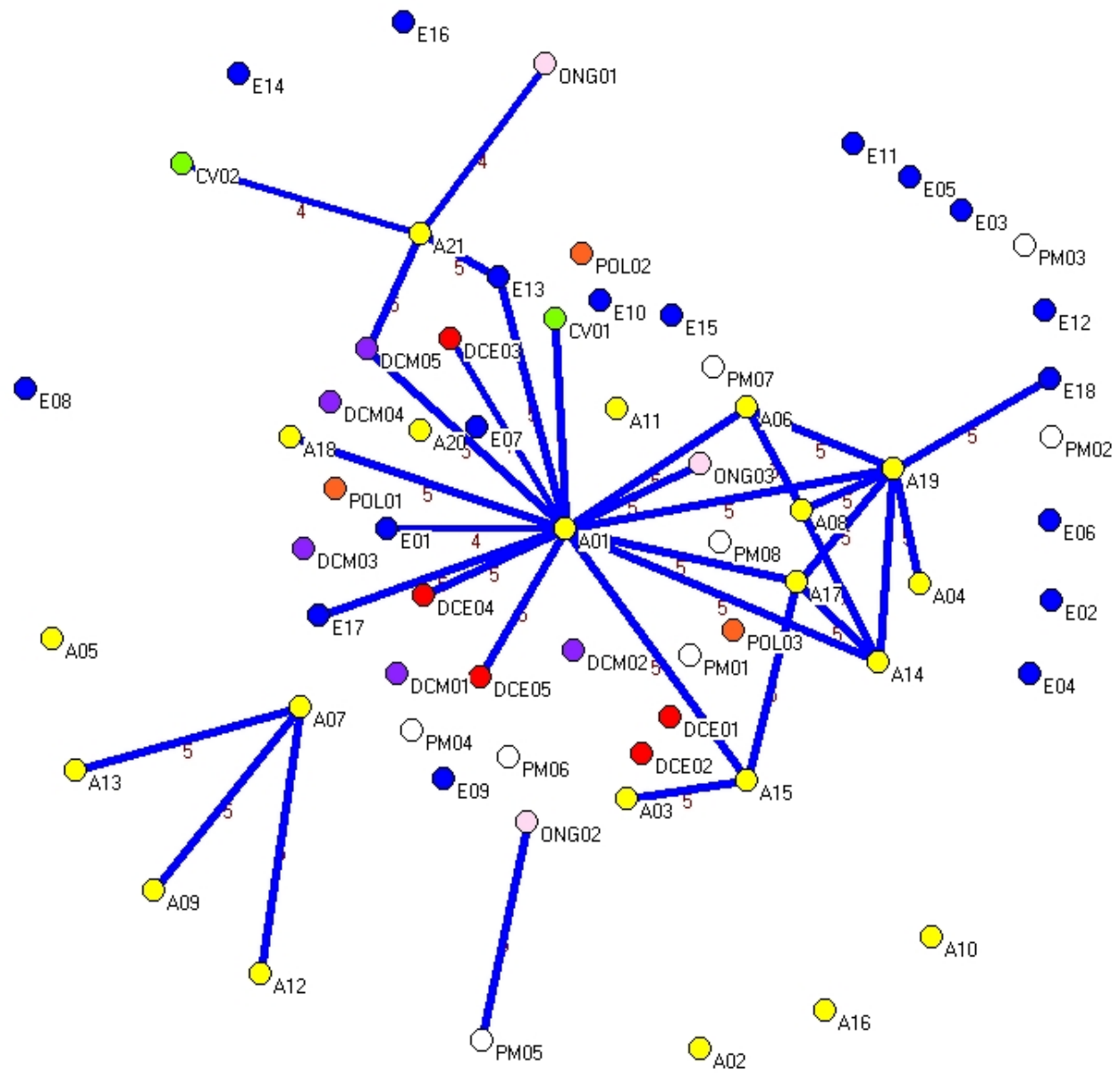

O Sociedade Civil O Cruz Vermelha O Defesa Civil Estadual O Defesa Civil Municipal

- Empresas Privadas O Organizações Não Governamentais $\bigcirc$ Prefeituras Municipais O Polícia Militar

GRAFO 12 - RELACIONAMENTOS COM INTENSIDADE SUPERIOR A 3 NO NÚCLEO DE APOIADORES

Fonte: A autora.

O grafo 13, por sua vez, permite a visualização dos relacionamentos de menor intensidade, onde constam apenas os pesos 1, 2 e 3 nos laços. A exclusão das linhas foi feita por meio do comando Network>CreateNew Network>Transform $>$ Remove $>$ Lines with value $>$ Higher than 3.

Com isso, se tem uma visualização da diferença entre os grafos 11 e 12, ou seja grafo 13 = grafo 11 - grafo 12 . 


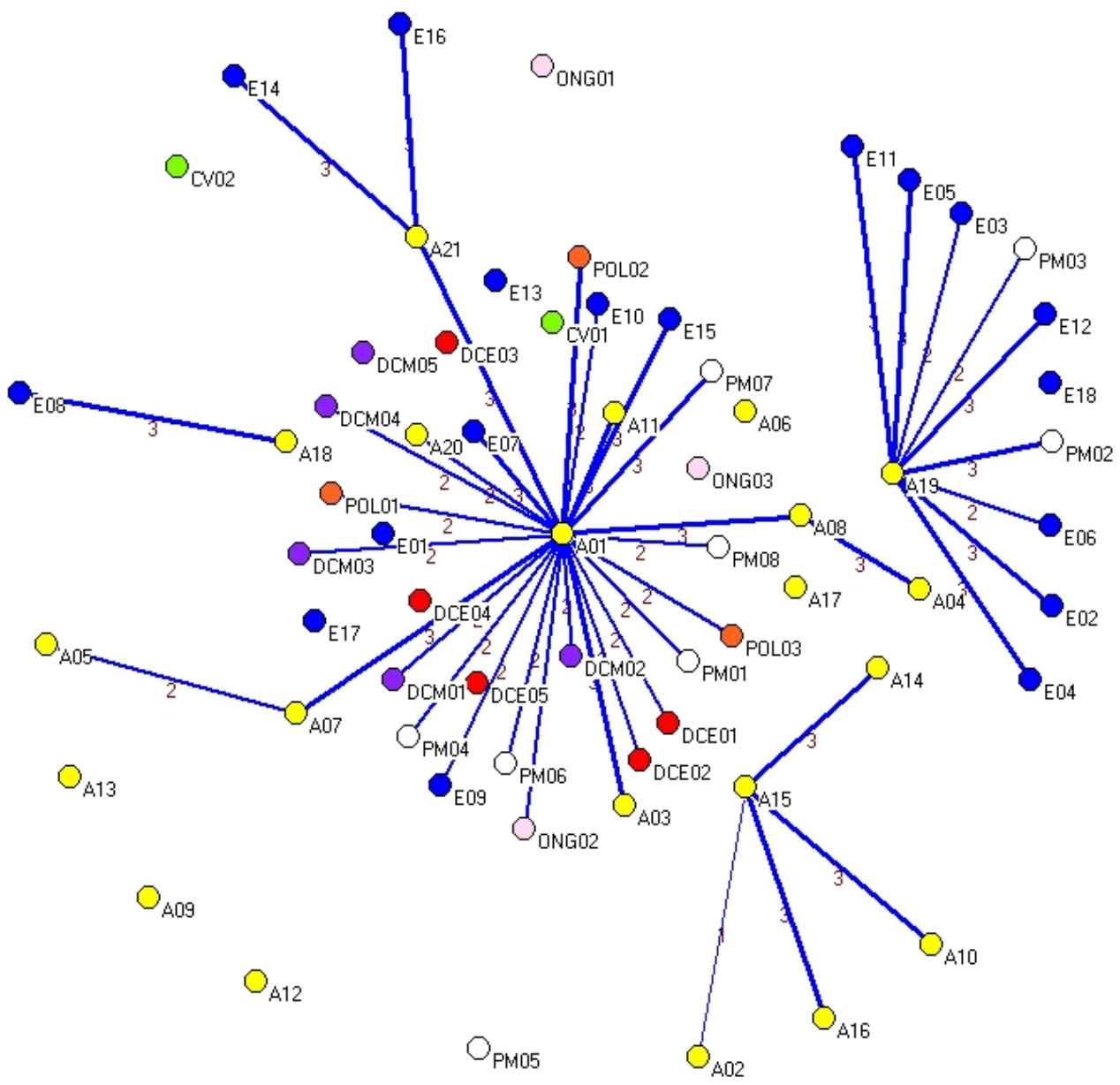

O Sociedade Civil O Cruz Vermelha $\bigcirc$ Defesa Civil Estadual O Defesa Civil Municipal

- Empresas Privadas O Organizações Não Governamentais O Prefeituras Municipais

O Polícia Militar

GRAFO 13 - RELACIONAMENTOS COM INTENSIDADE INFERIOR A 4 NO NÚCLEO DE APOIADORES

Fonte: A autora.

A partir da análise dos grafos 11 e 12 é possível identificar que, de maneira geral, os contatos estabelecidos pelos atores "A" com atores representativos de Empresas Privadas, Prefeituras Municipais e Polícia Militar foram de menor intensidade, se comparados aos contatos com outros tipos de atores na rede, como Defesa Civil Estadual e Cruz Vermelha. Entre os próprios atores A, observa-se a existência de contatos bastante frequentes em um grupo formado por A01, A15, A17, A14, A06, A08, A19. Pela análise realizada dos K-núcleos da rede, conforme se observa a partir do grafo 14 a seguir, tal grupo pode ser considerado o mais coeso da rede. 


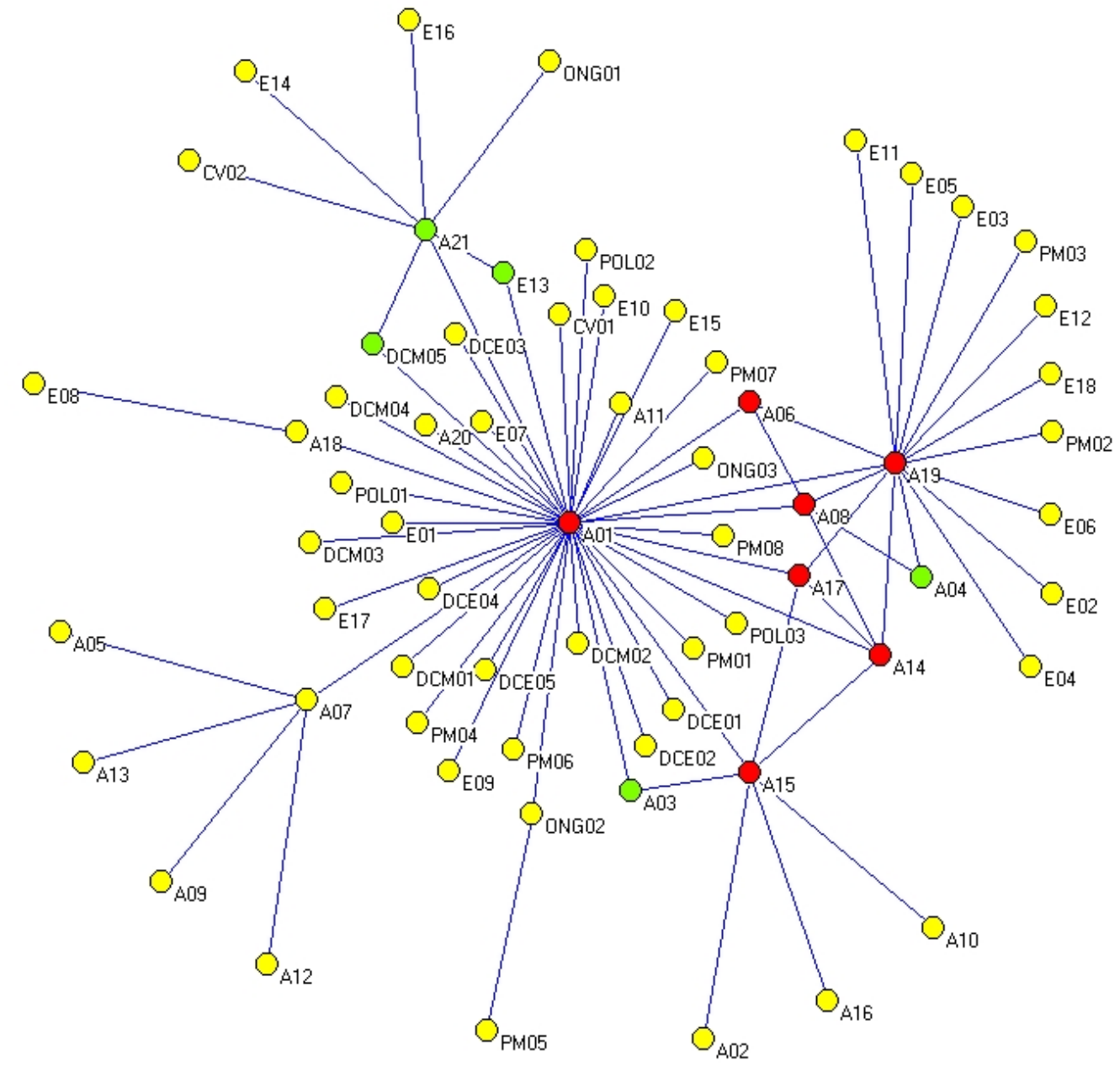

1-core

- 2-core

3-core

GRAFO 14 - K-CORES EXISTENTES NO NÚCLEO DE APOIADORES Fonte: A autora.

O k-core máximo localizado no Núcleo de Apoiadores foi um 3-core (atores em vermelho), representado pelos sete atores (A01, A15, A17, A14, A06, A08, A19). Comparando-se o grafo $14 \mathrm{com}$ o grafo 12 pode-se perceber que além deste grupo possuir a maior coesão da rede, também os relacionamentos ali estabelecidos estiveram entre as intensidades mais elevadas. Isso também é constatado para os 5 atores (em verde) pertencentes ao 2-core, onde existe intensidade elevada e também maior coesão. Os demais 53 atores (em amarelo) possuem apenas uma conexão cada. 


\subsection{SOBRE VELHOS E NOVOS RELACIONAMENTOS}

A análise de dados existente nesta seção relaciona-se ao quarto pressuposto $\left(\mathrm{P}_{4}\right)$ da pesquisa que considera que "no processo de estruturação das redes sociais de resposta a desastres naturais, os atores contam com laços relacionais préexistentes, mas também estabelecem novos laços de forma dinâmica".

Ao mesmo tempo, permite a compreensão de importantes aspectos relacionados ao alcance de dois objetivos específicos propostos:

$\mathrm{O}_{\mathrm{E} 1}$ : Descrever o surgimento de uma organização estruturada na forma de rede social no caso específico da resposta às chuvas de dezembro de 2013 no ES, bem como as atividades por ela desenvolvidas.

$\mathrm{O}_{\mathrm{E} 5}$ : Mapear a topologia da rede, identificando e analisando suas propriedades a partir da ARS.

O levantamento de dados, principalmente por meio dos questionários, permitiu identificar quais relacionamentos eram anteriores à formação da rede em análise e quais eram novos relacionamentos $\left(Q_{2}\right)$. Além disso, a entrevista realizada com $A 01$ esclareceu alguns importantes aspectos sobre a formação inicial da rede $\left(E_{A 2}\right)$, o que foi também útil na compreensão sobre a pré-existência de laços relacionais entre os atores. A abordagem da ARS foi utilizada para desenhar a rede, permitindo a visualização dos relacionamentos considerando a distinção entre laços antigos e laços novos.

\subsubsection{O velho e o novo se complementam}

O questionário solicitava aos respondentes, para cada um dos contatos que indicavam, que informassem se já conheciam essa pessoa. Caso marcassem sim, o campo seguinte se destinava a informar de onde a conhecia. Pode-se constatar que 
dentre os 77 relacionamentos que puderam ser mapeados na rede, 31 são referentes a relacionamentos pré-existentes e 46 refletem novos relacionamentos estabelecidos em razão das ações desenvolvidas pela rede. A tabela 10 apresenta os dados.

TABELA 10 - RELACIONAMENTOS PRÉ EXISTENTES E NOVOS

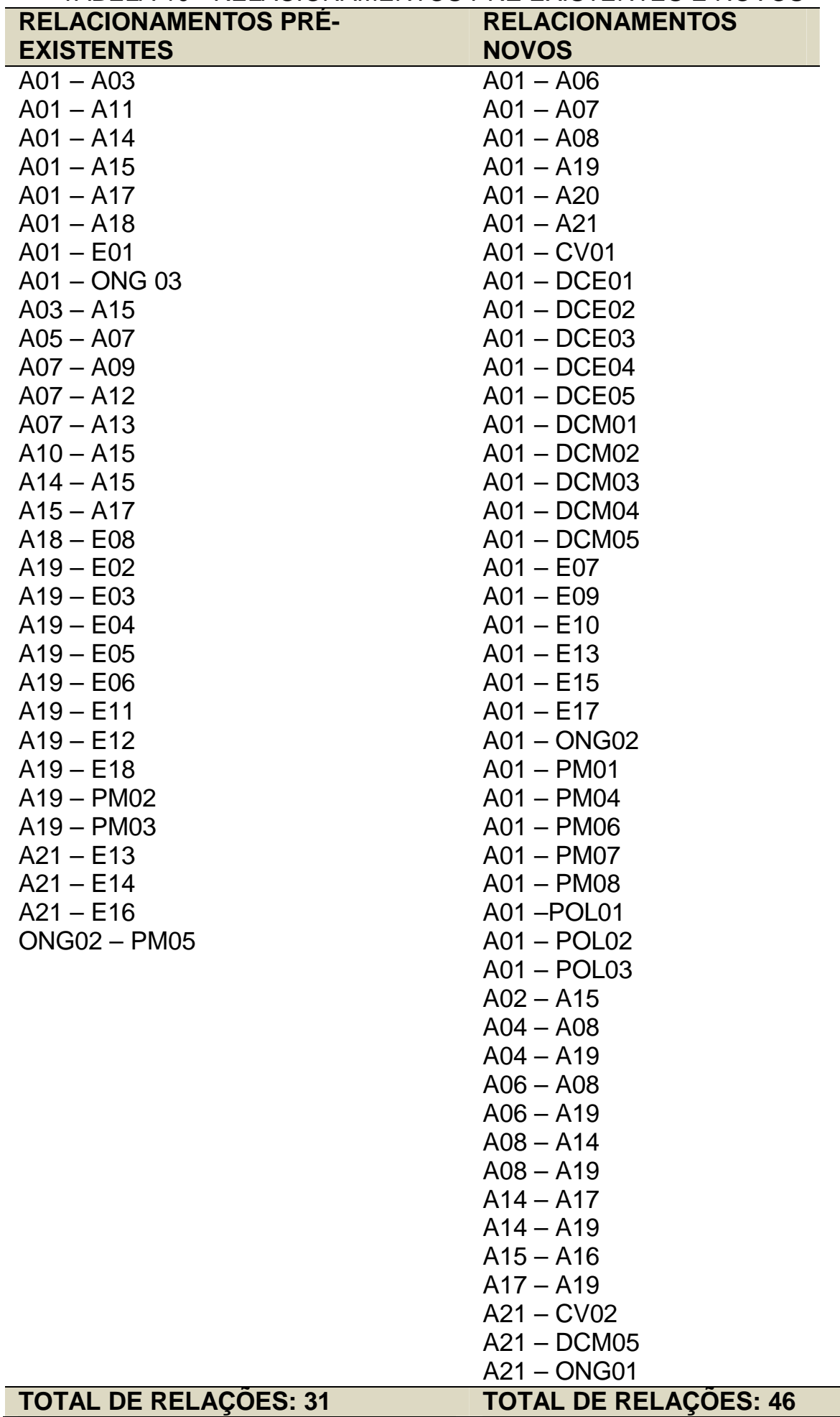


Assim, mais da metade dos relacionamentos mapeados, aproximadamente 59\%, descrevem relacionamentos surgidos após a data de 19 de dezembro, quando as atividades da rede tiveram início.

O grafo 15 a seguir, permite a visualização dessas relações, considerando que as linhas mais fortes representam os laços pré-existentes, e as linhas mais fracas aqueles surgidos após o dia 19 de dezembro, em função das atividades desenvolvidas pela rede.

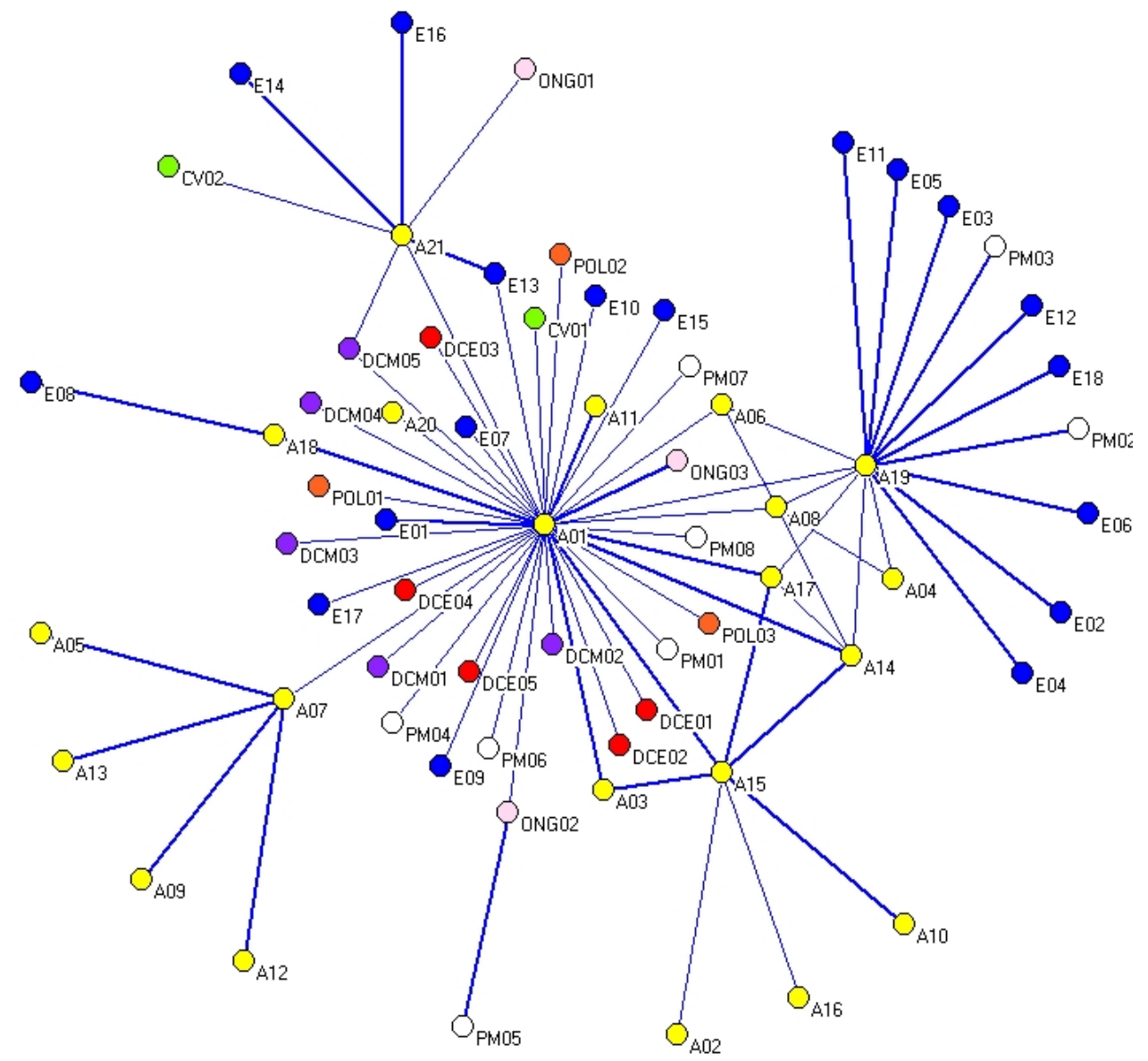

Relacionamentos Novos

Relacionamentos pré-existentes

O Sociedade Civil O Cruz Vermelha O Defesa Civil Estadual O Defesa Civil Municipal

- Empresas Privadas O Organizações Não Governamentais O Prefeituras Municipais Polícia Militar

GRAFO 15 - RELACIONAMENTOS NOVOS E PRÉ-EXISTENTES NO NÚCLEO DE APOIADORES Fonte: A autora.

Para a geração deste grafo, utilizou-se a opção existente no Pajek para desenho dos laços com diferentes espessuras, considerando o peso que foi dado a cada um dos 
tipos de relacionamentos. No arquivo net correspondente, relacionamentos préexistentes receberam peso 2 e relacionamentos novos, peso 1 . Assim, os préexistentes possuem aresta de espessura maior, e os novos, arestas de espessura menor. Por meio do comando existente na tela de desenho da rede Options>Lines>DiferentWidths, foi gerado o grafo.

Observa-se o fenômeno de crescimento da rede, que passou de 31 relacionamentos iniciais para 77, aumentando também o número de atores conectados. Embora o questionário possuísse uma questão sobre a data em que 0 ator iniciou suas atividades na rede, cuja intenção era mapear o crescimento da rede ao longo do tempo, não foi possível o aproveitamento das respostas, devido à imprecisão das mesmas. Muitos atores não souberam precisar a data em que começaram a ajudar e assim, considerando que o intervalo temporal de mobilização da rede foi de uma semana, uma pequena diferença de apenas um dia na inclusão de um determinado ator, poderia alterar significativamente toda a análise proposta.

É possível observar a partir da tabela 11, a seguinte relação entre o quantitativo de laços pré-existentes e de laços novos, para cada um dos atores do grupo emergente na rede em análise.

TABELA 11 - QUANTITATIVO DE RELACIONAMENTOS PRÉ-EXISTENTES E RELACIONAMENTOS NOVOS POR ATOR

ATOR RELACIONAMENTOS PRE-EXISTENTES RELACIONAMENTOS NOVOS

$\begin{array}{lll}\text { A01 } & 08 & 32 \\ \text { A02 } & 00 & 01 \\ \text { A03 } & 02 & 00 \\ \text { A04 } & 00 & 02 \\ \text { A05 } & 02 & 00 \\ \text { A06 } & 00 & 01 \\ \text { A07 } & 03 & 01 \\ \text { A08 } & 00 & 05 \\ \text { A09 } & 01 & 00 \\ \text { A10 } & 01 & 00 \\ \text { A11 } & 01 & 00 \\ \text { A12 } & 01 & 00 \\ \text { A13 } & 01 & 00 \\ \text { A14 } & 02 & 03 \\ \text { A15 } & 05 & 02 \\ \text { A16 } & 00 & 01 \\ \text { A17 } & 02 & 02 \\ \text { A18 } & 02 & 00 \\ \text { A19 } & 10 & 06 \\ \text { A20 } & 00 & 01 \\ \text { A21 } & 00 & 04\end{array}$

Fonte: A autora. 
Especificamente sobre os relacionamentos pré-existentes, 22 referem-se a vínculos profissionais, 06 a vínculos de amizade e 03 a vínculos familiares, conforme se pode observar a partir do quadro 11.

\begin{tabular}{|c|c|}
\hline ORIGEM & RELACIONAMENTOS PRE-EXISTENTES \\
\hline PROFISSIONAL & $\begin{array}{c}\text { A01-A03 } \\
\text { A01-A14 } \\
\text { A01-A18 } \\
\text { A01-E01 } \\
\text { A01-ONG03 } \\
\text { A03-A15 } \\
\text { A14-A15 } \\
\text { A18-E08 } \\
\text { A19-E02 } \\
\text { A19-E03 } \\
\text { A19-E04 } \\
\text { A19-E05 } \\
\text { A19-E06 } \\
\text { A19-E11 } \\
\text { A19-E12 } \\
\text { A19-E18 } \\
\text { A19- PM02 } \\
\text { A19- PM03 } \\
\text { A21-E13 } \\
\text { A21-E14 } \\
\text { A21-E16 } \\
\text { ONG02-PM05 }\end{array}$ \\
\hline TOTAL & 22 \\
\hline AMIZADE & $\begin{array}{l}\mathrm{A} 01-\mathrm{A} 11 \\
\mathrm{~A} 01-\mathrm{A} 15 \\
\mathrm{~A} 05-\mathrm{A} 07 \\
\mathrm{~A} 07-\mathrm{A} 13 \\
\mathrm{~A} 10-\mathrm{A} 15 \\
\mathrm{~A} 15-\mathrm{A} 17\end{array}$ \\
\hline TOTAL & 06 \\
\hline FAMILIAR & $\begin{array}{c}\mathrm{A} 01-\mathrm{A} 17 \\
\mathrm{~A} 07-\mathrm{A} 09 \\
\mathrm{~A} 07-\mathrm{A} 12\end{array}$ \\
\hline TOTAL & 03 \\
\hline
\end{tabular}

Os dados se aproximam da concepção de Quarantelli (2005) acerca das condições que viabilizam a ação de grupos emergentes em desastres naturais. Duas delas puderam ser claramente percebidas a partir dos dados apresentados. Existiam relacionamentos sociais relevantes antes da ocorrência do desastre e também determinados recursos específicos necessários à ação coletiva. Esses últimos se relacionam a existência de fontes materiais e humanas para a execução das tarefas, como também de conhecimento relevante a ser aplicado na situação, conforme já discutido na subseção 5.1.1 
Segundo o autor, relacionamentos sociais preexistentes, normalmente facilitadores do processo, estão usualmente atrelados a laços familiares, de amizade, vínculos religiosos ou até mesmo de vizinhança. No caso em análise pode-se observar também a existência dos vínculos profissionais, de maneira mais significativa. Ao mesmo tempo, os dados mostram que novos laços relacionais também foram construídos no processo de crescimento e auto-organização da rede, representados por trocas informacionais entre agentes que efetivamente não se conheciam antes de 19 de dezembro de 2013.

Assim, pode-se afirmar que as necessidades de donativos identificadas em diferentes pontos do estado, associadas a um forte sentimento de solidariedade por parte dos atores sociais, geraram a mobilização de laços relacionais pré-existentes, mas também a construção de novos laços de forma a suprir as necessidades informacionais no âmbito das ações da rede.

Considera-se, conforme apontam Pan, Pan e Leidner (2012) que nas redes de atuação na resposta aos desastres, o fluxo de informações está diretamente relacionado aos relacionamentos sociais. Os dados demonstram a relativa rapidez com que a rede saiu de 31 para 77 relacionamentos, quando se considera 0 intervalo de aproximadamente 8 dias. Percebe-se que praticamente todos os atores, em maior ou menor medida, foram capazes de acionar os contatos com pessoas que já conheciam e também de criar novos relacionamentos.

\subsubsection{A relevância de cada um}

Apesar de representarem o menor número entre os relacionamentos mapeados, os relacionamentos pré-existentes possuíram um papel fundamental para o início das ações, conforme já explicitado na seção 5.1 acerca do surgimento da rede.

Conforme destaca A01, o chat realizado no Facebook contou com a participação de pessoas que já faziam parte de sua rede de relacionamentos, embora nem todas tenham vindo a participar efetivamente na articulação das demandas ou em 
qualquer outra ação desenvolvida pela rede. Ainda assim, pode-se considerar que houve uma "semente" da rede, baseada essencialmente em relacionamentos préexistentes.

Nem todas as pessoas que estavam no chat chegaram a atuar na Praça do
Papa, mas é assim que funciona. Eu já participei de vários movimentos
associativistas e é sempre assim, você fala com cem, mas nem todos
retornam, e tem um grupo que faz a coisa ir pra frente. Em muitos
movimentos assim tem aquela coisa de querer fazer todo mundo participar,
de atingir um consenso [...] Tem acontecer ou não. Se você ficar tentando
essa meta sempre, é não [...] (TRECHO EXTRAÍDO DA ENTREVISTA COM
A01).

Uma breve análise qualitativa dos relacionamentos pré-existentes permite perceber que além daqueles presentes entre atores do grupo $A$, boa parte refere-se a relacionamentos desses com representantes de empresas, que vieram a viabilizar grandes volumes de doações, além do transporte de donativos às cidades afetadas, cedendo caminhões, e até mesmo helicópteros e aviões.

Nesse sentido, tais relações foram bastante importantes para a consecução das atividades da rede. Isso se torna mais claro a partir da visualização do grafo 16 onde estão presentes apenas os relacionamentos pré-existentes. É possível verificar como os atores A21 e A19 foram capazes de acionar seus laços já existentes, com pessoas representantes de empresas, para auxiliar na viabilização das ações da rede.

Nos relacionamentos de A21 estão E16, E14 e E13, todos representantes de empresas de comunicação que apoiaram as atividades com doações e também com divulgação de informações. A19 por sua vez, acionou seus laços com E02, E03, E04, E05, E06, E11, E12 e E18, cujas principais contribuições para as atividades da rede estão descritas a seguir:

E02: representante de uma empresa transportadora que fez doações de alimentos e material de limpeza e cedeu caminhões;

E03: representante de uma granja que cedeu caminhões e ajudou a distribuir as doações que eram enviadas para o município de Santa Maria de Jetibá, no interior do Estado;

E04: representante de uma empresa transportadora que fez doações de alimentos e ofereceu descontos para a compra de cestas básicas; 
E05: representante de uma empresa mineradora que cedeu helicóptero e caminhões e ajudou na distribuição das doações no município de São Domingos do Norte;

E06: representante de outra empresa mineradora que cedeu helicóptero para transportes de médicos e donativos ao interior;

E11: representante de uma empresa transportadora que fez doações de alimentos e material de limpeza e cedeu caminhões;

E12: representante de uma empresa transportadora que cedeu caminhões;

E18: representante uma empresa transportadora que fez doações de cestas básicas e cedeu caminhões;

Ao mesmo tempo, o grafo 16 a seguir, permite também a percepção clara da importância que os novos laços tiveram para a estruturação e para o desenvolvimento das atividades da rede.

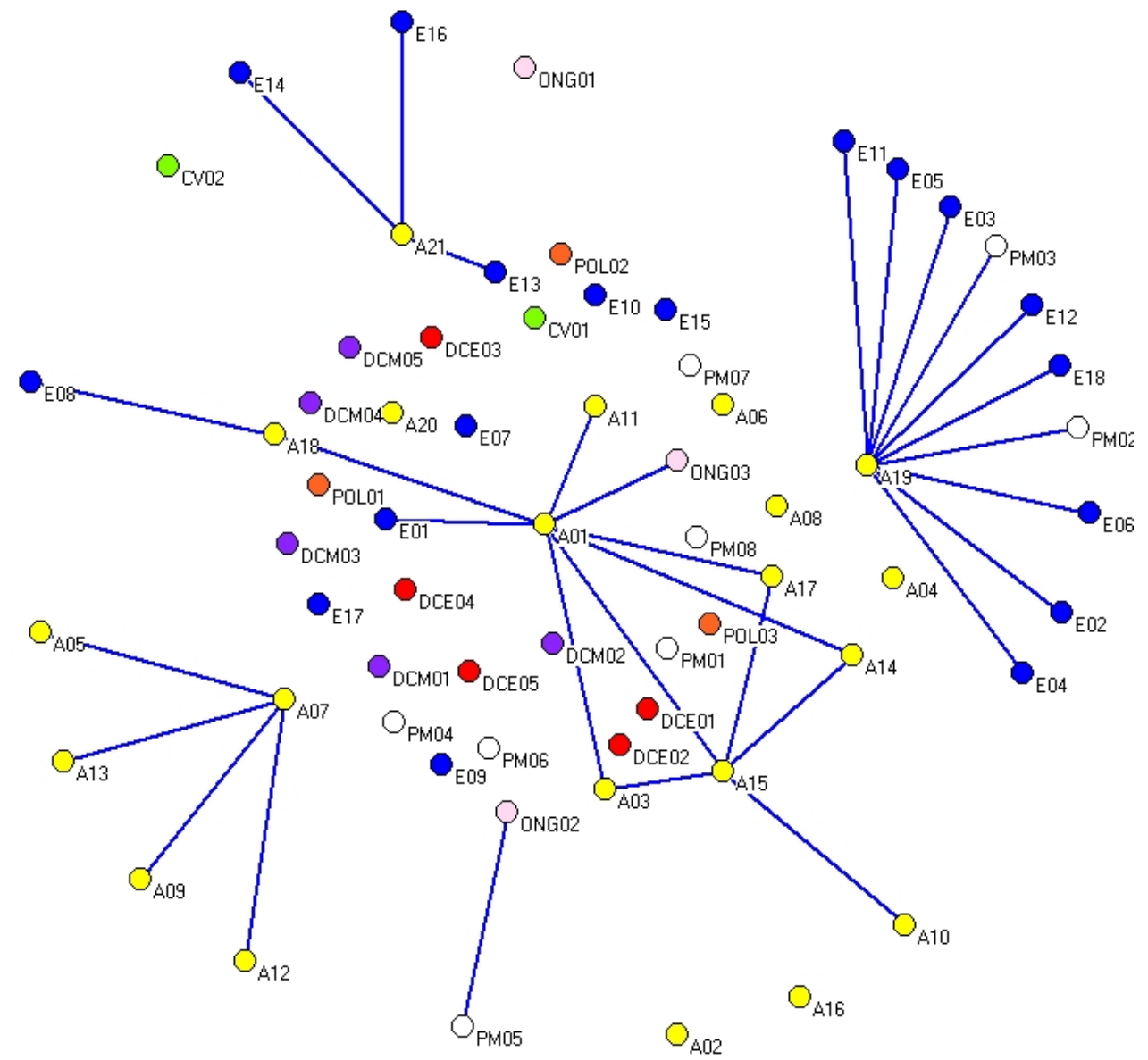


Observa-se que, sem os novos laços, construídos em função do engajamento dos atores nas atividades da rede, existiriam cinco componentes isolados, além de 32 atores sem qualquer conexão, o que teria inviabilizado o desenvolvimento das ações coletivas de dezembro de 2013, pelo menos, na dimensão em que ocorreram. Assim, pode-se concluir que esses novos laços foram essenciais para a conexão dos diferentes componentes da rede. Destacam-se nesse rol, os laços A01-A07 e A01-ONG02, cuja remoção aumentaria o número de componentes da rede, rompendo portanto, o contato entre dois grupos de atores e constituindo-se assim como pontes.

Percebe-se a importância dos novos relacionamentos, especialmente em sua função de estabelecimento de vínculos comunicacionais com agentes de organizações estabelecidas, expandidas e estendidas. Especificamente entre os atores do grupo A observa-se que muitos também teriam permanecido isolados, se não tivessem tido a habilidade de estabelecer contato com pessoas que ainda não conheciam.

Essa constatação enfatiza ainda mais a importância do que Pan, Pan e Leidner (2012) afirmam, sobre a importância dos laços relacionais pré-existentes e também da capacidade de criação de novos laços relacionais, por parte dos atores sociais em redes de resposta a desastres naturais.

Os dados coletados por meio do questionário permitiram, contudo, identificar que a maioria dos novos relacionamentos estabelecidos foi efêmera. Ou seja, existiram apenas em função das atividades exercidas na rede. Aproximadamente $75 \%$ desses relacionamentos não existem atualmente, tendo em vista que os atores não mantêm mais contato, e $25 \%$ se comunicam apenas raramente.

Uma análise interessante pode ser realizada a partir da inspeção visual do Núcleo de Apoiadores sem a presença de A01, constante no grafo 17 a seguir. Essa visualização permite verificar os relacionamentos existentes, sem a interferência direta do papel de A01. 


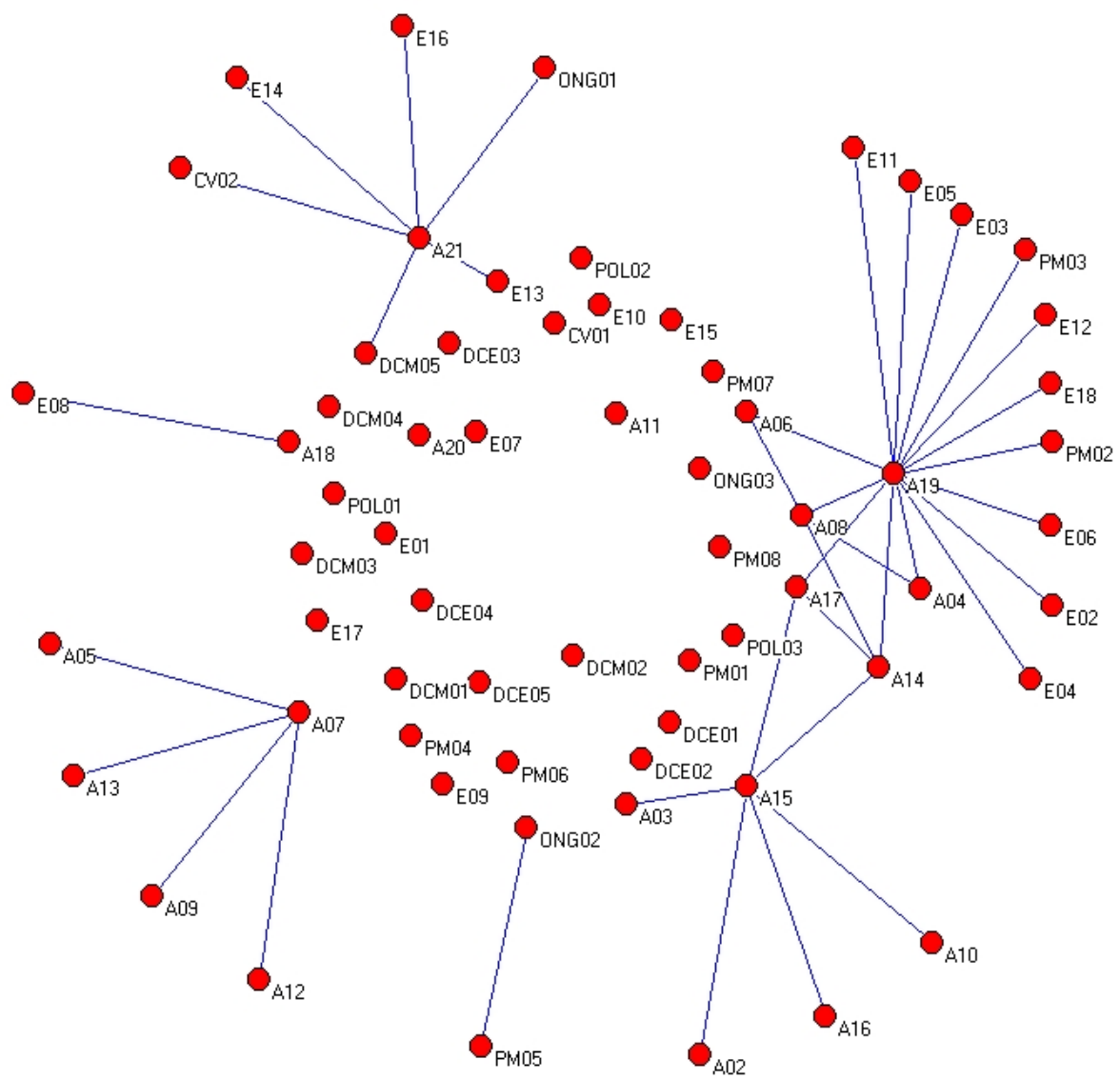

GRAFO 17 - NÚCLEO DE APOIADORES SEM A PRESENÇA DE A01

Fonte: A autora

Observam-se, sem a presença de A01, cinco componentes isolados no Núcleo de Apoiadores, comprovando ser esse ator um importante ponto de corte na rede. Percebe-se a formação de alguns subnúcleos, em que outros atores mobilizaram antigos relacionamentos ou criaram novos. Dentre esses subnúcleos, destaca-se o maior, composto por 21 atores, onde se encontra circunscrito o 3-core localizado na rede, conforme demonstrado no grafo 14, formado por seis atores, além de A01 (A15, A17, A14, A06, A08 e A19). Especificamente, neste 3-core, estão, em sua maioria, novos relacionamentos, como se pode observar quando se compara o grafo 17 com o grafo 15. À exceção dos relacionamentos de $A 15$ com A14 e A17, todos os relacionamentos deste 3-core trataram-se de laços que emergiram após o início das atividades.

Também são novos os relacionamentos estabelecidos por A15 com A16 e A02. Em outro componente, observa-se que A21 também foi capaz de estabelecer novos laços com DCM05, CV02 e ONG01, além de sua própria conexão com A01. 
Assim, não se discute que A01 foi o grande "mentor" de toda a articulação que culminou com a ação coletiva desenvolvida, tendo exercido o controle inicial sobre quem seriam os atores e também sobre que habilidades e conhecimentos seriam interessantes que fossem agregados por parte desses atores, conforme já discutido na seção 5.1. Também, é evidente a importância de A01 para que os relacionamentos entre esses cinco componentes fossem mantidos.

Contudo, as análises realizadas permitem verificar que o Núcleo de Apoiadores adquiriu certa dinâmica própria, independente da ação direta de A01, evidenciando traços de natureza emergente, onde surgiram novos e importantes relacionamentos que também contribuíram de forma significativa para que as ações fossem desenvolvidas.

\subsection{A REDE E A HIERARQUIA}

Esta última seção da análise de dados relaciona-se ao quinto pressuposto $\left(\mathrm{P}_{5}\right)$ da pesquisa que considera que "as estruturas usuais do Estado para a resposta a desastres naturais possuem como princípios o comando, o controle e a hierarquia. Por outro lado, a estruturação em rede, representada pelos grupos emergentes no pós-desastre natural, possui natureza autônoma, voluntária e solidária, cujas características denotam aproximações com a racionalidade substantiva".

Ao mesmo tempo, as análises a seguir realizadas permitem a compreensão de importantes aspectos relacionados ao alcance de dois dos objetivos específicos propostos:

$\mathrm{O}_{\mathrm{E} 3}$ : Identificar o relacionamento do grupo emergente com as organizações estabelecidas, para a gestão de desastres no ES, especialmente com a Defesa Civil Estadual.

OE4: Realizar uma análise comparativa entre as estruturas de ação da Defesa Civil Estadual e da rede de apoio às vítimas das chuvas de 2013 no ES. 
Sobre esses aspectos, tanto os questionários aplicados aos atores da rede, quanto as entrevistas realizadas com A01, os levantamentos não estruturados com A08 e A19, as entrevistas com a equipe da Defesa Civil Estadual (DCE) e com o Comandante da DCE à época do ocorrido, foram as principais fontes de evidências empíricas.

A entrevista realizada com A01, em sua finalidade de identificar como se deu o relacionamento da rede com a DCE $\left(E_{A 4}\right)$, foi fundamental para a análise sobre esse pressuposto. Complementarmente, duas outras finalidades dessa entrevista também apoiaram as análises realizadas, quais sejam: detalhar aspectos relacionados ao surgimento da rede, suas motivações, objetivos iniciais e forma de atuação $\left(E_{A 2}\right)$ e identificar quais as principais ações e como elas foram desenvolvidas pela rede durante as fortes chuvas de dezembro de $2013\left(E_{A 3}\right)$.

Ainda, a contribuição do Comandante da DCE foi significativa a partir de sua entrevista sobre o ocorrido em dezembro de 2013, em todas as finalidades definidas para essa coleta de dados: detalhar a estrutura do planejamento e da execução das ações de resposta a desastres naturais protagonizadas pela DCE ( $\left.E_{B 1}\right)$; identificar a percepção da DCE quanto à atuação do grupo emergente em estudo ( $\left.E_{B 2}\right)$; identificar em que medida as ações planejadas pela DCE puderam ser efetivamente executadas na ocasião $\left(E_{\mathrm{B} 3}\right)$ e descrever as características do processo decisório no âmbito da DCE, em ações de resposta a desastres naturais $\left(E_{B 4}\right)$.

A entrevista com a equipe da DCE, responsável pelas ações de resposta também foi essencial em todas as suas finalidades: identificar a dimensão do desastre ocorrido em dezembro de 2013 em relação à capacidade de resposta da DCE à época $\left(E_{C 1}\right)$; identificar a percepção da DCE quanto à atuação do grupo emergente em estudo $\left(E_{C_{2}}\right)$; verificar em que medida as ações planejadas pela DCE puderam ser efetivamente executadas na ocasião $\left(E_{C_{3}}\right)$; compreender como se deu a interação entre a DCE e o grupo emergente em estudo $\left(E_{C 4}\right)$ e levantar como a DCE trata as contribuições de grupos voluntários em situações de gestão de desastres naturais $\left(E_{C 5}\right)$.

O questionário foi também de grande utilidade sobre os aspectos discutidos nesta seção, já que identificou quais foram as motivações existentes para que cada um 
participasse das ações de apoio às vítimas das chuvas $\left(Q_{6}\right)$. Os dados passam a ser apresentados e analisados a seguir.

\subsubsection{Solidariedade e gratuidade como molas propulsoras}

As respostas ao questionário indicam, como já se esperava, que a maioria dos respondentes foi motivada por solidariedade e vontade de ajudar o próximo. Entre os 13 respondentes, 11 indicaram ser essa a sua motivação essencial. Os outros 02 responderam ter sido o convite de amigos a motivação preponderante para que se mobilizassem. Importante ressaltar que as ações foram iniciadas por volta do dia 19 de dezembro de 2013 e permaneceram acontecendo até alguns dias após o Natal. Ou seja, muitas dessas pessoas permaneceram trabalhando, voluntariamente, inclusive na véspera do Natal.

A entrevista de A01 traz também alguns subsídios importantes sobre esse aspecto. Nesse momento indicou que não se tratava de uma decisão "racional", conforme se pode observar pela transcrição do trecho abaixo:

[...] Eu tirei umas férias forçadas pra mim mesma. Eu parei de trabalhar, 10 dias e o tempo passou voando. A sorte é que caiu um pouco no Natal [...] Eu recusei dois serviços por conta disso. Dois serviços: um pelo SEBRAE que tinha me solicitado uma consultoria, e eu falei não posso fazer porque eu estou com outro compromisso, e uma consultoria particular que eu também não quis pegar. Assim, é um negócio que você olha e você fala: meu Deus, eu estou deixando de ganhar dinheiro, pagando para estar aqui! Mas não é racional, né? [...] (TRECHO EXTRAÍDO DA ENTREVISTA COM A01)

A partir deste trecho da entrevista, observa-se que na percepção de A01 o trabalho desenvolvido na Praça do Papa em dezembro de 2013, não esteve relacionado a nenhum interesse de ganho financeiro. Ao contrário, durante o período em que atuou na rede, A01 deixou de aceitar alguns trabalhos de consultoria, para que pudesse continuar seu trabalho voluntário.

A fala de A19 corrobora este pensamento de A01. O ator afirmou que, além de não possuir qualquer interesse de ganho financeiro com as atividades por ele 
desenvolvidas junto ao Núcleo de Apoiadores, chegou até mesmo a gastar dinheiro do próprio bolso para compra de cestas básicas e combustível, num montante de aproximadamente cinco mil reais.

A08 por sua vez, disse ter se envolvido nas atividades, por um forte sentimento de vontade de ajudar às vítimas do desastre em curso e que, enquanto esteve presente na Praça do Papa, "não sentia nem fome", tamanho foi seu envolvimento.

A01 exemplificou a atuação de outros voluntários, cuja descrição serve para auxiliar na compreensão do nível de compromisso e dedicação das pessoas que atuaram naquele momento em apoio às vítimas.

[...] Entre os motoristas dos caminhões tinha gente que voltava e fazia nova viagem e ficava virado. Foi linda a história, meia noite e meia eu recebi uma ligação de uma pessoa que a mãe não tinha chegado ainda, que tinha ido viajar. E eu preocupada: meu Deus, aconteceu alguma coisa com essa mulher! Aí, uma hora da manhã ela me liga e fala: chegou. A pessoa passou o Natal na estrada. Tem menino que fez não sei quantas viagens.[...] Essa mulher que passou o Natal na estrada, ela fez umas três viagens também, é uma graça! [...] (TRECHO EXTRAÍDO DA ENTREVISTA COM A01)

Outro aspecto interessante observado pela fala de A01 é que em vários momentos a entrevistada fez questão de afastar, das motivações ali existentes, qualquer interesse político partidário, ou qualquer tentativa de apropriação daquelas atividades por parte de políticos.

[...] Teve uma hora, por exemplo, que teve uma deputada federal que queria entrar no caminhão para entregar donativos lá em Vila Velha. Aí eu falei: essa mulher não entra aqui de jeito nenhum e fechei com os caras que estavam fazendo o carregamento. Aí a mulher ficou uma arara e disse, mas eu estou aqui como uma cidadã. Então eu falei, mas não vai usar isso no contexto político [...] O que começou a incomodar é que eles começaram a pensar que aquelas pessoas tinham um intento político. Gente, aquele grupo, assim, o núcleo duro, não estou dizendo que alguém que estava ajudando, não poderia ter, mas eu digo que aquele núcleo duro mesmo que ficava por conta de coordenações, vamos dizer assim, você não vai ver nenhum deles em chapa nenhuma e nem inscrito em partido [...]. (TRECHO EXTRAÍDO DA ENTREVISTA COM A01)

Da mesma maneira se posicionou $A 19$, quando afirmou que não gostou quando políticos tentaram tomar a frente do movimento, ou se apropriar das ações desenvolvidas pela rede, afirmando terem sido eles os responsáveis pelo envio de determinados caminhões ao interior. Segundo esse ator, tais políticos não obtiveram sucesso nessas tentativas em função das intervenções dos próprios atores do Núcleo de Apoiadores que não deixaram que isso acontecesse. 
As falas de A01, A08 e A19 corroboram os dados coletados por meio do questionário, em que 11 dos 13 respondentes indicaram ser a solidariedade a sua motivação principal e 2 indicaram ser a influência de amigos. Esses aspectos sobre a motivação dos respondentes para a participação na rede, mapeados a partir de questionários, entrevista e levantamentos não estruturados, permitem observar a presença da lógica da gratuidade e da solidariedade no contexto das ações desenvolvidas pelo Núcleo de Apoiadores. Contudo, não se pode afirmar que outras intencionalidades também não estiveram presentes como a promoção pessoal por exemplo, embora isso não tenha sido explicitado nos dados que puderam ser coletados.

A partir dos dados apresentados, pode-se afirmar que os vínculos mapeados na rede evidenciam a solidariedade e a participação voluntária como molas propulsoras da ação coletiva desenvolvida em apoio às vítimas das chuvas. A adesão às atividades foi decorrente de um exercício espontâneo de vontade, autonomia e cooperação para ajudar a quem precisava.

Conforme já discutido, a partir das observações de Martinho e outros (2003) a compreensão da participação em redes sociais passa pela noção de gratuidade que afasta das relações estabelecidas na rede a lógica da troca econômica, conforme se pode verificar, especialmente pela fala de A01. Tal constatação remonta o pensamento de Serva (1992) acerca da racionalidade substantiva e de como essa se faz presente no contexto de organizações alternativas, gerando a necessidade de um olhar diferenciado sobre a sua análise, distante da aproximação utilitarista.

\subsubsection{Divergências: a emergência $x$ o comando e controle}

De uma maneira geral, a partir da análise de trechos das entrevistas realizadas (a seguir exploradas) é possível observar a existência de divergências claras entre as percepções dos entrevistados sobre as ações de apoio às vítimas das chuvas de dezembro de 2013. 
A01 descreve a relação da rede com a Defesa Civil Estadual e com a Defesa Civil do Município de Vitória como uma relação bastante cooperativa, principalmente do ponto de vista da troca de informações para tomada de decisão sobre o que deveria ser enviado para cada município. É importante destacar que a Defesa Civil do município de Vitória esteve presente nas atividades desenvolvidas na Praça do Papa, embora ninguém da DCE tenha atuado in loco.

[...] a Defesa Civil me disponibilizou um mailing que tinha o telefone celular do prefeito até. Então assim, no início eles estavam perdidos e quando a gente chegou lá colocou uma organização. [...] Essa relação com a defesa civil começou já aqui de manhã quando eu comecei a ligar, mas eles estavam totalmente perdidos porque não sabiam como fazer [...] $A$ comunicação a gente tinha que tomar cuidado. Chegavam informações cruzadas, tipo: Rio Bananal, Barra de São Francisco. Acho que aconteceu um caso desses. Defesa Civil Estadual dizendo não precisa mais nada, aí o pessoal da cidade: precisamos. Ficava aquele negócio. Espera aí: precisa ou não precisa? Aí a gente tinha que promover o alinhamento entre a Defesa Civil Estadual e eles. Por quê? Pra não ficar mandando besteira. Então chegavam algumas pessoas dizendo: estão morrendo pessoas lá em Domingos Martins. E acabávamos descobrindo depois que estava tudo sob controle. Era aquela lei do gritar mais alto. Então a gente tinha que ter a frieza. A gente também abraçou a Defesa Civil Estadual como âncora, porque se não [...] Quem ajudou demais, principalmente no final quando a gente precisava tirar as coisas de lá foi a Defesa Civil de Vitória, porque eles não precisavam de muita ajuda, já que nesse município a coisa não estava tão caótica [...] (TRECHO EXTRAÍDO DA ENTREVISTA COM A01).

Chama a atenção neste trecho da fala de A01, a questão da promoção do "alinhamento" entre as informações que chegavam dos municípios e aquelas emanadas pelos atores da DCE, no sentido de evitar que fossem tomadas decisões errôneas quanto às ajudas a serem encaminhadas ao interior. Segundo a entrevistada, como as informações sobre as necessidades dos municípios eram aparentemente confusas e, em certos casos até inverídicas, buscava-se ancorar as decisões nas informações trocadas com a Defesa Civil.

Além disso, enquanto a percepção de A01 foi a de que os atores da rede foram de grande auxílio à Defesa Civil na organização das ações na Praça do Papa, tendo em vista que, segundo a entrevistada, as pessoas da Defesa Civil estavam "perdidas" diante de tudo que estava acontecendo, os entrevistados da Defesa Civil Estadual consideraram as ações da rede bastante desorganizadas e sem qualquer planejamento, o que não poderia trazer bons resultados.

Essa percepção de "desorganização", tanto por parte da equipe quanto do Comandante da Defesa Civil deve-se ao fato de que a estrutura de resposta a 
desastres da Defesa Civil é estritamente baseada no SCO e no PEPDEC, ou seja, em estruturas de ação onde são estreitos e sistemáticos o planejamento, a organização, a direção, a coordenação e o controle. Princípios esses, típicos de organizações militares e de engenharia e por meio dos quais a estrutura burocrática busca seu funcionamento eficaz e organizado, coforme destacam Motta e Vasconcelos, 2009.

Nesse sentido, é importante considerar que para o Comandante, a perspectiva de organização no caso da resposta a desastres naturais, está essencialmente vinculada à estrutura do SCO e também à execução do PEPDEC, como não poderia deixar de ser. A seguinte fala do entrevistado apresenta aspectos importantes da gestão do SCO e do PEPDEC, e de como isso foi realizado durante as chuvas de 2013.

[...] Naquela chuva de dezembro de 2013, quando começou a evoluir, eu me lembro de que Rio Bananal foi dia 17 que começou a agravar, e eu estava na Defesa Civil naquela ocasião. O governador estava me ligando e aí eu chamei um oficial e falei amanhã de manhã você já chega e já monta a sala, porque a coisa começou a ter múltiplas agendas. Além de agravar, tinha muita gente também entrando na área de operações. $E$ se você não tiver 0 controle disso, tem sobreposição de tarefas, desperdício de recurso, gente fazendo a mesma coisa. E paralelo ao SCO tem o nosso PEPDEC. O PEPDEC estabelece ações já pré acordadas, pré definidas, com os órgãos que compõem o comitê estadual. Isso é pactuado. Mas o mais importante de estar bem estabelecido é a questão de ter o ponto focal, porque assim, essa pessoa ela tem poder de decisão, então ele fala pelo dirigente do órgão, pelo prefeito [...] O SCO e o PEPDEC em dezembro funcionaram.[...] O princípio do SCO é um comando unificado. Cada um toma decisão na sua área de competência [...] (TRECHO EXTRAÍDO DA ENTREVISTA COM O COMANDANTE DA DEFESA CIVIL ESTADUAL)

Ao mesmo tempo, o Comandante reconhece que em alguns momentos as decisões acabam por escapar um pouco às determinações prévias do sistema, considerando as contingências, inevitáveis em situações como as de desastres naturais, e também a rapidez com que algumas decisões necessitam ser tomadas.

[...] Acontecem improvisos. Você não consegue. Ele te dá um direcionamento, mas tem situações que você... Por exemplo, eu falei do planejamento do dia seguinte, onde está tudo certo, aí chega no outro dia acontece um imprevisto. O SCO é muito baseado na administração por objetivos. Eu tenho objetivo para cumprir, mas tem contingência, se aparecer outra situação como você resolve? Então assim, você não pode ficar muito preso na cartilha. Conta muito a sua experiência também. [...] Foi uma experiência muito positiva, de muito aprendizado [...] (TRECHO EXTRAÍDO DA ENTREVISTA COM O COMANDANTE DA DEFESA CIVIL ESTADUAL). 
O trecho destacado denota a existência de contingências e a necessidade do improviso nas ações de resposta ao desastre. Conforme destaca Beagrie (2009) a improvisação é mesmo uma característica presente nas formas de respostas a desastres naturais, especialmente aquelas desenvolvidas nos períodos mais imediatos após o desastre, considerando as condições sempre atípicas e diferenciadas desses contextos, onde mesmo a existência de um planejamento prévio de ações pode não ser garantia de eficácia.

A existência de inúmeros formulários no SCO também foi destacada pelo Comandante que, apesar de se revelar em certa medida avesso ao seu preenchimento, reconhece a importância de tais documentos para que se consiga a coordenação e o controle adequado das ações.

Porque a metodologia americana é muito formulário, tem formulário pra
tudo. Então quando eu fiz o treinamento eu falei para o instrutor eu sou um
pouco avesso a esse negócio de preencher formulário. Mas é importante
você ter o registro disso [...] Então você consegue coordenar tudo o que
está empregado. Aí tem até os formulários para você passar a situação,
como começou o evento, como ele evoluiu, como ele está agora. Isso serve
para a transmissão do cargo de comandamento [...] (TRECHO EXTRAÍDO
DA ENTREVISTA COM O COMANDANTE DA DEFESA CIVIL ESTADUAL).

Essas observações realizadas pelo Comandante destacam uma característica típica da organização burocrática, conforme destaca Morgan (1996): a existência de linhas de comando e comunicação previamente definidas, por onde o fluxo de informações deve transitar. Nesse caso específico do SCO os formulários representam um importante formato da comunicação entre os atores por meio das linhas existentes no organograma.

Conforme também destaca o Comandante, a gestão adequada dos recursos para o SCO é questão essencial. Ainda mais importante é a identificação do que sejam efetivamente considerados recursos para o sistema, para que possam ser gerenciados adequadamente. A questão dos voluntários torna-se um problema nesse sentido, na visão do comandante.

Uma coisa interessante no SCO é que você tem os recursos. Tem alguém que vai cuidar só de recursos, então você sabe onde está tudo. E você tem recurso que está sobrando, ou que está mobilizado. Faltou recurso? Não, não faltou. Hoje já fechamos os 78 municípios, com os kits da defesa civil. [...]. Uma coisa que acontece muito em desastre, todo mundo quer ajudar. Vem gente sem você pedir ajuda, isso atrapalha mais [...] Esse é outro problema, começa a aparecer gente e isso te dá trabalho, porque isso não é recurso. Então você vai lá e fala: o que é que você tá fazendo aí? Às vezes 
ele está colocando a vida dele em risco e você não sabe nem que ele tá na operação [...] (TRECHO EXTRAÍDO DA ENTREVISTA COM O COMANDANTE DA DEFESA CIVIL ESTADUAL)

Os respondentes da equipe da DCE responsável pelas ações de resposta informaram que chegaram a ir até a Praça do Papa, mas que decidiram não participar e muito menos assumir a operação do que estava acontecendo ali, já que segundo eles, isso poderia levar a mais problemas do que soluções, considerando a total "falta de organização" com que as atividades estavam sendo conduzidas. Para eles, não havia coordenação nos processos desenvolvidos pela rede, e com isso, muitos donativos desnecessários foram arrecadados. Roupas de vestir, segundo a defesa civil, não precisariam ter sido enviadas, pois os itens necessários nesse tipo de situação são: colchões, água potável, cestas básicas e kits de higiene.

Mais especificamente, a entrevista com o Comandante esclarece esse aspecto importante acerca do papel da Defesa Civil nos contextos de resposta a desastres.

[...] Então essa questão de donativo, até por experiência própria, eu já falei, não assumimos. Então tem que ter outro órgão, que pode ser a assistência social. Porque a Defesa Civil fica sendo um órgão assistencial e eu não sou um órgão assistencial. Então olha, eu tenho aquela coisa pras primeiras 24 ou 48 horas, emergência, desabrigado. Está aqui o colchão, o sabonete, a pasta de dente, a cesta básica. Vai dar pra uma família de quatro pessoas por uns 15 dias, um pouco menos [...] (TRECHO EXTRAídO DA ENTREVISTA COM O COMANDANTE DA DEFESA CIVIL ESTADUAL).

A questão da ocorrência de roubos de donativos na Praça do Papa também foi lembrada pelos respondentes, segundo eles, devido à total falta de controle das operações realizadas.

Além disso, afirmaram que a quantidade de donativos enviada aos municípios foi superestimada pelos membros da rede, ou seja, os números divulgados no perfil Apoiadores do Facebook eram irreais, justamente por não ter havido um controle efetivo da arrecadação e da distribuição dos donativos.

Observa-se a questão do controle como uma prerrogativa do Estado, enquanto tal preocupação não se fez presente sobre o cidadão, o voluntário. No Núcleo de Apoiadores, o controle cedeu lugar à flexibilidade, o que levou, entre outras consequências, à ocorrência de roubos de donativos.

A partir do seu ponto de vista sobre a questão A01 defende que as ações desenvolvidas pela rede foram subestimadas pela Defesa Civil. 
[...] É e eu vou dizer, depois eles fizeram um evento e eles me convidaram, então eu fui. Quando mostraram as ações deles, as ações deles não chegavam a um bilésimo do que nós fizemos. E foi assim, como se só eles tivessem feito as coisas. Eu fiquei arrasada, eles se sentiram ameaçados. Por que sabe como é, o trabalho deles é muito bonito, receber a comida da Dilma, que ninguém fala, colchãozinho da Dilma que era enroladinho, baixinho. Aí eles lá com um mínimo de pessoas trabalhando. Nossa saiu tanta gente daqui, que foi de moto, que conseguia entrar em qualquer trilha, em qualquer lugar, alguns bombeiros particulares, o pessoal que tinha barco levava. Então assim eu acho que isso que é tão bonito quando você vê todo mundo trabalhando junto. Então o corpo de bombeiros tinha lá as coisas, o governo federal mandou tantos aviões, tantos disso, mas só que na hora precisou da ajuda da iniciativa privada [...] (TRECHO EXTRAÍDO DA ENTREVISTA COM A01).

\section{A percepção do Comandante da DCE quanto às ações desenvolvidas na Praça do}

Papa foi semelhante à de sua equipe, adicionando a preocupação com o volume de trabalho que a coordenação daquelas atividades poderia gerar para a defesa civil, já que as doações estavam sendo recebidas e encaminhadas sem nenhum controle.

[...] Bom, especificamente a Cruz do Papa, ela começou por uma rede de televisão que foi fazer uma campanha. A coisa tomou um pouquinho de corpo. A outra rede de televisão também quis fazer a mesma coisa e no meu ponto de vista a coisa fugiu ao controle. E fugiu ao controle e aí a Prefeitura de Vitória, por ter sido na capital e Vitória não ter sido atingida tão fortemente, o prefeito Luciano foi prá lá e começou com a defesa civil do município a coordenar aquilo. [...] Me lembro que o governador chegou até a ir lá, colocou o colete. Eu fui com ele, aí eu falei: governador, não assuma isso, não temos condições, não entra nessa. Queriam empurrar para o Governo, depois no palácio o prefeito Luciano insistiu. Eu falei governador não, porque foge ao controle. Porque a coisa é assim: muita gente querendo ajudar, querendo colaborar sim, mas muita gente também faz a limpeza em casa. Tinha só o sapato esquerdo, tinha biquíni [...] então assim, todo mundo quer doar. Ótimo, mas aí você tem que ter gente pra fazer a triagem: adulto, adulto masculino, feminino, criança, comida. Eu falei governador, não temos condições, deixa esse negócio pra lá. O que é que nos vamos fazer? (TRECHO EXTRAÍDO DA ENTREVISTA COM O COMANDANTE DA DEFESA CIVIL ESTADUAL)

O Comandante ainda demonstrou que donativos em excesso que acabaram chegando a alguns municípios, poderiam se transformar em um problema para a coordenação das atividades da própria Defesa Civil.

[...] Eu estive em Rio Bananal com governador, com ministro, com secretário nacional e eles já estavam recusando, dizendo não tragam mais pra cá, já estamos transferindo para outros municípios. Aí você acaba tendo outro problema: quem é que vai guardar esse material? Aí você tem problema de saque, de roubo, comida tem prazo de validade. Onde eu vou estocar isso? Eu não tenho local pra colocar gente. Eu vou ter que pegar um galpão, um ginásio, que eu poderia colocar como abrigo e eu vou ter que colocar isso tudo, depois eu vou ter que tomar conta e não deixar estragar. Por que o Ministério Público e a própria imprensa não entendem o porquê que está estragando [...] (TRECHO EXTRAÍDO DA ENTREVISTA COM O COMANDANTE DA DEFESA CIVIL ESTADUAL) 
A preocupação com uma provável intervenção da imprensa ou do Ministério Público numa eventual perda de alimentos por falta de encaminhamento aos necessitados em tempo hábil é reflexo das responsabilidades imbuídas ao respondente, em função de sua posição na estrutura racional legal, da instituição Corpo de Bombeiros.

Nesse sentido, o Comandante continua, apresentando algumas características da operação oficial da DCE em um contra ponto com as ações desencadeadas na Praça do Papa:

[...] Nós tínhamos uma central pra isso, nós montamos lá no pavilhão de Carapina, com o Major Pimenta e a SEAD. Montamos um centro de recepção e triagem, com telefone, instalamos linha telefônica. Então toda a logística partiu dali, com os helicópteros, usamos trem. Foi uma operação muito bacana. Mas lá, por uma decisão nossa, decisão de governo, lá só entrava doação oficial. Aquela doção que nós pedimos. Não adianta ir lá na Serra entregar nada que eu não vou receber. Porque lá eu tinha que montar as cestas básicas, que montar os colchões, então lá eu tinha o controle. Ligava para a assistência social do município, checava quem ia receber as doações. Porque qual é a preocupação? Dos donativos oficiais, do governo, eu tenho que prestar conta. Eu tenho que mandar um relatório com o CPF e o endereço de quem recebeu. E tudo estava no meu CPF porque eu é que recebi isso tudo do Governo Federal. E aí depois eu preciso saber quem recebeu. Cadê o formulário, preenchido com nome, com tudo?[...] Tanto é que lá na Praça do Papa, foi tonelada. A gente não. Agora o nosso aqui eu falei assim: olha são três mil cestas básicas, e então eu tenho que ter três mil CPFs. Então eu tenho esse controle. O que estava lá vinha tonelada, bota no relatório aí. Quem recebeu? Não sei. Está lá no município. Eu não me preocupei com aquilo porque eu não teria condições de absorver aquilo [...] (TRECHO EXTRAÍDO DA ENTREVISTA COM O COMANDANTE DA DEFESA CIVIL ESTADUAL)

Apesar de considerar as ações da rede na Praça do Papa descontroladas e descoordenadas, tanto a equipe da DCE, quanto o Comandante, reconheceram ter sido um bonito trabalho de solidariedade que auxiliou a DCE em um momento em que as demandas superaram a capacidade de resposta dos órgãos oficiais envolvidos. O comandante lembrou ainda, conforme mencionou também A01, que houve uma constante transferência de informações entre os atores da rede em análise e membros da DCE, para viabilizar a chegada dos donativos aos municípios atingidos.

[...] O que foi enviado pelo Governo Federal não teria dado conta de suprir a demanda naquele momento. Água foi um problema como eu falei. Nós recebemos 4000 cestas básicas, mas chegou no dia de Natal e até trazer lá de Minas, pra gente montar, foi muito complicado. A ajuda, a solidariedade dos capixabas foi fundamental. A minha observação aqui é no sentido da coordenação. Não teve uma coordenação. Como não teve uma coordenação a coisa começou a ter desvio. O pessoal furtou muito, desviou 
muito. Porque a pessoa quando está fazendo a seleção, ela pensa: nossa isso aqui é bom! E quem faz o controle disso? Não tem controle. Por que ali entra todo mundo. Você não faz um cadastro, quem são as pessoas que estão trabalhando ali, não tem um controle disso. Então assim, ajudou, mas em alguns pontos atrapalhou um pouquinho porque eu tive que me preocupar com isso. O que a gente conseguiu acertar na Cruz do Papa com a nossa defesa civil, com a defesa civil lá do município, com quem estava lá: olha, vocês carregam o caminhão, eu preciso mandar para esse município, então mandem direto para lá [...] (TRECHO EXTRAÍDO DA ENTREVISTA COM O COMANDANTE DA DEFESA CIVIL ESTADUAL)

A equipe de resposta a desastres da DCE informou, em sua entrevista, que tanto o SCO quanto o PEPDEC foram postos em prática em sua totalidade, durante as chuvas de 2013. Entretanto, também afirmaram que a situação superou em muito a capacidade de atendimento da DCE e assim, outras pessoas físicas e jurídicas necessitaram ser incorporadas à estrutura de ações, embora de maneira informal.

Sobre essa questão, os respondentes esclareceram que atualmente, após as chuvas de 2013, a Defesa Civil Estadual tem buscado realizar termos de cooperação técnica com pessoas jurídicas como ONGs e Associações para contato e capacitação de voluntários. O primeiro termo de cooperação técnica já foi firmado com o GECRE - Grupo Expedicionários Capixabas de Rádio Emissão e algumas ações decorrentes desse acordo já estão sendo implementadas, conforme esclarece esse trecho da fala do Comandante:

[...] Os Radioamadores, nós já incorporamos. Já fizemos agora dois treinamentos, tem a rede capixaba. A homologação deles lá em Brasília. Nós estamos agora com um projeto piloto em Santa Leopoldina. [...] (TRECHO EXTRAÍDO DA ENTREVISTA COM O COMANDANTE DA DEFESA CIVIL ESTADUAL)

A equipe esclareceu ainda que considera importante a possibilidade de incorporação de voluntários - pessoas físicas - ao sistema, porém dependem da solução de questões legais e burocráticas já que atualmente a celebração de termos de cooperação técnica só pode ocorrer com pessoas jurídicas. Segundo eles, a situação se agrava pelo fato dos processos para celebração de termos de cooperação técnica serem lentos demais.

Mais especificamente, a entrevista com o Comandante esclareceu outras questões importantes sobre a percepção da Defesa Civil quanto à contribuição de voluntários pessoas físicas nos processos de resposta a desastres naturais. No trecho a seguir o entrevistado destaca a dificuldade de alocação dos voluntários em atividades onde são realmente necessários, pois muitos querem fazer apenas aquilo que gostam: 
[...] Eu acho difícil, porque assim, o acesso está muito fácil. [...] Então assim, quem é essa instituição? Porque lá aparecia todo mundo. Ai o cara bota um uniforme, uma camiseta, nós somos o grupo SOS não sei o quê. Aí aparece lá. Nós identificamos alguns grupos de voluntários. Tem um acordo que eles assinam. O que é que você vai fazer no desastre que a defesa civil precise. Por que é assim, eu quero ficar lá na ponta. Mas eu não preciso que você fique lá na ponta, eu preciso de você aqui separando calçado. As pessoas não querem se sujeitar assim, querem fazer aquilo que lhes dá prazer. [...] (TRECHO EXTRAIIDO DA ENTREVISTA COM O COMANDANTE DA DEFESA CIVIL ESTADUAL)

\begin{abstract}
. Neste próximo trecho o Comandante aponta as dificuldades de conseguir o controle das ações dos voluntários quando se pensa em cadastros de pessoas físicas. Por isso, considera mais interessante a construção de parecerias com pessoas jurídicas, que já possuem uma organização intrínseca.
\end{abstract}

[...] Então assim, a gente estruturou esse programa de voluntários com esses termos de acordo. Com ONGs, com Igrejas, nesse sentido, eu vejo funcionar. Então isso vai entrar no PEPDEC e no SCO ele entra como recurso. Nós colocamos no PEPDEC na última revisão o pessoal de voluntariado da defesa civil, aí tem os contatos, incluímos o pessoal da psicologia, então o plano ele vai permitindo essa absorção e incremento. [...]. A gente não tem condições nesse momento, de ter, porque muita gente queria ser voluntário, pessoa física, mas eu não tenho condições, eu vou tratar de voluntariado pessoa jurídica. [...] Porque a gente vai ter que ter um controle assim, porque nem todo mundo tem condições de ser voluntário. Porque eu quero ser voluntário, mas eu não tenho condições. Outra, quem é essa pessoa? Vamos partir do pressuposto de que todo mundo é honesto, mas assim, você conhece essa pessoa? Aí você, não, você vai ficar aqui nessa sala, mas quem é esse cidadão? Então eu tenho que ter um cadastro antes, uma investigação, uma seleção, uma triagem. E com os grupos organizados fica mais fácil, porque eu tenho um responsável, tenho um CNPJ. Vamos acreditar que quem você está trazendo pertence ao seu grupo e você tem conhecimento de quem é essa pessoa, agora eu começar a buscar individualmente é acho um pouco difícil, não estou dizendo que é impossível, mas é difícil pra gente [...] (TRECHO EXTRAÍDO DA ENTREVISTA COM O COMANDANTE DA DEFESA CIVIL ESTADUAL)

Além disso, ao relembrar das atividades desenvolvidas na Praça do Papa, especialmente sobre o papel de A01 na ocasião, considerou delicada a questão da liderança e gerenciamento necessários a situações como aquela, argumentando que nem todas as pessoas interessadas em ajudar teriam o perfil para coordenar os trabalhos.

[...] Algumas pessoas tem liderança, tem iniciativa sim. Por que precisa ter um gerenciamento. E talvez até essa pessoa com certeza não imaginava. Então assim, eu quero fazer uma boa ação, vou dar uma ideia aqui, agora, eu vou tomar conta dessa ideia. Talvez por ser uma pessoa esclarecida, conseguiu aflorar essa questão. Mas poderia ser uma pessoa que ia ficar assim: e agora, o que é que eu faço? Fica com vocês aí, eu vou embora, porque eu não estou preparada pra isso. Tem pessoas que conseguem, mas tem pessoas assim, meu Deus, o que é que eu faço gora? E aí vai ficar um pouco à deriva. Quem é que assume essa liderança? [...] (TRECHO 
EXTRAÍDO DA ENTREVISTA COM O COMANDANTE DA DEFESA CIVIL ESTADUAL)

De uma maneira geral, os trechos destacados da entrevista com o Comandante e com a equipe de resposta a desastres da DCE, sobre as ações desenvolvidas pelo Núcleo de Apoiadores puderam demonstrar preocupação clara com questões relativas ao planejamento, à organização e ao controle das atividades. Como exemplo tem-se as falas sobre: a) a falta de registros detalhados sobre os quantitativos de doações encaminhadas aos municípios e sobre quem os recebia em cada local; b) o excesso de donativos enviados para alguns municípios; c) a ocorrência de roubos de donativos; d) a impossibilidade da DCE assumir a coordenação das atividades na Praça do Papa; e) a não identificação dos voluntários e e) a importância de uma liderança formal estabelecida para garantir a continuidade das atividades.

A questão da necessidade de estabelecimento de termos de cooperação com pessoas jurídicas também revela o forte aspecto de formalidade preconizado nas relações estabelecidas pela DCE com eventuais voluntários em ações de resposta a desastres. Embora reconhecendo a colaboração e a importância das ações desenvolvidas pela rede, o Comandante observa que o formato das ações, de natureza emergente e informal, refletiu em sua essência aspectos em enorme medida, contrários à lógica de ação preconizada pela Defesa Civil.

Após a exposição dos dados, é possível buscar uma comparação entre as lógicas de ação da Defesa Civil Estadual, e do Núcleo de Apoiadores, a partir da visualização das duas estruturas organizativas. A estrutura organizacional do SCO foi apresentada na figura 8, na seção 3.1. A estrutura do Núcleo de Apoiadores foi mapeada e analisada nesta pesquisa, observando-se as seções anteriores deste capítulo. Assim, tem-se a figura 19, que apresenta as duas estruturas lado a lado. 

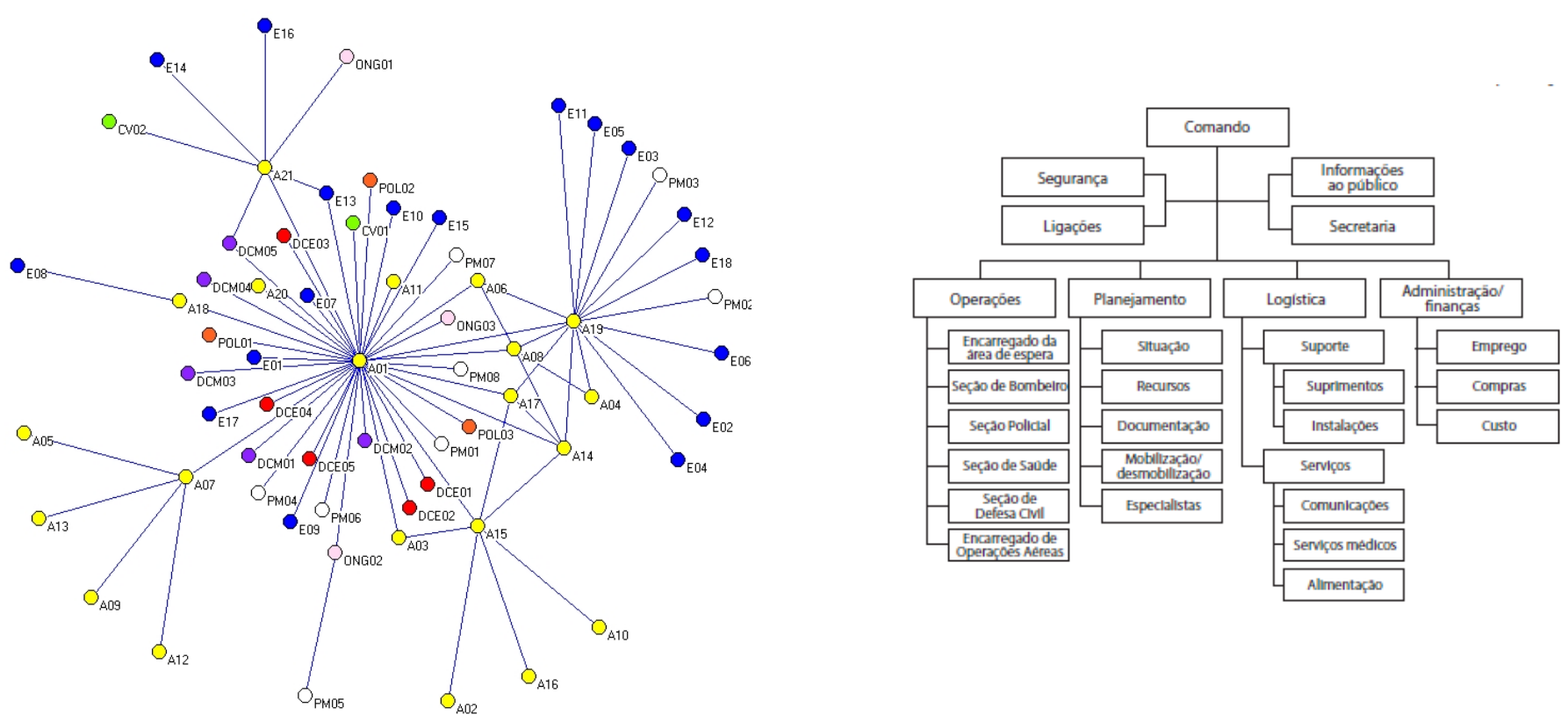

FIGURA 19 - ESTRUTURAS: O NÚCLEO DE APOIADORES E O SCO Fonte: A autora

Uma visualização comparativa entre as duas estruturas apresentadas permite verificar alguns pontos importantes.

O primeiro deles é que na rede as linhas de comunicação denotam uma estrutura horizontalizada. Ainda, considerando as topologias de rede propostas por Baran (1964), o Núcleo de Apoiadores pode ser considerado uma rede descentralizada, ou seja, que não se mantém conectada apenas por um único nó, possuindo mais de um centro. Assim, embora esteja longe de poder ser considerada uma rede distribuída, existem algumas possibilidades de caminhos diferenciados por onde a informação pode fluir, considerando os caminhos geodésicos e também os não geodésicos.

O segundo aspecto é que a estrutura do SCO apresenta característica verticalizada, onde as linhas de comunicação e comando são únicas entre as diferentes unidades. Existem quatro níveis em linha de autoridade hierárquica, além de unidades em assessoria, ligadas diretamente ao comando central do Sistema.

Como consequência, observa-se que enquanto no organograma estabelecido pelo $\mathrm{SCO}$, as linhas formais de comunicação representam possibilidades únicas de intermediação da informação entre os participantes das diferentes unidades, a estrutura do Núcleo de Apoiadores abre maiores possibilidades, embora ainda poucas, se comparadas às que poderiam ocorrer em uma rede totalmente distribuída. De qualquer maneira, verifica-se o que destaca Franco (2012) sobre a escassez de caminhos das estruturas hierárquicas. 
Tais aspectos refletem-se diretamente na forma de atuação diferenciada entre os dois formatos organizacionais, verificada nas falas dos entrevistados anteriormente destacadas nesta seção. O quadro 12 a seguir apresenta algumas características que puderam ser identificadas nas duas formas de atuação.

\begin{tabular}{|l|ll|}
\hline \multicolumn{1}{|c|}{$\begin{array}{c}\text { CARACTERISTICAS DA AÇÃO DO NÚCLEO } \\
\text { DE APOIADORES }\end{array}$} & \multicolumn{1}{|c|}{ CARACTERÍSTICAS DA AÇÃo DO SCO } \\
\hline Relacionamentos horizontais; & Relacionamentos hierárquicos; \\
\hline Descentralização e informalidade; & \begin{tabular}{l} 
Centralização e formalidade; \\
\hline Traços de emergência e auto-organização;
\end{tabular} & $\begin{array}{l}\text { Planejamento, direção, organização, comando e } \\
\text { controle; }\end{array}$ \\
\hline $\begin{array}{l}\text { Estratégias heurísticas e inventivas ao invés de } \\
\text { comportamentos sociais programados; }\end{array}$ & $\begin{array}{l}\text { Direcionamentos pré-determinados para o } \\
\text { comportamento individual; }\end{array}$ \\
\hline Elevada autonomia individual; & Baixa autonomia individual; \\
\hline $\begin{array}{l}\text { Linhas múltiplas de comunicação e interação } \\
\text { entre indivíduos; }\end{array}$ & $\begin{array}{l}\text { Linhas únicas de comunicação e interação entre } \\
\text { indivíduos; }\end{array}$ \\
\hline Flexibilidade; & $\begin{array}{l}\text { Rigidez, porém com certa flexibilidade em função } \\
\text { de contingências; }\end{array}$ \\
\hline Presença de ruído, incerteza e desordem; & $\begin{array}{l}\text { Supressão da incerteza, do ruído e da } \\
\text { desordem; }\end{array}$ \\
\hline Ação voluntária e solidária; & $\begin{array}{l}\text { Ação direcionada pelos preceitos técnicos e } \\
\text { legais da profissão; }\end{array}$ \\
\hline
\end{tabular}

QUADRO 12 - CARACTERÍSTICAS DA ATUAÇÃO DO GRUPO EMERGENTE E DO SCO Fonte: A autora.

A partir da análise do quadro, é possível um paralelo entre as características evidenciadas sobre a ação do Núcleo de Apoiadores, com aquelas inerentes às sociedades fundadas em soluções hipercomplexas, apresentadas por Morin (1974), conforme o quadro 1, na subseção 2.4.2. São bastante evidentes as congruências entre os indicadores característicos de soluções sociais hipercomplexas e aqueles destacados aqui sobre o grupo de apoio às vítimas das chuvas no ES. Aspectos como a descentralização, a existência de multilideranças, a não hierarquia, a elevada autonomia dos indivíduos, a flexibilidade, são claramente perceptíveis em ambos.

Ao mesmo tempo as sociedades tradicionais apontadas pelo autor, encontram-se mais relacionadas aos preceitos organizacionais burocráticos, identificados no SCO, como a hierarquia e centralização, comportamentos individuais direcionados por regras e normas rígidas e a baixa autonomia individual.

Merece destaque no pensamento de Morin, a ideia de solidariedade vivida. Para ele, a solidariedade vivida é uma espécie de cimento social, capaz de evitar que as 
sociedades hipercomplexas se desintegrem diante dos riscos inerentes ao aumento da autonomia e da liberdade dos indivíduos. Pode-se considerar que essa solidariedade se tornou de fato "vivida" a partir dos relacionamentos estabelecidos entre os indivíduos no Núcleo de Apoiadores. Esse, no contexto em análise, pode ser pensado como uma forma de organização que teve na solidariedade o "cimento" capaz de auxiliar significativamente na criação e manutenção de sua coesão e alinhamento para levar a cabo uma significativa ação coletiva, mesmo que, conforme o caso, por um pequeno intervalo de tempo.

Contudo, importa destacar que, embora as duas estruturas organizativas - Núcleo de Apoiadores e SCO - tenham sido aqui colocadas em comparação, não se trata de compreendê-las como mutuamente excludentes em contextos de resposta a desastres. Apenas se considerou a estratégia comparativa uma maneira interessante de buscar verificar mais claramente as características dos dois modelos organizativos. A própria base teórica aqui mobilizada, a partir de autores como Quarantelli (1993; 1995), Majchrzak, Jarvenpaa e Hollingshead (2007), Voorhees (2008) e Beagrie (2009) considera os dois formatos como componentes fortemente atuantes na resposta a desastres, embora o $\mathrm{SCO}$ se destaque como o formato mais tradicional.

Assim, compreende-se que, mesmo considerando todas as ponderações realizadas pelos entrevistados da Defesa Civil Estadual em relação à desordem e aos problemas eventualmente decorrentes, a ação voluntária aqui analisada, ainda assim revelou-se como um recurso bastante importante na resposta ao desastre de dezembro de 2013 no ES.

Numa visão de complementaridade e não de exclusão, é no mesmo sentido do pensamento de Voorhees (2008) que se considera que as formas oficiais de gestão de emergências, como o SCO, precisam incluir previsões para o gerenciamento de grupos emergentes de voluntários, como o que aqui se estudou. Se assim não ocorrer, pode-se vir a desperdiçar esse recurso valioso que é a ação voluntária e solidária comumente presente em situações de desastre.

Entretanto, os dados apresentados revelam que a gestão de voluntários por parte da Defesa Civil Estadual, ainda se encontra atrelada a um modelo que considera possível a celebração de termos de cooperação apenas com outras pessoas 
jurídicas, e em momento necessariamente anterior ao desastre. Dentro dessas premissas, e considerando a natureza do Núcleo de Apoiadores, ele estaria, ao menos por enquanto, fora da possibilidade de ser incluído como um recurso na estrutura do SCO utilizado pela Defesa Civil do Estado do ES. 


\section{FENÔMENOS DE COMUNICAÇÃO E MEDIAÇÃO DA INFORMAÇÃO EM REDES SOCIAIS DE RESPOSTA A DESASTRES NATURAIS: O CASO DAS CHUVAS DE 2013 NO ESTADO DO ESPÍRITO SANTO}

Os dados apresentados e analisados no capítulo anterior permitem o desenvolvimento de discussões e reflexões necessárias à construção de respostas para a questão estabelecida como problema da pesquisa: qual a natureza dos fenômenos de comunicação e mediação da informação, estruturados em redes sociais voltadas a ações de resposta a desastres naturais?

Os fenômenos de comunicação e mediação da informação apresentam-se aqui contextualizados na lógica das redes sociais que, por sua vez, inserem-se em um contexto bastante turbulento, dinâmico e específico: a resposta a desastres naturais. Nesse sentido, compreende-se que, no âmbito desta pesquisa, tais fenômenos necessitam ser discutidos a partir de uma perspectiva que considere tais especificidades.

Tal perspectiva baseia-se em um arcabouço teórico interdisciplinar aqui delineado, que em boa medida envolveu conceitos e fundamentos da Ciência da Informação, mas também das Teorias das Organizações - típicas dos estudos da Administração e das Ciências da Complexidade - sustentadas em variadas disciplinas como a Biologia, a Física, a Matemática e também as Ciências Sociais.

Parte desse referencial teórico já foi mobilizada nas análises realizadas no capítulo anterior, durante a apresentação dos dados. Baseando-se nessas análises, buscase a partir deste ponto, a discussão mais específica sobre a natureza dos fenômenos de comunicação e mediação da informação na rede em foco.

6.1 COMUNICAÇÃO E MEDIAÇÃO DA INFORMAÇÃO NO NÚCLEO DE APOIADORES 
É importante destacar que a comunicação evidenciou-se como um elemento condicionante na estruturação e organização no Núcleo de Apoiadores às vítimas das chuvas de 2013. Foi possível verificar que diferentes conteúdos informacionais delinearam os relacionamentos entre os atores, marcados fortemente pela utilização das novas TICs e por uma lógica de inteligência coletiva. Tais conteúdos eram derivados das atividades desenvolvidas pela rede que, por sua vez, emergiram a partir da busca pela articulação de demandas, captação de donativos e logística de envio dos mesmos às cidades afetadas.

Assim, pode-se tomar a comunicação como elemento condicionante - quando analisada no contexto da rede social em estudo - ou como elemento condicionado quando visualizada no âmbito das estruturas formais de resposta ao desastre, considerando linhas formais de autoridade e comunicação existentes nas estruturas hierárquicas organizacionais de resposta.

Tal constatação decorre da comparação realizada entre o Núcleo de Apoiadores - a rede social emergente - e o SCO - organização formal de resposta a desastres. Existe uma dualidade demonstrada por meio de algumas comparações que se expressaram tanto ao longo do referencial teórico quanto durante a apresentação e análise dos dados. Apenas para destacar as principais tem-se: emergência $x$ comando e controle; auto-organização $x$ normas e regulamentos; horizontalidade $x$ hierarquia; flexibilidade $\mathrm{x}$ rigidez; espontaneidade $\mathrm{x}$ planejamento; autonomia $\mathrm{x}$ heteronomia; descentralização $x$ centralização; imprevisibilidade $x$ previsibilidade; inteligência coletiva $x$ inteligência piramidal.

Especificamente sobre aspectos de mediação da informação, toma-se a proposta de fatores de mediação do conhecimento construída por Zins (2007) - Trabalhadores de Conhecimento, Conteúdos, Aplicações e Processos, Tecnologias de Informação e Conhecimento, Ambiente e Organizações - para a realização de algumas considerações, de acordo com dados apresentados em variados pontos do capítulo 5, conforme será destacado:

Sobre a dimensão dos Trabalhadores do Conhecimento que corresponde aos chamados profissionais de informação, argumenta-se que, a existência de um 
profissional da informação não foi necessária à situação aqui analisada, considerando os dados apresentados e analisados no capítulo 5. Ao menos não no sentido que os considera como sendo os bibliotecários, arquivistas e museólogos. Contudo, é importante lembrar o papel de A15, conforme a subseção 5.1.2, no sentido de que era profissional na área de comunicação e marketing e de que aplicou esses conhecimentos, experiências e habilidades em sua atuação na rede. O papel desse ator foi fundamental na mediação da comunicação entre o Núcleo da Rede de Apoiadores e os demais atores pertencentes à periferia da rede, por meio de sua atuação na administração do perfil Apoiadores no Facebook.

Entretanto, considerando-se que o estudo não levantou a atuação profissional de todos os demais atores, mas permitiu verificar que A01 era profissional da área de consultoria organizacional (subseção 5.4.1), que A08 era técnico em logística e que A19 atuava em serviços de manutenção de caminhões (subseção 5.1.2) é possível afirmar que esses atores não se tratavam de profissionais de informação. A01 e A19 estiveram em destaque entre os papeis de intermediação na rede, conforme demonstrado na subseção 5.2.3.

Sobre o fator Conteúdos, pode-se descrever um determinado rol de conteúdos nas trocas informacionais realizadas entre os agentes da rede, denominados temas gerais de informação, conforme demonstrado na apresentação dos dados na subseção 5.2.1. Acrescenta-se que tais temas gerais de informação foram levantados a partir da memória da informante A01, que os revelou por meio da entrevista, sem que tivesse consultado nenhuma anotação ou qualquer outra fonte onde esses conteúdos estivessem registrados. Por outro lado, talvez ainda possam existir registros dos conteúdos presentes nas trocas de informação realizadas por meio do Whatsapp entre os atores do Núcleo de Apoiadores, mas isso não pode ser evidenciado por meio da pesquisa.

As Aplicações relacionam-se ao desenvolvimento de determinados recursos projetados para atendimento de interesses, motivos e finalidades pelos quais a informação é mediada. Estão, portanto, relacionadas aos objetivos da ação coletiva da rede em análise, voltados para a articulação de demandas, captação de donativos e logística de envio dos mesmos às cidades afetadas, conforme se percebe especialmente a partir da figura 18 apresentada na subseção 5.1.2. Pode- 
se verificar que a busca e a troca de informações entre diferentes indivíduos pertencentes à sociedade civil, organizações estabelecidas, estendidas e expandidas, por meio de uma estrutura em formato de rede (conforme o grafo 6 apresentado na subseção 5.1.3), foi o formato identificado nesta pesquisa, para atendimento a esses interesses, motivos e finalidades do Núcleo de Apoiadores.

Sobre o fator relativo a Operações e Processos, os dados apresentados no capítulo 5 não puderam demonstrar a realização de "ações sistematizadas" por parte dos atores do Núcleo de Apoiadores, relacionadas à documentação, à representação, à organização, ao processamento, à divulgação, à publicação, ao armazenamento, à manipulação, à avaliação, à medição, à busca e à recuperação do conhecimento.

Quanto às Tecnologias de Informação e Conhecimento, foi possível perceber o uso intensivo de tecnologias como a telefonia móvel, além de ferramentas como o Facebook e o Whatsapp nas interações entre os atores da rede, conforme apresentado nas subseções 5.1.1 e 5.1.4, da apresentação e análise de dados.

O contexto social, cultural, legal e ético que representa o fator Ambiente em que se desenrola o processo de mediação aqui em discussão, possui como marca a motivação solidária, discutida na subseção 5.4.1. Um ambiente marcado por traços de emergência evidenciados na subseção 5.3 .2 e de auto-organização conforme subseção 5.1.2.

Sobre o fator Organizações também não foi possível a identificação de um formato tradicional de organização ou instituição, governamental, pública ou privada, realizando funções relacionadas com a organização da memória, serviços de informação, entre outros. Observou-se sim, uma organização em formato de rede, onde existiram trocas e intermediações informacionais, em uma topologia regulada pela própria comunicação entre os agentes, conforme se pode observar pelos dados apresentados nas subseções 5.2.1, 5.2.4, 5.3.1 e 5.3.2.

Considerando as análises e discussões anteriormente realizadas considera-se que a mediação da informação no Núcleo de Apoiadores, parece possuir uma realidade muito próxima daquela referenciada por Marteleto (2001), Tomaél e Marteleto (2006), Tang e outros (2010), quando consideram que a própria estrutura relacional de uma rede social é capaz de revelar as mediações ali existentes. 
Assim, tem-se que foram verificadas variadas nuances de poder distribuídas entre os atores, em função de um maior ou menor controle sobre os fluxos de informação ou de uma maior ou menor capacidade de articulação com grupos diferenciados, o que sustenta a ideia da descentralização da rede, apontada por Martinho e outros (2003) e Franco (2012). Assim, embora tenha ficado evidente que A01, A19 e A21 foram capazes de estabelecer um grande número de relacionamentos e de criar maiores possibilidades de mediação da informação, sendo fundamentais elementos de ligação, também se observa a importância de outros atores como A15, A17, A14, A06, A08 por fazerem parte de um importante núcleo de coesão e articulação de informações, de forma mais direta, entre os atores representantes da sociedade civil.

Buscando uma concepção de informação a partir de seu caráter crítico ou dialético, conforme destaca Marteleto (1987), é possível enxergar a capacidade transformadora da informação no contexto em análise, onde, por intermédio de trocas informacionais, uma estrutura organizativa de ação foi criada e potencializada, para além das estruturas formais estabelecidas na atuação de resposta ao desastre de dezembro de 2013.

Assim, tem-se que o SCO, a forma tradicional de abordagem utilizada na resposta a desastres, que foi plenamente utilizada em dezembro de 2013, baseia-se no organograma, planejado, vertical e centralizado estabelecendo e direcionando linhas de comunicação e comando, por onde a informação deve necessariamente fluir. Confere rigidez e controle à intermediação da informação, com base em normas e regras definidas a priori para a garantia da eficácia do sistema. Eficácia essa que é fundamental ao contexto de crise representado pela ocorrência de um desastre natural.

Por outro lado, a rede social analisada expressa a conectividade emergente, horizontal e dinâmica, dando forma a uma estrutura que em muitos aspectos apresenta desordem e ruído elevados. Nela, a mediação da informação pode se dar em uma maior gama de pontos, estabelecidos pela própria dinâmica da comunicação e da auto-organização da rede.

Assim, compreende-se que o grupo emergente na sociedade civil foi capaz de atuar nos processos de comunicação e mediação da informação entre agentes de organizações estabelecidas, e desses com agentes de organizações expandidas e 
estendidas, conferindo uma natureza alternativa e diferenciada a esses processos, levando-se à reflexão sobre o papel emancipatório da comunicação e mediação da informação neste contexto.

Esta afirmação decorre das análises realizadas no capítulo 5 que puderam demonstrar que o Núcleo de Apoiadores possuiu traços de emergência e autoorganização, em formato horizontalizado, onde se pode evidenciar muito mais autonomia que heteronomia. Embora isso possa ser afirmado apenas nos aspectos que se relacionaram à articulação das demandas por donativos para auxiliar as vítimas, pois se sabe que ações de resposta a desastres envolvem um universo bem mais amplo de atividades.

Corroborou-se o pensamento de Majchrzak, Jarvenpaa e Hollingshead (2007) quando afirmam que o modelo burocrático de ação, parece não ser suficiente para a acomodação de uma situação de crise multidimensional típica dos grandes desastres.

Foi nesse sentido que em dezembro de 2013 no ES, a hierarquia - caracterizada por Franco (2012) como possuidora de uma escassez de caminhos para os fluxos informacionais - teve lugar ao lado da rede - encarada como uma possibilidade de desconstrução da hierarquia. Nessa rede ficou demonstrada a importância relativa de cada um dos atores sobre os fluxos de informação entre os atores da sociedade civil, mas também entre os demais atores inseridos nos outros tipos de organização ali representados.

\subsection{COMPROVAÇÃO DOS PRESSUPOSTOS DA PESQUISA}

Sobre os cinco pressupostos estabelecidos na pesquisa, considera-se que por meio das análises realizadas no capítulo 5 , complementadas pelas discussões anteriores delineadas na seção 6.1, é possível apresentar as seguintes observações.

Em relação ao pressuposto 1: 
$P_{1}$ : Inserem-se no âmbito da Ciência da Informação como um fenômeno não clássico, cuja organização e animação encontram significativo suporte nas novas TICs.

Tem-se que:

Ficou evidenciada a natureza alternativa e diferenciada da organização em análise, em relação às formas de organização clássicas exploradas pela $\mathrm{Cl}$, como as bibliotecas, os arquivos e os museus. Essas, em grande medida, podem ser situadas no contexto das organizações tradicionais, inseridas na lógica hierárquica onde predominam aspectos de planejamento, organização, comando e controle. Por sua vez, o Núcleo de Apoiadores aqui em análise, revelou-se como um movimento com traços característicos de emergência. Observou-se o seu crescimento ao longo do próprio processo de ajuda às vítimas, revelando sua capacidade plástica e dinâmica, autorregulada e organizada por meio dos fluxos comunicacionais entre os diferentes agentes.

Percebeu-se a grande contribuição das novas TICs, tanto para a mobilização e divulgação de informações sobre as atividades da rede, quanto nas interações realizadas entre os atores. Compreende-se como fundamental o papel de tais tecnologias para que a rede possa ter alcançado tanta visibilidade e tenha conseguido superar em muito as suas próprias expectativas iniciais de ação. As tecnologias são capazes de conferir maior agilidade às trocas informacionais, propiciando relacionamentos entre agentes em pontos geográficos distintos, que, em função do desastre possuíam enormes limitações para o acesso físico.

Diante do exposto, considera-se que o pressuposto foi comprovado.

Em relação ao pressuposto 2:

$\mathrm{P}_{2:}$ A comunicação se apresenta como elemento regulador e essencial à sua autoorganização, a partir da qual se tornam possíveis a articulação das multilideranças e a coordenação de diferentes ações.

Tem-se que:

As interações comunicacionais entre os agentes deram forma à estrutura da rede, tendo sido possível ainda a identificação de variadas intensidades (frequência de 
interações) e densidades (variedade de conteúdos) nos laços relacionais estabelecidos;

As métricas de ARS realizadas sobre essa estrutura permitiram a percepção da importância relativa dos atores nas trocas de informação realizadas na rede, sendo possível a identificação daqueles com capacidade de exercício de maior poder sobre o controle dos fluxos de informação e que, consequentemente, puderam influenciar de forma mais decisiva sobre as ações desencadeadas pela rede.

Diante do exposto, considera-se que o pressuposto foi comprovado.

Em relação ao pressuposto 3:

$P_{3}$ : Em seu âmbito, a mediação da informação possui características diferenciadas em relação a algumas conceituações mais usuais da Ciência da Informação.

Tem-se que:

Ficou demonstrado, conforme argumentações da seção 6.1 que existem pontos de diferenciação entre fenômenos de mediação da informação observados na rede em análise, em relação a modelos usuais da $\mathrm{Cl}$, tomando-se como exemplo os chamados fatores de mediação propostos por Zins (2007). A mediação no contexto analisado prescinde, em grande medida, da atuação de profissionais de informação, tem caráter dinâmico, não sistematizado, marcado pelo uso de novas TICs e regulado pela própria estrutura auto-organizada da rede, que é o formato de organização na qual se desenrola.

Diante do exposto, considera-se que o pressuposto foi comprovado.

Em relação ao pressuposto 4:

$\mathrm{P}_{4}$ : Em seu processo de estruturação, os atores contam com laços relacionais préexistentes, mas também estabelecem novos laços de forma dinâmica.

Tem-se que:

De uma maneira geral, as atores acionaram relacionamentos já existentes, com outros atores da sociedade civil, e também com atores de empresas privadas e outras organizações representadas na rede. Foram capazes, ao mesmo tempo, de ir 
criando novos relacionamentos, para atender as necessidades de informação que surgiam em decorrência das atividades desenvolvidas pela rede. De 31 relacionamentos iniciais, a rede identificada contou com 77 relacionamentos ao todo. Apesar dessa capacidade para crescimento, agregando novos relacionamentos, foi possível observar também a efemeridade desses relacionamentos. Assim, no período de 8 dias em que a rede teve uma atuação mais efetiva, tais laços se evidenciaram, mas não se pode afirmar que tenham se tornado relacionamentos perenes, para além das atividades desenvolvidas em 2013.

Diante do exposto, considera-se que o pressuposto foi comprovado.

Em relação ao pressuposto 5:

$P_{5:}$ As estruturas usuais do Estado para a resposta a desastres naturais possuem como princípios o comando, o controle e a hierarquia. Por outro lado, a estruturação em rede, representada pelos grupos emergentes no pós-desastre natural, possui natureza autônoma, voluntária e solidária, cujas características denotam aproximações com a racionalidade substantiva.

Tem-se que:

Nos aspectos da pesquisa que compararam a ação da Defesa Civil Estadual e do Núcleo de Apoiadores na resposta ao desastre, verificou-se que a estrutura do SCO, formato de resposta típica aos desastres naturais, e que foi utilizado durante as chuvas de dezembro de 2013 no ES, é uma estrutura hierárquica, baseada em princípios militares de organização, inserida no âmbito do Corpo de Bombeiros Militar do ES.

Ao mesmo tempo, pode-se caracterizar a rede emergente como tendo sido motivada em grande medida por sentimentos de solidariedade, gratuidade e por ações voluntárias, onde houve uma busca pela melhoria do bem estar coletivo, mediada pela livre comunicação entre os indivíduos e alicerçada em uma organização autônoma, possibilitando uma aproximação com características da ação racional substantiva.

Diante do exposto, considera-se que o pressuposto foi comprovado. 


\section{CONSIDERAÇÕES FINAIS}

O presente estudo teve como objetivo analisar os fenômenos de comunicação e mediação da informação, estruturados em uma rede social de resposta a um desastre natural. Buscou-se a consecução deste objetivo geral, por meio da definição de objetivos específicos e da realização das seguintes etapas: a busca por um referencial teórico suficientemente adequado ao suporte de cada um dos objetivos específicos; a definição de determinados pressupostos e a identificação e organização de conexões entre tais pressupostos, objetivos específicos e etapas metodológicas da pesquisa, especialmente relacionadas à coleta e análise dos dados.

Tal modelo lógico norteou a elaboração do referencial teórico, a definição das etapas metodológicas, bem como o formato da apresentação e análise de dados, além da discussão dos resultados.

A partir dos dados apresentados e também das análises e discussões realizadas, à luz do referencial teórico, especialmente nos capítulos 5 e 6, compreende-se que os objetivos da pesquisa tenham sido plenamente alcançados. Assim, tem-se que:

- Foram descritos o surgimento da rede social de resposta às chuvas de dezembro de 2013 no ES, bem como as atividades por ela desenvolvidas $\left(\mathrm{OE}_{1}\right)$;

- Foram caracterizados os fenômenos de comunicação e mediação da informação, existentes nessa rede social $\left(\mathrm{OE}_{2}\right)$;

- Foi identificado o relacionamento dessa rede social, com as organizações estabelecidas para a gestão de desastres no ES, especialmente com a Defesa Civil Estadual $\left(\mathrm{OE}_{3}\right)$;

- Foi realizada uma análise comparativa entre as estruturas de ação da Defesa Civil Estadual e da rede social em estudo $\left(\mathrm{OE}_{4}\right)$;

- Foi mapeada a topologia dessa rede social, identificando e analisando algumas de suas propriedades a partir da Análise de Redes Sociais $\left(\mathrm{OE}_{5}\right)$. 
A partir das análises, reflexões e discussões realizadas sobre os dados coletados, tendo como base os conceitos da literatura, tornou-se possível a elaboração das seguintes conclusões acerca da realidade investigada neste trabalho.

O caráter de articulação de demandas, essência dos objetivos do Núcleo de Apoiadores, trouxe a necessidade de interações e mediações comunicacionais entre os chamados seekers e os providers (Modelo IOSP de Varda e outros (2008)), representantes de diferentes organizações. Assim, ocorreu uma união de esforços entre membros da sociedade civil, mas também desses com os de outros atores pertencentes a organizações estabelecidas (representando o Estado), expandidas e estendidas (tipologia de Quarantelli (1993; 1995)), para que pudessem realizar a contento todas as suas atividades.

Além disso, os processos de comunicação e mediação no Núcleo de Apoiadores estiveram fortemente ancorados em novas TICs, tanto nas etapas iniciais relacionadas à mobilização dos atores, quanto na consolidação das interações entre esses durante o período de articulação para atendimento às demandas por donativos. As novas TICs, especialmente a telefonia móvel, sites de redes sociais como o Facebook e aplicativos de relacionamento como o Whatsapp contribuíram significativamente para a consolidação dos objetivos coletivos definidos.

O Núcleo de Apoiadores, principalmente por intermédio de A15, utilizou-se de um site de rede social, o Facebook, para mediar sua conexão com atores pertencentes à periferia da rede de apoio. Considera-se que a utilização do Facebook teve um impacto bastante significativo sobre o número de pessoas que puderam tomar conhecimento sobre as ações, contribuir com doações e atuar como voluntários em atividades de suporte às vítimas das chuvas.

A comunicação atuou como elemento estruturante e condicionante dos relacionamentos estabelecidos entre os atores do Núcleo de Apoiadores, evidenciando a sua capacidade emancipatória no contexto analisado.

Observou-se a importância dos relacionamentos pré-existentes e também dos novos relacionamentos criados pelos atores, após o início das atividades do Núcleo de Apoiadores. O número de novos relacionamentos foi maior do que 0 de relacionamentos pré-existentes, caracterizando a capacidade da rede de "crescer", 
incorporando novos atores e criando novas linhas de comunicação para que pudesse atingir seus objetivos.

Algumas condições iniciais de suporte para a consolidação da ação do Núcleo de Apoiadores foram observadas, como a pré-existência de determinados conhecimentos e experiências, por parte dos atores, que puderam ser aplicados na situação aqui investigada. Também, fortes laços relacionais pré-existentes à ação, foram essenciais à mobilização inicial do Núcleo de Apoiadores, conforme já mencionado no parágrafo anterior, verificando-se a existência de vínculos familiares e os vínculos profissionais como os de maior impacto.

A01 possuiu papel essencial no Núcleo de Apoiadores, tanto por sua capacidade de articular os passos iniciais das ações desenvolvidas, por meio de seus relacionamentos pré-existentes, quanto para a manutenção da própria estrutura organizativa da rede, revelando-se como um ponto de corte (cutpoint) importante na rede. Entretanto, o Núcleo de Apoiadores não esteve totalmente na dependência da intervenção de $A 01$. Isso porque foi possível verificar que outros atores que não conheciam A01 inicialmente (como A08 e A19) foram se incorporando ao Núcleo e criando outros relacionamentos com outros atores, capazes, por exemplo, de dar forma ao core de atores mais coeso na rede, inserido em um grupo de 21 atores que se manteria conectado mesmo após uma eventual saída de A01 do processo. É nesse sentido, que uma ação inicialmente idealizada e direcionada por apenas um ator, passou a revelar características de emergência.

A concepção de que, em se tratando de redes sociais a mediação pode ser compreendida por meio da própria estrutura dos laços relacionais existentes entre os atores, parece ser bastante adequada ao contexto em análise. Assim, considerando as propriedades e métricas analisadas, por meio da ARS, tem-se que o Núcleo de Apoiadores foi capaz de atuar sobre a comunicação e mediação da informação entre agentes de organizações estabelecidas, e desses com agentes de organizações expandidas e estendidas, conferindo a esses processos uma natureza alternativa e diferenciada, em comparação ao que se pode verificar nas estruturas tradicionais de resposta a desastres naturais (SCO). Ao mesmo tempo, a comunicação e a mediação da informação revelaram seu caráter emancipatório, na medida em que 
foram condicionantes de uma estrutura organizativa que apresentou traços de emergência e auto-organização, com natureza horizontalizada e autônoma.

A solidariedade, a gratuidade e a participação voluntária foram molas propulsoras da ação coletiva desenvolvida pelo Núcleo de Apoiadores, refletindo características da chamada racionalidade substantiva. A adesão às atividades foi decorrente de um exercício espontâneo de vontade, autonomia e cooperação para ajudar a quem precisava. A ação colaborativa desenvolvida também evidenciou características de um fenômeno de inteligência coletiva, onde pode se observar uma divisão do trabalho de natureza auto-organizativa, tendo ocorrido uma acomodação natural e espontânea dos atores nas atividades desenvolvidas, embora inicialmente A01 tenha tido o papel de identificar habilidades e conhecimentos mais adequados à situação, entre seus relacionamentos pré-existentes.

Existiu uma clara divergência entre as percepções da representante do Núcleo de Apoiadores (sociedade civil) e a dos membros da Defesa Civil Estadual (Estado), quanto às atividades desenvolvidas pelo grupo emergente no apoio às vítimas. Tais divergências refletem o embate entre dois formatos distintos de organização, e, por consequência, entre duas dinâmicas bastante diferenciadas de ação e de comunicação e mediação da informação, no contexto da resposta a desastres naturais. Uma, no contexto da emergência, representada pela rede analisada; outra no contexto do comando e do controle do Estado, representada pelo SCO.

Entretanto, compreende-se que uma solução que considerasse a necessária complementaridade e não o embate entre as duas formas organizativas, de maneira a melhor aproveitar os benefícios de ambas, poderia vir a contribuir de maneira bastante positiva para os processos relacionados às ações de resposta a desastres naturais.

\subsection{CONTRIBUIÇÕES DO ESTUDO}


Considera-se que o presente estudo foi capaz de contribuir para uma melhor compreensão de um fenômeno que, no âmbito da Ciência da Informação ainda pode ser tido como algo relativamente novo e pouco explorado.

A pesquisa evidenciou características dos fenômenos de comunicação e mediação da informação no contexto específico e diferenciado das redes sociais atuantes na resposta a desastres naturais. Além de descrever aspectos relativos ao surgimento da uma rede dessa natureza, a pesquisa permitiu também a identificação de sua estruturação organizativa, revelando fenômenos de comunicação e mediação da informação ali existentes.

Ao mesmo tempo, ao trabalhar com a articulação entre construtos conceituais da Ciência da Informação e da Administração, contribui para ampliar as possibilidades de interdisciplinaridades entre esses dois campos de conhecimento, podendo levar ao enriquecimento de ambos.

\subsection{LIMITES DO TRABALHO}

Conforme já mencionado no capítulo 4 que trata do percurso metodológico da pesquisa, a principal limitação do estudo foi decorrente do tempo transcorrido entre a ocorrência do fenômeno e a realização da coleta de dados para a pesquisa.

Muitas pessoas não possuíam mais os contatos de seus relacionamentos na rede, como telefone, ou email. Além disso, em muitas situações, os contatos fornecidos não estavam corretos, em função de mudanças variadas como de emprego ou de telefone pessoal. Nesse sentido, a tarefa de mapeamento da rede foi bastante dificultada, não tendo sido possível obter as respostas de todos os atores cujo perfil estava inserido no escopo do trabalho. 


\subsection{SUGESTÕES PARA TRABALHOS FUTUROS}

A tese não esgota as possibilidades de abrangência e aprofundamento sobre o tema da pesquisa, restando ainda diversificadas possibilidades para a abordagem dos fenômenos aqui discutidos. Assim, como sugestões para novas pesquisas têm-se:

- A realização de um estudo que mapeie também os relacionamentos existentes entre membros de organizações estabelecidas, expandidas e estendidas, ampliando assim os limites da rede estudada, para além do grupo emergente;

- A incorporação da métrica de centralidade de fluxo de intermediação, nas análises sobre a rede, que classifica os atores que são intermediários em todos os fluxos de informação possíveis e não apenas nos caminhos geodésicos. Tal métrica é bastante adequada aos estudos de mediação da informação nas redes sociais, conforme destacam Tomaél e Marteleto (2006) e não pode ser calculada por meio do software utilizado neste estudo, o Pajek;

- Um estudo que considere a rede formada a partir das interações realizadas por intermédio de sites de redes sociais, em situações de resposta a desastres naturais;

- Uma pesquisa que possa ser conduzida senão durante o desenvolvimento das atividades de uma rede de resposta a um desastre, mas ao menos imediatamente após essas atividades, de maneira que se torne possível o mapeamento completo da rede, evitando a dificuldade de recuperação de dados em função do tempo decorrido. 


\section{REFERÊNCIAS}

ALMEIDA, M. A. Mediações da cultura e da informação:perspectivas sociais, políticas e epistemológicas. Inf. Inf., Londrina, v. 19, n. 2, p. 191-214, maio./ago. 2014. Disponível em:<http:www.uel.br/revistas/informacao/>. Acesso em: 15 mar.2015

ALMEIDA JÚNIOR, O. F. Mediação da informação e múltiplas linguagens. Pesq. bras. Ci. Inf., Brasília, v.2, n.1, p.89-103, jan./dez. 2009. Disponível em:< http://inseer.ibict.br/ancib/index.php/tpbci/article/viewArticle/17>. Acesso em: 15 mar.2015.

APOIADORES. Rede de apoio social às vítimas da chuva no Espírito Santo. Disponível em: https://www.facebook.com/pages/Apoiadores-Rede-de-Apoio-Social$\% \mathrm{C3} \% \mathrm{~A} 0 \mathrm{~s}-\mathrm{V} \% \mathrm{C} 3 \%$ ADtimas-das-Chuvas-no-Esp\%C3\%ADrito-Santo/5. Acesso em 19 dez. 2013.

ASHBY, W. R. An Introduction to Cybernetics. London: Chapman \& Hall, 1999.

AXELROD, R. The evolution of strategies in the iterated Prisoner's Dilemma. In: DAVIS, L. (Ed.). Genetic algorithms and simulated annealing. London: Pitman and Los Altos, 1987. p. 32-41.

BARABÁSI, A.-L. Linked: a nova ciência dos networks. Rio de Janeiro, Ed. Leopardo: 2009.

BARABÁSI, A.-L.; ALBERT, R. Emergence of scaling in random networks. Science, New York, v. 286, p. 509-512, oct., 1999.

BARRAKET, J. et. al. Spontaneous volunteering during natural disasters.

Brisbane, Australia, The Australian Centre for Philanthropy and Nonprofit Studies, Queensland University of Technology, 2013. Disponível em:

<http://eprints.qut.edu.au/61606/1/Spontaneous_Volunteering_Final_Report_July_31 _(2).pdf. Acesso em: 24 mar. 2014.

BARRETO, A. A. A questão da informação. Revista São Paulo em Perspectiva. São Paulo, Fundação Seade, v. 8, n. 4, 1994.

BEAGRIE, A. Emergent Groups in Disaster Response. Brisbane: University of Queensland, Australian Red Cross, 2009. Disponível em:<http://www.yarraranges.vic.gov.au/files/72b35eb5-9301-41f8-8fee9e52011387fe/Emergent_groups_in_disaster_response.pdf >. Acesso em 14 mar. 2014.

BENKLER, Y. The wealth of networks: how social production transforms markets and freedom. 2006. Disponível em: ‘http://creativecommons.org/licenses/by-ncsa/2.5/>. Acesso em 14 abr.2013.

BERNAL, C.C. $O$ ciberespaço: palavra, norma e liberdade. Caracterologia do ciberespaço a partir da ideia de Inteligência Coletiva em Pierre Lévy. 2010. 180 f. Dissertação. (Mestrado Acadêmico em Filosofia) - Centro de Humanidades, 
Universidade Estadual do Ceará, Fortaleza, 2010. Disponível em:

$<$ http://www.uece.br/cmaf/dmdocuments/dissertacao2009_ciberespaco_palavra_nor ma_liberdade.pdf>. Acesso em: 26 mai. 2014.

BERTONE, P.; MARINHO, C. Gestão de riscos e resposta a desastres naturais: a visão do planejamento. In: VI CONGRESSO CONSAD DE GESTÃO PÚBLICA. 2013, Brasília. Anais eletrônicos... Disponível em:

$<$ http://www.escoladegoverno.pr.gov.br/arquivos/File/2013/V CONSAD/VI CONSAD 1069.pdf >. Acesso em: 20 mar.2014.

BOCCALETTI, S. et al. Complex networks: structure and dynamics. Physics Reports, v. 424, n. 4-5, p. 175-308, fev. 2006.

$\mathrm{BOHN}, \mathrm{A}$. et.al. Making friends and communicating on Facebook: implications for the access to social capital. Social Networks, vol.37, p.29-41, 2014.

BORGATTI NETO, R. Perspesctivas da complexidade aplicadas à gestão de empresas. 2008. 414f. Tese (Doutorado em Engenharia de Produção) - Escola Politécnica, Universidade de São Paulo, São Paulo, 2008. Disponível em: <http://www.teses.usp.br/teses/disponiveis/3/3136/tde-03062008-100514/>. Acesso em: 26 mai. 2014.

BRAGA, K. S. Aspectos relevantes para seleção de metodologia adequada à pesquisa social em Ciência da Informação. In: MUELLER, Susana Pinheiro, Machado. (Org). Métodos para pesquisa em Ciência da Informação. Brasília: Thesaurus, 2007.

BRAGA, E. C. As redes sociais e suas propriedades emergentes como a inteligência coletiva: a criação do comum e da subjetividade. Revista Digital de Tecnologias Cognitivas, São Paulo, n. 2, p. 48-59, jul./dez.2009. Disponível em: http://www4.pucsp.br/pos/tidd/teccogs/artigos/2009/edicao 2/3-

as redes sociais e suas propriedades emergentes como a inteligencia coletivaa criacao do comum e da subjetividade-eduardo cardoso braga.pdf, Acesso em 19 out. 2013.

BRASIL. Ministério da Integração Nacional. Secretaria Nacional de Proteção e Defesa Civil. Política Nacional de Defesa Civil. Brasília, 2007. Disponível em: <http://www.defesacivil.gov.br/publicacoes/publicacoes/pndc.asp>. Acesso em: 10 set. 2013.

. Ministério da Integração Nacional. Secretaria Nacional de Defesa Civil. Diagnóstico do Plano Nacional de Gestão de Risco e Resposta a Desastre. Brasília: FGV Projetos, 2012a.

. Ministério da Integração Nacional. Centro Nacional de Gerenciamento de Riscos e Desastres (CENAD). Anuário brasileiro de desastres naturais 2011. Brasília, 2012b. Disponível em:<http://www.integracao.gov.br/c/document_library/get_file?uuid=e3cab906-c3fb49fa-945d-649626acf790\&groupld=185960 >. Acesso em 14 fev. 2013.

. Ministério da Integração Nacional. Principais ações do programa 2040.

[s.d.] Disponível em: <http://www.mi.gov.br/acoes-2040> Acesso: em 18 jul. 2013. 
CALAZANS, A.T.S. Estudo de caso: uma estratégia de pesquisa. In: MUELLER, S. P. M. (Org). Métodos para pesquisa em Ciência da Informação. Brasília:

Thesaurus, 2007.

CAPRA, F. A teia da vida. São Paulo: Cultrix, 1996.

As conexões ocultas. São Paulo: Cultrix, 2002.

CARRINGTON, P. J.; SCOTT, J.; WASSERMAN, S. (Eds.) Models and methods in social network analysis. 9th. ed. Cambridge University Press, 2012.

CASTELLS, M. A sociedade em rede. 8 ed. São Paulo: Paz e Terra, 1999.

CHUVA no ES já é a maior desde que começaram as medições. Terra, 24 dez.

2013. Disponível em: < http://noticias.terra.com.br/brasil/cidades/chuva-no-es-ja-e-amaior-desde-que-comecaram-as-

medicoes,3f78ea9f84523410VgnCLD2000000dc6eb0aRCRD.html > Acesso em: 24 dez. 2013

CORNING, P. A. The synergism hypothesis: on the concept of synergy and its role in the evolution of complex systems. Journal of Social and Evolutionary Systems, v. 21, p. 133-172, 2000.

CORPO DE BOMBEIROS MILITAR DO ESPÍRITO SANTO. Defesa Civil do Espírito Santo. 2014. Relatório Operacional Chuvas no ES: dezembro de 2013. Disponível em: http://en.calameo.com/read/0000230949c2662aa9b85. Acesso em 15 fev. 2014.

DAVALLON, J. A mediação: a comunicação em processo? Prisma.com. n.4. 2007. Disponível em:<http://revistas.ua.pt/index.php/prismacom/article/view/645>. Acesso em 15 mar.2015.

DE NOOY, W.; MRVAR, A.; BATAGELJ, V. Exploratory social network analysis with Pajek. Cambridge: Cambridge University Press, 2005.

DI FELICE, M. As formas digitais do social e os novos dinamismos da sociabilidade contemporânea. In: I ABRAPCORP - I Congresso Brasileiro Científico de Comunicaçao Organizacional e de Relaçoes Públicas, 2007, São Paulo. Anais eletrônicos... Disponível em:< http://www.abrapcorp.org.br/anais2007/trabalhos/gt3/gt3_felice.pdf>. Acesso em 22 dez. 2013.

ÉRDI, P. Complexity Explained. Springer-Verlag Berlin Heidelberg, 2008.

ES tem 23 mortos e mais de 61 mil fora de casa por causa da chuva. UOL., 26 dez. 2013. Disponível em: <http://noticias.uol.com.br/cotidiano/ultimasnoticias/2013/12/26/es-tem-22-mortos-e-mais-61-mil-fora-de-casa-por-causa-dachuva.htm> Acesso em: 26 dez. 2013.

ESPÍRITO SANTO (Estado). Corpo de Bombeiros Militar do ES. Coordenadoria Estadual de Proteçao e Defesa Civil. Histórico de desastres do Estado do Espírito Santo: 2000 - 2009. 2010. Disponível em:<http://www.defesacivil.es.gov.br/files/pdf/historico_de_desastres.pdf> Acesso em: 23 nov. 2014. 
. Corpo de Bombeiros Militar do ES. Coordenadoria Estadual de Proteçao e Defesa Civil. Plano Estadual de proteção e defesa civil. 2014. Disponível em:<http://www.defesacivil.es.gov.br/files/pdf/PEPDEC\%20Outubro\%202014-2.pdf > Acesso em: 23 nov. 2014.

Secretaria do Meio Ambiente e Recursos Hídricos. Instituto Estadual do Meio Ambiente. Atlas de vulnerabilidade às inundações no Estado do Espírito Santo 2013. 2013. Disponível em:<http://www.meioambiente.es.gov.br/download/2013_Atlas_de_Vulnerabilidade_I nundacoes.pdf> Acesso em: 23 nov. 2014.

FAYOL. H. Administração industrial e geral. São Paulo: Atlas, 1987.

FERNANDES, J. H. C. Sistemas Complexos. Brasília: Universidade de Brasília, Departamento de Ciência da Computação, 2008. Disponível em:< http://www.cic.unb.br/ jhcf/MyBooks/cegsic/2008_2009/GSIC001_Sistemas_Comple xos_2008.pdf $>$. Acesso em: 14 mar. 2013.

FRANCO, A. Topologias de Rede. 2008. Disponível

em:<http://augustodefranco.locaweb.com.br/cartas_comments.php?id=249_0_2_0_ C> Acesso em 13 mar. 2014

. A Rede. São Paulo: 2012. Disponível em: <http://net-hcw.ning.com/page/arede>. Acesso em 23 jun. 2015.

FREEMAN, L. C. Centrality in social networks: conceptual clarification. Social Networks. v. 1, p. 215-239, 1979. 1-20, 2000.

Visualizing social networks. Joss: Journal of Social Structure, v. 1, n. 1, p. . The development of social network analysis - with an emphasis on recent events. In: SCOTT, J.; CARRINGTON, P. (eds.). Sage Handbook of Social Network Analysis. London: Sage Publications Inc, 2011.

GOMES, F. Com as fortes chuvas, enchentes podem ser maiores do que a de 1979, diz Incaper. Reportagem. Gazeta Online, 2013. Disponível em:< http://gazetaonline.globo.com/_conteudo/2013/12/noticias/cidades/1473152-com-asfortes-chuvas-enchentes-podem-ser-maiores-do-que-a-de-1979-diz-incaper.html> Acesso em: 24 dez. 2013

GOVERNO do ES estima reconstrução em $\mathrm{R} \$ 540$ milhões. Portal do Governo do Estado do Espírito Santo, 02 jan. 2014. Disponível em:

<http://www.es.gov.br/Noticias/167148/governo-do-es-estima-reconstrucao-em-r540-milhoes.htm>. Acesso em: 15 jan. 2014.

HANNEMAN, R. A.; RIDDLE, M. Introduction to social network methods.

Riverside, 2009. Disponível em: <http://faculty.ucr.edu/ hanneman/ > Acesso em: 25 mar. 2012.

HEYLIGHEN, F. Modelling Emergence. World Futures: the Journal of General Evolution 31 (Special Issue on Emergence, edited by G. Kampis), v. 31, p. 89-104, 1991. 
Self-organization in communicating groups : the emergence of coordination, shared references and collective intelligence. In: MASSIP-BONET, À.; BASTARDASBOADA, A. (Eds.). Complexity perspectives on language, communication and society: understanding complex systems. Springer- Verlag Berlin Heidelberg, 2013.

HOLLAND, J. H. Complexity: a very short introduction. New York: Oxford University Press, 2014.

HOUAISS, A.; VILLAR, M. de S. Minidicionário Houaiss da Língua Portuguesa. Rio de Janeiro: Objetiva, 2001.

HOWE, J. The rise of crowdsourcing. Wired Magazine, n.14, jun., 2006.

HUISMAN, M.; VAN DUIJN, M.A.J. Software for social network analysis. In: CARRINGTON, P. J.; SCOTT, J.; WASSERMAN, S. (Eds) Models and methods in social network analysis. 9th. ed. Cambridge: Cambridge University Press, 2012.

IBGE. Perfil dos municípios brasileiros 2012. Rio de Janeiro, 2013. Disponível em: < ftp://ftp.ibge.gov.br/Perfil_Municipios/2012/munic2012.pdf > Acesso em 14 out. 2013.

IZQUIERDO, L. R.; HANNEMAN, R. A. Introduction to the formal analysis of social networks using mathematica. 2006. Disponível em: < http://faculty.ucr.edu/ hanneman/mathematica_networks.pdf >. Acesso em: 22.mar.2014.

JENKINS, B. H. Collective Intelligence vs The Wisdom of Crowds. 2006. Disponível em:

$<$ http://henryjenkins.org/?s=Collective+Intelligence+vs.+The+Wisdom+of+Crowds $+B$ y>. Acesso em 15 dez. 2013.

JOHNSON, S. Emergência: a dinâmica de rede em formigas, cérebros, cidades e softwares. Rio de Janeiro: Zahar, 2003.

JUSTI JUNIOR, G. et.al. Análise de redes sociais em uma situação de gerenciamento de crise. In: CONGRESSO LATINO IBEROAMERICANO DE INVESTIGAÇAO OPERATIVA. SIMPÓSIO BRASILEIRO DE PESQUISA OPERACIONAL, 2012, Rio de Janeiro. Anais eletrônicos...Disponível em:<http://www.din.uem.br/sbpo/sbpo2012/pdf/arq0423.pdf>. Acesso em: 20 ago.2013.

KAUFFMAN, S. At home in the universe: the search for the laws of selforganization and complexity. Nova York: Oxford University Press, 1995.

KELLY, K. Out of Control. 2008. Disponível em: <http://kk.org/books/ooc-mf.pdf>. Acesso em 12 fev. 2013.

LÉVY, P. Cibercultura. 3a . ed. Rio de Janeiro: Ed. 34, 1999.

A inteligência coletiva: por uma antropologia do ciberespaço. 8. ed. São Paulo: Edições Loyola, 2011. 
LOPES, J. Novos paradigmas: hipercomplexidade e autopoiese - algumas considerações para a defesa da alfabetização, leitura e escrita. Leitura: Teoria e Prática. Campinas, n. 37, 2001.

LOURENÇO, R. S. Análise de redes sociais na produção criativa: uma aplicação aos compositores da bossa nova. 2012. 46 f. Dissertação. (Mestrado Profissional em Economia) - Escola de Economia de São Paulo, Fundação Getúlio Vargas (FGV). São Paulo, São Paulo, 2012. Disponível em: < https://bibliotecadigital.fgv.br/dspace/handle/10438/10049>. Acesso em 15.mar 2015.

MAJCHRZAK, A.; JARVENPAA, S.; HOLLINGSHEAD, A. Coordinating expertise among emergent groups responding to disasters. Organization Science, v. 18, n. 1, p. 147-161, jan- feb, 2007.

MARIN, A.; WELLMAN, B. Social network analysis: an introduction. In: CARRINGTON, P.; SCOTT, J. (eds.) Handbook of social network analysis. London: Sage Publications Inc., 2010.

MARTELETO, R. M. Informação : elemento regulador dos sistemas, fator de mudança social ou fenômeno pós-moderno?. Ci. Inf., Brasília, v. 16, n. 2, p. 169180, 1987.

Análise de redes sociais: aplicação nos estudos de transferência da informação. Ci. Inf., Brasília, v. 30, n. 1, p. 71-81, 2001.

Redes sociais, mediação e apropriação de informações: situando campos, objetos e conceitos na pesquisa em Ciência da Informação. Pesq. Bras.Ci. Inf., Brasília, v.3, n. 1, p.27-46, jan./dez., 2010.

MARTELETO, R. M.; SILVA, A. B. DE O. Redes e capital social : o enfoque da informação para o desenvolvimento local. Ci. Inf., Brasília, v. 33, n. 3, p. 41-49, 2004.

MARTELETO, R. M.; TOMAÉL, M. I. A Metodologia de Análise de Redes Sociais. In: VALENTIM, Marta Lígia Pomim. (Org). Métodos Qualitativos de Pesquisa em Ciência da Informação. São Paulo:Polis, 2005.

MARTINHO, C. et al. (Org.). Redes: uma introdução às dinâmicas da conectividade e da auto-organização. Brasília, DF: WWF-Brasil, 2003.

MATHEUS, R. F. et.al. Análise de redes sociais como metodologia de apoio para a discussão da interdisciplinaridade na ciência da informação. Ci. Inf., Brasília, v. 35, n. 1, p. 72-93, 2006.

MATHEUS, R. F.; SILVA, A. B. O. Análise de redes sociais como método para a ciência da informação. Datagramazero, Rio de Janeiro, v.7, n. 2, abr. 2006.

MAXIMIANO, A. C. A. Teoria geral da Administração: da revolução urbana à revolução digital.São Paulo: Atlas, 2009.

MITCHELL, M. Complexity: a guide tour. New York, Oxford University Press: 2009. 
MORAES, H. J. P. Inteligência coletiva: o ciberespaço como retrato da sociedade ou uma discussão da ética da estética. Revista Famecos. Porto Alegre, v. 18, n. 2, p. 542-556, maio/agosto 2011.

MORENO, J. L. Who shall survive? 2nd. ed. New York: Beacon House, Inc., 1953.

MORGAN, G. Paradigmas, metáforas e resolução de quebra cabeças na teoria das organizações. In: CALDAS, M. P; BERTERO, O. Teoria das Organizações. São Paulo: Atlas, 2007.

.Imagens da Organização. São Paulo: Atlas, 1996.

MORIN, E. Complexity. International Social Science Journal: The sciences of life and of society. Vol. XXVI, N 04 4, 1974. Disponível em:

$<$ http://escoladeredes.net/group/bibiotecaedgarmorin > Acesso em: 23 mar. 2015. 1990.

. Introdução ao pensamento complexo. 2 ed. Lisboa: Instituto A. Piaget,

. Introdução ao pensamento complexo. Porto Alegre: Sulina, 2006.

A Complexidade e a liberdade. THOT- Associação Palas Athena, São

Paulo, n. 67, 1998, p. 12-19. Disponível em:

$<$ http://escoladeredes.net/group/bibiotecaedgarmorin > Acesso em: 23 mar. 2015.

Organization and Complexity. Annals of the New York Academy of

Sciences. Tempos in science and nature: structures, relations, and complexity. v. 879, p. 115-121, jun. 1999.

El Paradigma Perdido: ensayo de bioantropologia. Barcelona: Editorial Kairós, 2005. 7. ed.

MOTTA, F. C. P.; VASCONCELOS, I. F. G. de. Teoria Geral da Administração. 3.ed. São Paulo: Cengage Learning, 2009.

MULLINS, J. HOW CROWDSOURCING HAS HELPED IN HAITI. New Scientist, v. 205, n. 2745, p. 8-9, 2010.

NATIONAL RESEARCH COUNCIL. Aplications of social network analysis for building community disaster resilience. Workshop Summary. Washington, D. C: The National Academies Press, 2009.

NETO, V. L. da C., A Visão de Complexidade de Edgar Morin para o Entendimento da Verdade nos Estudos Organizacionais. CONVIBRA 2014. Disponível em:<http://www.convibra.com.br/artigo.asp?ev=23\&id=10489>. Acesso em: 12 jun. 2015.

NETO,R.C.D.A; BARBOSA, R.R; CENDÓN, B.V. A construção de metodologia de pesquisa qualitativa com vistas à apreensão da realidade organizacional brasileira: estudos de casos múltiplos para proposição de modelagem conceitual integrativa. Inf. \& Soc.: Est., João Pessoa, v.16, n.2, p.63-78, jul./dez. 2006.

NOLTE, I. M.; BOENIGK, S. A study of ad hoc network performance in disaster response. Nonprofit and Voluntary Sector Quarterly, v. 42, n. 1, p. 148-173, 2013. 
NOUBEL, J.F. Collective Intelligence: the invisible revolution. 2006. Disponível em: $<$ http://www. TheTransitioner.org/ic>. Acesso em 15 out. 2013.

OLIVEIRA, M. DE. Livro texto do projeto Gerenciamento de desastres - Sistema de Comando de Operações. Florianópolis: Ministério da Integração Nacional, Secretaria Nacional de Defesa Civil, Universidade Federal de Santa Catarina, Centro Universitário de Estudos e Pesquisas Sobre Desastres, 2010. Disponível em:< http://www.defesacivil.mg.gov.br/conteudo/arquivos/manuais/apostila/Manual.SCO.U FSC.pdf> Acesso em 22 set. 2014.

ONU. Brasil entre os mais afetados em 2011, alerta ONU. 2012a.Disponível em:< www.onu.org.br/brasil-entre-os-mais-afetados-pelos-desastres-climaticos-em2011-alerta-onu>. Acesso em: 15 mar. 2013.

Desastres naturais causam perdas de 15 bilhões de reais, diz Banco Mundial. 2012b. Disponível em: <http://www.onu.org.br/desastres-naturais-no-brasilcausaram-perdas-de-15-bilhoes-de-reais-diz-banco-mundial/print/>. Acesso em: 15 mar. 2013.

Prejuízos por desastres naturais somam 2,5 trilhões de dólares, só neste século, calcula ONU. 2013. Disponível em: <http://www.onu.org.br/prejuizospor-desastres-naturais-somam-25-trilhoes-de-dolares-so-neste-seculo-calcula-onu/>. Acesso em: 15 mar. 2013.

.Estratégia Internacional para Redução de Desastres. Marco prioridades de ação de Yogo. 2005. Tradução e editoração: Luís Felipe Lopes de Lima Lins. Departamento de Minimização de Desastres. Secretaria Nacional de Defesa Civil. Disponível em: $<$ http://www.integracao.gov.br/cidadesresilientes/pdf/mah ptb brochura.pdf $>$. Acesso em: 20 jul. 2013.

OTTE, E.; ROUSSEAU, R. Social network analysis: a powerful strategy, also for the Information Sciences. Journal of Information Science, v. 28, n. 6, p. 441-453, 1 dez. 2002.

PALEN, L. et.al. Crisis informatics : studying crisis in a networked world. THIRD INTERNATIONAL CONFERENCE ON E-SOCIAL SCIENCE. 2007, Ann Arbor, Michigan. Anais eletrônicos... Disponível em:

$<$ https://www.cs.colorado.edu/ palen/palen_papers/palen-crisisinformatics.pdf>. Acesso em 12. ago. 2013.

PAN, S. L.; PAN, G.; LEIDNER, D. E. Crisis response information networks. Journal of the Association for Information Systems, v. 13, n. 1, p. 31-56, 2012.

PERIM, M. Litoral do ES registra maior volume de chuva no mundo, aponta instituto. Reportagem. G1, 2013. Disponível em:<http://g1.globo.com/espiritosanto/noticia/2013/12/litoral-do-es-registra-maior-volume-de-chuva-no-mundoaponta-instituto.html> Acesso em: 24 dez. 2013

PINHEIRO, L.V.R. Informação: esse obscuro objeto da Ciência da Informação. Morpheus - Revista Eletrônica em Ciências Humanas, Rio de Janeiro, v.2, n.4, 2004. 
PREFEITURA MUNICIPAL DE VITÓRIA. Plano de contingência do município de Vitória. 2007. Disponível

em:<http://www.vitoria.es.gov.br/arquivos/20090911_plano_defesa_civil.pdf>. Acesso em: 22 jun.2014.

QUARANTELLI, E. L. Organizational response to the Mexico City earthquake of 1985: characteristics and implications. Natural Hazards, v. 8, n. 1, p. 19-38, jul. 1993.

Emergent behaviors and groups in the crisis time of disasters. Newark: Disaster Research Center. University of Delaware, 1995. Disponível em:< http://udspace.udel.edu/handle/19716/634>. Acesso em 24 jun. 2014.

QUARANTELLI, E. L.; DYNES, R. R. Response to social crisis and disaster. Annual Review of Sociology, v. 3, n. 1, p. 23-49, ago. 1977.

RAMOS, A. G. A nova ciência das organizações. Rio de Janeiro: Editora da Fundação Getúlio Vargas, 1989.

RECUERO, R. DA C. A rede é a mensagem: efeitos da difusão de informações nos sites de redes social. In: VIZER, E. (Org.) Lo que Mcluhan no previó. 1ed. Buenos Aires: Editorial La Crujía, 2012, v. 1, p. 205-223.

Redes sociais na Internet. Porto Alegre: Editora Sulina, 2009.

RHEINGOLD, H. Net Smart: how to thrive online. Mit Press, 2012.

ROBINS, G. ; PATTISON, P. Interdependencies and social processes: dependence graphs and generalized dependence structures. In: CARRINGTON, P. J.; SCOTT, J.; WASSERMAN, S. (Eds) Models and methods in social network analysis. 9th. ed. Cambridge University Press, 2012.

RODRIGUEZ, H.; TRAINOR, J.; QUARANTELLI, E. L. Rising to the challenges of a catastrophe: the emergent and prosocial behavior following Hurricane Katrina. The annals of the American Academy of Political and Social Science, New York, v. 604, n. 1, p. 82-101, jan. 2006.

ROSSONI, L. GRAEML, A. A Influência da imersão institucional e regional na cooperação entre pesquisadores no Brasil. REDES - Revista hispana para el análisis de redes sociales, Vol.16,n. 9, jun. 2009

Disponível em: < http://revista-redes.rediris.es/html-vol16/vol16_9.htm>. Acesso em: 07 nov.2015

SARACEVIC, T. Information Science. In: BATES, M. J.; MAACK, M.N. (Eds.) Encyclopedia of Library and Information Science. New York: Taylor \& Francis, 2009. p. 2570-2586..Disponível em: < https://comminfo.rutgers.edu/ tefko/SaracevicInformationScienceELIS2009.pdfAcess o em: 20 mar.2012.

SAWYER, R. K. Social emergence: societies as complex systems. New York: Cambridge University Press, 2005.

SCOTT, J. What is social network analysis ? London: Bloomsbury Academic, 2012. 
SERVA, M. O paradigma da complexidade e a análise organizacional. Revista de Administração de Empresas. São Paulo, v.32, n. 2, p. 26-35, abr/jun/1992.

A racionalidade substantiva demonstrada na prática administrativa. Revista de Administração de Empresas. São Paulo, v.37, n 2, p.18-30, abr/jun 1997.

SERRA, J. P. Manual de teoria da comunicação. Universidade da Beira Interior. Covilhã, 2007. Disponível em: <http://www.livroslabcom.ubi.pt/book/51>. Acesso em: 18 mai. 2015

SHADECK, R. et. al. A atuação da secretaria nacional de defesa civil (Sedec) na gestão de riscos e resposta a desastres naturais. In: VI CONGRESSO CONSAD DE GESTÃO PÚBLICA. 2013, Brasília. Anais eletrônicos... Disponível em: $<$ http://www.escoladegoverno.pr.gov.br/arquivos/File/2013/V CONSAD/VI CONSAD 1069.pdf >. Acesso em: 20 mar.2014.

SOARES. R. H. S. Métodos para análise da comunicação e mediação da informação em organizações públicas por meio de redes sociais mapeadas a partir de publicações oficiais.2014. 155 f. Dissertação (Mestrado em Ciência da Informação) - Programa de Pós-Graduação em Ciência da Informação, Universidade de Brasília, Brasília - DF, 2014.Disponível em: <

http://repositorio.unb.br/bitstream/10482/15743/1/2014_RafaelHenriqueSantosSoare s\%20(2).pdf>Acesso em: 20 out. 2015.

SOLACHIDIS, V. et.al. Collective intelligence generation from user contributed content. In: A. FINK, et.al.(Eds.) Advances in data analysis, data handling and business intelligence. Springer-Verlag Berlin Heidelberg, 2010.

STROGATZ, S. H. Exploring complex networks. Nature, v. 410, n. 6825, p. 268-76, 8 mar. 2001.

SUROWIECKI, J. The wisdom of crowds. New York: Anchor Books, 2004.

TAKAHASHI, T. (Org.). Livro verde da Sociedade da Informação no Brasil. Brasília: Ministério da Ciência e Tecnologia, 2000. Disponível em:<http://www.mct.gov.br/upd_blob/0004/4795.pdf>. Acesso em: 15 mar. 2013.

TANG, J. et. al. Analysing information flows and key mediators through temporal centrality metrics. (2010) Disponível em:

<http://www.ucl.ac.uk/ ucfamus/papers/sns10.pdf>. Acesso em: 07 jul. 2014.

TOBIN, G.A; MONTZ, B. E. Natural hazards: explanation and integration. New York: The Gilford Press, 1997.

TOMAÉL, M. I. Redes sociais, conhecimento e inovaçao localizada. Inf . Inf . , Londrina, v. 12, n. especial, 2007.

TOMAÉL, M. I.; MARTELETO, R. M. Redes Sociais: posições dos atores no fluxo da informação. Enc. Bibli: R. Eletr. Bibliotecon. Ci. Inf., Florianópolis, n. esp., 1ํㅗㅇ. 2006.

TOMAÉL, M. I.; MARTELETO, R. M. Redes sociais de dois modos : aspectos conceituais. Transinformação, Campinas, v. 25, n. 3, p. 245-253, 2013. 
UNIVERSIDADE FEDERAL DE SANTA CATARINA. Centro de Estudos e Pesquisas em Desastres Naturais. Atlas brasileiro de desastres naturais: 1991 a 2010. Florianópolis, 2012. Disponível em: <http://150.162.127.14:8080/atlas/Brasil

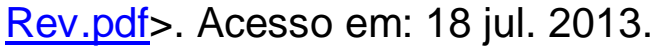

VALENTE, T.W. Networks models and methods for studying the difusion of innovations. In: CARRINGTON, P. J.; SCOTT, J.; WASSERMAN, S. (Eds). Models and methods in social network analysis. 9th.ed. Cambridge: Cambridge University Press, 2012.

VARDA, D. M. et. al. Social network methodology in the study of disasters: issues and insights prompted by post-Katrina research. Population Research and Policy Review, v. 28, n. 1, p. 11-29, 22 nov. 2008.

VICKERY, B.; VICKERY, A. Information Science in theory and practice. K. G. Saur: 34, 2004.

VOORHEES, W.R. New Yorkers Respond to the World Trade Center Attack: An Anatomy of an Emergent Volunteer Organization. Journal of Contingencies and Crisis Management, v. 16, n.1, mar. 2008.

WASSERMAN, S.; FAUST, K. Social network analysis: methods and aplications. 19th.ed. New York: Cambridge University Press, 2009.

WATTS, D. J. The "new" science of networks. Annual Review of Sociology, v. 30, n. 1, p. 243-270, ago. 2004.

WATTS, D. J.; STROGATZ, S. H. Collective dynamics of "small-world" networks. Nature, v. 393, n. 6684, p. 440-2, 4 jun. 1998.

WEBER, M. Ensaios de sociologia. 5. Ed. Rio de Janeiro: Guanabara, 1982.

WERSIG,G.; NEVELING, U. The phenomena of interest to Information Science. Information Scientist, v. 9, n. 4, p.127-140, 1975

WILLIAMS, K.; DURRANCE, J. C. Social networks and social capital : rethinking theory in community informatics. The Journal of Community Informatics, v. 4, n. 3, p. 1-20, 2008.

WOOLLEY, A. W. et. al. Evidence for a collective intelligence factor in the performance of human groups. Science, New York, v. 330, n. 6004, p. 686-8, 29 out. 2010.

YIN, R. K. Estudo de caso: planejamento e métodos. 3. ed. Porto Alegre: Bookman, 2005.

ZHAO, Y.; ZHU, Q. Evaluation on crowdsourcing research: current status and future direction. Information Systems Frontiers, v. 16, p. 417 - 434, abr. 2012.

ZINS, C. Knowledge map of information science: Research Articles. Journal of the American Society for Information Science and Technology. 58(4):526-535, 2007. 10pp. Disponível em: <http://www.success.co.il/is/zins_kmapof_is.pdf>. Acesso em: 15 ago. 2014. 


\section{APÊNDICES}




\section{APÊNDICE A - QUESTIONÁRIO}

\section{APOIO ÀS VÍTIMAS DAS CHUVAS DE DEZEMBRO DE 2013 NO ES}

\section{ESCLARECIMENTOS SOBRE A PESQUISA}

Esta pesquisa está sendo desenvolvida no âmbito do Doutorado Interinstitucional em Ciência da Informação, realizado por meio de parceria entre a Universidade de Brasília - UnB e a Universidade Federal do Espírito Santo - UFES. Tem por finalidade principal, estudar as ações de apoio às vítimas das chuvas de dezembro de 2013 no ES.

Desde já agradecemos por sua participação e esperamos que com os resultados deste trabalho, possamos ter condições de conhecer mais profundamente o papel e as características da ação da sociedade civil organizada, bem como das instituições envolvidas em ações de resposta a desastres naturais.

Para garantir os resultados esperados com a pesquisa, é muito importante que consigamos mapear o maior número possível de pessoas que participaram das ações de apoio as vítimas das chuvas de dezembro de $\mathbf{2 0 1 3}$, bem como a natureza das conexões que estas pessoas estabeleceram com as demais neste processo. Assim, solicitamos que você tente resgatar da maneira mais fiel possível, as memórias e registros sobre a sua atuação naquele momento. Sua contribuição será fundamental para o bom andamento da nossa pesquisa.

Mais uma vez agradecemos sua disponibilidade e boa-vontade em nos auxiliar neste trabalho que acreditamos poderá ser de grande valia para toda a sociedade do nosso estado.

A seguir, como parte do protocolo da pesquisa científica, você será direcionado para o Termo de Consentimento Livre e Esclarecido para que tenhamos devidamente registrada a sua concordância em participar do estudo.

Atenciosamente,

Julia Bellia Margoto

Professora do Departamento de Administração da UFES

DINTER- UnB/UFES em Ciência da Informação

Pesquisadora Responsável 
APOIO ÀS VítIMAS DAS CHUVAS DE DEZEMBRO DE 2013 NO ES

\section{TERMO DE CONSENTIMENTO LIVRE E ESCLARECIDO}

Você está sendo convidado a participar da pesquisa "As redes sociais e as ações de resposta a desastres naturais: o caso das chuvas de dezembro de 2013 no ES" sob responsabilidade da pesquisadora Profa. Julia Bellia Margoto.

A pesquisa tem como objetivo investigar e caracterizar a rede de apoio às vítimas das chuvas que ocorreram em dezembro de 2013 no estado do Espírito Santo, por meio da sua relação com conceitos da metodologia de análise de redes sociais. Você responderá a um questionário que busca levantar dados relativos ao surgimento da rede, bem como sua composição e formas de atuação. O estudo está sendo realizado como parte de uma tese de doutorado, em desenvolvimento pela pesquisadora no âmbito do Doutorado Interinstitucional em Ciência da Informação, realizado em uma parceria entre a UnB - Universidade de Brasília e a UFES.

A resposta às perguntas está ocorrendo online, pela ferramenta virtual Survey Monkey. Se você está sendo convidado a preencher este questionário é porque outro participante desta rede de apoio realizou a indicação do seu nome. Esclarecemos que os dados referentes a nomes e contatos dos participantes serão utilizados apenas com a finalidade de localização para convite sobre a participação na pesquisa. Tais informações não serão incluídas no relatório final da tese e serão tratadas de forma sigilosa pela pesquisadora.

Você não terá benefícios pessoais diretos ao participar da pesquisa, mas contribuirá para o melhor entendimento do papel e das características das ações da sociedade civil organizada, bem como das instituições envolvidas em ações de resposta a desastres naturais. Assim você poderá ser beneficiado indiretamente. A pesquisadora não terá nenhum benefício pessoal/financeiro com esta pesquisa, exceto a produção acadêmica dela decorrente.

Você não terá quaisquer despesas ou danos em decorrência de sua participação, apenas o investimento de parte de seu tempo na resposta do questionário.

Lembramos que, por se tratar de uma pesquisa "on line", ela não está isenta de falhas técnicas decorrentes dessa modalidade de coleta de dados (problemas de sistema; indisponibilidade provisória das páginas; perda das informações e necessidade de reinserção dos dados).

Durante qualquer etapa (antes, durante ou após o preenchimento do instrumento), você possui o direito de recusar-se a participar da pesquisa ou retirar seu consentimento, sem penalidades ou prejuízos pessoais. Os dados que serão coletados farão parte do relatório final da tese (com exceção dos nomes e contatos pessoais, conforme já mencionado) e não serão utilizados individualmente para qualquer outra finalidade administrativa ou comercial. Os dados poderão ser utilizados em pesquisas futuras que sejam relacionadas com a temática deste estudo.

A qualquer momento durante o preenchimento do questionário, assim como em momento posterior ou anterior à participação, você poderá entrar em contato com a pesquisadora para quaisquer esclarecimentos acerca da pesquisa. O telefone para contato e o email é: julia.margoto@gmail.com.

Ao assinalar a opção "aceito participar", a seguir, você declara que autoriza a sua participação no projeto de pesquisa e que seus dados coletados serão utilizados como parte de um relatório de pesquisa científica. Você também declara de que foi informado, de forma clara e detalhada, dos objetivos e dos procedimentos a serem utilizados para a coleta de dados, assim como esclarecido o fato de que sua participação não lhe acarretará quaisquer prejuízos.

Julia Bellia Margoto

Professora do Departamento de Administração da UFES

DINTER- UnB/UFES em Ciência da Informação

Pesquisadora Responsável

* 1. Recebi as informações sobre os objetivos da pesquisa de forma clara e concordo em participar do estudo "As redes sociais e as ações de resposta a desastres naturais: o caso das chuvas de dezembro de 2013 no ES."

Aceito participar da pesquisa 
APOIO ÀS VÍTIMAS DAS CHUVAS DE DEZEMBRO DE 2013 NO ES

\section{Seus dados}

*1. Seu nome completo

*2. Seu telefone e email de contato (estas informações serão tratadas de forma sigilosa no relatório da pesquisa)

3. A qual instituição/empresa/organização você pertencia em dezembro de 2013 ?

Defesa Civil Estadual

Corpo de Bombeiros do ES

TV Vitória

Cruz Vermelha

Defesa Civil Municipal

Prefeitura Municipal

Organização Não Governamental

Uma empresa privada que apoiou as ações (shopping, padaria, transportadora, etc.)

Nenhuma

Outra instituição relacionada às ações de Defesa Civil (especifique)

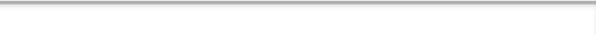

4. Caso na pergunta anterior você tenha escolhido Defesa Civil Municipal ou Prefeitura Municipal, indique abaixo o município.

* 5. Indique abaixo sua(s) principal(is) motivação(ões) para atuar no apoio às vítimas da chuva em 2013

$\square$ Fazia parte de suas obrigações profissionais

$\square$ Você tinha parentes entre as vitimas da chuva

$\square$ Por solidariedade e vontade de ajudar o próximo

$\square$ Por convite de amigos

$\square$ Outra motivação (especifique) 
* 6. Como ficou sabendo das ações de apoio às vítimas da chuva, especialmente aquelas desenvolvidas na Praça do Papa?

Amigos ou conhecidos

Familiares

Meios de Comunicação (rádio, TV, internet, mídias sociais)

Outro (especifique)

7. Indique a data em que você iniciou sua participação nas ações de apoio às vítimas. (Se não se recorda precisamente, tente indicar ao menos o período)

* 8 . Indique abaixo a(s) atividade(s) em que você atuou no apoio às vítimas da chuva em dez/2013.

Contatos com Prefeituras, Corpo de Bombeiros, Cruz Vermelha ou Defesa Civil para levantamento de necessidades de donativos

Administração da página dos Apoiadores no Facebook

Contatos com Empresas Privadas ou pessoas físicas para solicitação de donativos ou viabilização de recursos como caminhões, aviões, embalagens, lanches

Coordenação de atividades de recebimento, separação, organização ou embalagem de donativos recebidos na Praça do Papa

Articulação com as instituições envolvidas nas ações de apoio às vítimas, visando à organização e à continuidade do andamento das atividades

Recebimento, separação, organização ou embalagem de donativos recebidos na Praça do Papa

Contatos com Prefeituras Municipais para viabilização da chegada dos donativos às cidades afetadas

Acompanhamento das viagens de caminhão/avião com donativos para as cidades afetadas

Idas às cidades afetadas nos caminhões/aviōes para entrega dos donativos

Outras atividades(especifique)

9. Apresente a seguir as principais dificuldades que você enfrentou para desenvolver estas atividades.

* 10. Para a realização destas atividades, com quantas pessoas, aproximadamente, você manteve contato? (É muito importante que você preencha os nomes e contatos destas pessoas nas páginas a seguir do questionário. Por favor não deixe de fazê-lo)

Até 5 pessoas

Entre 6 e 10 pessoas

Entre 11 e 15 pessoas

Mais de 15 pessoas 


\section{APOIO ÀS VÍTIMAS DAS CHUVAS DE DEZEMBRO DE 2013 NO ES}

\section{QUESTÕES SOBRE SEUS CONTATOS}

\section{Orientações sobre as próximas questões}

Tente se recordar de todas as pessoas com as quais você conversou naquele período para a finalidade de auxílio às vítimas das chuvas. Não importa a frequência. Mesmo que você tenha falado com essa pessoa uma única vez, é importante citar. Mesmo que não possua mais o telefone, indique em maiores detalhes o cargo e a instituição em que a pessoa trabalhava, ou até mesmo o facebook. Para o mapeamento da rede de apoio precisamos muito contactar senão todas, ao menos um número bem próximo de $100 \%$ das pessoas que apoiaram as ações de resposta às chuvas.

A partir daqui, as páginas de respostas se referem às pessoas com as quais você manteve contato na ocasião das chuvas em 2013. Assim, as perguntas nas próximas páginas se repetem, pois deverão ser respondidas, cada uma delas, para contatos diferentes.

Ao responder "sim" para a questão 13 (que pergunta se você possui outros contatos), você será direcionado para uma nova página do questionário, onde deverá iniciar o preenchimento de informações sobre um novo contato. Se responder não, o questionário estará concluído.

O questionário oferece a possibilidade de inclusão de até 15 contatos diferentes. Caso suas conexões apresentem uma maior quantidade de contatos, enviaremos um outro questionário para complementação.

Contamos com você! 


\section{APOIO ÀS VÍTIMAS DAS CHUVAS DE DEZEMBRO DE 2013 NO ES}

Informações sobre seus contatos - Contato 1

1. Informe o nome do contato (não há problemas se não se recorda do nome completo)

2. Se possível, indique aqui o telefone ou e-mail deste contato

3. Instituição/Empresa/Organização à qual pertencia este contato em dezembro de 2013

Defesa Civil Estadual

Corpo de Bombeiros do ES

TV Vitória

Cruz Vermelha

Defesa Civil Municipal

Prefeitura Municipal

Organização Não Governamental

Uma empresa privada que apoiou as ações (shopping, padaria, transportadora, etc.)

Nenhuma

Outra instituição relacionada a ações de Defesa Civil (especifique)

4. Caso você tenha marcado na pergunta anterior a opção Defesa Civil Municipal ou Prefeitura Municipal, indique aqui o município.

5. Nos contatos que você realizou com esta pessoa durante as ações para auxílio às vítimas da chuva do ES em dezembro de 2013, você:
Recebia informações
Enviava informações
Ambos

6. Quantas vezes você se comunicou com essa pessoa durante as ações de apoio às vítimas?
Mais de 15 vezes
Entre 11 e 15 vezes
Entre 5 e 10 vezes
Entre 2 e 4 vezes
Uma única vez 
7. Como você se comunicava com esta pessoa neste período?

$\square$ Pessoalmente

Telefone fixo

Telefone celular

Facebook

$\square$ Whatsapp

Outro (especifique)

8. Você já conhecia este contato antes de participar destas ações de apoio às vítimas da chuva?

Sim

Não

9. Caso você tenha respondido "sim" à questão $n^{\circ} 08$, indique abaixo, de onde conhecia esta pessoa:

10. Caso você tenha respondido "não" à questão $n^{\circ} 08$, marque as alternativas que melhor caracterizam o seu contato inicial com esta pessoa durante as ações de apoio às vítimas das chuvas (aqui é necessário que você escolha mais de uma alternativa):

Foi a pessoa quem fez o primeiro contato

Foi você quem fez o primeiro contato

Por intermédio de outras pessoas envolvidas na rede de apoio

Durante o desenrolar das atividades, sem o intermédio de terceiros

Houve uma necessidade específica que motivou o primeiro contato com esta pessoa (necessidades de donativos, caminhões, informações, apoio às atividades na Praça do Papa, dentre outras)

Não houve necessidade específica que tenha motivado o primeiro contato com essa pessoa

Outra razão e/ou característica do seu primeiro contato com essa pessoa

11. As principais informações trocadas por você e esta pessoa, durante as ações de apoio às vítimas, eram relativas a?

Necessidades de donativos

Necessidades de voluntários

Saída de caminhões para os municípios

Pontos de coleta de donativos

$\square$ Necessidades de caminhões ou outros meios de transporte de donativos

Divulgação de conteúdos na página do Facebook

Outras informações (especifique) 
12. Assinale a opção que melhor descreve seus contatos com essa pessoaatualmente.

Frequentemente entro em contato com essa pessoa.

Regularmente entro em contato com essa pessoa.

Raramente entro em contato com essa pessoa.

Não tenho mais contato com essa pessoa.

13. Você fez contato com outra(s) pessoa(s) além desta por ocasião do apoio às vítimas das chuvas de 2013? Se indicar sim, por favor continue o preenchimento com as informações sobre os outros contatos. Elas são muito importantes para o bom andamento da pesquisa.
Sim

Não 